\title{
Infrared absorption cross-sections in HITRAN2016 and beyond: expansion for climate, environment, and atmospheric applications
}

Article

Accepted Version

Creative Commons: Attribution-Noncommercial-No Derivative Works 4.0

Kochanov, R.V., Gordon, I. E., Rothman, L. S., Shine, K. P., Sharpe, S. W., Johnson, T. J., Wallington, T. J., Harrison, J. J., Bernath, P. F., Birk, M., Wagner, G., Le Bris, K., Bravo, I. and Hill, C. (2019) Infrared absorption cross-sections in HITRAN2016 and beyond: expansion for climate, environment, and atmospheric applications. Journal of Quantitative Spectroscopy and Radiative Transfer, 230. pp. 172-221. ISSN 0022-4073 doi: https://doi.org/10.1016/j.jgsrt.2019.04.001 Available at https://centaur.reading.ac.uk/83089/

It is advisable to refer to the publisher's version if you intend to cite from the work. See Guidance on citing.

To link to this article DOI: http://dx.doi.org/10.1016/j.jqsrt.2019.04.001

Publisher: Elsevier

All outputs in CentAUR are protected by Intellectual Property Rights law, including copyright law. Copyright and IPR is retained by the creators or other copyright holders. Terms and conditions for use of this material are defined in 
the End User Agreement.

www.reading.ac.uk/centaur

\section{CentAUR}

Central Archive at the University of Reading

Reading's research outputs online 


\title{
Infrared absorption cross-sections in HITRAN2016 and beyond: Expansion for climate, environment, and atmospheric applications
}

\author{
R.V. Kochanov ${ }^{a, b^{*}}$, I.E. Gordon ${ }^{a}$, L.S. Rothman ${ }^{a}$, K.P. Shine ${ }^{c}$, S.W. Sharpe ${ }^{d}$, T.J. Johnson ${ }^{d}$, T.J. \\ Wallington $^{e}$, J.J. Harrison ${ }^{f 1, f 2, f 3}$, P.F. Bernath ${ }^{g}$, M. Birk ${ }^{h}$, G. Wagner ${ }^{h}$, K. Le Brisi, I. Bravoj, C. Hillk
}

a Harvard-Smithsonian Center for Astrophysics, Atomic and Molecular Physics Division, Cambridge MA, USA

${ }^{b}$ Tomsk State University, Laboratory of Quantum Mechanics of Molecules and Radiative Processes, Tomsk State University, Tomsk, Russia

c University of Reading, Dept. of Meteorology, Reading, UK;

${ }^{d}$ Battelle Pacific Northwest National Laboratory, Richland WA, USA;

${ }^{\mathrm{e}}$ Ford Motor Company, Research \& Advanced Engineering, Dearborn MI, USA

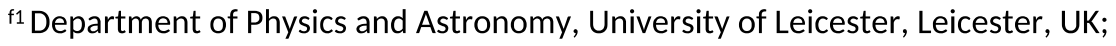

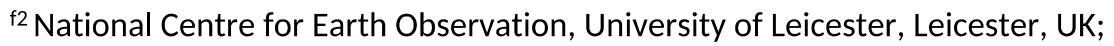

${ }^{\text {f3 }}$ Leicester Institute for Space and Earth Observation, University of Leicester, Leicester, UK; g Old Dominion University, Dept. of Chemistry \& Biochemistry, Norfolk VA, USA;

${ }^{\mathrm{h}}$ DLR, Institute for Remote Sensing Technology, Wessling, Germany;

' St. Francis Xavier University, Department of Physics, Antigonish, NS, Canada

j University of Castilla-La Mancha, Dept. of Physical Chemistry, Faculty of Pharmacy, Albacete, Spain

${ }^{k}$ International Atomic Energy Agency (IAEA), Vienna, Austria

*Corresponding author. Email address: rkochanov@cfa.harvard.edu

\section{Abstract}

Spectroscopic analysis of hydrocarbons, halocarbons and related species is required in atmospheric applications such as climate-change research, tracking of pollution and biomass burning, and remote sensing. Critically evaluated line-by-line spectroscopic data are needed for such analyses. To address this need we report the large addition of spectra to the HITRAN2016 database. This extension increases the number of molecules in the database by almost a factor of 6 from that in HITRAN2012. Spectra from the Pacific Northwest National Laboratory database (Appl. Spectrosc. 2004;58:1452-61) and the Hodnebrog et al. compilation (Rev Geophys 2013;51:300-78) have been integrated into HITRAN2016. Spectra from high-resolution laboratory observations, predominantly from Fourier transform spectrometers, are now provided 
1 for 328 compounds in the IR spectral range. Spectra for atmospherically-important compounds

2 organized by chemical category are presented. The HITRAN infrastructure (www.hitran.org),

3 HITRAN Application Programming Interface (HAPI), and best practices for searching and

4 downloading data are discussed.

5 1. Introduction

6 Human activities result in the emission of a diverse range of gases into the atmosphere,

7 including hydrocarbons, halocarbons, acids, alcohols, amines, sulfur- and nitrogen-containing

8 species. Emission of radiatively-potent compounds into the atmosphere can cause significant

9 changes in the climate [1]. In addition to water vapor, carbon dioxide, methane, and nitrous oxide (see the line-by-line section of the HITRAN database [2]), halogen-containing organic compounds contribute significantly to the atmospheric radiative budget. Since the middle of the twentieth century, much attention has been paid to hydrocarbons, halocarbons and related species. The radiative forcing of climate change from increased atmospheric levels of halogencontaining organic compounds over the period $1750-2011$ is approximately $20 \%$ of that from increased levels of carbon dioxide over the same period [3]. Emissions of reactive volatile organic compounds (VOCs) are implicated in photochemical ozone formation and local air quality degradation.

Halogen-containing organic compounds are used in a broad range of production and industrial activities, including fire suppression, air conditioning, refrigeration, heat transfer, electronics, and semiconductor manufacture. The spectroscopic signatures of these compounds have been suggested as potential indicators of "intelligent" life on exoplanets [4]. In addition, chlorine- and bromine-containing compounds can participate in chemistry leading to stratospheric ozone depletion. Some halogen-containing compounds (such as saturated perfluorocarbons (PFCs)) have extremely long lifetimes - thousands of years - due to very strong C-F bonds [5] with very high global warming potentials. Significant efforts have been expended to develop substitute compounds for chlorofluorocarbons (CFCs), hydrochlorofluorocarbons (HCFCs), and hydrofluorocarbons (HFCs), ideally with much less global warming and ozone depletion potentials (GWPs and ODPs). Detailed knowledge of the spectroscopy of halogen-containing organic compounds is paramount for monitoring their atmospheric abundances and thus required to assess their contributions to radiative forcing of climate change. Many of these same species are powerful greenhouse gases, and assessments of this impact also require detailed spectroscopic knowledge. 
To control emission of pollutant gases, many ongoing efforts are being made which originated

2 in the 1980s in the framework of the United Nations (UN) environment programs and

3 agreements. The HITRAN2016 database edition includes many of the halocarbons and related

4 gases controlled under United Nations agreements. These agreements include the Montreal

5 Protocol on Substances that Deplete the Ozone layer (see http://ozone.unep.org) and its

6 amendments, and the Framework Convention on Climate Change (UNFCCC) (see

7 https://unfecc.int/process). A major use of cross-section data in HITRAN is thus for the

8 calculation of the effects on climate of such gases as well as for monitoring emissions and

Table 1. Overview of inclusion of halocarbons in United Nations protocols and agreements.

\begin{tabular}{lllllll}
\hline Process (focus) & $\begin{array}{l}\text { Protocol, } \\
\text { Adjustment or } \\
\text { Amendment (Year) }\end{array}$ & $\begin{array}{l}\text { Number } \\
\text { of CFCs }\end{array}$ & $\begin{array}{l}\text { Number } \\
\text { of } \\
\text { Halons }\end{array}$ & $\begin{array}{l}\text { Number } \\
\text { of } \\
\text { HCFCs }\end{array}$ & $\begin{array}{l}\text { Number } \\
\text { of HFCs }\end{array}$ & $\begin{array}{l}\text { Number of } \\
\text { other } \\
\text { related } \\
\text { substances }\end{array}$ \\
\hline Montreal (ozone) & Montreal 1987 & 5 & 3 & & & \\
Montreal (ozone) & London 1990 & 15 & 3 & 34 & & 2 \\
Montreal (ozone) & $\begin{array}{l}\text { Copenhagen 1992 } \\
\text { Meijing 1999 }\end{array}$ & 15 & 37 & 40 & & 3 \\
Montreal (ozone) & 15 & 38 & 40 & 18 & \\
UNFCCC (climate) & Kigali 2016 & & & & 13 & 8 \\
UNFCCC (climate) & Kyoto 1997 & & & & 13 & 9 \\
\hline
\end{tabular}

18 Note: For more details of those falling within the Montreal Protocol on Substances that Deplete the Ozone Layer see http://ozone.unep.org. For those falling within the Framework Convention on Climate Change (UNFCCC), see https://unfccc.int/process.

The HITRAN database [2] is the most commonly used source of reference molecular spectroscopic data for molecules of atmospheric interest. A major extension of the number of large complex molecules represented in HITRAN, as well as of the spectral range, temperature, and pressure coverage for many of them is described in the present article. The compounds discussed in the present paper are mostly considered in terms of their Earth climate and environmental relevance but are also important in astrophysics, theoretical and fundamental physics, biology, and metrology. We do not consider these applications in any detail in this 
1 paper; detailed information on the relevance of emissions of such gases to radiative forcing of

2 climate change, and metrics such as the Global Warming Potential, and the methods by which

3 these are calculated, can be found in [1].

4 The HITRAN2016 database provides absorption cross-sections for more than 328

5 hydrocarbons, halocarbons and related compounds (approximately six times more than the

6 HITRAN2012 edition [6]) as a supplement to the discrete molecular transitions in the traditional

7 part of HITRAN. For some molecules (e.g. ethane and methyl bromide), HITRAN provides both

8 line-by-line parameterization and experimental cross-sections. This can arise when the cross-

9 sections have some information that is absent in the line-by-line part of HITRAN, or for cases

10 when the line-by-line data are not precise enough. The IR spectral data, which comprise the

11 focus of the present paper, are mostly air-, self-, or nitrogen-broadened measured with Fourier

12 transform spectrometers using a range of resolutions at a variety of temperatures. In the

13 following sections of this paper we provide a general overview of the cross-sections in the

14 HITRAN database, followed by a description of the spectral data separated by categories.

15 Finally, we give a more detailed outline of the corresponding part of the HITRANonline web

16 interface, which provides tools for searching and plotting the molecular cross-sections.

\section{Formalism and history for the HITRAN cross-sections}

The HITRAN spectroscopic database [2] was designed to provide a machine-readable compilation of basic spectroscopic parameters that could be used in radiative-transfer computer codes. The acronym HITRAN stands for High resolution Transmission; the high resolution implies that the database is intended to enable the user to simulate spectra in as fine detail as possible. The HITRAN project began in the 1960s and culminated in the first line list in 1973 [7]. The effort was supported by the US Air Force and initially had the objective to cover the main absorbing gases in the terrestrial atmosphere $\left(\mathrm{H}_{2} \mathrm{O}, \mathrm{CO}_{2}, \mathrm{O}_{3}, \mathrm{~N}_{2} \mathrm{O}, \mathrm{CO}, \mathrm{CH}_{4}\right.$, and $\left.\mathrm{O}_{2}\right)$ in the spectral interval covering approximately 1 to 10 micrometers. The scope of the database at the time was driven by sensor technology and the speed of computer calculations.

The main goal of HITRAN, including its cross-section part, is to provide fundamental parameters for radiative transfer in gaseous media using the Lambert-Beer law of absorption, namely

$$
\tau(v)=e^{-k(v) L}
$$

where $\tau(v)$ is the spectral transmittance at wavenumber $v, k(v)$ is a normalized absorption coefficient in $\mathrm{cm}^{-1}$, and $L$ is an increment of path through the media in $\mathrm{cm}$. The absorption crosssection is in units of $\mathrm{cm}^{2} /$ molecule and is often expressed by 


$$
\sigma(v, T, p)=-\frac{\ln \tau(v)}{\rho \mathrm{L}}
$$

2 where $\rho$ is the volume density $\left(\right.$ molecule $\left./ \mathrm{cm}^{3}\right)$. The absorption coefficient and absorption crosssections can be calculated from the parameters in the line-by-line portion of the data base (see Appendix of the HITRAN1996 paper [8]). The cross-section portion provides experimental cross-sections as a function of wavenumber recorded at different thermodynamic conditions. A powerful tool for calculating cross-sections and other parameters from the line-by-line data is now provided with the database and is called the HITRAN Application Programming Interface (HAPI) [9]. It is worth noting that in Eq. (2) the Napierian logarithm is used, while many experimental spectra obtained using manufacturer software employ base 10 logarithms. The conversion is straightforward and one just needs to multiply those experimental cross-section by $\ln (10)^{1}$.

Over time, the uses of HITRAN have caused the database to expand significantly. They now include astrophysical, medical, pollution monitoring, and many other applications. The expansion has been in:

(1) Spectral range which now covers the microwave through ultraviolet, corresponding to pure-rotation, rovibrational, and electronic transitions;

(2) Additional molecules and their important isotopologues. As of the current 2016 edition [2] there are 49 molecules with an associated 126 isotopologues represented in the highresolution (line-by-line) portion of the database. This expansion has been driven by the increase in the number of applications of HITRAN;

(3) Increase in the number of parameters for each transition. This increase in parameters has been driven by both the sophistication in transmission and radiance models as well as the improvement in observational and archiving techniques, for example, greater signal-to-noise, higher resolution, superior photometric accuracy, and more efficient data handling. Table 1 of Ref. [2] shows the current list of parameters.

Many bands of molecular spectra are currently intractable to theoretical treatment. This situation is particularly true for large polyatomic molecules, for which the following problems can arise simultaneously: they have dense spectra with many low-lying vibrational modes (thus a complete representation in a line list requires a vast number of hot bands and combination bands), they have many resonances that are difficult to characterize, and finally, they have complicated line-shape phenomena, including line-mixing. The solution that has been taken is to provide the user with absorption cross-sections, $\sigma\left(\mathrm{cm}^{2} /\right.$ molecule $)$, that have been measured in controlled laboratory experiments. To be useful, these cross-section spectra should be given at

\footnotetext{
${ }^{1}$ The same conversion rule applies to the intensity parameters of the line-by-line part of HITRAN
} 
many pressure and temperatures so that the radiative-transfer codes can interpolate to obtain reasonable simulations. They should also be obtained for different broadening gases, for example self, nitrogen, and oxygen. Note that applying these cross-sections in a radiativetransfer code, while perhaps not a satisfying physical approach, nonetheless can achieve quite satisfactory results since the cross-sections may possess within them many of the missing ingredients of the line-by-line approach. Thereby, the fidelity of a simulation using absorption cross-sections can be quite good if they are obtained with accurate measurements (that is, welldetermined amounts of the gas and perturber in question, adequate resolution, good calibration) and have a large representative range of temperature-pressure measurements. To achieve better modeling accuracy, it is also important that the cross-sections do not possess such artifacts as mixture contaminations, channel fringes, zero level offsets, etc. An interesting approach for interpolating cross-sectional data obtained at different temperatures and pressures was proposed by Toon (https://mark4sun.jpl.nasa.gov/pseudo.html). This approach, known as "pseudo-lines", fits multiple cross-sectional data to a "pseudo" line list where the "lines", although in HITRAN format, are simply a fitting tool. In other words, the end product is a HITRAN-formatted "line list" that allows experimental cross-sections at any temperature and pressure within the range probed by experiment to be reproduced.

The absorption cross-section component of the HITRAN compilation was introduced in the mid-1980s [10] with a major dedicated update carried out for the 1992 edition by Massie and Goldman [11] . High-resolution spectra taken by Fourier-Transform spectrometers (FTS) were already available that had been digitized into convenient forms [12]. Many more laboratories began acquiring lists of infrared cross-sections taken by FTS, primarily of polyatomic molecules in the long wavelength region of the spectrum. These efforts include the Pacific Northwest National Laboratory (PNNL) [13], the State University New York at Stony Brook (hereafter referred to as SUNY) under the support of the US Dept of Energy Atmospheric Radiation Measurement (ARM) program [14,15], the Rutherford Appleton Laboratory (RAL) in the UK [16], the US National Institute of Standards and Technology [17], and the Université Libre de Bruxelles, Belgium[18].

In addition to the infrared cross-sections, the majority of ultraviolet data in HITRAN are in the form of cross-sections. In this paper, however, we will focus on the revision and expansion of the IR cross-sections.

Table 2 illustrates the evolution of the HITRAN cross-section data from the 1986 to 2016 version. For comparison purposes, only molecules from HITRAN2012 are given in this summary (as we discuss in this paper HITRAN2016 has substantially more molecules). The "o" 
1 sign means that the data have not been changed in the corresponding database issue. The "+"

2 sign signifies a change for the given molecule. A change in an edition can mean several different

3 things: (a) new data completely replacing old data; (b) new data added in a new spectral region,

4 with old data kept in other regions, (c) new data added and old data relegated to a supplemental

5 folder since they were deemed to be good but in some way duplicated the new data.

$\mathrm{HNO}_{3}$ was added in the 1986 edition with the idea that as high-resolution line-by-line data

7 (line-by-line parameters) were eventually obtained, the corresponding cross-sections would be

removed from the database. However, this protocol seems to be inconsistent, since for other molecules, such as $\mathrm{SF}_{6}$ and $\mathrm{ClONO}_{2}$, there are both cross-sections as well as line-by-line parameters, at least for some spectral regions. The idea here was that there are a significant number of missing hot bands from the line-by-line part, as well as other unsolved spectroscopic phenomena. Therefore, cross-sections for these latter two molecules were retained in the current HITRAN issue.

Note that the whole idea of archiving cross-sections in HITRAN is counter to the overall HITRAN philosophy of providing basic parameters that one can use to calculate radiative transfer in diverse environments based on good physics. On the other hand, the philosophy of HITRAN also promotes providing the user with the "best" tools for these calculations. Since molecules with extremely congested lines, with low-lying fundamentals, with extremely difficult line-shape properties, etc, are not yet treatable in a satisfactory way, the experimental crosssections will remain in HITRAN for the foreseeable future.

Table 2. Evolution of IR cross-section data sets in the HITRAN versions since 1986 until 2016 (only molecules from HITRAN2012 are explicitly shown here). The "o" sign means that the data have not been changed in the corresponding database issue. The sign "+" signifies a change for the given molecule.

\begin{tabular}{|c|c|c|c|c|c|c|c|c|}
\hline Molecule & & & HIT & $\mathrm{ANec}$ & ition & & & \\
\hline Chemical formula/ common name & 1986 & 1992 & 1996 & 2000 & 2004 & 2008 & 2012 & 2016 \\
\hline $\mathrm{C}_{2} \mathrm{H}_{6}$ / Ethane & & & & & & & + & + \\
\hline $\mathrm{CH}_{3} \mathrm{OH} /$ Methanol & & & & & & & + & o \\
\hline $\mathrm{CH}_{3} \mathrm{CH}_{2} \mathrm{CH}_{3} / \mathrm{C}_{3} \mathrm{H}_{8} /$ Propane & & & & & & & + & + \\
\hline $\mathrm{CH}_{3} \mathrm{COCH}_{3} /$ Acetone & & & & & & & + & + \\
\hline $\mathrm{CH}_{3} \mathrm{CHO} /$ Acetaldehyde & & & & & & & + & + \\
\hline $\mathrm{CH}_{3} \mathrm{CCIF}_{2} / \mathrm{HCFC}-142 \mathrm{~b}$ & & & & & & & + & + \\
\hline $\mathrm{BrONO}_{2} /$ Bromine nitrate & & & & & & & + & + \\
\hline $\mathrm{ClOOCl} /$ Chlorine peroxide & & & & & & & + & o \\
\hline $\mathrm{CH}_{3} \mathrm{CN}$ / Acetonitrile / Methyl cyanide & & & & & & + & + & + \\
\hline $\mathrm{CH}_{3} \mathrm{C}(\mathrm{O}) \mathrm{OONO} 2 / \mathrm{PAN}$ & & & & & & + & + & o \\
\hline $\mathrm{C}_{6} \mathrm{H}_{6} /$ Benzene & & & & & & + & $\mathrm{o}$ & o \\
\hline $\mathrm{SF}_{5} \mathrm{CF}_{3} /$ Trifluoromethyl sulfur pentafluoride & & & & + & + & o & $\mathrm{o}$ & + \\
\hline $\mathrm{C}_{2} \mathrm{~F}_{6} /$ Hexafluoroethane / CFC-116 & & & & + & 0 & o & 0 & + \\
\hline $\mathrm{CHCl}_{2} \mathrm{CF}_{3} / \mathrm{HCFC}-123$ & & & & + & o & o & o & + \\
\hline $\mathrm{CHClFCF}_{3} / \mathrm{HCFC}^{-124}$ & & & & + & o & o & $\mathrm{o}$ & + \\
\hline
\end{tabular}


$\mathrm{CH}_{3} \mathrm{CCl}_{2} \mathrm{~F} / \mathrm{HCFC}-141 \mathrm{~b}$

$\mathrm{CH}_{3} \mathrm{CClF}_{2} / \mathrm{HCFC}-142 \mathrm{~b}$

$\mathrm{CHCl}_{2} \mathrm{CF}_{2} \mathrm{CF}_{3} / \mathrm{HCFC}-225 \mathrm{ca}$

$\mathrm{CCIF}_{2} \mathrm{CF}_{2} \mathrm{CHClF} / \mathrm{HCFC}-225 \mathrm{cb}$

$\mathrm{CH}_{2} \mathrm{~F}_{2} / \mathrm{HFC}-32$

$\mathrm{CHF}_{2} \mathrm{CF}_{3} / \mathrm{HFC}-125$

$\mathrm{CHF}_{2} \mathrm{CHF}_{2} / \mathrm{HFC}-134$

$\mathrm{CFH}_{2} \mathrm{CF}_{3} / \mathrm{HFC}-134 \mathrm{a}$

$\mathrm{CF}_{3} \mathrm{CH}_{3} / \mathrm{HFC}-143 \mathrm{a}$

$\mathrm{CH}_{3} \mathrm{CHF}_{2} / \mathrm{HFC}-152 \mathrm{a}$

$\mathrm{SF}_{6} /$ Sulfur hexafluoride

$\mathrm{CHClF}_{2} / \mathrm{HCFC}-22$

$\mathrm{CClF}_{3} / \mathrm{CFC}-13$

$\mathrm{C}_{2} \mathrm{ClF}_{5} / \mathrm{CFC}-115$

$\mathrm{ClONO}_{2} /$ Chlorine nitrate

$\mathrm{CCl}_{3} \mathrm{~F} / \mathrm{CFC}-11$

$\mathrm{CCl}_{2} \mathrm{~F}_{2} / \mathrm{CFC}-12$

$\mathrm{N}_{2} \mathrm{O}_{5}$ / Dinitrogen pentoxide

$\mathrm{CF}_{4} / \mathrm{CFC}-14$

$\mathrm{C}_{2} \mathrm{Cl}_{2} \mathrm{~F}_{3} / \mathrm{CFC}-113$

$\mathrm{C}_{2} \mathrm{Cl}_{2} \mathrm{~F}_{4} / \mathrm{CFC}-114$

$\mathrm{CCl}_{4}$ / Carbon tetrachloride

$\mathrm{HNO}_{4} /$ Peroxynitric acid

$\mathrm{CHCl}_{2} \mathrm{~F} / \mathrm{HCFC}-21$

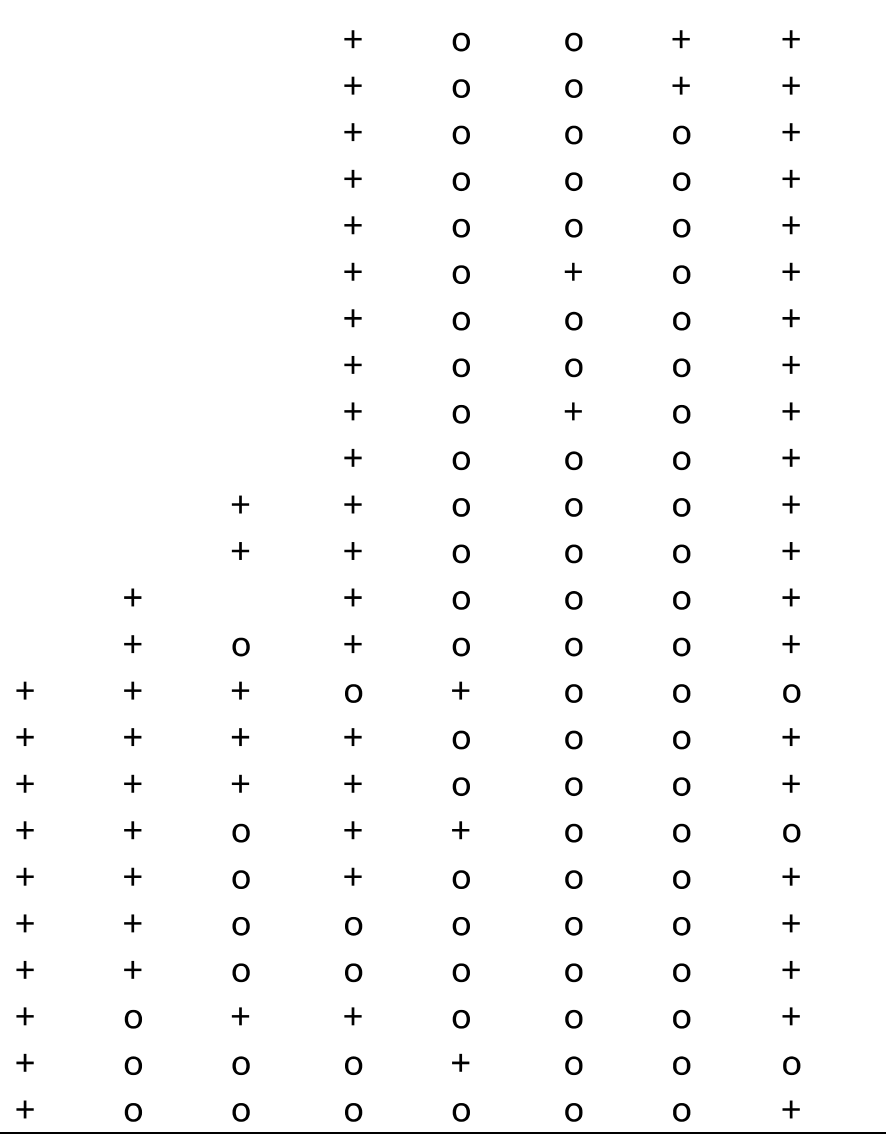

1

The earliest editions of HITRAN presented data in ASCII; there was also a real concern about minimize storage space in that chosen format. This legacy has been inherited to some extent. When the cross-sections were added to the HITRAN compilation, the traditional line-by-line portion was composed of records (transitions) of 100 characters in length. Although the

transitions were in text format, they were given the file extension ".par". It was decided to cast

the cross-sections also in records of 100 characters, although each record would contain ten

values (fields) of the cross-sections. These cross-sections would be ordered from lowest to

highest wavenumber of the set. The values would be given at equal wavenumber intervals. For each molecule, it was thus necessary to have metadata not only to name the molecule, but also give the lowest and highest wavenumber, the temperature and pressure of the set, the number of individual cross-sections, and associated laboratory details such as the resolution of the experiment and the diluent gas if any. The metadata are given in a 100-character header before each group of temperature-pressure sets. The molecules are each contained in a file with the extension ".xsc". Individual files will thus have several embedded headers depending on how many temperature-pressure sets exist. Table 3 illustrates the metadata in the header.

Table 3. Metadata header for cross-section data. 


\begin{tabular}{|c|c|c|c|}
\hline Molecule & 20 & Character & Chemical formula (right adjusted) \\
\hline Minimum wavenumber, $v_{\min }$ & 10 & Real & Start of range $\left(\mathrm{cm}^{-1}\right)$ \\
\hline Maximum wavenumber, $v_{\max }$ & 10 & Real & End of range $\left(\mathrm{cm}^{-1}\right)$ \\
\hline Number of cross-sections in set & 7 & Integer & Number of cross-sections in set \\
\hline Temperature, $T$ & 7 & Real & Temperature $(\mathrm{K})$ of set \\
\hline Pressure, $P$ & 6 & Real & Pressure of set in Torr \\
\hline \multicolumn{4}{|l|}{ Maximum cross-section value } \\
\hline in set, $\sigma_{\max }$ & 10 & Real & Useful for scaling plots ( $\mathrm{cm}^{2} /$ molecule) \\
\hline Instrument resolution & 5 & Real & See note \\
\hline Common name & 15 & Character & Familiar name of molecule \\
\hline Not currently used & 4 & & Reserved for future use \\
\hline Broadener & 3 & Character & Air, $\mathrm{N}_{2}$, or (if left blank) self-broadened \\
\hline Reference & 3 & Integer & Index pointing to source of data \\
\hline
\end{tabular}

1 Note: Most cross-sections have been taken from Fourier transform spectrometer (FTS) measurements. In

2 that case the resolution is given in $\mathrm{cm}^{-1}$. There are some cross-sections taken from grating spectrometer

3 measurements in the UV. In those cases, the instrument resolution is given in milli-angströms in the form $4 \quad \mathrm{xxx} \mathrm{m} \AA$, where $\mathrm{xxx}$ are up to three digits.

5 Several remarks should be made concerning the format of the cross-sections. It was decided

6 early on to not have any negative absorption values. Some of the experiments contained small

7 negative values, usually within experimental uncertainties, and these were zeroed out, partly in

8 response to the preferences of some radiative-transfer codes. Subsequently, a small percentage

9 of users objected to this procedure, because the negative absorption values were a useful

10 indicator of systematic errors in the measurements. Setting the negative values to zero creates a

11 bias when used in retrievals since the average cross sections will be positive when they should be

12 zero instead. This may affect retrieval of the species in question as well as other species having absorption in that spectral range. For this reason, we now preserve the original data in a supplemental folder in addition to the "rectified" files.

Another aspect of the original spectra requires an extra step when mapping to the HITRAN format. If the cross-sections obtained cover a very wide spectral range, and there are obvious regions between bands with basically no data, we occasionally break these spectra into multiple sets, thereby avoiding many records of zero values. Thus, for the case of two distinct spectral regions, the data in HITRAN would appear in two sets in the molecule file with different headers within the file. This is especially true for the older files, when disk space was more of an issue.

In most cases the total number of cross-sections in a set is not a multiple of 10 . The last record of a file will be extended with zero values; this should cause no problem since the header gives the number of cross-sections in the set, $N$. The equal wavenumber interval is thus simply $\Delta v=\left(v_{\max }-v_{\min }\right) / N$.

As new cross-section data are validated and added to HITRAN, another dilemma arises. The older data may have slightly different temperature-pressure sets than the new. Mixing them with the newer data might cause discontinuities. In this case the data is validated using several criteria (spectral coverage, source-to-source comparison, stated accuracies, agreement with third-party 
1 data etc...). If the old data are deemed to be fairly reliable, they are not discarded, but rather also

2 relegated to the supplemental folder. The situation is less of a problem if the older data do not overlap the newer with respect to the wavenumber coverage; in that case they are simply

4 retained.

As mentioned above, the cross-section values, $\sigma$, are presented at a uniform wavenumber grid.

6 This only presents a problem for some ultraviolet sets where they were measured by a grating

7 spectrometer and hence obtained at equal wavelength spacing. We have resampled them onto a

uniform wavenumber grid where they reside in the principal folder, but now retain the original values in the supplemental folder.

Finally, it should be mentioned that the HITRAN and HITEMP [19] databases do not adhere to SI units. For instance, the line centers are given in wavenumbers $\left(\mathrm{cm}^{-1}\right)$. Not only are centimeters used throughout, but atmosphere (atm) and Torr are used for pressure, the latter in the headers of the cross-sections. The choice of units is in harmony with many standard radiative-transfer codes.

\section{Description of the cross-section data molecule by molecule}

In the HITRAN2016 release, the spectral data for more than 320 molecules have been either added, or updated. To assist the user in searching molecules in the HITRAN database, the gases are organized into several categories. In this section we give a description of each category, and characterize and compare the spectra for important molecules from each category. In addition, in HITRANonline supplemental folder (https://hitran.org/suppl/xsec/) we provide summary tables (Table S1, Table S2, and Table S3) containing metadata for sources, molecules, and crosssections. These tables can be found using the link in the Supplemental tab at the cross-section search page in the HITRAN web site. More details on the general usage of the HITRANonline web-interface can be found in Ref. [20], and more specifically to cross-sections in Section 4.

When there were different data sources with similar coverage of broadening conditions, spectral intervals, temperature, pressure, etc., we compared the data to decide if the corresponding spectra should be included in the database, and if so, should they be available via the HITRANonline web interface or instead relegated to the supplemental folder. The latter is used either for storing the original spectra with non-zeroed negative absorption (if any), or for storing the data sources which were "worse" by some measure (e.g., stated accuracy, spectral coverage, number of temperature and pressure sets), but nevertheless have complementary information which could be useful for some applications. Here we put the word "worse" in 
1 quotes since in many cases it is impossible to state that one dataset is generally superior to

2 another. This arises, for example, when one dataset has more temperature and pressure sets while

3 another has better resolution. However, since the HITRAN database strives to facilitate the

4 user's choice and provide spectroscopic data for many applications, we made remarks on the

5 differences of such data, and specified which cross-sections were made available via the

6 HITRANonline web interface (further "included in HITRANonline"), which were relegated to

7 the supplemental folder, and which were not included at all.

8 Figure 1 shows the molecules in the cross-section part of the HITRAN2016 issue (large

9 circles in blue) and those from the HITRAN2012 cross-section part (medium circles in olive).

10 The molecules from the line-by-line part of the HITRAN2016 database are in magenta (small

11 circles). The plot displays the molecular weights versus number of atoms. It can be seen that the

12 range of sizes of molecules in the database has been greatly expanded with inclusion of species

13 such as halogenated aldehydes, alcohols, ethers, and long-chain hydrocarbons. The molecule

14 with the largest molecular weight in HITRAN2016 is PFTBA, perfluorotributylamine,

15 (measured by Godin et al. [21]) while the molecule with the largest number of atoms is

16 hexadecane (measured by PNNL $[13,22]$ ).

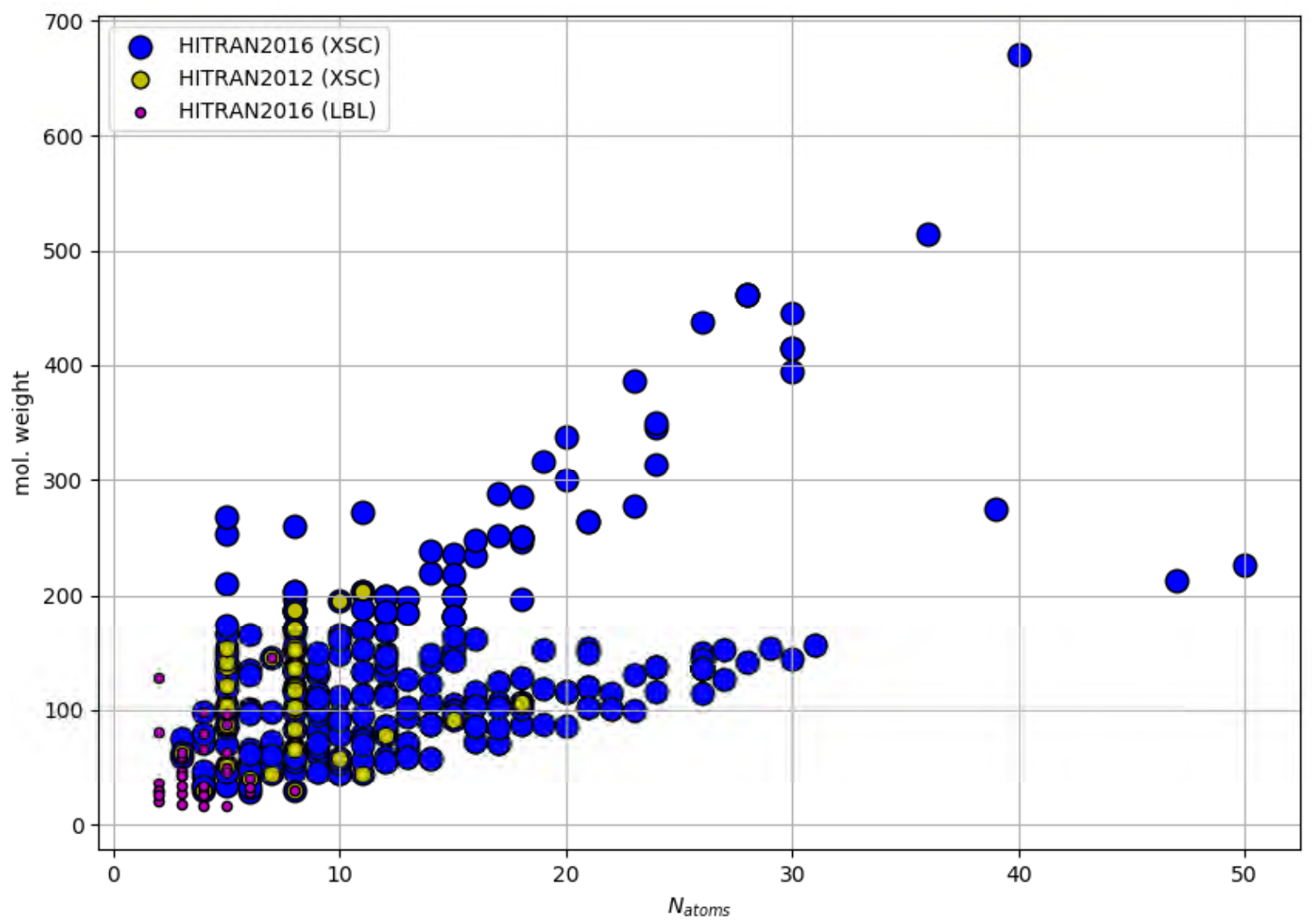


1 Figure 1. Overview of the molecular weights vs number of atoms for molecules from the

2 HITRAN database. All molecules from the cross-section part ("XSC") of HITRAN2016 are

3 highlighted in blue, while those from HITRAN2012 are in olive. The molecules from the line-

4 by-line part ("LBL") of HITRAN2016 are in magenta.

5 In the following, we give a brief summary of the data sources that provided either a large

6 number of molecules, or a detailed set of temperatures and pressures.

7 Hodnebrog et al. [1] compiled absorption cross-sections of more than 200 halocarbons and related compounds from experimental and ab initio studies and calculated radiative efficiencies, global warming potentials, and global temperature potentials of these gases. These climate metrics were adopted in the Intergovernmental Panel on Climate Change Fifth Assessment Report [3]. The Hodnebrog et al [1] compilation focused on available room-temperature measurements (as these were the most widely available) although selected lower-temperature measurements were included for some gases.

In the PNNL DOE (Department of Energy) database, Sharpe and co-workers [13] recorded the broadband quantitative reference spectra of 462 molecules for applications in tropospheric monitoring or laboratory studies near standard atmospheric pressure and ambient temperature . Each molecule has a single spectrum (600 to $\left.6500 \mathrm{~cm}^{-1}\right)$ at both 298.15 and $323.15 \mathrm{~K}$ and, if the vapor pressure was sufficient, also at $278.15 \mathrm{~K}$. The spectrum was derived from a series of single measurements using a variety of analyte partial pressures (the range often covering more than two orders of magnitude) in 760 Torr of $\mathrm{N}_{2}$ diluent. The analyte/ $\mathrm{N}_{2}$ mixtures were generated by either of two methods. The first method used a static system (Sharpe et al. [13]) with the passive vapor pressure of liquid or an aliquot of the gas added followed by addition of the $\mathrm{N}_{2}$ ballast; quantitation was achieved using the ideal gas law. The second method (Johnson et al. [23]) used a disseminator system where the liquid analyte was dispensed at the tip of a syringe and flash-vaporized into a flowing stream of $\mathrm{N}_{2}$ gas; quantitation was achieved using total mass calculations from the syringe pump rate in $\mu 1 / \mathrm{min}$ and the $\mathrm{N}_{2}$ gas flow rate. In both cases spectra were recorded using a Bruker IFS 66v/S spectrometer at $0.11 \mathrm{~cm}^{-1}$ resolution and boxcar apodization; protocols and instrument details can be found in Johnson et al. [23]

While the technical aspects of the data were identical, a subsequent project produced the PNNL SERDP (Strategic Environmental Research and Development Program) database of IR spectra (https://datahub.pnnl.gov/projects/serdp). Although smaller in quantity (55 molecules), the PNNL SERDP database (Johnson et al. [22]) was focused on VOCs and oxygenated-VOCs (OVOCs) associated with forest fires and biomass burning. 
1 New absorption cross-sections, measured by Harrison et al. [24-28], have been derived for

2 the halogen species HFC-23, HFC-134a, CFC-12, HCFC-22, and $\mathrm{CCl}_{4}$, and improve upon those

3 in previous versions of HITRAN. Multiple air-broadened spectra were recorded in a $26 \mathrm{~cm}$ path

4 length sample cell by FTS over a range of atmospherically relevant temperatures and pressures.

5 These studies provide spectra with extended wavenumber, temperature, and pressure ranges, and

6 having high signal to noise ratio. The spectra are compared with those from previous HITRAN

7 issues - see the corresponding references by Harrison (and coauthors). These datasets are

8 principally intended for use in infrared limb sounding by instruments such as the ACE-FTS and 9 MIPAS.

Fourier transform infrared measurements of bromine nitrate by Birk and Wagner [29] have been performed in the spectral region $675-1400 \mathrm{~cm}^{-1}$ at $0.014 \mathrm{~cm}^{-1}$ spectral resolution. Absorption cross-sections were derived from 38 spectra covering the temperature range from 203 to $296 \mathrm{~K}$ and air pressure range from 0 to 190 mbar (where 0 means there is only the absorber in the gas) applying a global least squares fitting approach. Bromine nitrate was generated in a complicated chemical process from $\mathrm{HNO}_{3} \rightarrow \mathrm{N}_{2} \mathrm{O}_{5} \rightarrow \mathrm{ClONO}_{2} \rightarrow \mathrm{BrONO}_{2}$, where $\mathrm{ClONO}_{2}$ required the production of $\mathrm{Cl}_{2} \mathrm{O}$ from $\mathrm{HgO}+\mathrm{Cl}_{2}$. The measurements of pure and air-broadened bromine nitrate were carried out in a sealed-off $22 \mathrm{~cm}$ absorption path cell which was mounted inside the sample compartment of the spectrometer and cooled by flowing methanol through a glass double jacket and the flanges. Decomposition was low, especially at lower temperatures, since chemically inert materials were used: Pyrex glass, PFA-coated steel, Teflon, and $\mathrm{AgCl}$ as windows.

Rodriguez et al. [30] recorded experimental absorption spectra of allyl trifluoroacetate (ATFA) and vinyl trifluoroacetate (VTFA). Cross-sections were measured at $298 \mathrm{~K}$ and no dependence on total pressure was observed. These data were then used to calculate the radiative efficiencies and global warming potentials of these gases using the methodology described by Hodnebrog et al. [1]

Rodriguez et al. [31] measured absorption spectra of hydrofluoroether HFE-7300 and HFE7500 at $298 \mathrm{~K}$ and 25-150 Torr total pressure. No dependence on total pressure was observed for both compounds. The cross-sections were then adopted for the calculation of the radiative efficiencies along with the global warming potentials using the methodology described by Hodnebrog et al. [1].

For the CFCs, HCFCs, and fluorinated species from the list below, measured by Le Bris et al. [21,32-39], the experimental acquisitions of the absorption spectra were performed on pure 
1 vapor samples using a Bomem DA8 spectrometer with a globar source, a $\mathrm{KBr}$ beamsplitter and a

$2 \mathrm{MCT}$ (mercury cadmium telluride) detector. Depending on the compound, the spectral range

3 covers all the fundamental modes from the mid-500 $\mathrm{cm}^{-1}$ up. Two types of acquisitions have

4 been carried on:

- Cross-sections in a low-temperature range and at a resolution of $0.02 \mathrm{~cm}^{-1}\left(0.05 \mathrm{~cm}^{-1}\right.$ for CFC-113) for temperature-dependent cross-sections of molecules that are relatively abundant in the atmosphere, and currently or possibly detectable by remote sensing techniques (CFC-113 [32], HCFC-142b [33], HCFC-141b [34], HFC-143a [35]).

- Cross-sections at room temperature and above and at a resolution of $0.1 \mathrm{~cm}^{-1}$ to calculate the radiative efficiency and global warming potential of new or minor atmospheric compounds (PFTBA [21], HFIP [36], PFPO [37], PFD [38], HFC-43-10mee [39])

For each temperature-pressure set, hundreds of scans were co-added to create an average absorption spectrum. Using the method presented by Sharpe et al. [13], optical depths corresponding to too optically thin or thick are eliminated. The composite spectrum for a given temperature is obtained by calculating the cross-section at zero partial pressure from a linear or quadratic fit of the optical depth versus the partial pressure for each wavenumber.

Uncertainties are given using the $95 \%$ confidence interval (two standard deviations). The processed experimental data were validated by a comparison with theoretical calculations performed using density functional theory and ab-initio methods. In recent papers from this group [36,38,39]], the theoretical calculations have also been used to extend the spectral range of the cross-sections to the lower fundamental modes. Synthetic spectra in the $0-550 \mathrm{~cm}^{-1}$ spectral region were created after calibration of the theoretical wavenumbers and integrated intensities of the modes with respect to the experimental data in the $550-3500 \mathrm{~cm}^{-1}$ spectral range. 


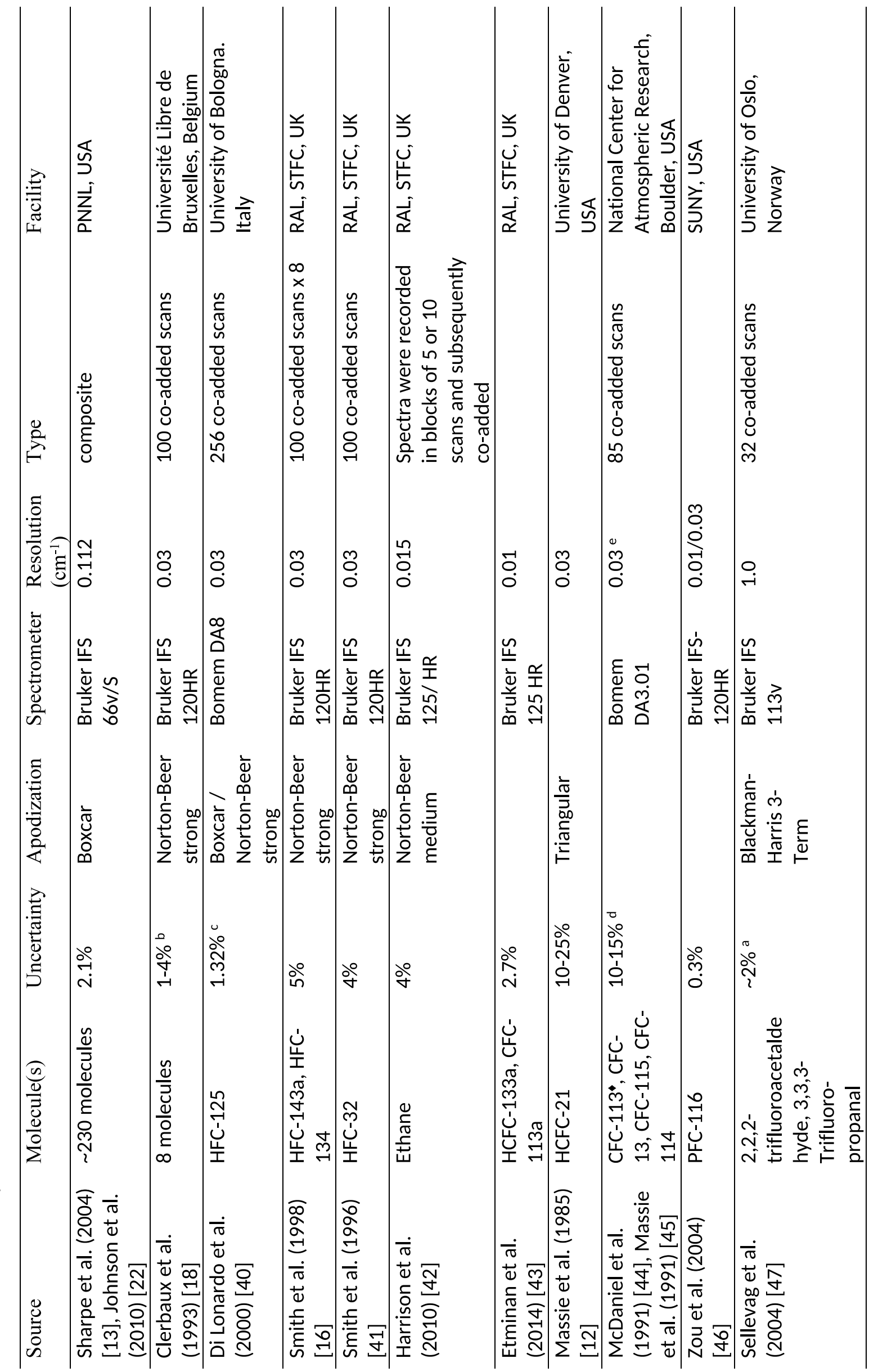




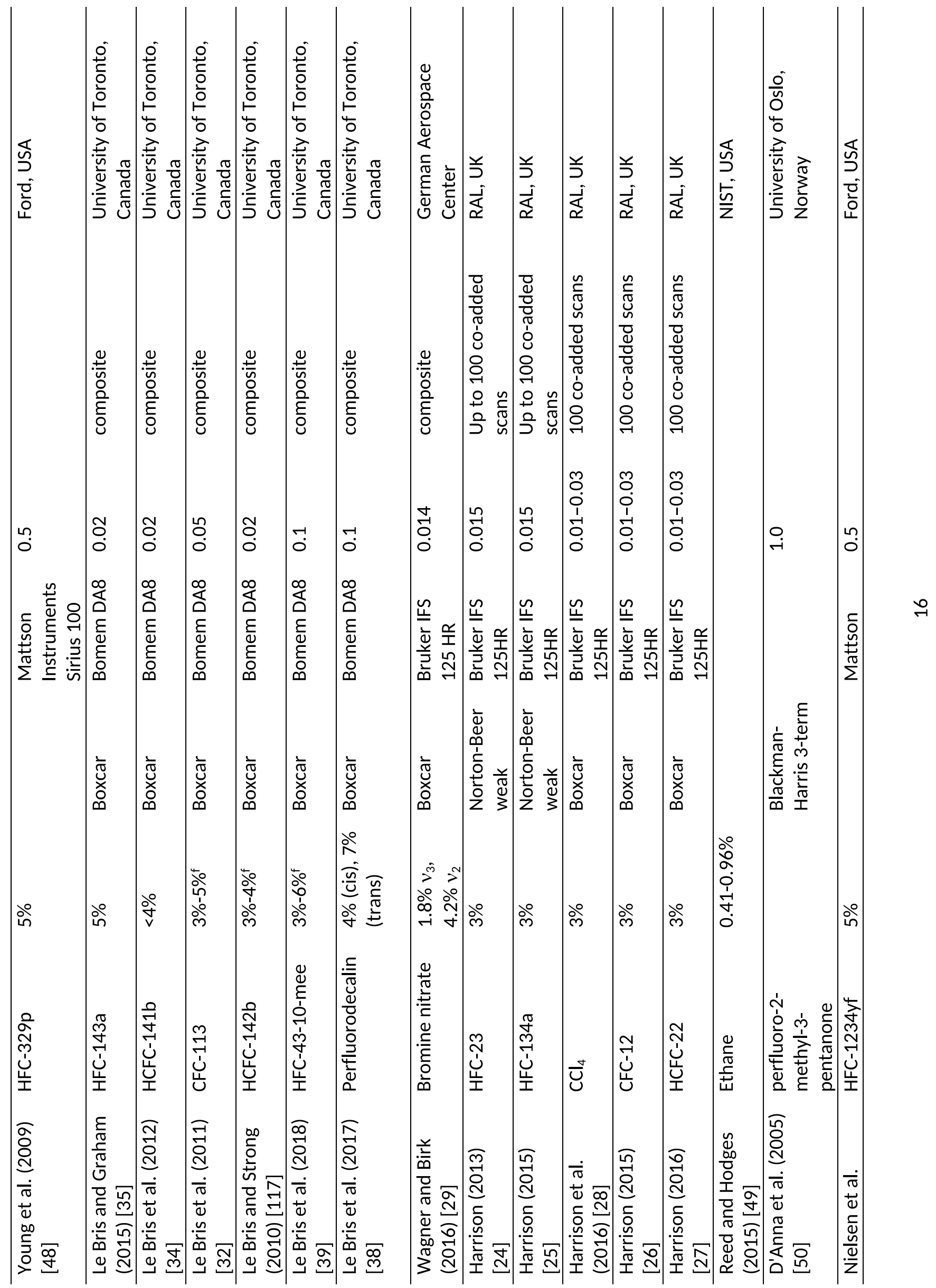




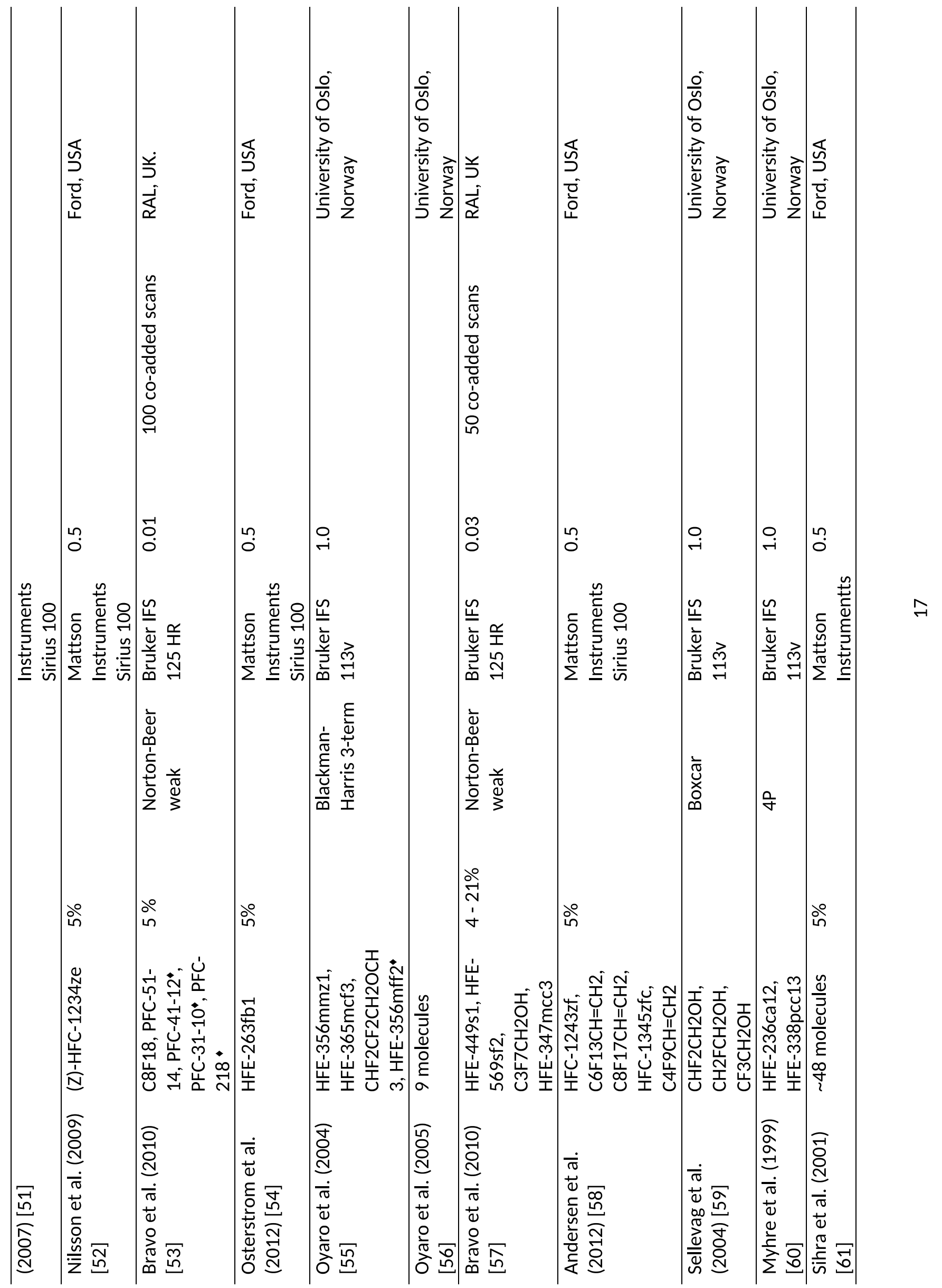




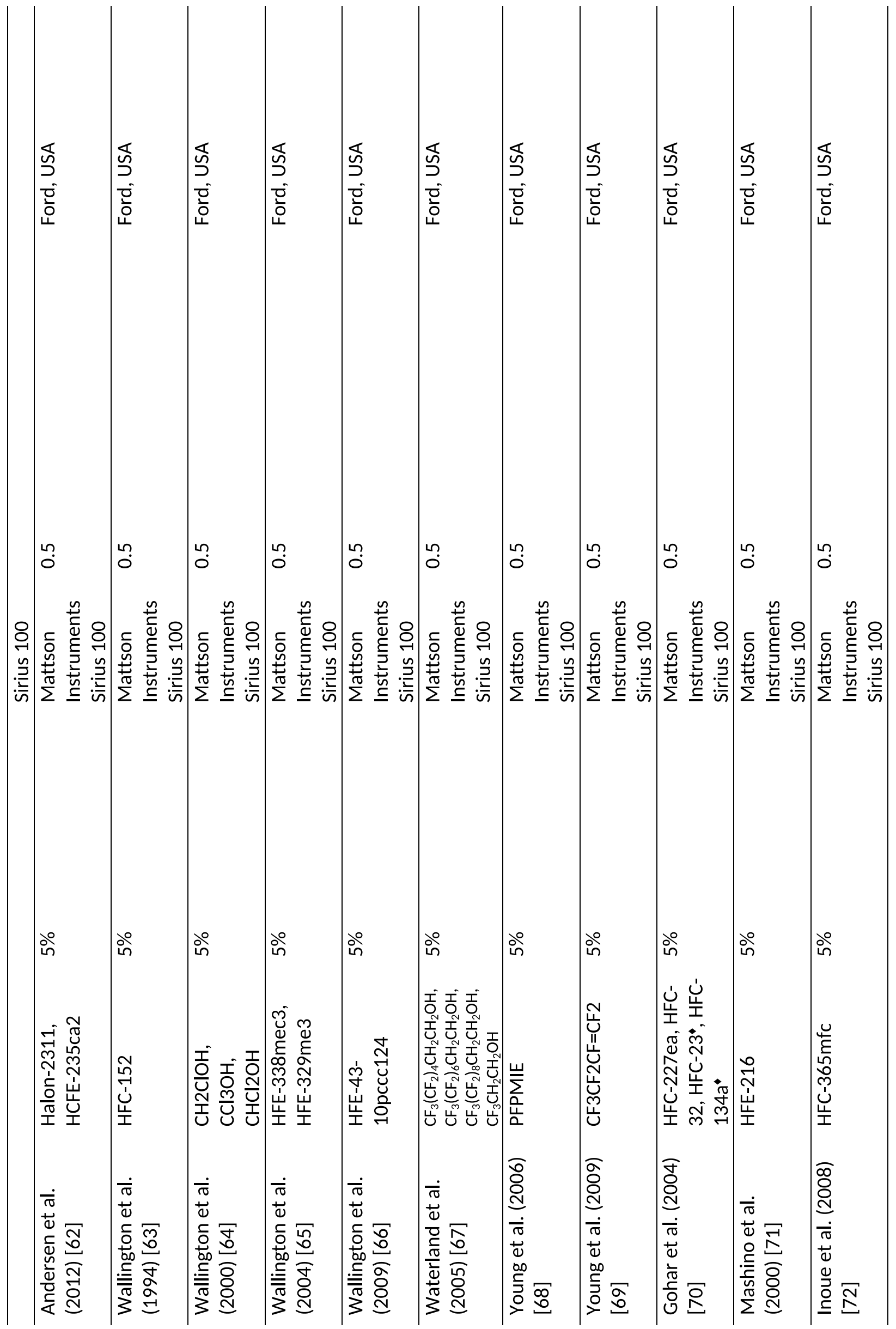




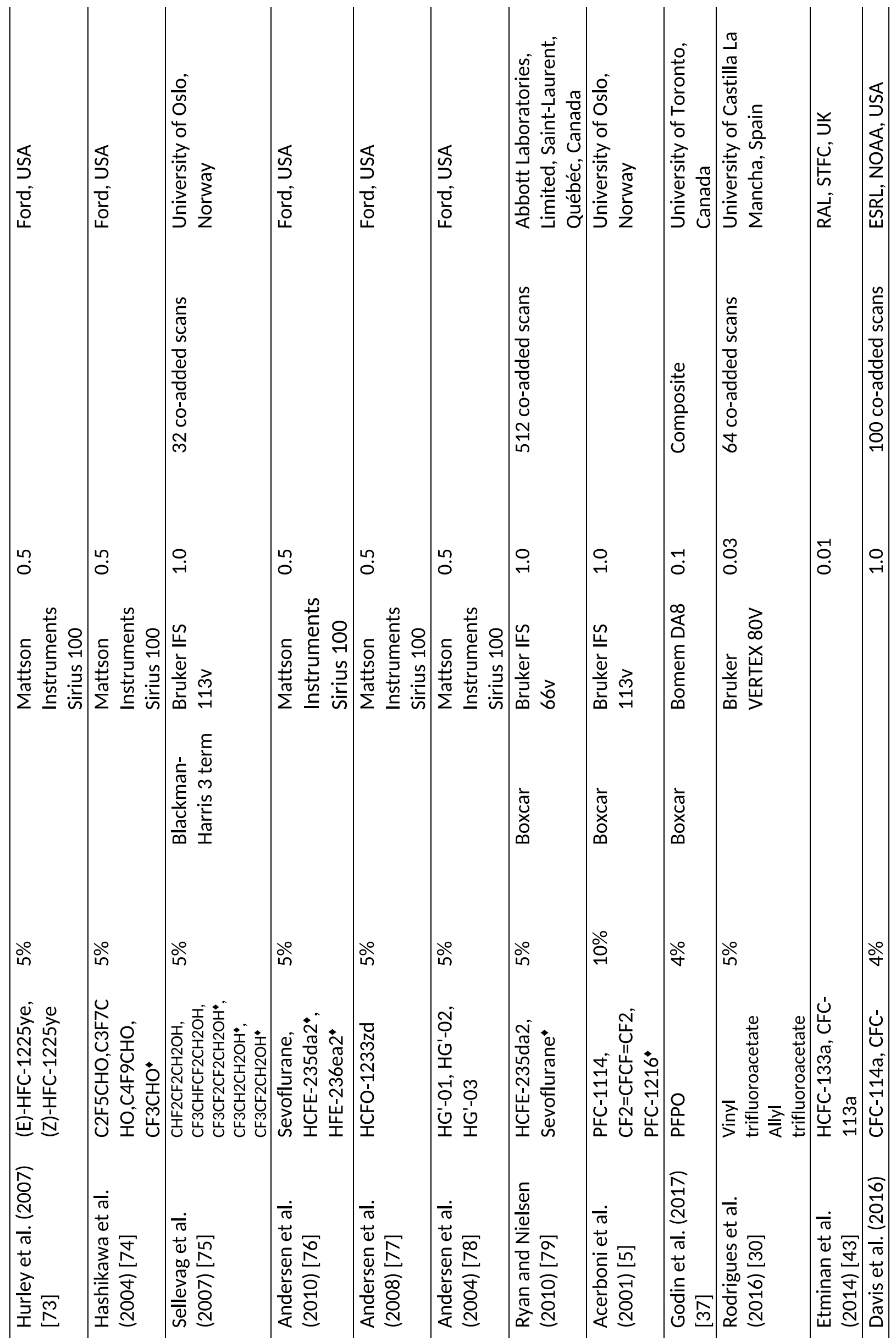




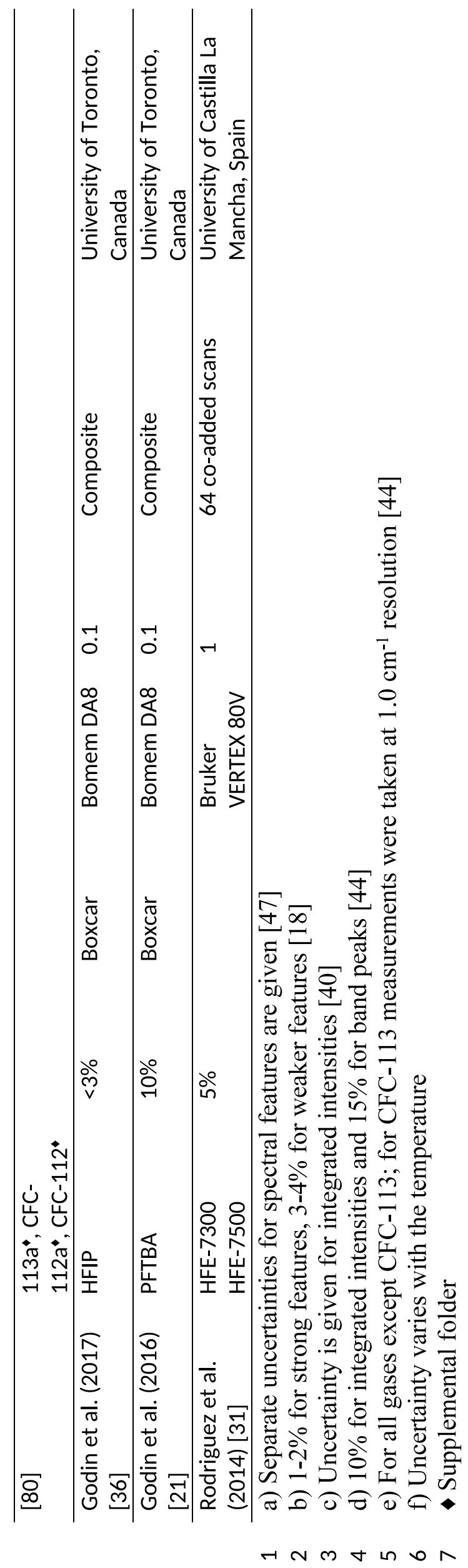




\section{$1 \quad 3.1$. Alcohols, ethers and other oxygenated hydrocarbons}

2 The compounds from this category are used in industrial applications, as solvents, in organic

3 synthesis, electrical systems, production of drugs, resins, explosives, fragrances, as well as in the

4 food and textile industries. Spectroscopic monitoring of molecules from this category can be

5 used in tracking the effluents of biomass burning [13,22], including from forest and rural fires.

6 Oxygenated molecules are typically reactive towards hydroxyl radicals, have relatively short

7 atmospheric lifetimes, and small global warming potentials.

8 The HITRAN2012 [6] edition contained only three molecules from this category, namely acetaldehyde, formaldehyde, and acetone; these molecules are found in the Earth's atmosphere [81-84]. The infrared data for these molecules were already included either in the line-by-line or in the cross-sections parts of the previous HITRAN issue. The cross-sections part from HITRAN2012 included 31 temperature and pressure sets for acetone [83-85] (including scaled cross-sections), 16 sets for acetaldehyde [82], and approximately 44600 transitions for formaldehyde for the region of the strongest IR absorption $(6 \mu \mathrm{m})$ [6]. These data have not been changed in the HITRAN2016 edition [2].

The latest HITRAN2016 update [2] contains over seventy new compounds in this category. The summary of new molecules is shown in Table 5. The new data can be divided into two sources: the original Department of Energy (PNNL-DOE) data [13], and more recently published measurements of compounds relative to the biomass burning, performed by the same laboratory under the same conditions, but providing a new data set sponsored by the Strategic Environmental Research and Development Program (PNNL-SERDP) [22].

New data for acetaldehyde, formaldehyde, and formic acid were added in HITRAN2016, which thus combines information available with HITRAN2012 with new data. PNNL data for acetaldehyde span a wider wavenumber range than the previous HITRAN data from the work by Tereszchuk and Bernath [82], and have stronger absorption features in the low-wavenumber range near $1500 \mathrm{~cm}^{-1}$ (see Figure 2) comparing to the $2400-3400 \mathrm{~cm}^{-1}$ range from the HITRAN2012 release. The HITRAN2012 spectral coverage corresponds to Tereszchuk and Bernath (blue color in Figure 2). This data was made available through HITRANonline in addition to spectra from Tereszchuk and Bernath. Spectra for formaldehyde and formic acid from PNNL are in a good agreement with the absorption cross-sections generated from the lineby-line HITRAN data. Comparisons of PNNL with HITRAN for both these molecules were previously published in Ref. [86]. These spectra are available in the supplemental folder of the database compilation. 
1 For acetone, the PNNL data do not provide new strong features, but do display a saturated

2 band at the lower edge of the PNNL spectral range. However, the strongest feature centered at

$31750 \mathrm{~cm}^{-1}$ in HITRAN2012 (scaled data from Refs. [83] and [85]) was cut-off at $1780 \mathrm{~cm}^{-1}$,

4 while PNNL, although having lower resolution and thermodynamic range, provides this feature

5 uncut. For this reason, the PNNL data were included into the supplemental folder (as a post-

6 release [2] update) and will be considered for including to the HITRANonline interface in the

7 future.

8 For around half of the molecules from Refs. [13,22], the original PNNL data were overwritten 9 by the cross-sections supplied in Ref. [22], some of them re-measured, such as crotonaldehyde

$10(\sim 7 \%$ difference in integrated intensities at room temperature between Refs. [13] and [22], acetol

11 ( $\sim 6.7 \%$ difference), and methyl propyl ketone (1.3\% difference). In Table 5, spectra for all

12 molecules are given for 760 Torr pressure, and for a maximum of three temperatures, which are

13 specified for each molecule separately. All spectra are nitrogen-broadened, with additional self-

14 broadened data for only glycoaldehyde due to its rapid dimerization upon nitrogen pressure-

15 broadening (in the table the corresponding entry is marked as "neat"). For methyl propyl ketone,

16 new sets $(298.15 \mathrm{~K}$ and $323.15 \mathrm{~K})$ were added from Ref. [22] to the $278.15 \mathrm{~K}$ set from the

17 original PNNL database.

18 For four compounds, high-quality data are present in the NIST quantitative infrared database

19 [17]. We used these data to validate the spectra added to the HITRAN database. Figure 3 shows

20 comparisons between PNNL and NIST measurements for ethyl alcohol, ethyl acrylate,

21 methylethyl ketone, and ethyl acetate (at the same thermodynamic conditions). PNNL (green)

22 spectra are overlapped by NIST (blue). It is interesting to note that the NIST data have uniformly

23 larger absorption, having noticeable intensity differences in the stronger bands, which possibly

24 can be attributed to the intensity calibration. Quantitatively, the integrated intensities for these room-temperature spectra are in good agreement, and their relative residuals $(3.1 \%$ for ethyl alcohol, $2.6 \%$ for ethyl acrylate, $0.7 \%$ for methylethyl ketone, and $0.35 \%$ for ethyl acetate) are within the combined measurement uncertainties of the PNNL and NIST measurements (see

Table 4). Integration was performed over the $500-4000 \mathrm{~cm}^{-1}$ wavenumber range. 


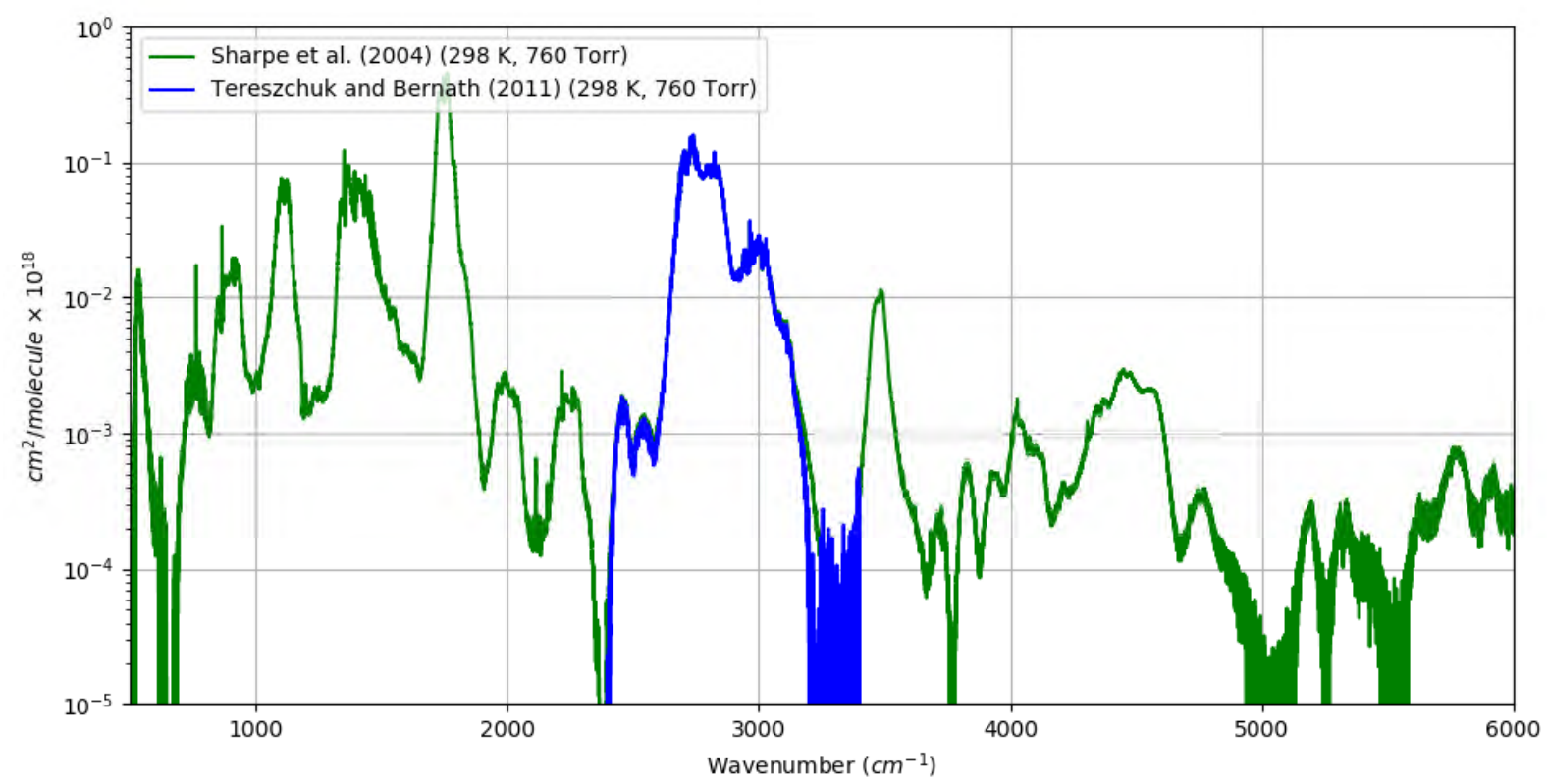

Figure 2. Comparison of the spectral coverage for the acetaldehyde (acetylaldehyde) data from PNNL [13] which are new to HITRAN and those from Tereszchuk and Bernath [82] represented in the HITRAN2012 [6] database. The HITRAN2016 set is a combination of the spectra from these two sources.
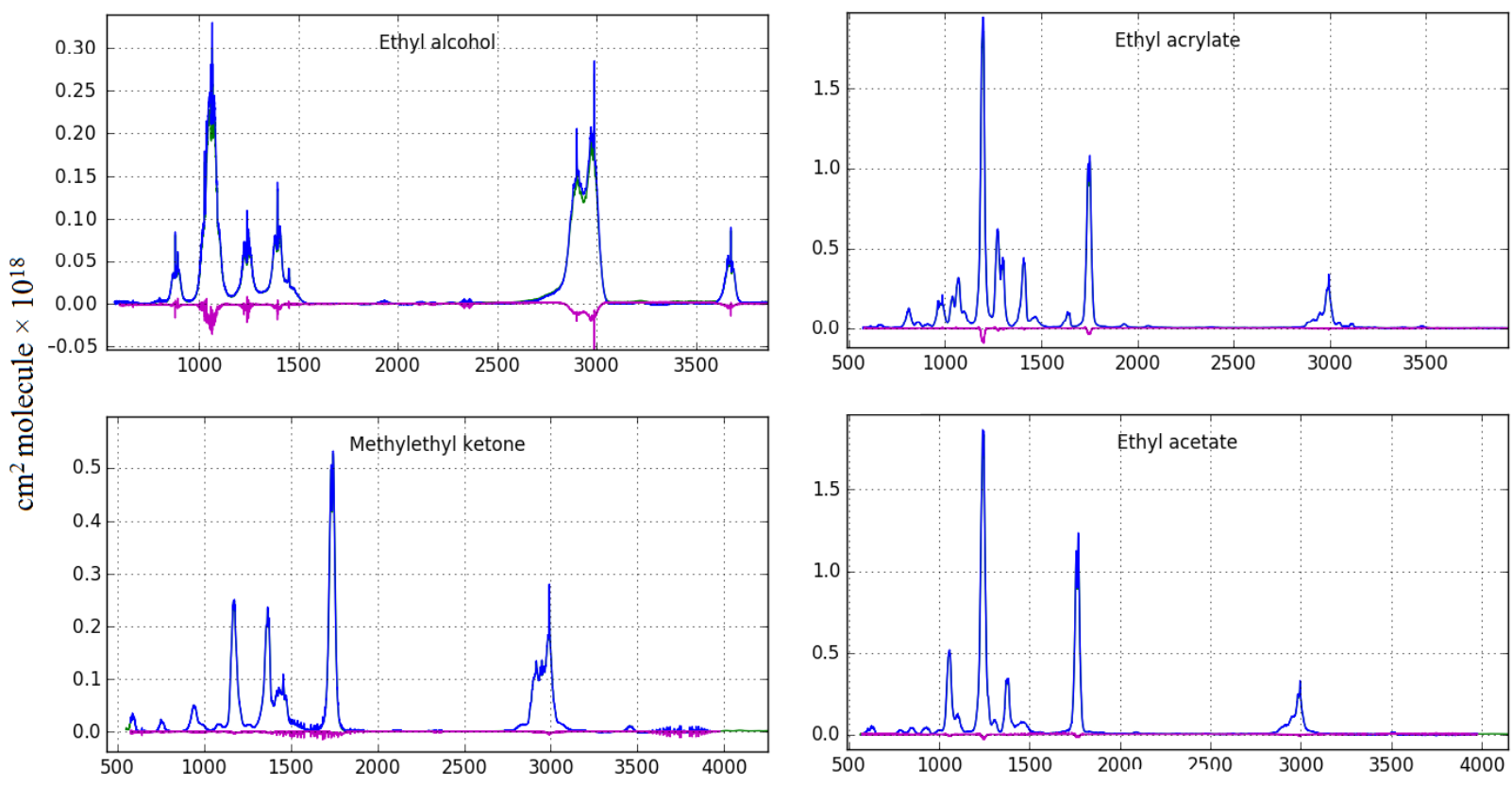

6

Table 5. PNNL data for alcohols, ethers and other oxygenated hydrocarbons.

\begin{tabular}{|c|c|c|c|}
\hline Molecule & CAS & Range, $\mathrm{cm}^{-1}$ & $\mathbf{T}, \mathbf{K}$ \\
\hline \multicolumn{4}{|c|}{ PNNL - SERDP DATA / Johnson et al. [22] } \\
\hline 1-Penten-3-ol & $616-25-1$ & $550-7300$ & $298.15,323.15$ \\
\hline 2,3-Butanedione & $431-03-8$ & $580-6500$ & $278.15,298.15,323.15$ \\
\hline
\end{tabular}




\begin{tabular}{|c|c|c|c|}
\hline 2,3-Dimethylfuran & 14920-89-9 & $510-6500$ & $278.15,298.15,323.15$ \\
\hline 2,5-Dimethylfuran & $625-86-5$ & $550-7000$ & $278.15,298.15,323.15$ \\
\hline 2,6-Dimethoxyphenol & $91-10-1$ & $580-6500$ & 323.15 \\
\hline 2-Hexanol & $626-93-7$ & $520-7250$ & $298.15,323.15$ \\
\hline 2-Methylfuran & $534-22-5$ & $550-6500$ & $278.15,298.15,323.15$ \\
\hline 2-Nonanone & $821-55-6$ & $550-6500$ & $298.15,323.15$ \\
\hline 2-Pentylfuran & $3777-69-3$ & $550-7300$ & $298.15,323.15$ \\
\hline 3,3-Demethyl-2-pentanol & $19781-24-9$ & $520-7250$ & $298.15,323.15$ \\
\hline 3-Methoxyphenol & $150-19-6$ & $550-6500$ & $323.15,333.15$ \\
\hline 3-methylfuran & $930-27-8$ & $550-6500$ & $278.15,298.15,323.15$ \\
\hline 3-Pentanol & $584-02-1$ & $570-7250$ & $298.15,323.15$ \\
\hline 4-Methyl-1-pentanol & $626-89-1$ & $520-7250$ & $298.15,323.15$ \\
\hline 4-Methylvaleric acid & $646-07-1$ & $500-7300$ & $323.15,338.15$ \\
\hline 4-Penten-1-ol & $821-09-0$ & $520-7400$ & $298.15,323.15$ \\
\hline 5-nonanol & $623-93-8$ & $580-7200$ & $298.15,323.15$ \\
\hline Acetol & $116-09-6$ & $435-6500$ & $298.15,323.15$ \\
\hline Acrylic acid & $79-10-7$ & $525-6500$ & 323.15 \\
\hline Cineole & $470-82-6$ & $520-7300$ & 323.15 \\
\hline Diacetone alcohol & $123-42-2$ & $520-7000$ & $298.15,323.15$ \\
\hline Ethyl benzoate & $93-89-0$ & $600-6500$ & 323.15 \\
\hline Furfural & $98-01-1$ & $550-6500$ & $298.15,323.15$ \\
\hline Geraniol & $106-24-1$ & $600-6500$ & 323.15 \\
\hline Glycoaldehyde & $141-46-8$ & $570-6500$ & $298.15,323.15$ \\
\hline Glycoaldehyde (neat) $\dagger$ & $141-46-8$ & $570-6500$ & $298.15,332.15$ \\
\hline Glyoxal & $107-22-2$ & $600-6500$ & $278.15,298.15,323.15$ \\
\hline Guaiacol & $90-05-1$ & $520-7250$ & $298.15,323.15$ \\
\hline Hexyl acetate & $142-92-7$ & $580-6500$ & $298.15,323.15$ \\
\hline Isobutyric acid & $79-31-2$ & $530-7250$ & 337.15 \\
\hline Isopentyl acetate & $123-92-2$ & $550-6500$ & $298.15,323.15$ \\
\hline Isovaleraldehyde & $590-86-3$ & $500-6500$ & $278.15,298.15,323.15$ \\
\hline Limonene oxide & $1195-92-2$ & $510-6500$ & $298.15,323.15$ \\
\hline Menthol & 89-78-1 & $580-6500$ & 323.15 \\
\hline Methyl 2-methylbutyrate & $868-57-5$ & $520-6500$ & $298.15,323.15$ \\
\hline Methyl acetoacetate & $105-45-3$ & $520-6500$ & $298.15,323.15$ \\
\hline Methyl vinyl ether & $107-25-5$ & $550-6500$ & $278.15,298.15,323.15$ \\
\hline Methylglyoxal & $78-98-8$ & $550-6500$ & $298.15,323.15$ \\
\hline Octanoic acid & $124-07-2$ & $550-6500$ & $298.15,323.15$ \\
\hline Phenol & $108-95-2$ & $550-7300$ & $298.15,323.15$ \\
\hline Propylene carbonate & $108-32-7$ & $600-6500$ & $298.15,323.15$ \\
\hline trans-Crotonaldehyde & $123-73-9$ & $500-6500$ & $278.15,298.15,323.15$ \\
\hline Valeraldehyde & $110-62-3$ & $600-6500$ & $278.15,298.15,323.15$ \\
\hline Valeric acid & $109-52-4$ & $520-7100$ & 340.15 \\
\hline Methyl propyl ketone $\ddagger$ & $107-87-9$ & $520-6500$ & $278.15,298.15,323.15$ \\
\hline
\end{tabular}

\begin{tabular}{lccc}
\hline & PNN - DOE DATA / Sharpe et al. [13] \\
\hline Acetic acid & $64-19-7$ & $550-7100$ & $298.15,323.15$ \\
\hline Acetylaldehyde & $75-07-0$ & $510-6500$ & $278.15,298.15,323.15$ \\
\hline Acrolein & $107-02-8$ & $540-6500$ & $278.15,298.15,323.15$ \\
\hline Benzaldehyde & $100-52-7$ & $600-6500$ & $278.15,298.15,323.15$ \\
\hline Benzyl alcohol & $100-51-6$ & $550-7400$ & $298.15,323.15$ \\
\hline
\end{tabular}




\begin{tabular}{llll}
\hline Dimethyl ether & $115-10-6$ & $600-6500$ & $278.15,298.15,323.15$ \\
\hline Ethyl acetate & $141-78-6$ & $565-6500$ & $278.15,298.15,323.15$ \\
\hline Ethyl acrylate & $140-88-5$ & $580-6500$ & $278.15,298.15,323.15$ \\
\hline Ethyl alcohol & $64-17-5$ & $600-7500$ & $278.15,298.15,323.15$ \\
\hline Ethyl formate & $109-94-4$ & $600-6500$ & $278.15,298.15,323.15$ \\
\hline EVE & $109-92-2$ & $570-6500$ & $278.15,298.15,323.15$ \\
\hline Formic acid, dimer & $14523-98-9$ & $540-7200$ & $278.15,298.15$ \\
\hline Furan & $110-00-9$ & $550-6500$ & $278.15,298.15,323.15$ \\
\hline Furfuryl alcohol & $98-00-0$ & $550-7300$ & $298.15,323.15$ \\
\hline Isophorone & $78-59-1$ & $600-6500$ & $298.15,323.15$ \\
\hline m-Cresol & $108-39-4$ & $570-6500$ & $298.15,323.15$ \\
\hline Methyl butyl ether & $628-28-4$ & $600-6500$ & $278.15,298.15,323.15$ \\
\hline Methyl isoamyl ketone & $110-12-3$ & $550-6500$ & $298.15,323.15$ \\
\hline Methyl methacrylate & $80-62-6$ & $550-6500$ & $278.15,298.15,323.15$ \\
\hline Methyl nitrite & $624-91-9$ & $520-6500$ & $278.15,298.15,323.15$ \\
\hline Methyl pivalate & $598-98-1$ & $550-6500$ & $278.15,298.15,323.15$ \\
\hline Methyl propionate & $554-12-1$ & $530-6500$ & $278.15,298.15,323.15$ \\
\hline Methyl salicylate & $119-36-8$ & $550-6500$ & $298.15,323.15$ \\
\hline Methylethyl ketone & $78-93-3$ & $550-6500$ & $278.15,298.15,323.15$ \\
\hline Nitrobenzene & $98-95-3$ & $550-6500$ & $298.15,323.15$ \\
\hline Propionaldehyde & $123-38-6$ & $520-6500$ & $278.15,298.15,323.15$ \\
\hline All
\end{tabular}

1 All spectra are broadened by nitrogen and recorded at $0.112 \mathrm{~cm}^{-1}$ resolution.

$2 \uparrow$ Self-broadened spectra, provided in Johnson et al. [22], in addition to the air-broadened data

$3 \$$ Two cross-sections for Methyl propyl ketone from Sharpe et al. [13] were superseded by the later work

4 of Johnson et al. [22].

5 3.2. Halogenated Alcohols and Ethers

A significant number of halogenated alcohols and ethers have been added to the HITRAN database. In this section the fluorinated and chlorinated compounds are presented. Stretching

8 modes of the C-F and C-O bonds occur between 1000 and $1360 \mathrm{~cm}^{-1}$ depending on the

9 molecule; fluorinated compounds absorb in the atmospheric window region and are of interest

10 for climate science. The molecules have a broad range of lifetimes [87] from days to more than a

11 century in the case of $\mathrm{CHF}_{2} \mathrm{OCF}_{3}$ and a broad range of uses such as in anesthetics and heat

12 transfer agents. Although some of species are powerful greenhouse gases, on a molecule-permolecule basis, and potentially ozone depleting substances (ODSs) when they contain chlorine, current emissions and atmospheric abundances are small, so far leading to negligible effects. These compounds have GWPs that are lower than for the corresponding HFCs and HCFCs, thus making halogenated alcohols and ethers potential HFC and HCFC substitutes [88]. In this subsection, we give an overview for the compounds in HITRAN. Many of the spectra were measured at room temperature, either air- or self-broadened, and were previously compiled in the review on halocarbons and related compounds by Hodnebrog and coauthors [1]. Other data were obtained from the PNNL database [13] and measurements published by Godin et al. [36,37] and Rodriguez et al. [30,31]. In this section we consider the category of all compounds 
corresponding to halogenated alcohols and ethers divided into the subcategories of hydrofluoro ethers (HFEs), fluorinated polyethers (HFPEs and PFPEs), fluorinated alcohols, and fluorinated aldehydes, ketones, and acids.

\subsubsection{Hydrofluoroethers (HFEs)}

Hydrofluoroethers (HFEs) are a potential replacement for chlorofluorocarbons (CFCs), hydrofluorocarbons (HFCs), hydrochlorofluorocarbons (HCFCs), and halons. HFEs have higher reaction rates with the atmospheric oxidants such as $\mathrm{OH}$ radicals, which reduces their atmospheric lifetimes relative to CFCs $[30,31,57,65]$. HFEs do not contain chlorine and thus do not take part in the chlorine-based catalytic destruction of atmospheric ozone $[54,89]$. This makes HFEs an attractive replacement to CFCs and their derivatives in various applications, such as, for instance, production of carrier fluids for lubricants, cleaning solvents for electronic components, fire suppression agents, heat transfer fluids (e.g. in air conditioners and refrigeration), and anesthetic agents [30,54,55,57,62,76,79]. Due to the C-F and C-O bonds, fluorinated ethers and polyethers absorb in the atmospheric window and contribute to radiative forcing of climate change $[66,68]$. Figure 4 shows the spectra of the five compounds (HFEs and PFPEs) having 100-year GWPs higher than 5000 [1]

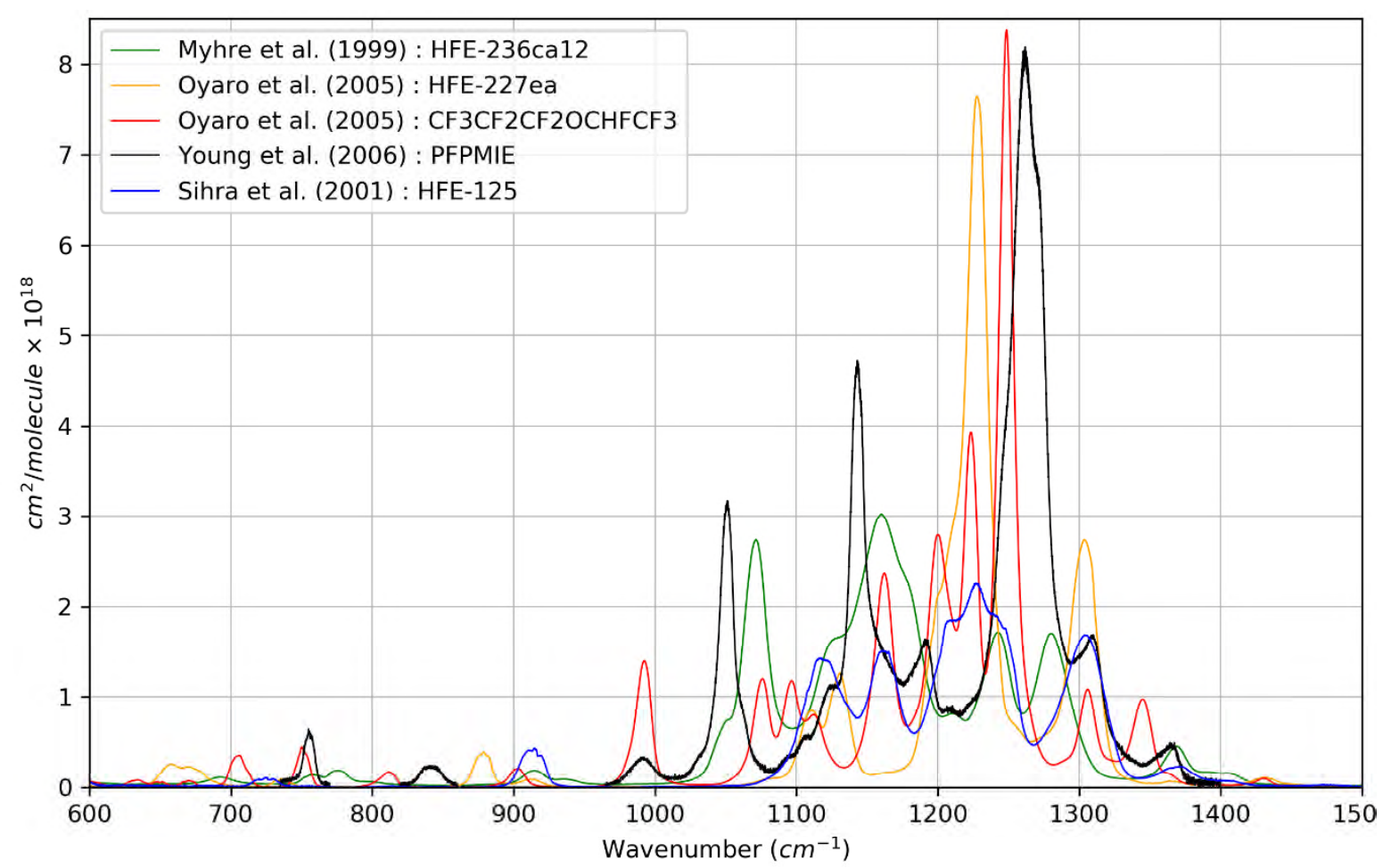

Figure 4. Spectra of five fluorinated ethers and polyethers in HITRAN2016 having the largest 100-year GWP values among halogenated alcohols and ethers category: HFE-236ca12 (HG-10) [60], HFE-227ea [56], Fluoroether E-1 $\left(\mathrm{CF}_{3} \mathrm{CF}_{2} \mathrm{CF}_{2} \mathrm{OCHFCF}_{3}\right)$ [56], PFPMIE [68], and HFE- 
1125 [61]. Corresponding 100-year GWPs are 5350, 6450, 6490, 9710, and 12400, respectively

$2[3]$.

\section{3.2.2. Fluorinated polyethers (HFPEs and PFPEs)}

$4 \quad$ Fluorinated polyethers (FPEs) contain multiple oxygen atoms creating a chain of hydrocarbon groups. Similar to HFEs, FPEs have been used as CFC replacements as heat transfer fluids, refrigeration working fluids, solvents, fire suppressants, and heat exchange agents $[60,66,68,78]$. As with HFEs, FPEs do not contain chlorine and thus do not contribute to chlorine-based catalytic destruction of atmospheric ozone [66].

The HITRAN2016 edition includes two groups of fluorinated polyethers, hydrofluoropolyethers (HFPEs) and perfluoropolyethers (PFPEs). The presence of multiple ether groups and C-H bonds in HFPEs generally limits the atmospheric lifetimes and GWPs of these substances mainly by reactions with atmospheric $\mathrm{OH}$ radicals [66,78]. A subgroup of HFPEs, HGaldens, with the general formula $\mathrm{CHF}_{2} \mathrm{O}\left(\mathrm{CF}_{2} \mathrm{O}\right)_{\mathrm{m}}\left(\mathrm{CF}_{2} \mathrm{O}\right)_{n} \mathrm{CF}_{2} \mathrm{H}$ have low reactivity towards $\mathrm{OH}$ radicals, long atmospheric lifetimes, and high GWPs [1].

Unlike HFPEs, PFPEs have all hydrogen atoms substituted by fluorine. This makes these compounds unreactive in the lower atmosphere due to the lack of the $\mathrm{C}-\mathrm{H}$ bonds. The absence of sites for $\mathrm{OH}$ reaction leads to long atmospheric lifetimes and hence high GWPs. The lifetimes of PFPEs are limited by photolysis in the upper atmosphere [68].

The HITRAN2016 update includes self-broadened [31,55-57], air-broadened [54,61,65,71] and nitrogen-broadened spectra [89] for fluorinated ethers, polyethers, and esters measured at room temperature (295-298 K). For these molecules, as well as for the rest of the subgroups of halogenated alcohols and ethers, the full list of molecules made available through the HITRANonline interface is presented in Table 6 and Table 7. Table 6 contains data provided in Hodnebrog et al. [1] with original sources given in the table, while Table 7 lists data from Godin et al. [36,37], Rodriguez et al. [30,31], and the PNNL database [13].

For a number of molecules, comparisons were made where possible to decide which data should be provided via the HITRANonline interface, and which should be put into the supplemental folder. Figure 5 shows spectra from different sources for molecules from HFE, HFPE, and PFPE subcategories. Spectra for HFE-263fb1 were published by Osterstrom et al. [54] and Oyaro et al. [56]. Agreement in spectral band shapes and integrated band intensities is very good ( $\sim 0.15 \%)$. According to Ref. [56], these compounds did not show "discernible dependency in their absorption cross section by the addition of $\mathrm{N}_{2}$ to atmospheric pressure". Spectra from Ref. [54] were included in the HITRANonline web interface because of their 
higher resolution. For HFE-356mff2, spectra from Sihra et al. [61] and Oyaro et al. [55] had been compared. There is good agreement between the band shapes and the difference in the reported integrated band intensities is $\sim 3.3 \%$ which lies well within the combined experimental uncertainties (see Table 4). Due to higher resolution, the data from Ref. [61] were included to the HITRANonline interface. Spectra for HFE-245fa2 were measured in Refs. [61] and [56] with a good agreement in their integrated intensities (1.65\%). The spectra with higher resolution, provided in Ref. [61], were included in HITRANonline. For HFE-7200 and HFE-7000 (HFE347mcc3), the spectra published by Bravo et al. [57] were included in HITRANonline. Figure 5 displays comparisons of spectra from this source with Ref. [61] and Ninomyya et al [89] for HFE-7200 and HFE-347mcc3 respectively. In both cases, the data from Ref. [57] had higher resolution $\left(0.1 \mathrm{~cm}^{-1}\right.$ for HFE-7200 and $0.03 \mathrm{~cm}^{-1}$ for HFE-7000). The data provided in Ref. [57] are self-broadened; no significant differences between self- and air-broadened spectra for this molecule were reported [57]. Since the data from this reference show non-linearity at the edges of the spectra (as can be seen by the low-resolution residual on the plots) it was decided to relegate the other data $[61,89]$ on these molecules to the supplemental folder.

For general anesthetic gases, the HITRAN2016 edition includes self- and air-broadened spectra of HCFE-235ca2 (enflurane), HCFE-235da2 (isoflurane), HFE-236ea2 (desflurane), and HFE-347mmzl (sevoflurane) previously published by Ryan and Nielsen [79] and Andersen et al. $[62,76]$. Figure 5 shows spectra for isoflurane, sevoflurane, and desflurane. Measurements for isoflurane were published by Sihra et al. [61], Andersen et al. [76], and Ryan and Nielsen [79] . The total integrated absorption reported in these three studies agrees within 5.7\%. For the strongest band, the data from Ref. [76] have the largest absorption, followed by Ref. [79], then by Sihra et al. [61]. Spectra from Ref. [76] do not include small features at $500 \mathrm{~cm}^{-1}$. All three sources have the same uncertainty (see Table 4), and the corresponding spectra agree well within the stated uncertainty. Spectra from Ref. [79] were included in the HITRANonline web interface since it roughly represents the mean value for the band shapes of the two other spectra, and gives the same GWP value that was obtained in Hodnebrog et al. [1] using the data from Ref. [76]. Spectra from Refs. [76] and [61] were placed in the supplemental folder of the HITRAN database. For sevoflurane, there is excellent agreement in band shapes and integrated intensities $(\sim 0.3 \%)$ in the spectra published by Andersen et al. [76] and Ryan and Nielsen [79]; the spectra from Ref. [76] were included in the HITRANonline web interface due to their better resolution. Desflurane spectra considered in the comparison were published by Andersen et al. [76] and Oyaro et al. (2005) [56]. The integrated intensities differ by $6.6 \%$, which is within the combined uncertainties. The cross-section values from Ref. [76] are uniformly larger than those from Ref. 
1 [56], with the difference being more pronounced in the absorption peaks. Although having

2 similar integrated cross-sections, the data from Oyaro et al. are more complete in terms of the

3 spectral range and contain minor features. Spectra from Ref. [56] have been made available via

4 HITRANonline because of their greater stated accuracy (2\%). The spectra from Ref. [76] were

5 added to the supplemental folder.

6 For H-Galdens (HFPEs), the HITRAN2016 edition includes the following data published in 7 different years: HG'-01, HG'-02, and HG'-03 from the work by Andersen et al. [78], HG-01 and

8 HG-10 from Myhre et al. [60], and HG-11 from Wallington et al. [66]. In Figure 5, the

9 comparison for HG-11 is shown. The spectrum from Ref. [66] has been made available through the HITRANonline web interface because it supersedes that published by Sihra et al. [61].

For PFPEs, the database update includes only PFPMIE spectra, which was initially published by Young et al [68] and, like many other molecules, is provided in HITRAN format in Ref. [1]. For fluorinated esters, the recently measured self-broadened data published by Rodriguez et al. [30] have been included for allyl 2,2,2-trifluoroacetate (ATFA) and vinyl 2,2,2-trifluoroacetate (VTFA).
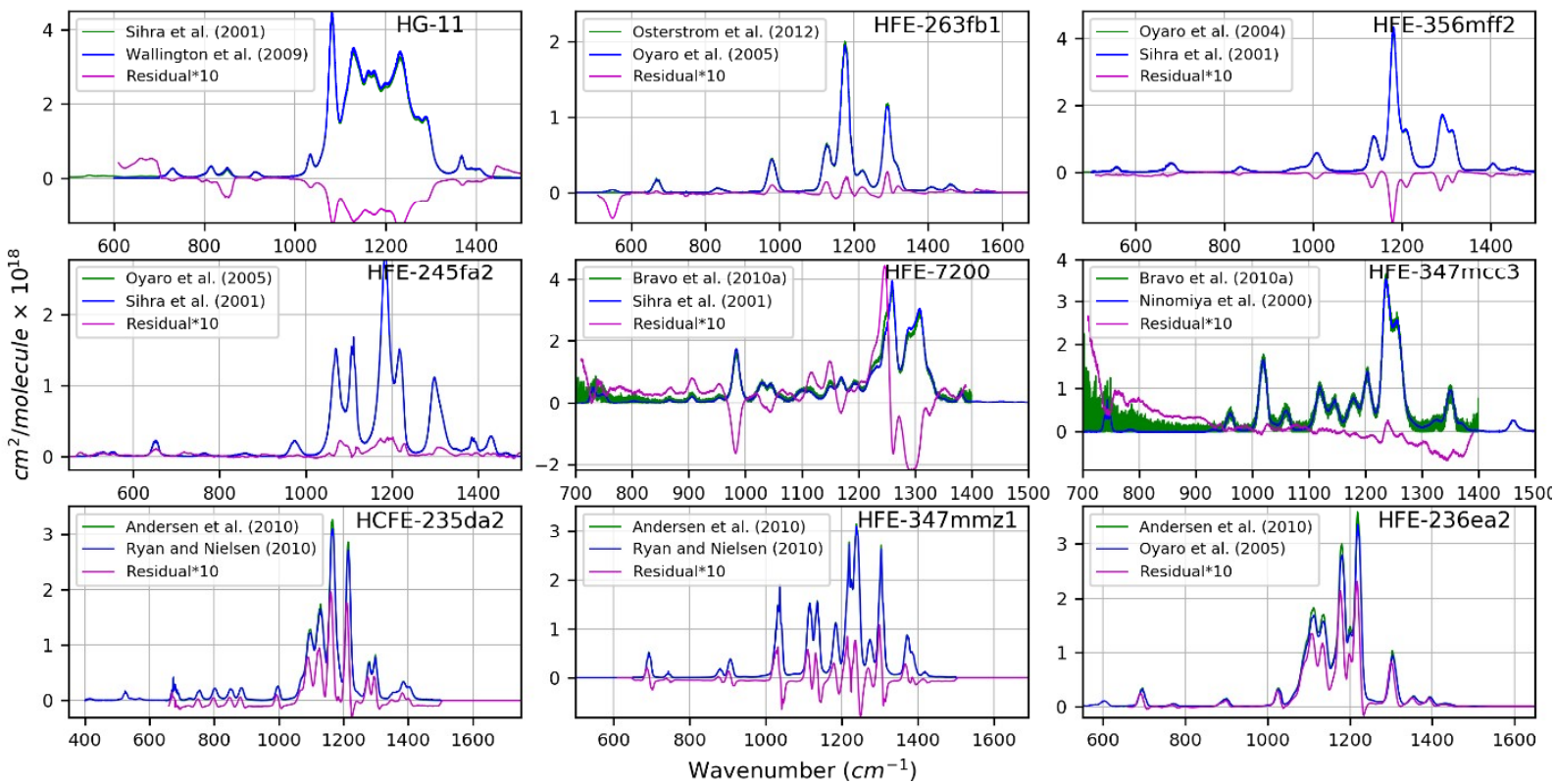

Figure 5. Spectra for HFEs, HFPEs, and anesthetics. The residuals (magenta derived from the green minus blue lines in each frame) are multiplied by 10. Due to the fact that in all cases the spectral resolutions for the raw spectra are different, the wavenumber-dependent residuals were calculated on spectra with the final resolution degraded to $10 \mathrm{~cm}^{-1}$ to show the systematic discrepancies. The data made available through the HITRANonline web interface are outlined in

Table 6 for each molecule. 
Fluorinated alcohols are used in electronic and industrial applications, and in organic synthesis $[37,47]$. Due to the presence of the C-F bond, these compounds absorb in the atmospheric window region, however because their atmospheric lifetimes are relatively short they have small global warming potentials [1]. The compounds from this subclass, which are included in the HITRAN2016 edition, include partially fluorinated alcohols and fluorotelomer alcohols (FTOHs).

For partially-fluorinated alcohols, the HITRAN2016 edition includes the following updates: the spectra recently published by Godin et al. for 2,2,3,3,3-pentafluoropropan-1-ol / PFPO [37] and 1,1,1,3,3,3-hexafluoropropan-2-ol / HFIP [36]. Spectra for both molecules are selfbroadened, recorded with $0.1 \mathrm{~cm}^{-1}$ resolution, and have a strong absorption in the $500-1500 \mathrm{~cm}^{-1}$ spectral range. A brief description of these cross-sections is given in Table 7. Figure 6 shows a comparison of the room-temperature spectra for 2,2,3,3,3-pentafluoropropanol published by Godin et al [37] and Sellevag et al. [75]. Older data published in Ref. [75] were measured with lower resolution. The data from Godin et al. [37] were included in the HITRANonline interface, while the data from Ref. [75] were placed in the supplemental folder. Note that the latter data contain the uncut spectral features below $600 \mathrm{~cm}^{-1}$. The integrated absorption between those cross-sections differs by $8 \%$, which can possibly be attributed to the intensity calibration. For 2,2,2-trifluoroethanol $\left(\mathrm{CF}_{3} \mathrm{CH}_{2} \mathrm{OH}\right)$ and 2-fluoroethanol $\left(\mathrm{CH}_{2} \mathrm{FCH}_{2} \mathrm{OH}\right)$, room-temperature spectra were compared between two sources, namely the PNNL database [13] and Sellevag et al. [59]. These comparisons are also presented in Figure 6. Data from PNNL have been included in the HITRANonline interface since they are better resolved and provide more temperature coverage. Due to the additional features at the lower wavenumber range, spectra from Sellevag et al. have also been included in HITRANonline. For 2,2,3,3,4,4,4-heptafluorobutan-1-ol, a comparison was made between the room-temperature spectra published by Bravo et al. [57] and Sellevag et al. [75] with an integrated absorption cross-section difference of $6.1 \%$, which lies within the combined uncertainties (see Table 4). Data from Ref. [57] have been included in HITRANonline for this molecule. Three more molecules (2,2-difluoroethanol, 2,2,3,3tetrafluoro-1-propanol, and 2,2,3,4,4,4-hexafluoro-1-butanol) from Refs. [59] and [75] have been included in HITRANonline. Cross-sections for fluorotelomer alcohols $(1 \mathrm{H}, 1 \mathrm{H}, 2 \mathrm{H}, 2 \mathrm{H}$ Perfluorononan-1-ol, 1H,1H,2H,2H-perfluoroundecan-1-ol, 3,3,4,4,5,5,6,6,7,7,7undecafluoroheptan-1-ol, and 3,3,3-Trifluoropropan-1-ol) were included in HITRANonline from the work by Waterland et al. [67]. For one of these molecules, 3,3,3-trifluoropropan-1-ol $\left(\mathrm{CF}_{3} \mathrm{CH}_{2} \mathrm{CH}_{2} \mathrm{OH}\right)$, comparison with the data from Ref. [75] is displayed in Figure 6. Data from Ref. [75] have been added to the supplemental folder since it has the uncut absorption features 
1 below $650 \mathrm{~cm}^{-1}$. Finally, three molecules from the chloroethenes subclass (chloromethanol, 2 dichloromethanol, trichloromethanol) published by Wallington et al. [64] have been included in 3 HITRANonline.
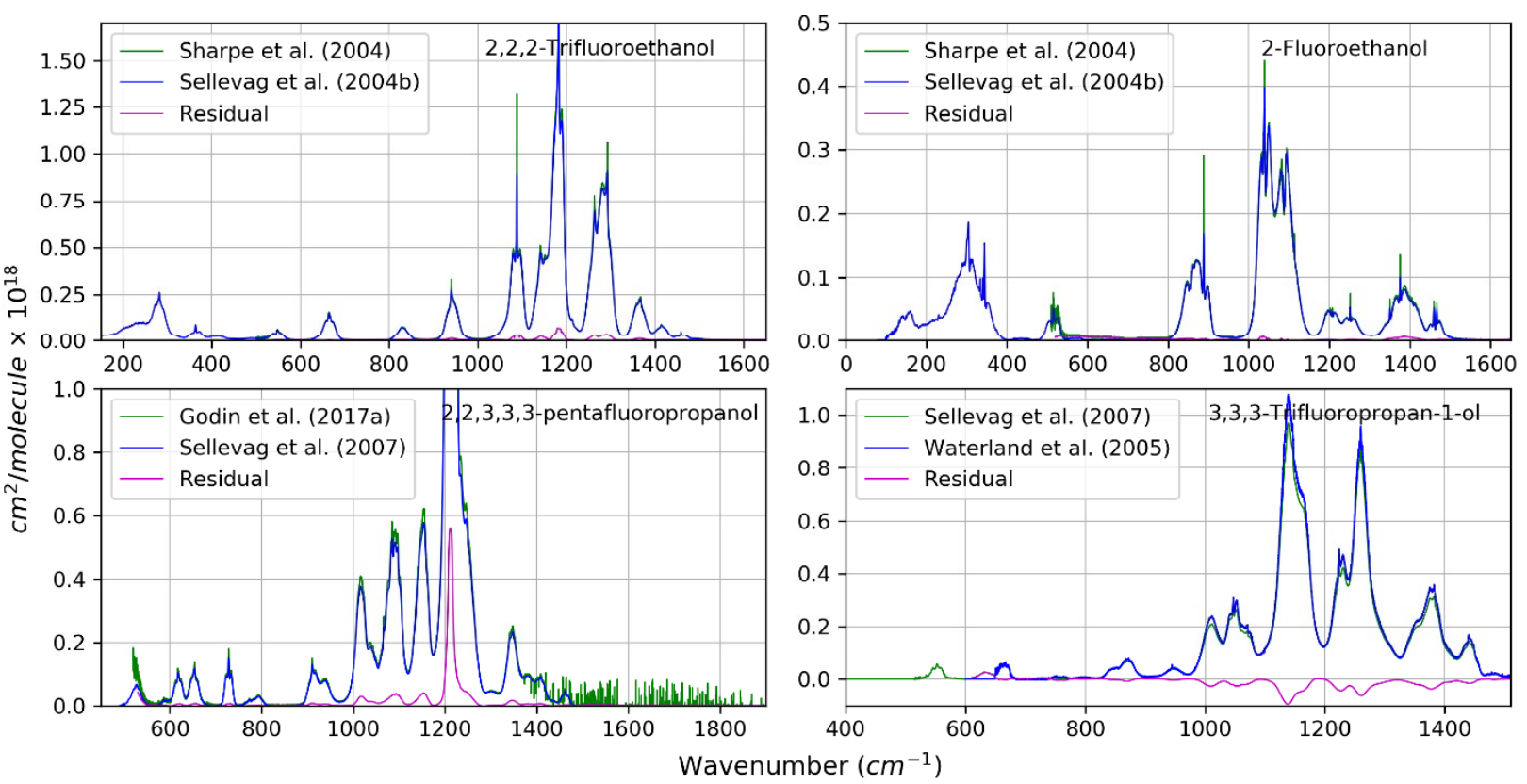

4

5

6

Figure 6. Spectra for the fluorinated alcohols. The residual (magenta derived from the green minus blue lines in each frame) is given on the same scale as the spectra. The spectral resolutions for the raw spectra are different, and wavenumber-dependent residuals were calculated using spectra with resolution degraded to $10 \mathrm{~cm}^{-1}$ to show the systematic discrepancies. The data made available via the HITRANonline web interface are outlined in Table 6 and Table 7 for each molecule.

\subsubsection{Fluorinated aldehydes, ketones, and acids}

A number of fluorinated aldehydes, ketones and acids were added to the HITRAN database. Aldehydes are the degradation products of alcohols and HFCs [74]. Three perfluoroalkyl aldehydes (pentafluoropropionaldehyde, heptafluorobutyraldehyde, and nonafluoropentanal) were added from the work by Hashikawa et al. [74]. For 2,2,2-trifluoroacetaldehyde $\left(\mathrm{CF}_{3} \mathrm{CHO}\right)$, spectra were measured both in Refs. [74] and Sellevag et al. [47]. In the latter reference the uncertainties are given for each band separately in Table 1 of their paper, and the overall uncertainty for intensity is less than two percent. In Hashikawa et al. [74], the uncertainty is 5\% over the whole range. According to the figures, the integrated intensity of the spectrum from Hashikawa et al. is lower by $16 \%$, and has a partly negative baseline, possibly due to miscalibration. The agreement between these two spectra is good and lies within the combined uncertainties. The data from Ref. [47] have been included in HITRANonline, while spectra from Ref. [74] have been put in the supplemental folder, as well as the raw data from Ref. [47] containing some negative values. In addition, the spectra from Ref. [47] for 3,3,3-Trifluoropropanal have been included in HITRANonline. Finally, spectra for two ketones, chloroacetone 
1 and perfluoro-2-methyl-3-pentanone, and trifluoroacetic acid, have been included in

2 HITRANonline from Refs. [13], [50], and [13] respectively. The brief outline of the

3 experimental conditions for all molecules described in this section can be found in Table 6 and

4 Table 7.

5 Table 6. Spectra from the review on halocarbons and related compounds (Hodnebrog et al. [1])

6 for halogenated alcohols and ethers.

\begin{tabular}{|c|c|c|c|c|c|c|}
\hline Molecule & CAS & $\begin{array}{c}\mathbf{T} \\
(\mathbf{K})\end{array}$ & $\begin{array}{c}\text { P } \\
\text { (Torr) }\end{array}$ & Broadener & $\begin{array}{c}\text { Resolution } \\
\left(\mathbf{c m}^{-1}\right)\end{array}$ & Source \\
\hline HG-01 & $73287-23-7$ & 296 & 700 & air & 0.25 & \multirow{3}{*}{ Andersen et al. (2004) [78] } \\
\hline HG-02 & $485399-46-0$ & 296 & 700 & air & 0.25 & \\
\hline HG-03 & $485399-48-2$ & 296 & 700 & air & 0.25 & \\
\hline HFE-347mmz1 & $28523-86-6$ & 298 & 700 & air & 0.25 & Andersen et al. (2010) [76] \\
\hline HCFE-235ca2 & $13838-16-9$ & 298 & 700 & air & 0.25 & Andersen et al. (2012) [62] \\
\hline $\begin{array}{l}2,2,3,3,4,4,4- \\
\text { Heptafluorobutan-1-ol }\end{array}$ & $375-01-9$ & 298 & & & 0.1 & \multirow{4}{*}{ Bravo et al. (2010) [57] } \\
\hline HFE-347mcc3 & $375-03-1$ & 298 & & & 0.03 & \\
\hline HFE-449s1 & & 298 & & & 0.1 & \\
\hline HFE-7200 & & 298 & & & 0.1 & \\
\hline $\begin{array}{l}\text { perfluoro-2-methyl-3- } \\
\text { pentanone }\end{array}$ & $756-13-8$ & 298 & & air & 1 & D'Anna et al. (2005) [50] \\
\hline Heptafluorobutyraldehyde & $375-02-0$ & 296 & 700 & air & 0.5 & \multirow{3}{*}{ Hashikawa et al. (2004) [74] } \\
\hline Nonafluoropentanal & $375-53-1$ & 296 & 700 & air & 0.5 & \\
\hline Pentafluoropropionaldehyde & $422-06-0$ & 296 & 700 & air & 0.5 & \\
\hline HFE-216 & $1187-93-5$ & 296 & 700 & air & 0.25 & Mashino et al. (2000) [71] \\
\hline HG-01 & $188690-78-0$ & 296 & & air & 1 & \multirow{2}{*}{ Myhre et al. (1999) [60] } \\
\hline HG-10 & $78522-47-1$ & 296 & & air & 1 & \\
\hline HFE-263fb1 & $460-43-5$ & 296 & 700 & air & 0.25 & Osterstrom et al. (2012) [54] \\
\hline $\begin{array}{l}\text { 1,1,2,2-Tetrafluoro-3- } \\
\text { methoxy-propane }\end{array}$ & $60598-17-6$ & 298 & & & 1 & \multirow{3}{*}{ Oyaro et al. (2004) [55] } \\
\hline HFE-356mmz1 & $13171-18-1$ & 298 & & & 1 & \\
\hline HFE-365mcf3 & $378-16-5$ & 298 & & & 1 & \\
\hline $\begin{array}{l}\text { 1,1,2-Trifluoro-2- } \\
\text { (trifluoromethoxy)-ethane }\end{array}$ & $84011-06-3$ & 298 & & & 1 & \multirow{6}{*}{ Oyaro et al. (2005) [56] } \\
\hline $\begin{array}{l}\text { 1-Ethoxy-1,1,2,3,3,3- } \\
\text { hexafluoropropane }\end{array}$ & $380-34-7$ & 298 & & & 1 & \\
\hline Fluoroether E-1 & $3330-15-2$ & 298 & & & 1 & \\
\hline HFE-227ea & $2356-62-9$ & 298 & & & 1 & \\
\hline HFE-236ea2 & $57041-67-5$ & 298 & & & 1 & \\
\hline HFE-263m1 & $690-22-2$ & 298 & & & 1 & \\
\hline HCFE-235da2 & $26675-46-7$ & 298 & & & 1 & $\begin{array}{l}\text { Ryan and Nielsen (2010) } \\
\text { [79] }\end{array}$ \\
\hline 2,2,2-trifluoroacetaldehyde & $75-90-1$ & 298 & & & 1 & \multirow{2}{*}{ Sellevag et al. (2004) [47] } \\
\hline 3,3,3-Trifluoro-propanal & $460-40-2$ & 298 & & & 1 & \\
\hline 2,2,2-Trifluoroethanol & $75-89-8$ & 293 & & & 1 & \multirow{3}{*}{ Sellevag et al. (2004) [59] } \\
\hline 2,2-Difluoroethanol & $359-13-7$ & 293 & & & 1 & \\
\hline 2-Fluoroethanol & $371-62-0$ & 293 & & & 1 & \\
\hline 2,2,3,3-Tetrafluoro-1-propanol & $76-37-9$ & 298 & & & & \multirow[b]{2}{*}{ Sellevag et al. (2007) [75] } \\
\hline $\begin{array}{l}2,2,3,4,4,4-H e x a f l u o r o-1- \\
\text { butanol }\end{array}$ & $382-31-0$ & 298 & & & & \\
\hline HFE-125 & $3822-68-2$ & 296 & 700 & air & 0.5 & \multirow{7}{*}{ Sihra et al. (2001) [61] } \\
\hline HFE-143a & $421-14-7$ & 296 & 700 & air & 0.5 & \\
\hline HFE-245fa2 & $1885-48-9$ & 296 & 700 & air & 0.5 & \\
\hline HFE-356mff2 & $333-36-8$ & 296 & 700 & air & 0.5 & \\
\hline i-HFE-7100 & $163702-08-7$ & 296 & 700 & air & 0.5 & \\
\hline i-HFE-7200 & $163702-06-5$ & 296 & 700 & air & 0.5 & \\
\hline n-HFE-7100 & $163702-07-6$ & 296 & 700 & air & 0.5 & \\
\hline Chloromethanol & $62-51-1$ & 295 & 700 & $\mathrm{~N} 2$ & 0.25 & \multirow{3}{*}{ Wallington et al. (2000) [64] } \\
\hline Dichloromethanol & $35911-93-4$ & 295 & 700 & $\mathrm{~N} 2$ & 0.25 & \\
\hline Trichloromethanol & $35911-92-3$ & 295 & 700 & $\mathrm{~N} 2$ & 0.25 & \\
\hline HFE-329me3 & $428454-68-6$ & 296 & 700 & air & 0.25 & \multirow{2}{*}{ Wallington et al. (2004) [65] } \\
\hline HFE-338mec 3 & $56860-85-6$ & 296 & 700 & air & 0.25 & \\
\hline
\end{tabular}




\begin{tabular}{|c|c|c|c|c|c|c|}
\hline \multicolumn{2}{|l|}{ HG-11 } & 296 & 700 & air & 0.25 & Wallington et al. (2009) [66] \\
\hline $\begin{array}{l}\text { 1H,1H,2H,2H-Perfluorononan- } \\
1 \text {-ol }\end{array}$ & $755-02-2$ & 296 & 700 & air & 0.5 & \multirow{4}{*}{ Waterland et al. (2005) [67] } \\
\hline $\begin{array}{l}\text { 1H,1H,2H,2H- } \\
\text { Perfluoroundecan-1-ol }\end{array}$ & $87017-97-8$ & 296 & 700 & air & 0.5 & \\
\hline $\begin{array}{l}\text { 3,3,4,4,5,5,6,6,7,7,7- } \\
\text { Undecafluoroheptan-1-ol }\end{array}$ & $185689-57-0$ & 296 & 700 & air & 0.5 & \\
\hline 2,2,3,3,3-pentafluoropropanol & $2240-88-2$ & 296 & 700 & air & 0.5 & \\
\hline PFPMIE & 1309353-34-1 & 296 & 700 & air & 0.25 & Young et al. (2006) [68] \\
\hline
\end{tabular}

1 Table 7. Spectra from the PNNL database (Sharpe et al. [13]) and more recently published 2 sources for halogenated alcohols and ethers.

\begin{tabular}{|c|c|c|c|c|c|c|}
\hline Molecule & CAS & $\begin{array}{c}\mathbf{T} \\
(\mathbf{K})\end{array}$ & $\begin{array}{c}\mathbf{P} \\
\text { (Torr) }\end{array}$ & Broadener & $\begin{array}{r}\text { Resolution } \\
\left(\mathbf{c m}^{-1}\right)\end{array}$ & Source \\
\hline Trifluoroacetic acid & $76-05-1$ & 298.15 & 760.0 & $\mathrm{~N}_{2}$ & 0.112 & \multirow{6}{*}{ Sharpe et al. [13] } \\
\hline 2-Fluoroethanol & $371-62-0$ & $298.15,323.15$ & 760.0 & $\mathrm{~N}_{2}$ & 0.112 & \\
\hline $\begin{array}{l}\text { bis(2-Chloroethyl) } \\
\text { ether }\end{array}$ & $111-44-4$ & $298.15,323.15$ & 760.0 & $\mathrm{~N}_{2}$ & 0.112 & \\
\hline 2,2,2-Trifluoroethanol & $75-89-8$ & $\begin{array}{l}278.15, \\
298.15,323.15\end{array}$ & 760.0 & $\mathrm{~N}_{2}$ & 0.112 & \\
\hline $\begin{array}{l}\text { Ethyl 2,2,2- } \\
\text { trifluoroacetate }\end{array}$ & $383-63-1$ & $\begin{array}{l}278.15, \\
298.15,323.15\end{array}$ & 760.0 & $\mathrm{~N}_{2}$ & 0.112 & \\
\hline Chloroacetone & $78-95-5$ & $\begin{array}{l}278.15, \\
298.15,323.15\end{array}$ & 760.0 & $\mathrm{~N}_{2}$ & 0.112 & \\
\hline HFE-7300 & $132182-92-4$ & 298.00 & & & 1 & \multirow{2}{*}{ Rodriguez et al. [31] } \\
\hline HFE-7500 & $297730-93-9$ & 298.00 & & & 1 & \\
\hline $\begin{array}{l}\text { Allyl 2,2,2- } \\
\text { trifluoroacetate }\end{array}$ & $383-67-5$ & 298.00 & & & 0.03 & \multirow{2}{*}{ Rodriguez et al. [30] } \\
\hline $\begin{array}{l}\text { Vinyl 2,2,2- } \\
\text { trifluoroacetate }\end{array}$ & $433-28-3$ & 298.00 & & & 0.03 & \\
\hline $\begin{array}{l}1,1,1,3,3,3- \\
\text { Hexafluoropropan-2-ol }\end{array}$ & $920-66-1$ & $\begin{array}{l}300.40, \\
303.50, \\
312.10, \\
326.80, \\
335.60, \\
343.10, \\
353.80,362.40\end{array}$ & & & 0.1 & Godin et al. [36] † \\
\hline $\begin{array}{l}\text { 2,2,3,3,3- } \\
\text { pentafluoropropanol }\end{array}$ & $422-05-9$ & $\begin{array}{l}297.80, \\
303.60, \\
311.90, \\
317.50, \\
324.40, \\
334.20, \\
343.10, \\
352.80,362.20\end{array}$ & & & 0.1 & Godin et al. [37] $\dagger$ \\
\hline
\end{tabular}

$3 \uparrow$ Detailed information on the experimental conditions can be found in the corresponding 4 references.

5 3.3. Hydrofluorocarbons

6 Hydrofluorocarbons (HFCs) are widely used as replacement for ozone depleting substances

7 (ODS) such as CFCs and HCFCs in industrial and domestic applications and are included in the

8 Kyoto Protocol and the Kigali Agreement. HFCs are used in fire suppression, heat transfer,

9 refrigeration, air conditioning, foam blowing, solvent production, and cleaning applications

$10[72,90,91]$. The absence of $\mathrm{Cl}$ or $\mathrm{Br}$ atoms means that HFCs do not contribute to stratospheric

11 ozone depletion [52,69]. However, because of their strong absorption in the 8-13 $\mu \mathrm{m}$

12 atmospheric window, some members of this class of compounds are potent greenhouse gases

$13[1,91,92]$. The tropospheric lifetimes for HFCs are determined mostly by the reaction with $\mathrm{OH}$ 
1 radicals [52,72] and range from days to centuries depending on the reactivity of the HFC. We

2 describe the infrared spectra for two groups of HFCs, namely saturated and unsaturated

3 hydrofluorocarbons.

\section{$4 \quad$ 3.3.1. Saturated HFCs}

5 The saturated HFCs, i.e. those containing only single interatomic bonds, have been widely

6 used since the early 1990s after emissions of CFCs were controlled by the Montreal Protocol

7 [93]. The most abundant HFC in the atmosphere is HFC-134a, with a global-mean surface

8 concentration of approximately $100 \mathrm{ppt}$ [94], with several others with concentrations exceeding 1

9 ppt, followed by HFC-23 (about 30 ppt) which is mostly emitted as a by-product of HCFC-22

10 production [3]. The 2011 radiative forcing due to HFCs is about $0.024 \mathrm{~W} \mathrm{~m}^{-2}$, about $1.3 \%$ of the

11 forcing due to $\mathrm{CO}_{2}[3]$.

The HITRAN2016 database release includes cross-sections for HFCs which have been introduced in HITRAN for the first time, namely HFC-161, HFC-152, HFC-41, HFC-272ca, HFC-143, HFC-365mfc, HFC-245fa, HFC-236cb, HFC-43-10mee, HFC-329p, HFC-227ca, HFC-227ea, HFC-245cb, HFC-236fa, HFC-23. Cross-sections for these molecules have been provided by Harrison et al. [24][25], Hodnebrog et al. [1], Le Bris et al. [39], and Sharpe et al. [13]. The comparison overview of the saturated HFCs having the largest GWP values is shown in Figure 7.

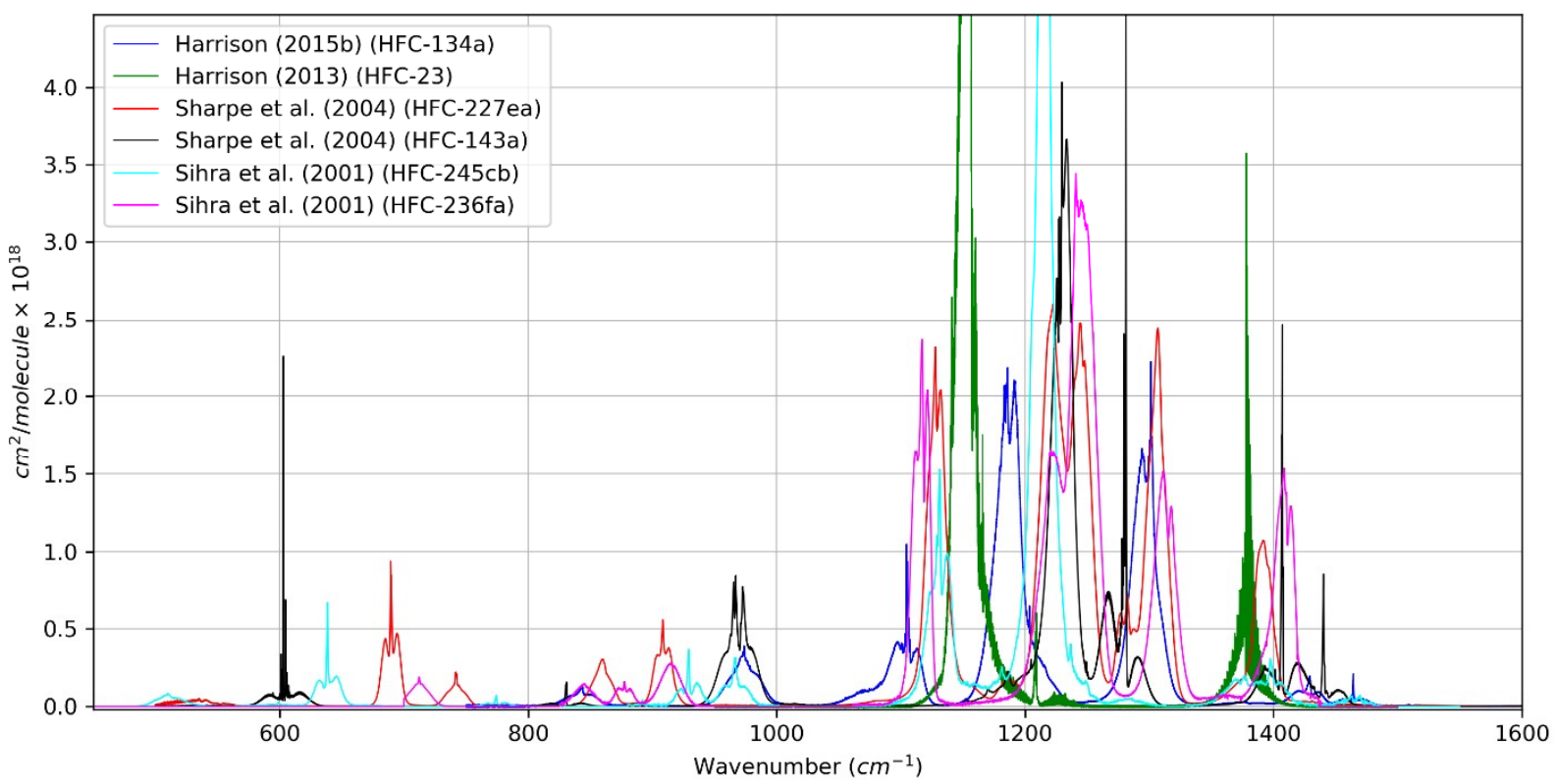

Figure 7. Spectra for HFC-134a, HFC-23, HFC-227ea, HFC-143a, HFC-245cb, and HFC21236 fa. 
HFC-152a (1,1-difluoroethane, $\left.\mathrm{CH}_{3} \mathrm{CHF}_{2}\right)$ is a saturated compound with a small GWP which is used in refrigeration and aerosol products. The HITRAN2012 edition included data from

4 Clerbaux et al. [18]. These data were measured at a temperature range of 253-287 $\mathrm{K}$ and "no

5 dependence of these cross-sections on pressure was found" [18]. The spectra from this reference are retained in HITRAN2016 with no changes. Additional spectra from different sources have been added to the HITRAN2016 issue for temperatures of $253 \mathrm{~K}, 278 \mathrm{~K}, 296 \mathrm{~K}$, and $323 \mathrm{~K}$. For $253 \mathrm{~K}$, data provided by Highwood and Shine [90] have been included in HITRANonline. These self-broadened spectra were originally measured by Vander Auwera at $0.03 \mathrm{~cm}^{-1}$ resolution and described in Ref. [95]. According to our comparisons, the spectra from Refs. [90] and [95] are somewhat better resolved compared to the old data from Clerbaux et al., although the nominal resolution is the same for both sources. For temperatures near $253 \mathrm{~K}$, spectra from Refs $[90,95]$ have smaller integral intensity with the discrepancies of $4.3 \%$ for strongest band near $1140 \mathrm{~cm}^{-1}$, $5.4 \%$ and $6.5 \%$ for weaker bands at 950 and $1450 \mathrm{~cm}^{-1}$ respectively, compared to Ref. [18]. At temperatures near $270 \mathrm{~K}$, excellent agreement can be observed between the data from PNNL and Clerbaux et al. $(<0.8 \%)$. At temperatures near $296 \mathrm{~K}$, data from Clerbaux et al. [18], Sihra et al. [61], and Sharpe et al. (PNNL) [13] have been compared. Data from Clerbaux et al. have more resolved spectral features, while the resolution of spectra from PNNL and Sihra et al. are comparable. PNNL data have a wider spectral range and contain weak (but visible on a linear scale) features at lower and higher wavenumbers. Data from Clerbaux et al., having the intensity uncertainty of 3\%, agree well with Sihra et al. (0.1\%-1.6\%) and with PNNL (4\%) in terms of integrated intensities. PNNL spectra, having wider spectral coverage than Sihra et al., smaller uncertainty, and comparable resolution, have been made available via the HITRANonline interface. Data from Sihra et al. have been relegated to the supplemental folder. For $323 \mathrm{~K}$, only data from PNNL are present.

\subsubsection{HFC-125}

HFC-125 (pentafluoroethane, $\mathrm{C}_{2} \mathrm{HF}_{5}$ ) is a fire suppression agent and refrigerant. While it has no ozone depleting effect, it has a significant global warming potential. HITRAN2016 inherited high-resolution data from HITRAN2012 provided by Di Lonardo and Masciarelli [40]. This dataset contains both self- and air-broadened spectra at a range of temperatures between $200 \mathrm{~K}$ and $295 \mathrm{~K}$, and pressures between 150 Torr and 600 Torr (for air-broadened spectra). It is important to note that one self-broadened spectrum from Di Lonardo and Masciarelli has a large shift on a wavenumber scale, which possibly can be explained by errors in the data format. This spectrum (293K) was removed from the HITRANonline web interface and placed into the supplemental folder. The rest of the data from Di Lonardo and Masciarelli are available in the 
1 HITRANonline interface. Additional data published by Young et al. [48], Sihra et al. [61], and

2 Sharpe et al. (PNNL) [13], spanning temperatures from $253 \mathrm{~K}$ to $323 \mathrm{~K}$, have been considered

3 for incorporation into the database. The $253 \mathrm{~K}$ spectra from Highwood and Shine [90] was

4 omitted for this molecule because it was originally measured and provided to the HITRAN

5 database by Di Lonardo and Masciarelli [40]. PNNL data agree well with Di Lonardo and

6 Masciarelli at all available temperatures. The intensities integrated between $1000-1400 \mathrm{~cm}^{-1}$

7 agree well within the combined experimental uncertainties $(2.3 \%$ for $273-278 \mathrm{~K}$ and $2.6 \%$ for

8 293-298K) for these sources. At 293-298K, in addition to spectra from these sources, data from

9 Sihra et al. and Young et al. have been included in the comparison, as well as spectra from the

NIST database [17]. Comparison shows that data from Young et al. disagree with most of the other published spectra, having integrated intensity residuals of $9.2 \%, 5.67 \%, 6.9 \%$, and 9.03\% compared to Di Lonardo and Masciarelli, Sihra et al., PNNL, and NIST respectively. The latter sources have internal agreement of not worse than $3.9 \%$ for integrated intensities in the 1000 $1400 \mathrm{~cm}^{-1}$ interval. For this reason, and assuming that data from Sihra et al. does not have omitted from HITRAN.

\subsubsection{HFC-134}

HFC-134 (1,1,2,2-tetrafluoroethane, CHF2CHF2) is not currently in common usage, although it has RE of $0.19 \mathrm{~W} \mathrm{m-2} \mathrm{ppb-1} \mathrm{which} \mathrm{is} \mathrm{comparable} \mathrm{to} \mathrm{HFC-23} \mathrm{[1].} \mathrm{The} \mathrm{HITRAN2016}$ issue includes self- and air-broadened spectra provided by Smith et al. [16] for a range of temperatures from $203 \mathrm{~K}$ to $297 \mathrm{~K}$. This set of data is unchanged from HITRAN2012. Besides these data, the new spectra from PNNL containing absorption for higher temperatures have been included in HITRANonline. The data provided by Hodnebrog et al. (originating from Sihra et al) $[1,61]$ were measured under conditions similar to PNNL, but with slightly lower resolution. These data contain additional band features at lower wavenumbers $\left(<600 \mathrm{~cm}^{-1}\right)$ absent in the PNNL spectra; thus they have been added to the supplemental folder.

\subsubsection{HFC-143a}

HFC-143a (1,1,1-trifluoroethane, $\left.\mathrm{CH}_{3} \mathrm{CF}_{3}\right)$ is used as a substitute for CFCs and HCFC in refrigeration [35] and has one of the largest 100-yr GWP values (4800 [3]) in the HFC category. HITRAN includes the data provided by Smith et al. [16] available via HITRANonline, and Di Lonardo and Masciarelli [40] in supplemental folder. These data were inherited by HITRAN2016 from previous editions. Other data for this molecule were provided by Sihra et al. [61], Sharpe et al. (PNNL) [13], and more recently by Le Bris and Graham [35]. The full dataset can be divided into two parts. The first part contains the self-broadened spectra from Refs. 
$1[16,35,40]$, and the second part the air- and nitrogen-broadened ones from Refs. [13,16,40,61].

2 Measurements performed in Smith et al. and Di Lonardo and Masciarelli demonstrate the strong

3 dependence of the spectral line shape on the presence of the broadener. For this reason, both self-

4 and nitrogen-broadened spectra have been included in HITRANonline. For the nitrogen-

5 broadened data, the composite PNNL measurements for $278.15 \mathrm{~K}, 298.15 \mathrm{~K}$, and $323.15 \mathrm{~K}$ have

6 been included in HITRANonline. The similar data from Sihra et al., when compared with PNNL,

7 did not reveal any additional spectral features. For this reason the spectra from Sihra et al. have

8 been omitted. The recent self-broadened composite measurements performed by Le Bris and

9 Graham have been included in HITRANonline. In Ref. [35] a review and comparison of the data in HITRAN2012 on this molecule was presented, raising a problem of the wavenumber shift of the spectra provided by Smith et al. The integrated intensities in Smith et al. agree well with the ones from Le Bris and Graham, while the spectra from Di Lonardo and Masciarelli (supplemental folder) have somewhat lower intensities. It should be noted that the PNNL data

HFC-227ea $\left(1,1,1,2,3,3,3\right.$-heptafluoropropane, $\left.\mathrm{CF}_{3} \mathrm{CHFCF}_{3}\right)$ is a saturated $\mathrm{HFC}$ with a 100 -yr GWP of 3350 [3] and is used in fire suppression. This molecule has been introduced in HITRAN for the first time. Three sources of spectra have been considered for this molecule, namely Gohar et al. [70], Sihra et al. [61], and Sharpe et al. [13]. The data from Sihra et al. were omitted because extended versions of the same data were provided in Gohar et al. These data were measured at $296 \mathrm{~K}$ and 700 Torr, broadened by air. Another set of data have been measured by PNNL (Sharpe et al.) and incorporated cross-sections for three temperatures $(278.15,298.15$, $323.15 \mathrm{~K})$. Although the difference of absorption integrated on a wide spectral range (800-1600 $\mathrm{cm}^{-1}$ ) is noticeable, this difference is within the combined uncertainties of the sources (see Table 4) and is approximately $7.4 \%$. The PNNL spectra have been included in HITRANonline. The spectra from Gohar et al. include two minor features which are either absent (near $450 \mathrm{~cm}^{-1}$ ), or distorted (near $500 \mathrm{~cm}^{-1}$ ) in the PNNL spectra; for this reason, the data from Gohar et al. was also made available via HITRANonline interface. 
HFC-41 (fluoromethane, $\mathrm{CH}_{3} \mathrm{~F}$ ) is a flammable gas at room temperature and pressure. For this compound, the considered spectra are from two sources: PNNL [13] and Sihra et al. [61]. The discrepancy in integrated intensities is around $12 \%$, which is greater than the combined uncertainty of both sources $(\sim 7 \%)$. This probably reflects calibration problems, or to differences between experimental conditions for the spectra of the same temperature (700 Torr and air broadening in Sihra et al., and 760 Torr and nitrogen broadening for PNNL). Spectra from Sihra et al. have been put in the supplemental folder, while the PNNL data are included in HITRANonline. Both data sets should be considered by the user until the differences are resolved.

\subsubsection{7. $H F C-32$}

HFC-32 (difluoromethane, $\mathrm{CH}_{2} \mathrm{~F}_{2}$ ) is a replacement for CFCs and HCFCs [41] and for higherGWP HFCs in air-conditioning units. It has a 100-yr GWP of 677 [3]. For HFC-32, a wide range of temperature and pressure sets was provided to previous HITRAN editions by Smith et al. [41]. These sets include air- and self-broadened cross-sections for temperatures between $203 \mathrm{~K}$ and $297 \mathrm{~K}$, and pressures up to 760 Torr. The cross-sections were measured with $4 \%$ accuracy [41]. considered from the following sources: Highwood and Shine [90], Gohar et al. [70], Sihra et al. [61] and Sharpe et al. [13]. Three cross-sections from Highwood and Shine, provided in Hodnebrog et al. [1], are originally from two sources: Beukes and Nicolaisen [96] for 450-630 $\mathrm{cm}^{-1}$, and Smith et al. [41] for the rest of the wavenumber range. Only data from Beukes and Nicolaisen were added to HITRAN. The spectra from Sihra et al. were omitted because data from Gohar et al. are an extended version [70] of those from Sihra et al. The spectra containing additional features absent in Smith et al., namely PNNL (near 1850-3620 $\mathrm{cm}^{-1}$ ), Gohar et al. (near 490-570 $\mathrm{cm}^{-1}$ ), and Highwood and Shine (near 400-600 $\mathrm{cm}^{-1}$ ), have been included in HITRANonline. At 253K, the data from Gohar et al. agree well with Smith et al. (5\% for intensity integrated in $1000-1250 \mathrm{~cm}^{-1}$ range). Near $280 \mathrm{~K}$, only data from PNNL and Smith et al. are present, which also have a good agreement (5\% for the strong band in 1000-1200 $\mathrm{cm}^{-1}$ range). Near $296 \mathrm{~K}$, besides the spectra from Smith et al., the data from Gohar et al. were added since they contained additional features in the lower wavenumber range (near $500 \mathrm{~cm}^{-1}$ ). The PNNL spectra were also added for the same reason. These data have been included in HITRANonline. It is also worth noting that PNNL HFC-32 spectra cover temperatures up to $323 \mathrm{~K}$, as is the case for most gases that PNNL measured. The user should use the PNNL datasets to obtain more reliable extrapolations to temperatures higher than $300 \mathrm{~K}$. 
The atmospheric abundance of 1,1,1,2-tetrafluoroethane (HFC-134a, $\left.\mathrm{CH}_{2} \mathrm{FCF}_{3}\right)$ has increased rapidly since the late 1990 s and continues to rise. HFC-134a has mostly replaced CFC-12 in several refrigeration and air-conditioning applications. With an atmospheric lifetime of 13.4 years and a 100-yr GWP of 1300 [3], HFC-134a is currently the most abundant HFC in the atmosphere.

The retrieval of HFC-134a profiles from ACE-FTS (Atmospheric Chemistry Experiment Fourier transform spectrometer) [97] spectra was the first space-based measurements [98] for any HFC. The retrievals employed a window from 1180 to $1200 \mathrm{~cm}^{-1}$ using a set of crosssections from Nemtchinov and Varanasi [99]. A new set of high-resolution IR absorption crosssections have been determined by Harrison [25] over the spectral range 750-1600 $\mathrm{cm}^{-1}$ using a high-resolution FTIR spectrometer (Bruker IFS 125HR) and a 26-cm-pathlength cell. Spectra of HFC-134a/dry synthetic air mixtures were recorded at $0.015 \mathrm{~cm}^{-1}$ resolution (calculated as $\left.0.9 / \mathrm{MOPD}^{2}\right)$ at a number of temperatures and pressures (22-761 Torr and 191-296 K) appropriate for atmospheric conditions.

This new dataset is now included in HITRANonline. The spectra from Nemtchinov and Varanasi are now available in the HITRAN supplemental folder. Besides the data from Harrison et al. [25], datasets from two sources, namely Highwood and Shine [90] (using data from Beukes and Nicolaisen [96] between 50 and $650 \mathrm{~cm}^{-1}$ and Newnham et al. [100] between 650 and 1600 $\mathrm{cm}^{-1}$ ) and PNNL [13] have been included in HITRANonline for the low and high temperature range respectively. These datasets are complementary to those from Harrison et el. in terms of the wavenumber range since they contain additional features below $700 \mathrm{~cm}^{-1}$ and above 1600 $\mathrm{cm}^{-1}$.

\subsubsection{9, HFC-23}

Trifluoromethane $\left(\mathrm{HFC}-23, \mathrm{CHF}_{3}\right)$ is a long-lived species with 222 years lifetime. This gas is emitted primarily as a by-product in HCFC-22 production. It has a large GWP of 12400 [3], and prior to the early 2000s it was the dominant HFC in the atmosphere, later overtaken by HFC134a. Nevertheless, the atmospheric abundance of HFC-23 continues to rise, and it is being closely monitored by the international community [101].

Previously the only available cross-sections were those derived from spectra recorded by Chung [102]. However, these data were not included in the HITRAN database. This dataset was used to create a set of HFC-23 pseudo-lines, which were utilized in the first remote-sensing

\footnotetext{
2 Maximum Optical Path Difference
} 
1 measurements of this molecule taken by the balloon-borne MkIV interferometer and the ACE-

2 FTS. These cross-sections suffer from a number of problems: they do not cover an appropriate

3 range of atmospheric pressures and do not extend as low as $195 \mathrm{~K}$. Furthermore, some

4 measurements are under-resolved, while others appear to suffer from erroneously recorded

5 absorber amounts, and there are inconsistencies in the wavenumber calibration. These problems

6 all contributed to a large bias in the retrieved HFC-23 profiles.

7 A new HFC-23 cross-section dataset from Harrison [24] over the range $950-1500 \mathrm{~cm}^{-1}$ has

8 been included in HITRAN2016. It was determined from spectra of HFC-23/dry synthetic air

9 mixtures recorded using a high-resolution FTIR spectrometer (Bruker IFS 125HR) and a 26-cm-

10 pathlength cell. Spectra were recorded at $0.015 \mathrm{~cm}^{-1}$ resolution (calculated as $0.9 / \mathrm{MOPD}$ ) at a

11 number of temperatures and pressures (23-762 Torr and 188-294 K) appropriate for atmospheric 12 conditions.

13 Data for this molecule provided by Highwood and Shine [90] (from the measurements of 14 McPheat and Duxbury [103]) were recorded at 253K. It is worth noting that there was a fairly 15 large discrepancy for the integrated band intensities ( $20 \%$ for the $1000-1600 \mathrm{~cm}^{-1}$ range)

16 between Refs. [24] and [90], which lies outside of the combined experimental uncertainty.

17 Considering this, most of the data from Ref. [90] were omitted, except the low-wavenumber

18 band which has been placed in the supplemental folder. Further investigations should be made

19 before elevating these data to the HITRANonline web interface.

20 Other considered data contain fewer temperature and pressure sets and are either for room temperature (Gohar et al. [70], Sihra et al. [61]) or for 5-50 ${ }^{\circ} \mathrm{C}$ (PNNL [13]). Data from Sihra et al. coincide with those from Gohar et al. except having a slightly narrower wavenumber range. The spectrum from Gohar et al. contains a weak feature near $500 \mathrm{~cm}^{-1}$ which is absent in all other sources; it has been placed in the supplemental folder. The PNNL data have been included in HITRANonline to improve the higher-temperature extrapolations (near 350K).

\subsubsection{HFC-43-10mee}

HFC-43-10mee is used as a cleaning solvent in electronics. It is sold as a mixture of two diastereomers (erythro and threo) which have the same estimated lifetime of 16.1 years. The global mean tropospheric abundance was $0.211 \pm 0.046 \mathrm{ppt}$ in 2012 [104]. Its 100-year GWP is 1410 [39].

Data from the PNNL database [13] have been included in HITRAN16. Another data set has recently been published by Le Bris et al. [39]. The pure vapor spectra of Le Bris et al. overlap well with the PNNL broadened spectra. The two sets of data agree very well at around 300K 
1 with a difference of integrated intensities of only $1 \%$. The difference is $6 \%$ at $320 \mathrm{~K}$ but is

2 within the combined experimental uncertainties. The PNNL and Le Bris et al. data have been

3 included in HITRANonline (Ref. [39] as a post-release update).

\section{3.3.2. Unsaturated HFCs}

5 Hydrofluoroolefins (HFOs, fluorinated alkenes, unsaturated HFCs) are of industrial and

6 scientific interest as next-generation replacements for saturated HFCs in the applications mentioned above $[73,91,105][106]$. The unsaturated HFCs (HFOs) contain at least one carboncarbon double bond, which makes them more reactive towards $\mathrm{OH}$ radicals and $\mathrm{O}_{3}$ than their saturated analogues [105] leading to short atmospheric lifetimes and low GWPs. The atmospheric fate of hydrofluoroalkenes is mainly reaction with $\mathrm{OH}$ radicals with reaction with ozone playing a minor role; chlorine-initiated degradation may also contribute in coastal regions [92].

Spectra for around twelve fluoroolefins have been added to HITRAN, including data from Refs. $[51,52,58,73]$ which are either air- or nitrogen broadened. These data were provided by Hodnebrog et al. [1]. The HITRAN2016 edition also includes three different temperature spectra from PNNL [13] for vinyl fluoride (HFC-1141) and more recent helium-broadened data from Refs. [92] and [91]. Figure 8 shows the overview for those spectra. These molecules are (E)HFC-1225ye, (Perfluoro-n-butyl)ethylene, (perfluoro-n-octyl)ethylene, (Z)-HFC-1225ye, (Z)HFC-1234ze, HFC-1132a, HFC-1141, HFC-1234yf, HFC-1243zf, HFC-1345zfc, TE-6, (E)HFC-1234ze (see the Table 8). All these species have short lifetimes (two weeks or less) and thus extremely small GWPs. Lifetimes and GWPs can be found in Ref. [3] for all the molecules described in this subsection.

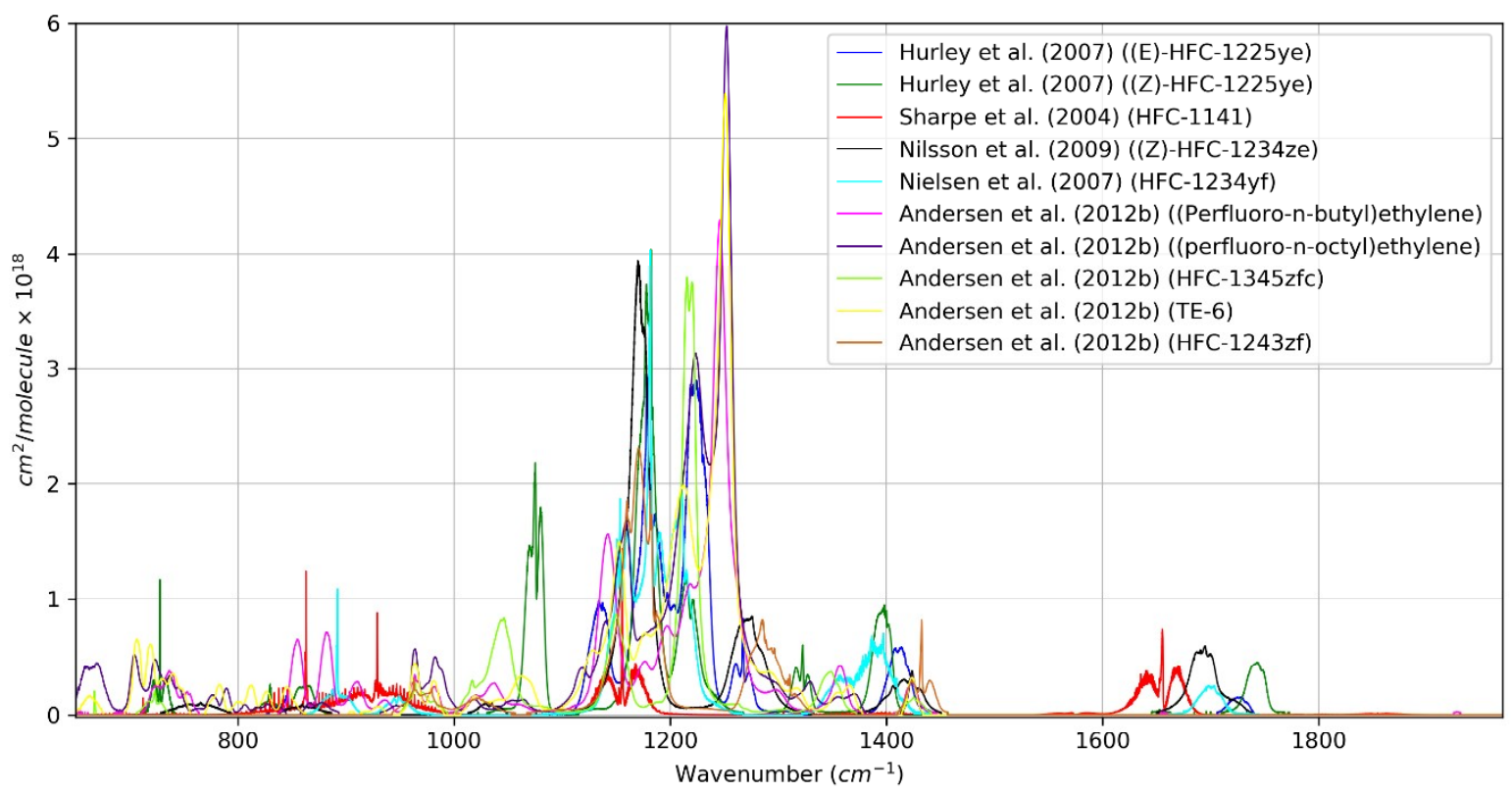


1 Figure 8. Spectra for unsaturated HFCs included in HITRAN2016. All spectra were recorded at $2 \quad 296 \mathrm{~K}$ in 700 Torr total pressure except PNNL which were recorded at 760 Torr pressure and 3 three temperatures (see Table 9).

4 A summary of spectra (for saturated and unsaturated HFCs) available through the

5 HITRANonline web interface is given in Table 8 for the data from Hodnebrog et al. [1] (and the 6 references within), in Table 9 for the PNNL data, and in Table 10 for the spectra recently

7 published by Harrison, Le Bris, and coauthors.

8 Table 8. Spectra from the review on halocarbons and related compounds (Hodnebrog et al. [1]) 9 for hydrofluorocarbons.

\begin{tabular}{|c|c|c|c|c|}
\hline Molecule & CAS & Range, $\mathbf{c m}^{-1}$ & $\mathbf{T}, \mathbf{K}$ & Res, $\mathbf{c m}^{-1}$ \\
\hline \multicolumn{5}{|l|}{ Andersen et al. (2012) [58] } \\
\hline (Perfluoro-n-butyl)ethylene & $19430-93-4$ & $650-1999$ & 298 & 0.25 \\
\hline (perfluoro-n-octyl)ethylene & $21652-58-4$ & $650-1999$ & 298 & 0.25 \\
\hline HFC-1243zf & $677-21-4$ & $650-1999$ & 298 & 0.25 \\
\hline HFC-1345zfc & $374-27-6$ & $650-1999$ & 298 & 0.25 \\
\hline TE-6 & $25291-17-2$ & $650-1999$ & 298 & 0.25 \\
\hline \multicolumn{5}{|l|}{ Gohar et al. (2004) [70] } \\
\hline HFC-227ea & $431-89-0$ & $400-1550$ & 296 & 0.5 \\
\hline HFC-32 & $75-10-5$ & $400-1550$ & 296 & 0.5 \\
\hline \multicolumn{5}{|c|}{ Beukes and Nicolaisen (2000) [96] } \\
\hline HFC-134a ${ }^{\dagger}$ & $811-97-2$ & $75-590$ & 253 & \\
\hline \multicolumn{5}{|l|}{ Newnham et al. (1996) [100] } \\
\hline HFC-134a ${ }^{\dagger}$ & $811-97-2$ & $600-1540$ & 253 & \\
\hline \multicolumn{5}{|l|}{ Vander Auwera (2000) [95] } \\
\hline HFC-152a ${ }^{\dagger}$ & $75-37-6$ & $830-1500$ & 253 & 0.03 \\
\hline \multicolumn{5}{|c|}{ McPheat and Duxbury (2000) [103] } \\
\hline $\mathrm{HFC}-32^{\dagger}$ & $75-10-5$ & $450-630$ & 253 & 0.03 \\
\hline \multicolumn{5}{|l|}{ Hurley et al. (2007) [73] } \\
\hline (E)-HFC-1225ye & $5595-10-8$ & $650-2000$ & 296 & 0.25 \\
\hline (Z)-HFC-1225ye & $5528-43-8$ & $650-2000$ & 296 & 0.25 \\
\hline \multicolumn{5}{|l|}{ Inoue et al. (2008) [72] } \\
\hline HFC-365mfc & $406-58-6$ & $600-2000$ & 296 & 0.25 \\
\hline \multicolumn{5}{|l|}{ Nielsen et al. (2007) [51] } \\
\hline HFC-1234yf & $754-12-1$ & $700-2000$ & 296 & 0.25 \\
\hline (Z)-HFC-1234ze & $29118-25-0$ & $600-2000$ & 296 & 0.25 \\
\hline \multicolumn{5}{|l|}{ Sihra et al. (2001) [61] } \\
\hline HFC-143 & $430-66-0$ & $350-1550$ & 296 & 0.5 \\
\hline HFC-161 & $353-36-6$ & $350-1600$ & 296 & 0.5 \\
\hline HFC-227ca & $2252-84-8$ & $400-1550$ & 296 & 0.5 \\
\hline HFC-236cb & $677-56-5$ & $300-1550$ & 296 & 0.5 \\
\hline HFC-236fa & $690-39-1$ & $350-1500$ & 296 & 0.5 \\
\hline HFC-245cb & $1814-88-6$ & $400-1550$ & 296 & 0.5 \\
\hline HFC-245fa & $460-73-1$ & $640-1500$ & 296 & 0.5 \\
\hline HFC-272ca & $420-45-1$ & $300-1500$ & 296 & 0.5 \\
\hline \multicolumn{5}{|l|}{ Wallington et al. (1994) [63] } \\
\hline HFC-152 & $624-72-6$ & $700-3100$ & 296 & 0.25 \\
\hline \multicolumn{5}{|l|}{ Young et al. (2009) [48] } \\
\hline HFC-329p & $375-17-7$ & $500-4000$ & 296 & 0.25 \\
\hline
\end{tabular}

$10 \uparrow$ Self-broadened data for the molecules from Highwood and Shine [40]. Other data in this table

11 were measured at 700 Torr total pressure broadened by air.

12 Table 9. PNNL-DOE data for hydrofluorocarbons.

\begin{tabular}{lll}
\hline \multicolumn{1}{c}{ Molecule } & \multicolumn{1}{c}{ CAS } & Range, $\mathbf{~ c m}^{-1}$ \\
\hline HFC-1141 & $75-02-5$ & $500-6500$ \\
\hline HFC-125 & $354-33-6$ & $510-6500$ \\
\hline
\end{tabular}




\begin{tabular}{lll}
\hline HFC-134 & $359-35-3$ & $570-6500$ \\
\hline HFC-143a & $420-46-2$ & $500-6500$ \\
\hline HFC-152a & $75-37-6$ & $525-6500$ \\
\hline HFC-227ea & $431-89-0$ & $500-6500$ \\
\hline HFC-32 & $75-10-5$ & $510-6500$ \\
\hline HFC-41 & $593-53-3$ & $600-6500$ \\
\hline HFC-43-10mee & $138495-42-8$ & $500-6500$ \\
\hline
\end{tabular}

1 Spectra from Sharpe et al. [13] broadened by $\mathrm{N}_{2}$. Spectra were recorded at $278.15 \mathrm{~K}, 298.15 \mathrm{~K}$,

2 and $323.15 \mathrm{~K}, 760$ Torr total pressure, and $0.112 \mathrm{~cm}^{-1}$ resolution.

3 Table 10. More recent data for hydrofluorocarbons.

\begin{tabular}{llllll}
\hline \multicolumn{1}{c}{ Molecule } & \multicolumn{1}{c}{ CAS } & ${\text { Range, } \mathbf{~ c m}^{-1}}^{-1}$ & $\mathbf{T}, \mathbf{K}$ & \multicolumn{1}{c}{ p, Torr } & \multicolumn{1}{c}{ Source } \\
\hline HFC-23 & $75-46-7$ & $950-1500$ & $187.6-294.4$ & $23-762.4$ & Harrison (2013) [24] \\
\hline HFC-134a & $811-97-2$ & $750-1600$ & $190.9-295.8$ & $22.4-760.8$ & Harrison (2015) [25] \\
\hline HFC-143a & $420-46-2$ & $550-3500$ & $263-283$ & & Le Bris and Graham (2015) [35]† \\
\hline HFC-43-10mee & $138495-42-8$ & $550-3500$ & $305-340$ & & Le Bris et al. (2018) [39]
\end{tabular}

$\dagger$ Self-broadened data from Le Bris and Graham [35], measured with $0.03 \mathrm{~cm}^{-1}$ resolution.

5 Spectra published by Harrison $[24,25]$ were recorded with air as a bath gas with $0.015 \mathrm{~cm}^{-1}$

6 resolution. Full lists of cross-sections for these molecules can be found in the corresponding

7 references.

\section{$8 \quad 3.4$. Bromocarbons, Hydrobromocarbons, and Halons}

9 This class of gases has been widely used in fire extinguishing equipment and, in the case of

$10 \mathrm{CH}_{3} \mathrm{Br}$, fumigants in agriculture. Lifetimes range from months for the hydrobromocarbons, which react readily with $\mathrm{OH}$, to several decades for fully-halogenated species such as $\mathrm{CBrF}_{3}$ (Halon 1301). The presence of bromine (and in some cases chlorine too) makes them potentially potent ODSs. Bromine atoms are regarded as 60 times more powerful than chlorine atoms in calculations of the $\mathrm{EESC}^{3}\left(\mathrm{ODGI}^{4}\right.$ [107]). Halon production and consumption has been banned under the Montreal Protocol. They also contribute to the greenhouse effect because of absorption in the thermal infrared. The most abundant bromine containing gas in the atmosphere is $\mathrm{CH}_{3} \mathrm{Br}$ whose concentration peaked at nearly $10 \mathrm{ppt}$ in the late-1990s but has since fallen to approximately 7 ppt, believed to be near its natural background. H-1211 and H-1301 have abundances of around $2.5 \mathrm{ppt}$, appear to have peaked, and have started falling. The radiative forcing associated with these species is less than $0.1 \%$ that of $\mathrm{CO}_{2}$ [3] but their contribution to ozone depletion is substantial; when measured by the EESC it is about $25 \%$ of the total midlatitude EESC [107].

Bromocarbons, hydrobromocarbons, and halons are a category which is relatively new to HITRAN. Despite the presence of some bromine-containing species in the line-by-line section of the HITRAN database, the cross-section part of the database did not contain data on such species

${ }^{3}$ Equivalent Effective Stratospheric Chlorine

${ }^{4}$ Ozone Depleting Gas Index 
1 until HITRAN2012 [6]. The atmospherically-important molecule - bromine nitrate - was first introduced in the HITRAN2012 issue. In HITRAN2016, we completely updated the set of absorption cross-sections for this molecule with the recent high-quality spectra measured by

$4 \quad$ Wagner and Birk [29]. In addition, we introduced into the cross-section part ten more molecules measured by PNNL [13] and Ford Motor Company (hereafter referred to as Ford) [61,62]. For methyl bromide, the data have been added to the supplemental folder for the reason of the presence of the high-quality spectroscopic transitions in the line-by-line part [2].

In Table 11, the list of bromocarbons, hydrobromocarbons, and halons available in HITRANonline is given. Comparisons between different sources were made for all molecules except six, for which the data were only available from one source: halon-2311 [62], halon-1201 [61], halon-1202, bromochloromethane, tribromomethane, and 1,2-dibromoethane [13]. We briefly outline the comparisons made for the rest of the molecules in this section.

\subsubsection{Halon-1211}

\subsubsection{Halon-1301}

Halon-1301 (bromotrifluoromethane, $\mathrm{CBrF}_{3}$ ) spectra from PNNL [13] are available at three temperatures along with the single temperature and pressure set from Sihra et al. [61]. The spectrum has three isolated features: a C-Br stretch feature near $700 \mathrm{~cm}^{-1}$ and other features at $1050-1150 \mathrm{~cm}^{-1}$ and $1150-1300 \mathrm{~cm}^{-1}$. The agreement between spectra from PNNL and Sihra et al. is good and is within the combined experimental uncertainties ( $8 \%$ for $1050-1150 \mathrm{~cm}^{-1}$ and $7 \%$ for $1150-1300 \mathrm{~cm}^{-1}$ ). As for halon-1211, the room temperature set from Sihra et al. contains no additional features and thus is omitted, while the PNNL data have been included in HITRANonline. 
For halon-2402 (1,2-dibromotetrafluoroethane, $\mathrm{CBrF}_{2} \mathrm{CBrF}_{2}$ ), excellent agreement is found between PNNL data $(278.15,298.15$, and $323.15 \mathrm{~K})$ and Sihra et al. [61]: integrated intensity differences are $1.3 \%$ for the $700-950 \mathrm{~cm}^{-1}$ range and $1.8 \%$ for the $950-1300 \mathrm{~cm}^{-1}$ range. The band shapes for all bands are in a good agreement as well. As for Halon-1301 and Halon-1211, the PNNL data were included in HITRANonline. However, since the spectrum from Sihra et al. contains fine-grained features which are probably due to a higher resolution, it has been placed in the supplementary folder rather than omitted completely.

\subsubsection{Methylene bromide}

Available spectra for methylene bromide (dibromomethane, $\mathrm{CH}_{2} \mathrm{Br}_{2}$ ) are from PNNL [13] and Sihra et al [61]. For two major isolated features at $650 \mathrm{~cm}^{-1}$ and $1200 \mathrm{~cm}^{-1}$, the integrated intensities differ by $4.8 \%$ and $3.8 \%$ respectively. PNNL spectra have a much wider range and a number of weaker, but noticeable features above $1500 \mathrm{~cm}^{-1}$. Data from Sihra et al. do not reveal additional spectral features, and some details of the spectra are missing due to lower resolution. The data from PNNL have been included in HITRANonline, while the data from Sihra et al. have been omitted.

\subsubsection{Methyl bromide}

For methyl bromide (bromomethane, $\mathrm{CH}_{3} \mathrm{Br}$ ), the HITRAN2016 line-by-line section includes 36911 transitions for the two most abundant isotopologues $\left({ }^{79} \mathrm{Br}\right.$ and $\left.{ }^{81} \mathrm{Br}\right)$ in the $794-1706 \mathrm{~cm}^{-1}$ range. In our earlier work (Kochanov et al. [86]) we had commented on 10-20\% discrepancies (in terms of integrated band intensities) between cross-sections generated from line-by-line and the PNNL database. It is interesting to check if the same holds when compared with experimental cross-sections from other sources The absorption cross-sections have been published for this molecule by Sharpe et al. (PNNL) [13], Chu et al. (NIST) [17], and Sihra et al. [61]. The data with the widest spectral range are supplied by PNNL and cover three temperature ranges $(278.15,298.15,323.15 \mathrm{~K})$ and have features up to $6500 \mathrm{~cm}^{-1}$. Three features in the atmospheric window have been measured in PNNL, NIST, and Ford (Ref. [61]). Integrated intensities for these features reported in these three sources agree well within 5\%. The HAPIgenerated absorption coefficient for the HITRAN line-by-line data disagrees with all the three sources by $12-17 \%$ over the $850-1100 \mathrm{~cm}^{-1}$ range and by $9-14 \%$ over the $1240-1620 \mathrm{~cm}^{-1}$ range. The additional absorption in Refs. $[13,17,61]$ reflect possible impurities in the sample, missing hot bands, line-mixing effect in the Q-branches, or differences in the isotopic abundances in the samples. For this reason, we put the PNNL cross-sections in the supplemental folder. Figure 9 shows the overview for the spectra comparison for this molecule. In this figure, all sources cover the atmospheric window region, while PNNL and NIST data contain additional features above 
$12000 \mathrm{~cm}^{-1}$. The spectrum generated using HAPI from the line-by-line data is highlighted in cyan.

2 The data from Sihra et al. were omitted because the wavenumber scale is shifted in this spectrum

3 due to possible calibration problems (Figure 10). The intensity discrepancies between the line-

4 by-line data and raw cross-sections will hopefully be resolved in future HITRAN issues.

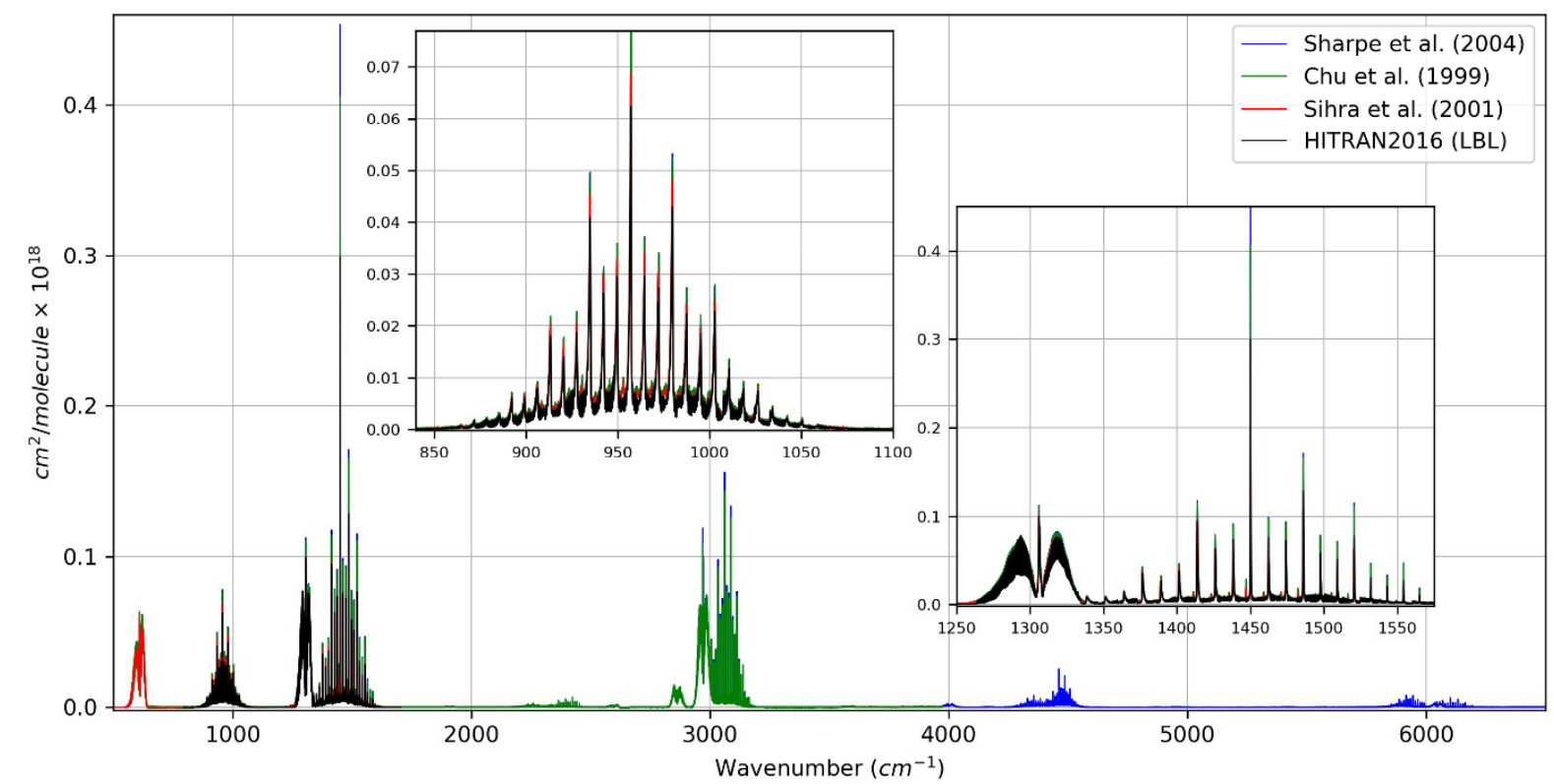

7

Figure 9. Absorption spectra for methyl bromide. The spectral features at $1000 \mathrm{~cm}^{-1}$ and 1500 $\mathrm{cm}^{-1}$ are zoomed in in the insets.

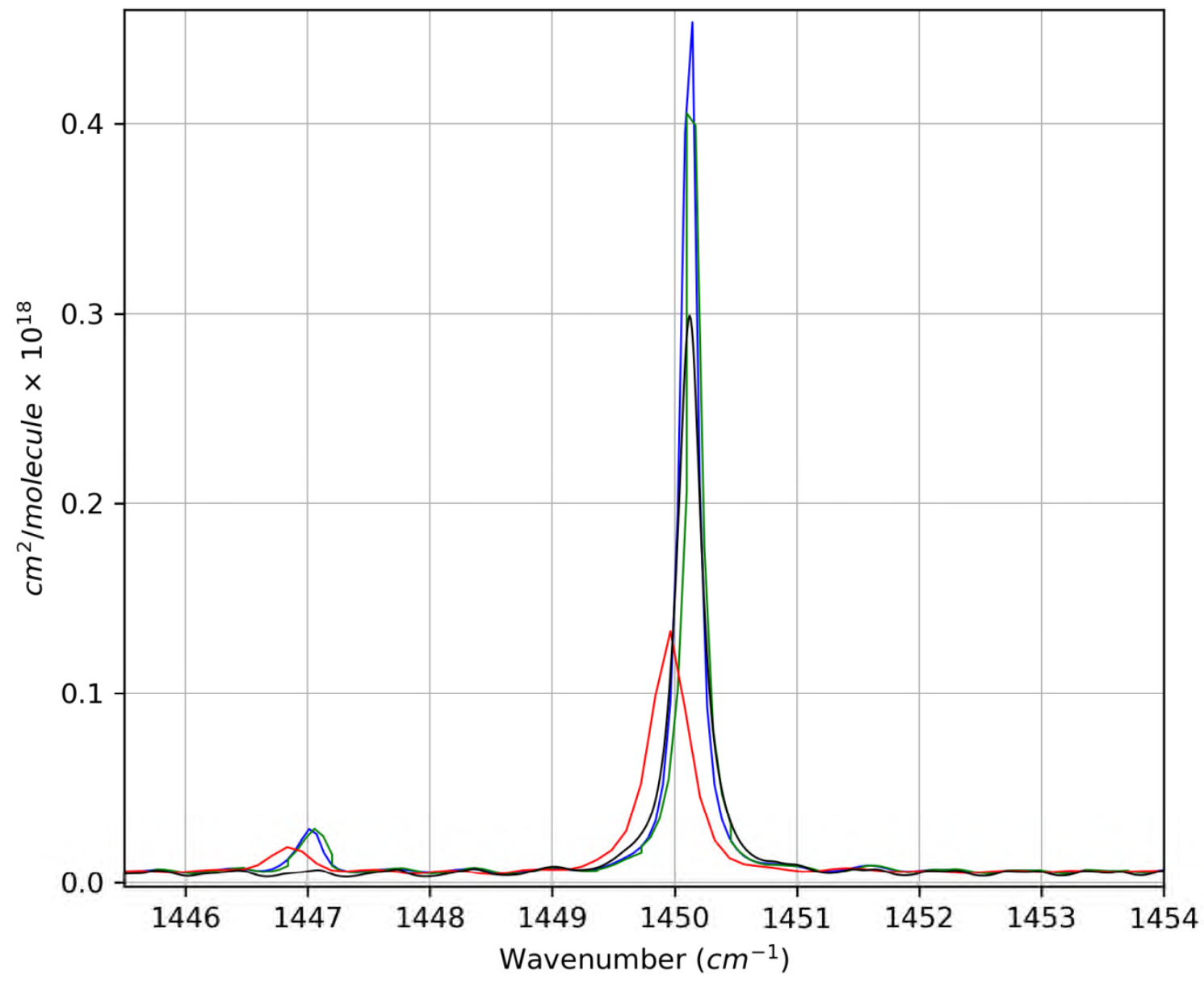


1 Figure 10. Absorption spectra comparison for methyl bromide. Data from Sihra et al. [61] in red

2 vs. PNNL [13] (in blue), NIST [17] (in green) and HAPI-generated spectra from the line-by-line

3 HITRAN2016 line-by-line data [2] (in cyan). The wavenumber shift in spectra from Sihra et al.

4 is approximately $0.1 \mathrm{~cm}^{-1}$.

\subsubsection{Bromine nitrate}

7 Despite its low abundance, stratospheric bromine has a considerable impact on stratospheric ozone $[108,109]$. The abundance of the reservoir species bromine nitrate, $\mathrm{BrONO}_{2}$, is required to determine the inorganic stratospheric bromine budget, gain insight into bromine partitioning in the stratosphere, and validate photochemical models. $\mathrm{BrONO}_{2}$ has been detected in the stratosphere by MIPAS/ENVISAT [110] and the MIPAS-B2 balloon [111] instrument using the strong infrared $v_{3}$ band near $800 \mathrm{~cm}^{-1}$. Retrieval accuracy was limited to $20 \%$ by the insufficient absorption cross-section data [112] because the only absorption cross-section measurements available for pure $\mathrm{BrONO}_{2}$ were at ambient temperature.

New temperature and air pressure dependent absorption cross-sections of the $v_{3}\left(765-850 \mathrm{~cm}^{-}\right.$ ${ }^{1}$ ) and $v_{2}\left(1230-1320 \mathrm{~cm}^{-1}\right)$ bands have been measured by Wagner and Birk [29] at a resolution of $0.5 \mathrm{MOPD}=0.014 \mathrm{~cm}^{-1}$. The measurements consisted of more than 30 transmittance spectra covering the temperature range 204 to $293 \mathrm{~K}$ and air pressure range 0 to $180 \mathrm{mbar}$. The spectra were baseline corrected, contaminant spectra were removed, and temperature and pressure dependent absorption cross-sections were fitted as a two-dimensional polynomial in $\ln$ (pressure) and temperature. The overall scalar uncertainties for the $v_{3}$ and $v_{2}$ absorption cross-sections are about $2 \%$ and $4 \%$, respectively. The polynomial coefficients together with software to convert to absorption cross-sections at desired temperatures and pressures are available in HITRAN2016 in the supplementary folder. Additionally, 33 absorption spectra for each band, $v_{3}$ and $v_{2}$, calculated for the approximate pressures and temperatures of the laboratory measurements, have been included in HITRANonline. Details of measurements, analysis, statistical and systematic uncertainties are given in Ref. [29].

HITRAN2012 had zero-pressure spectra with lower resolution for this molecule only in the region of the $v_{3}$ band. The $296 \mathrm{~K}$ cross-sections were previously provided by Höpfner et al. [110], and were scaled to obtain an estimation of the lower-temperature spectra at $218 \mathrm{~K}$. Here we give a comparison of these spectra with the new data from Wagner and Birk (Figure 11). The differences in integrated intensities are $5 \%$ both for $218 \mathrm{~K}$ and $293 \mathrm{~K}$, and there are systematic differences in the band shapes of these spectra. The data from Ref. [110] have been removed from the web interface and placed to the supplemental folder. Having nearly the same temperature and pressure conditions, the data from Wagner and Birk have sharper line features 
1 originating from the higher spectral resolution. The spectral set for bromine nitrate from

2 HITRAN2012 previously available through HITRANonline has thus been replaced by the data 3 from Wagner and Birk.

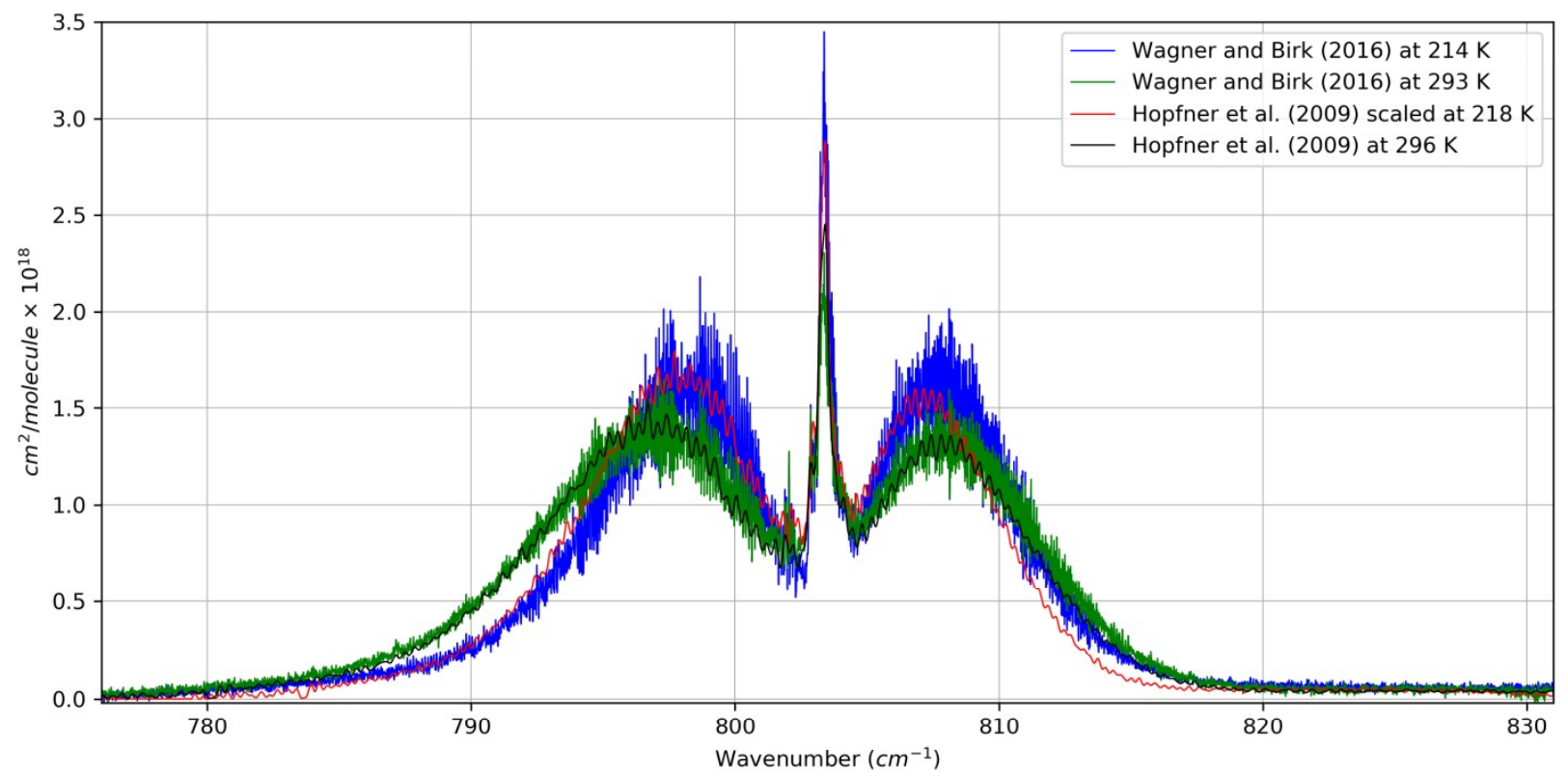

Figure 11. Self-broadened $v_{3}$ band of bromine nitrate measured by Wagner and Birk [29] and Höpfner et al. [110] for 214-218K and 293-296K. 
Table 11. Summary of the spectra for bromocarbons, hydrobromocarbons, and halons.

\begin{tabular}{|c|c|c|}
\hline Molecule & CAS & Range, $\mathbf{c m}^{-1}$ \\
\hline \multicolumn{3}{|c|}{ Sharpe et al. (2004) [13], measured at 5, 25, and 50C, $760 T$ Torr, $N_{2}$-broadened, $0.112 \mathrm{~cm}^{-1}$ resolution } \\
\hline Bromochloromethane & $74-97-5$ & $550-7100$ \\
\hline Tribromomethane & $75-25-2$ & $600-6500$ \\
\hline 1,2-Dibromoethane & $106-93-4$ & $570-6500$ \\
\hline Halon-1202 & $75-61-6$ & $575-6500$ \\
\hline Halon-1211 & $353-59-3$ & $600-6500$ \\
\hline Halon-1301 & $75-63-8$ & $510-6500$ \\
\hline Halon-2402 & $124-73-2$ & $550-6500$ \\
\hline Methylene bromide & $74-95-3$ & $540-7100$ \\
\hline \multicolumn{3}{|c|}{ Sihra et al. [61], measured at $296 \mathrm{~K}, 700 \mathrm{Torr}$, air-broadened, $0.5 \mathrm{~cm}^{-1}$ resolution } \\
\hline Halon-1201 & $1511-62-2$ & $500-1550$ \\
\hline \multicolumn{3}{|c|}{ Andersen et al. [62], measured at $298 \mathrm{~K}, 700 \mathrm{Torr}$, air-broadened, $0.25 \mathrm{~cm}^{-1}$ resolution } \\
\hline Halon-2311 & $151-67-7$ & $600-1499$ \\
\hline \multicolumn{3}{|c|}{ Wagner and Birk [29]†, measured with $0.014 \mathrm{~cm}^{-1}$ resolution } \\
\hline Bromine Nitrate & $40423-14-1$ & $765-1320$ \\
\hline
\end{tabular}

$\dagger$ Spectra from Ref. [49] were measured at 204-293 K temperatures and 0-141 Torr pressure

3 ranges. The full list of cross-sections can be found in the corresponding reference.

\subsection{Chlorocarbons and Hydrochlorocarbons}

The chlorocarbons and hydrochlorocarbons category is relatively new to HITRAN. In prepresent in the cross-section part, and methyl chloride $\left(\mathrm{CH}_{3} \mathrm{Cl}\right)$ in the line-by-line part. In the HITRAN2016 [2] issue, we have included a number of chloroalkanes, chloroalkenes, and chlorine-containing aromatic hydrocarbons for the first time. Table 12 and Table 13 represent a summary of the molecules from this category. Among them one can outline different isomers of chloromethane, chloroethene, chlorobenzene, chloropropane, and vinyl chloride. A large number of the spectra for these molecules has been provided by the PNNL database [13]. Also, for 1,2dichloroethane and chloroform, a high-resolution spectrum was provided in the Hodnebrog review [1] by Highwood and Shine [90] (sourced from the laboratory measurements of Refs. [95] and [103] respectively). Finally, recently published spectra from Harrison et al. [28] and Wallington et al. [113] have also been adapted.

Most of the gases in this class, the hydrochlorocarbons, have lifetimes ranging from months to a few years, except $\mathrm{CCl}_{4}$, whose lifetime is 26 years. Because of the presence of chlorine, these ODSs are controlled under the Montreal Protocol, and concentration of methyl chloroform $\left(\mathrm{CH}_{3} \mathrm{CCl}_{3}\right)$ has undergone a dramatic decrease from an early 1990 s peak in excess of $130 \mathrm{ppt}$ to current values of a few ppt. $\mathrm{CCl}_{4}$ is currently the most abundant of this class of molecules (around $80 \mathrm{ppt}$ ). Despite its concentration falling from an early 1990s peak in excess of $100 \mathrm{ppt}$ [94], $\mathrm{CCl}_{4}$ is an important contributor to radiative forcing $\left(0.015 \mathrm{~W} \mathrm{~m}^{-2}\right.$ in 2011 or about $1 \%$ of that due to $\mathrm{CO}_{2}$ ) [3] and contributes about 25\% to the total mid-latitude EESC [107]. More detailed discussion of $\mathrm{CCl}_{4}$ is given below. 
Figure 12 displays spectra for 1,1,1-trichloroethane, 1,1,2-trichloroethane, trichloroethylene,

2 and tetrachloroethylene from PNNL and NIST [17] which show a good agreement. As in

3 previous sections, we use the data from NIST to cross-validate the spectral datasets. In this

4 section, we give a more detailed outline of comparisons for several molecules of the major

5 atmospheric and remote sensing importance in this category.

6
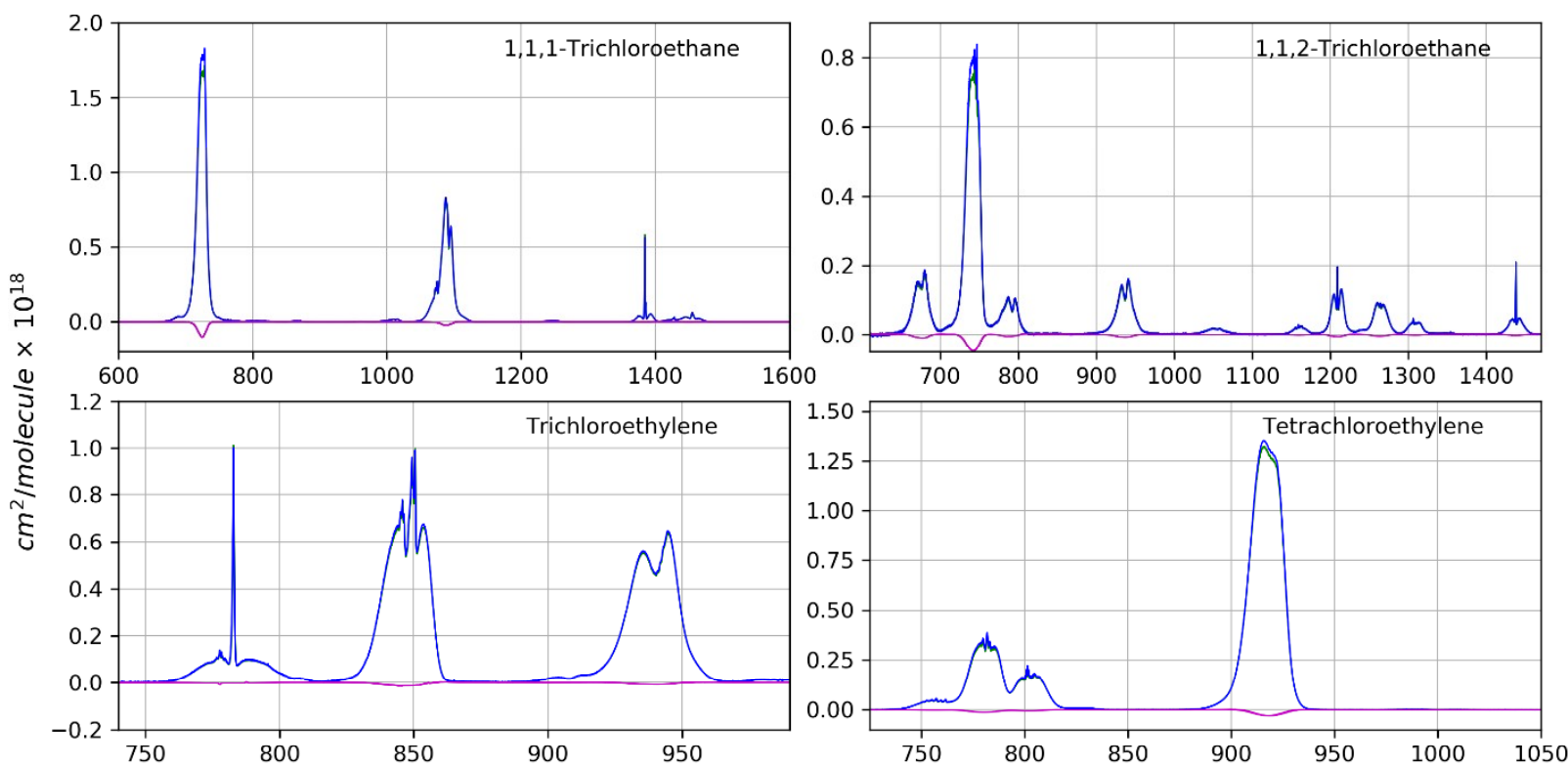

Wavenumber $\left(\mathrm{cm}^{-1}\right)$

8 Figure 12. Absorption from NIST [17] in blue and PNNL [13] in green. The residual (magenta)

9 between PNNL and NIST is given in the same scale.

\subsubsection{1,2-Dichloroethane}

1,2-Dichloroethane $\left(\mathrm{CH}_{2} \mathrm{ClCH}_{2} \mathrm{Cl}\right)$ is a halocarbon species which is often used in chemical synthesis. For this molecule, spectra from PNNL [13], NIST [17], and Vander Auwera [95] have been compared. It should be noted that only PNNL contains multiple-temperature spectra for this molecule. Since one of the temperature and pressure sets are nearly the same for all sources, we have presented the comparison of the band shapes in Figure 13. The resolution and broadener for datasets from PNNL and NIST are the same (see Table 4), whereas the resolution for the data from Vander Auwera [95] is $0.03 \mathrm{~cm}^{-1}$. The spectra from Ref. [95] have more resolved band structure than the rest of the sources, although some negative absorption values exist at the edges of the spectral features. Spectra from PNNL have additional noticeable features in the mid- and near-IR spectral range which is covered neither by NIST, nor by the data from Vander Auwera (2000). Although spectra from PNNL have uniformly lower intensity than NIST, the agreement between all three sources is very good and lies within the combined experimental uncertainties for all spectral features $(0.2-4.9 \%)$ except the weak feature in the atmospheric window in the 
$1860-1050 \mathrm{~cm}^{-1}$ spectral range. For this latter band, the disagreement between Vander Auwera

2 (2000) data and both PNNL and NIST is around 19\% and can possibly be attributed to the

3 spectral calibration. It should also be noted that the data from Ref. [90] for this molecule does

4 not contain the weak features in the zero-filled areas between the strongest bands in the

5 atmospheric window (which is, however, negligible for the GWP estimation purposes). We have

6 included the PNNL data for all three temperatures in HITRANonline. The $293 \mathrm{~K}$ set from

7 Highwood and Shine/Vander Auwera also was included in HITRANonline for the reason of

8 having more resolved spectral structure which can possibly be useful for remote-sensing 9 purposes.

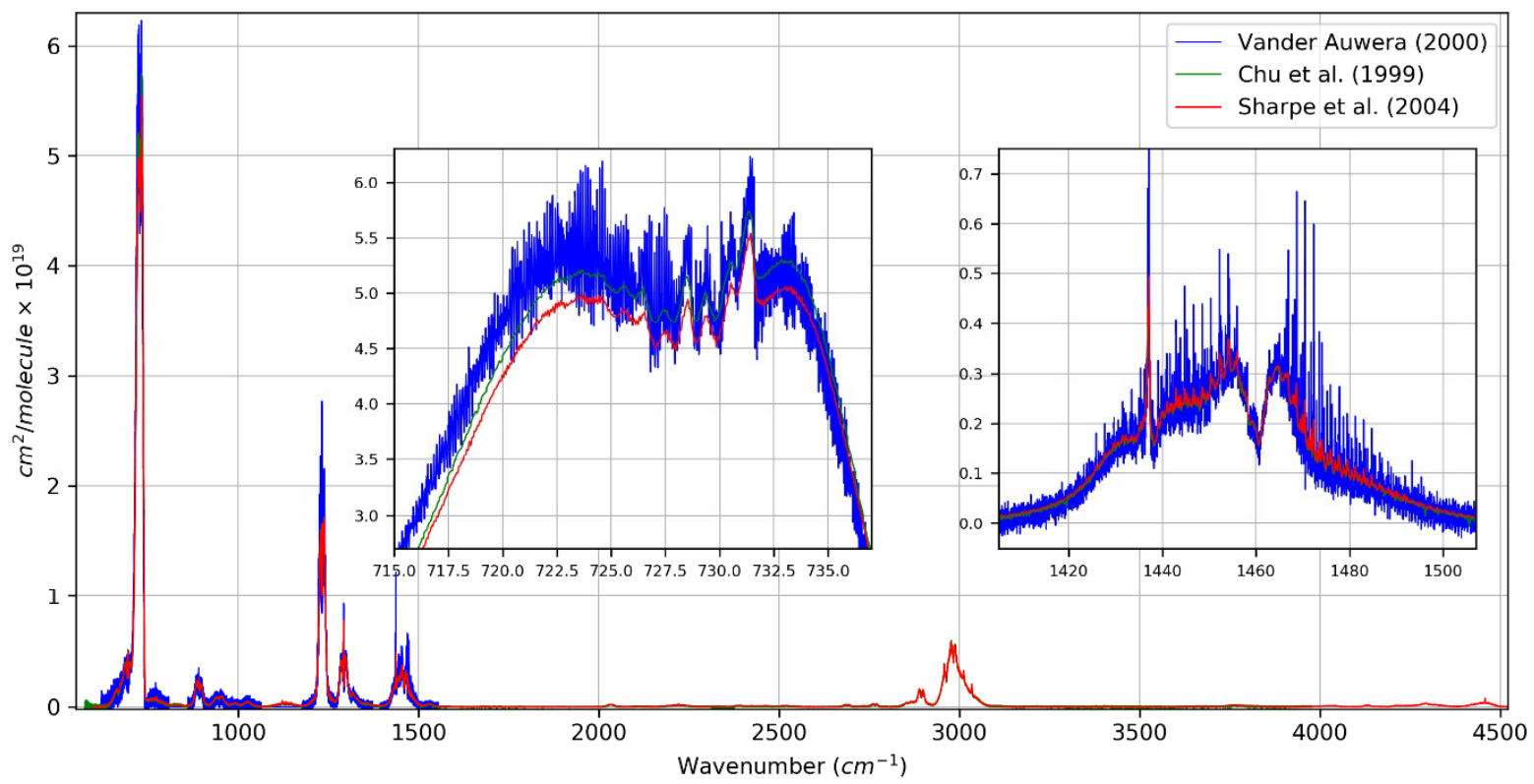

Figure 13. Absorption cross-section comparison for 1,2-dichloroethane.

\subsubsection{Chloroform}

Chloroform (trichloromethane, $\mathrm{CHCl}_{3}$ ) is a compound widely used in chemical synthesis, as a reagent, solvent, and anesthetic. In addition to the spectra from Highwood and Shine [90] (McPheat and Duxbury [103]), NIST [17] and PNNL [13], the data from Wallington et al. [113] have been considered in the evaluation for this molecule. In Ref. [113] the scaled PNNL crosssections at 296K have been supplied for four (hydro) chlorocarbons: chloroform, carbon tetrachloride, methyl chloride, and methylene chloride. Spectra from PNNL are given at three temperatures, whereas the data from McPheat and Duxbury [103] were supplied only at $295 \mathrm{~K}$, and were split by wavenumber range into five files (for $640-710 \mathrm{~cm}^{-1}, 725-805 \mathrm{~cm}^{-1}, 880-1150$ $\mathrm{cm}^{-1}, 1175-1250 \mathrm{~cm}^{-1}$, and 1300-1600 $\mathrm{cm}^{-1}$ wavenumber ranges). The data from McPheat and Duxbury has higher spectral resolution than the rest of the data $\left(0.01 \mathrm{~cm}^{-1}\right)$. The comparison shows that for the integrated intensity of the strongest band in the $730-800 \mathrm{~cm}^{-1}$ spectral region 
1 the agreement between NIST, PNNL, Wallington et al., and McPheat and Duxbury is within 8\%.

2 For other regions (Figure 14), the agreement between all sources except McPheat and Duxbury

3 is better and lies within 5-6\%, while the latter disagrees with the rest by $25 \%$, which can be

4 attributed to calibration problems. Users should keep in mind this discrepancy when using the

5 data for this molecule. Also, the visual comparison of the band shapes shows that the McPheat

6 and Duxbury spectra contain additional absorption, which is missing both in PNNL and NIST

7 spectra (see the insets in Figure 14). This additional absorption can be due to presence of

8 isomers or other contaminants. The data from PNNL and McPheat and Duxbury (only the strong

9 feature between 725-805 $\mathrm{cm}^{-1}$ ) have been included in HITRANonline. Since the data from

McPheat and Duxbury is of higher resolution $\left(0.01 \mathrm{~cm}^{-1} \mathrm{vs} 0.1 \mathrm{~cm}^{-1}\right.$ in PNNL, NIST, and

Wallington et al.), it can be useful in remote sensing and spectral analyses. For this reason, these data (except the $725-805 \mathrm{~cm}^{-1}$ feature) have been placed in the supplemental folder.

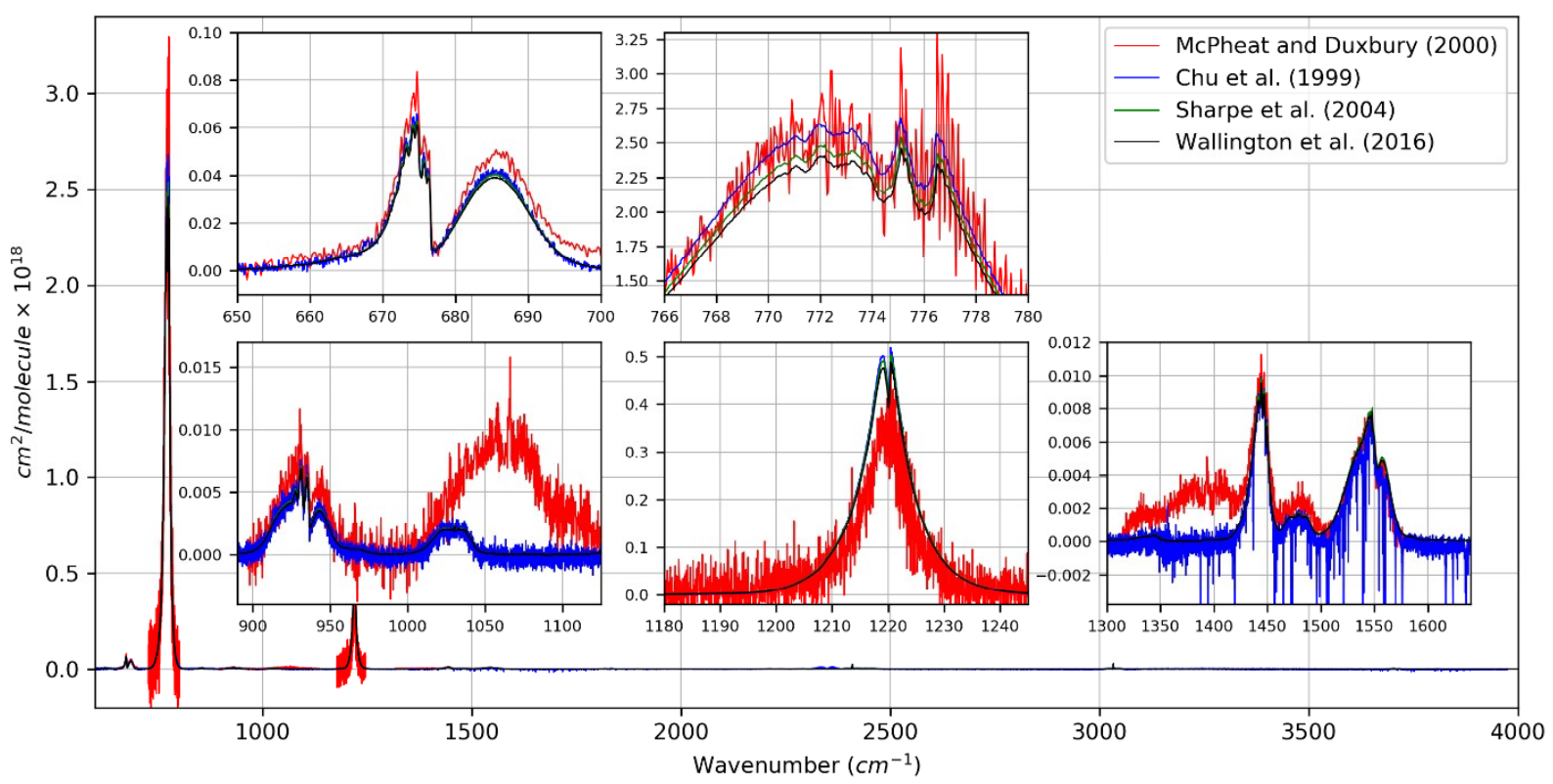

Figure 14. Absorption cross-section comparison for chloroform. The insets show the difference in the band shapes at $1000 \mathrm{~cm}^{-1}$ and $1500 \mathrm{~cm}^{-1}$. The contaminant lines at $1400-1600 \mathrm{~cm}^{-1}$ are due to water vapor absorption.

\subsubsection{Carbon tetrachloride}

As carbon tetrachloride $\left(\mathrm{CCl}_{4}, \mathrm{CFC}-10\right)$ does not occur naturally in the Earth system, its presence in the atmosphere, soil and ocean arises solely through its anthropogenic sources. In the early twentieth century, carbon tetrachloride found many uses, e.g. in dry cleaning (excellent solvent properties). However, its largest industrial application was as a feedstock in the production of CFC-12 and CFC-11 (trichlorofluoromethane). The realization that $\mathrm{CCl}_{4}$, like CFCs, could destroy stratospheric ozone resulted in its regulation under the Montreal Protocol, 
1 leading to a decline in its use. Under the terms of the Protocol, production and consumption of

$2 \mathrm{CCl}_{4}$ were eliminated for developed countries in 1996 and for developing countries in 2010

3 [114]. There are no limits on the use of $\mathrm{CCl}_{4}$ as a feedstock, however, so it is still used, for example, in the production of hydrofluorocarbons. Besides being an ozone-depleting substance, with an ozone depletion potential of 0.72 [115], $\mathrm{CCl}_{4}$ is also a strong greenhouse gas with a lifetime of 26 years and a 100-year GWP of 1730 [3]. Recently there has been renewed interest in carbon tetrachloride, on account of the inconsistency between observations of its abundance and estimated sources and sinks [114,116]. For example, the 2007-2012 emissions estimate based on the UNEP reported production and feedstock usage is near zero. However, the observed inter-hemispheric gradient for $\mathrm{CCl}_{4}(1.5 \pm 0.2 \mathrm{ppt}$ for 2000-2012) provides evidence for ongoing emissions. Additionally, the decline of atmospheric concentrations is slower than can be accounted for by our current best estimates of the total $\mathrm{CCl}_{4}$ lifetime and its uncertainties.

Remote-sensing measurements which provide vertical profiles into the stratosphere, e.g. the ACE-FTS [117], are particularly useful in validating stratospheric loss rates in atmospheric models (the atmospheric loss of $\mathrm{CCl}_{4}$ is essentially all due to photolysis in the stratosphere). The previous absorption cross-section dataset available in HITRAN was provided by Nemtchinov and Varanasi [118]. For HITRAN 2016, this has been replaced by a new dataset from Harrison et al. [28] over the spectral range $700-860 \mathrm{~cm}^{-1}$. Spectra were recorded using a high-resolution FTS (Bruker IFS 125HR) for mixtures of $\mathrm{CCl}_{4}$ with dry synthetic air in a 26-cm-pathlength cell at spectral resolutions between 0.01 and $0.03 \mathrm{~cm}^{-1}$ (calculated as $0.9 / \mathrm{MOPD}$ ) over a range of temperatures and pressures appropriate for upper troposphere - lower stratosphere conditions $(7.5-760$ Torr and $208-296 \mathrm{~K})$.

The previous data of Nemtchinov and Varanasi cover 208-297K and 8-760 Torr ranges for temperature and pressure respectively, and have not been changed since HITRAN2000. The detailed comparison of the Varanasi and Harrison et al. spectra for $\mathrm{CCl}_{4}$ can be found in Ref. [28]. We give only a brief visual comparison for the sets which have the same temperatures and pressures. Figure 15 displays spectra from Varanasi, Harrison et al. [28], PNNL [13], NIST [17], and Wallington et al. [113]. In Figure 15, the panels correspond to the different approximate temperature and pressure conditions, at which the comparisons were made. It is clearly seen (and described furthermore in Ref. [28]), that cross-sections from Harrison et al. have higher $(\sim 5.5 \%)$ intensities than PNNL, Varanasi, and Wallington et al. spectra. The intensities of the spectra from Harrison et al. were calibrated using the NIST database, which results in a better agreement with ground-based measurements [28]. For this reason, the spectra provided by Harrison et al., have been included in HITRANonline, while the old dataset (Varanasi et al.) have been placed in 
1 the supplemental folder along with the PNNL set which contains additional $50^{\circ} \mathrm{C}$ temperature spectra.
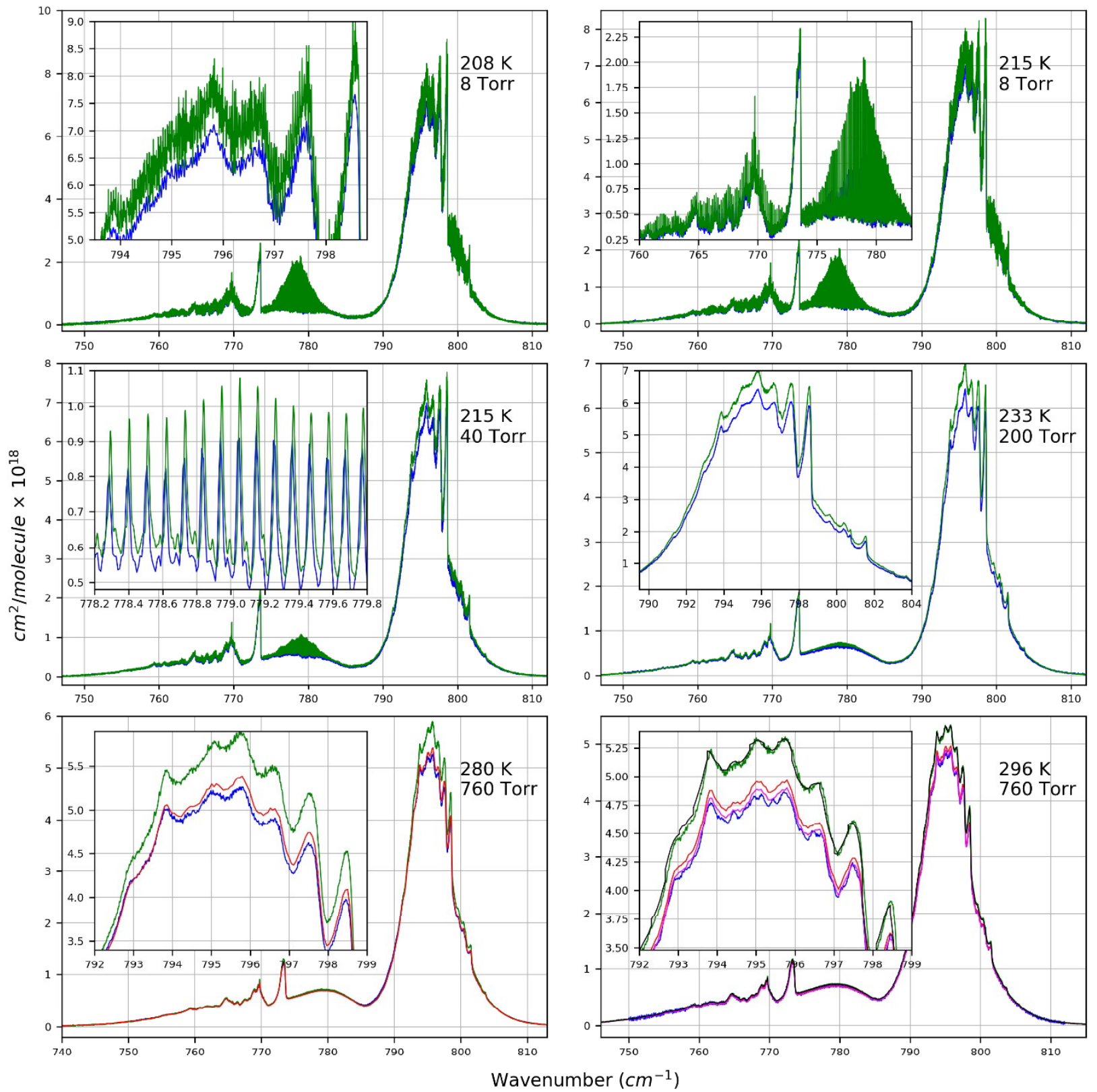

\subsubsection{Methyl chloride}

For methyl chloride (chloromethane, $\mathrm{CH}_{3} \mathrm{Cl}$ ), the line-by-line part of the HITRAN database includes the spectral transitions for the two most abundant isotopologues within a broad wavenumber range $\left(0.8-3198 \mathrm{~cm}^{-1}\right)$. For the details concerning the line-by-line spectra of $\mathrm{CH}_{3} \mathrm{Cl}$, 

the user can refer to the HITRAN2016 [2] and HITRAN2012 [6] papers. The agreement

2 between the absorption cross-sections generated from HITRAN2016 line-by-line data, and

3 PNNL spectra, is acceptable both in terms of the line shape and integrated intensities (12\% and

$4 \quad 6 \%$ for the two strongest bands). This is not surprising because for many bands the intensities

5 were scaled to reproduce the PNNL spectrum. See HITRAN2012 [6] and Nikitin et al. [119] for

6 details. Since there exist high-quality line-by-line data for this molecule, we omit the absorption

7 cross-sections from the interactive HITRANonline page to encourage the users to take advantage

8 of the line-by-line data. However, since the PNNL spectra contain additional features in the

9 higher wavenumber range $\left(>4000 \mathrm{~cm}^{-1}\right)$, these spectra have been placed in the supplemental 10 folder.

Table 12. PNNL-DOE data for chlorocarbons and hydrochlorocarbons

\begin{tabular}{|c|c|c|}
\hline Molecule & CAS & Range, $\mathrm{cm}^{-1}$ \\
\hline 1,1,1,2-Tetrachloroethane & $630-20-6$ & $530-6500$ \\
\hline $1,1,1-\mathrm{TCE}$ & $71-55-6$ & $500-6500$ \\
\hline 1,1,2,2-Tetrachloroethane & $79-34-5$ & $530-6500$ \\
\hline 1,1,2-Trichloroethane & $79-00-5$ & $600-6500$ \\
\hline 1,1-Dichloroethane & $75-34-3$ & $560-6500$ \\
\hline 1,2-Dichloroethane & $107-06-2$ & $600-6500$ \\
\hline 1,2-Dichloropropane & $78-87-5$ & $590-6500$ \\
\hline 1,2-Diclorobenzene & $95-50-1$ & $600-6500$ \\
\hline 1,3-Dichlorobenzene & $541-73-1$ & $600-6500$ \\
\hline 1,3-Dichloropropane & $142-28-9$ & $570-6500$ \\
\hline 1,4-Dichlorobenzene $†$ & $106-46-7$ & $600-6500$ \\
\hline Chlorobenzene & $108-90-7$ & $600-6500$ \\
\hline Chloroethane & $75-00-3$ & $590-6500$ \\
\hline Chloroform & $67-66-3$ & $580-7200$ \\
\hline Hexachloro-1,3-butadiene $\dagger$ & $87-68-3$ & $530-6500$ \\
\hline Methylene chloride & $75-09-2$ & $600-6500$ \\
\hline Tetrachloroethylene & $127-18-4$ & $600-6500$ \\
\hline Trichloroethylene & $79-01-6$ & $595-6500$ \\
\hline Vinyl chloride & $75-01-4$ & $540-6500$ \\
\hline cis-1,3-Dichloropropene & $10061-01-5$ & $600-6500$ \\
\hline trans-1,2-Dichloroethene & $156-60-5$ & $540-6500$ \\
\hline trans-1,3-Dichloropropene & $10061-02-6$ & $600-6500$ \\
\hline
\end{tabular}

Spectra from Sharpe et al. [13] broadened by $\mathrm{N}_{2}$. Spectra were recorded at $278.15 \mathrm{~K}, 298.15 \mathrm{~K}$, $323.15 \mathrm{~K}$ (except for 1,4-dichlorobenzene and hexachloro-1,3-butadiene), 760 Torr total pressure, and $0.112 \mathrm{~cm}^{-1}$ resolution.

$\uparrow$ Spectra for 1,4-dichlorobenzene and hexachloro-1,3-butadiene were recorded at 25 and $50^{\circ} \mathrm{C}$

Table 13. Measurements from Harrison et al [28] and Hodnebrog et al [1]

\begin{tabular}{lllllll}
\hline \multicolumn{1}{c}{ Molecule } & CAS & $\begin{array}{l}\text { Range } \\
\left(\mathbf{c m}^{-1}\right)\end{array}$ & $\begin{array}{c}\text { T } \\
(\mathbf{K})\end{array}$ & $\begin{array}{c}\text { P } \\
(\text { Torr) }\end{array}$ & $\begin{array}{c}\text { Resolution } \\
\left(\mathbf{c m}^{-1}\right)\end{array}$ & Source \\
\hline 1,2-Dichloroethane & $107-06-2$ & $620-1570$ & 293 & & & Vander Auwera (2000) [95] \\
\hline Chloroform & $67-66-3$ & $725-805$ & 295 & & 0.01 & McPheat and Duxbury (2000) [103] \\
\hline
\end{tabular}


$\begin{array}{llllllll}\text { Carbon tetrachloride } & 56-23-5 & 700-860 & 207.9-296.4 & 7.501-760 & 0.01-0.03 & \text { Harrison et al. (2016) [28] }\end{array}$

1 Spectra from Ref. [95] are self-broadened. Cross-sections from the work by Harrison et al. were

2 recorded with air as a bath gas with $0.01-0.03 \mathrm{~cm}^{-1}$ resolution range. The full list of these cross-

3 sections and a more detailed description of the experimental conditions can be found in Ref.

4 [28].

\section{$5 \quad 3.6$. Hydrocarbons}

6 Hydrocarbons have short atmospheric lifetimes and are not well mixed in the atmosphere.

7 Hydrocarbons are important molecules in many fields. In previous HITRAN editions, the

8 hydrocarbons have been predominantly in the line-by-line section, which included the smallest

9 alkanes methane and ethane and selected unsaturated compounds (acetylene, ethylene, and

10 diacetylene). The cross-section part included data for propane and ethane in the $2500-3300 \mathrm{~cm}^{-1}$

11 spectral window. The data for three isomers of xylene (meta-, ortho-, and para-) were present

12 only in the UV range. In the recent HITRAN2016 [2] edition, high-resolution infrared spectra

13 have been added for around thirty alkanes, alkenes, and aromatic hydrocarbons. Table 14 and

14 Table 15 present the summary of all these compounds available via HITRANonline web

15 interface.

16 For most of the molecules from this category, the data from PNNL $[13,22]$ have been added

17 to the database. For ethane, high-quality frequency-stabilized cavity ring-down (FS-CRDS) spectra have also been included. In the case of acetylene, when the line-by-line data superseded the cross-sections, the data on the cross-section have been omitted. Below we give a brief characterization of the comparisons for a number of molecules. For the spectra for eight compounds originated from PNNL, the comparisons with the NIST [17] infrared database have been made to validate the spectra (Figure 16). In comparisons in this figure, all spectra are given at $296 \mathrm{~K}$ and 760 Torr. NIST spectra used in this comparison are taken with the Boxcar apodization and $0.125 \mathrm{~cm}^{-1}$ resolution. The residual between PNNL and NIST is in magenta. The agreement between the integrated intensities is good and lies within the experimental uncertainties stated in both sources. 

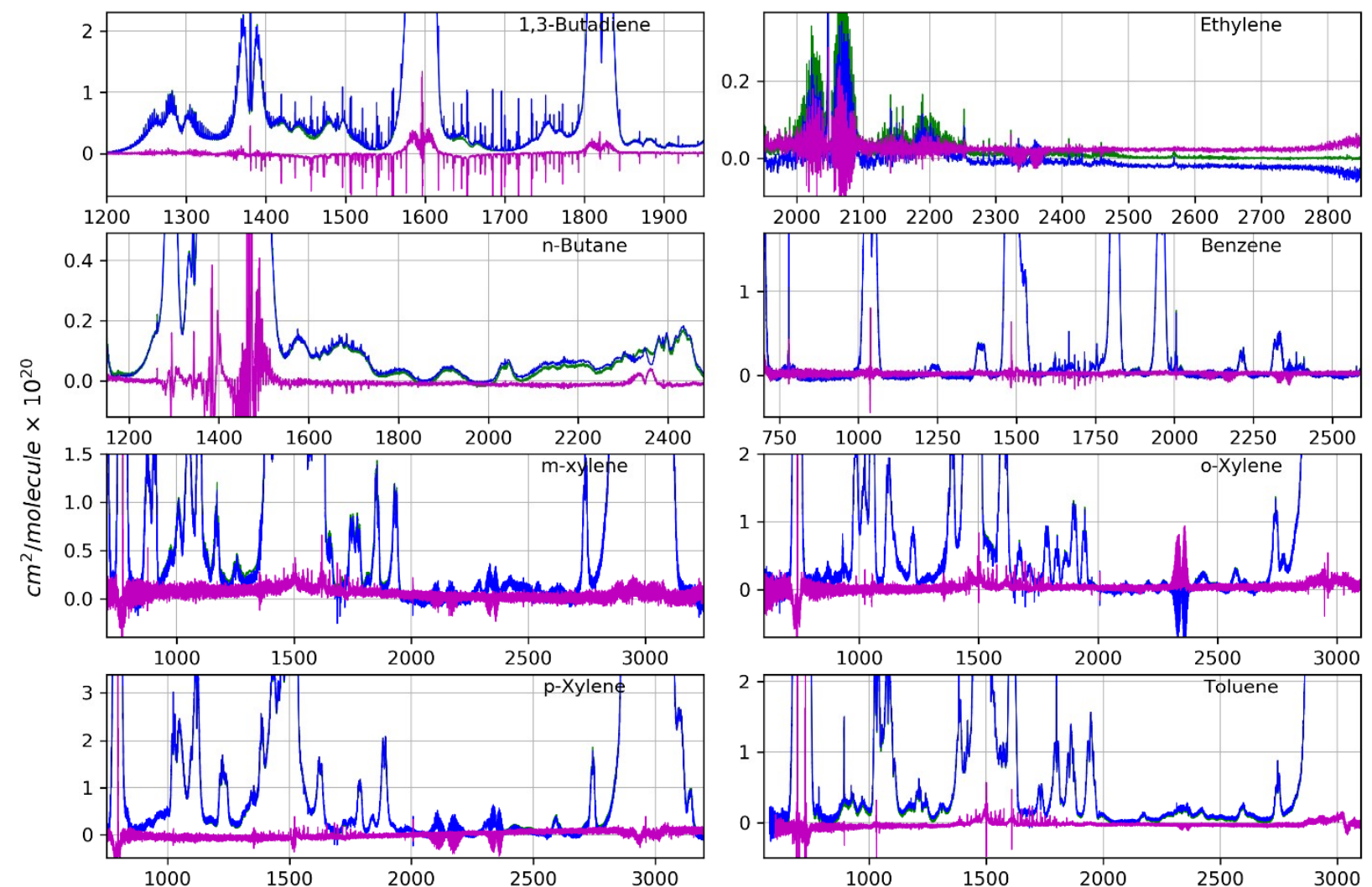

1

Wavenumber $\left(\mathrm{cm}^{-1}\right)$

Figure 16. Comparison of PNNL [13] and NIST [17] spectra for eight hydrocarbons (see labels in each panel). NIST spectra are in blue, PNNL are in green, residual (PNNL-NIST) are in magenta. All spectra are recorded at $296 \mathrm{~K}$ and 760 Torr. The residual shows traces of minor contamination in the NIST spectra (possibly due to $\mathrm{H}_{2} \mathrm{O}, \mathrm{CO}_{2}$, and $\mathrm{CO}$ ).

\subsubsection{1,3-butadiene}

PNNL and NIST spectra for 1,3-butadiene $\left(\mathrm{C}_{4} \mathrm{H}_{6}\right)$ agree very well in terms of integrated intensities. For the region with strongest absorption, $700-1200 \mathrm{~cm}^{-1}$, the agreement is within $2.2 \%$, while in the rest of the range it is $0.11 \%$. However, the NIST spectrum has additional sharp spectral lines which are not present in the PNNL spectrum. Those lines potentially signify the presence of contaminants in the gas mixtures in the NIST experiment. In particular, NIST spectra have a well-resolved additional band in the $2300-2380 \mathrm{~cm}^{-1}$ region, which belongs to carbon dioxide.

\subsubsection{Ethylene}

Ethylene (ethene, $\mathrm{C}_{2} \mathrm{H}_{4}$ ) spectra are present in the line-by-line part of the HITRAN database and were updated in the recent HITRAN2016 edition. The ethylene transitions cover all strong spectral bands in the region below $3200 \mathrm{~cm}^{-1}$. Since the PNNL spectra have additional lowintensity spectral features, we have included the cross-sections for three temperatures from PNNL in the HITRAN2016 edition. To encourage the user to take advantage of the line-by-line data, the PNNL cross-sections have been placed in the supplemental folder. With the update of 
1 the line-by-line data in the HITRAN2016 edition, the agreement with the PNNL cross-sections

2 became significantly better (see the comparison of the update with the HITRAN2012 edition

3 given in Figure 25 in Ref. [2]). For the PNNL and NIST comparison, the agreement of the

4 integrated intensities is also good for the two strongest bands (less than $0.6 \%$ difference in the

$5 \quad 600-1300 \mathrm{~cm}^{-1}$ and $2800-3400 \mathrm{~cm}^{-1}$ regions). For the weaker bands, integrated intensities agree

6 within $2.2 \%$ in the interval $1350-1550 \mathrm{~cm}^{-1}$, and worse in the $1840-1940 \mathrm{~cm}^{-1}$ range $(4.4 \%)$. The

7 latter can be due to the influence of the minor negative baseline drift for NIST spectrum for this

8 molecule in the full spectral range.

\section{$9 \quad 3.6 .3 . n$-Butane}

10 Similar to 1,3-butadiene, the spectrum for $n$-butane $\left(\mathrm{C}_{4} \mathrm{H}_{10}\right)$ from NIST contains additional spectral lines which are likely due to contaminants. This molecule absorbs intensively in the full spectral range. We have compared the integrated intensities between NIST and PNNL in two regions: $500-2000 \mathrm{~cm}^{-1}$ and $2000-4000 \mathrm{~cm}^{-1}$. The discrepancies in intensities are $0.35 \%$ and $1.53 \%$ respectively. The PNNL spectra for n-butane have been included in HITRANonline.

\subsubsection{Benzene}

For benzene $\left(\mathrm{C}_{6} \mathrm{H}_{6}\right)$, the spectral data are available in both PNNL and NIST databases. Spectra from PNNL have already been included in previous HITRAN editions. The HITRAN2016 edition has the data for benzene unchanged. The overall wide-range agreement of the integrated intensities between PNNL and NIST is excellent $(0.2 \%)$. However, for most of the features, the NIST line intensity is systematically stronger than that of PNNL which is compensated by the minor negative baseline drift in the NIST spectrum. Like some of the previous molecules mentioned in this section, the NIST data contains additional sharp spectral lines possibly due to contaminants.

\subsection{5. m-Xylene, o-Xylene, and p-Xylene}

For m/o/p-isomers of xylene (dimethylbenzene, $\left.\mathrm{C}_{6} \mathrm{H}_{5}\left(\mathrm{CH}_{3}\right)_{2}\right)$, previous HITRAN editions included only spectra in the UV range. In HITRAN2016 we have included IR spectra from PNNL for these molecules in the HITRANonline interface. The spectra for these molecules have also been measured by NIST. From the comparisons of PNNL and NIST spectra, it is clear that the integrated intensities over a wide range $\left(500-3500 \mathrm{~cm}^{-1}\right)$ are in very good agreement $(2.5 \%$ $1.8 \%$, and $0.2 \%$ for $\mathrm{m}-, \mathrm{o}-$, and $\mathrm{p}$-xylene respectively). Again, NIST spectra have presumably minor artifacts such as additional contaminant bands in the $2000-2500 \mathrm{~cm}^{-1}$ range. 


\subsubsection{Toluene}

For toluene $\left(\mathrm{C}_{6} \mathrm{H}_{5} \mathrm{CH}_{3}\right)$, the previous HITRAN editions included only the UV spectra. The IR data from PNNL have been included in HITRANonline. For toluene, the agreement between PNNL and NIST integrated cross-sections is $1.6 \%$. The NIST spectrum has slight line-shape artifacts at the top of the Q-branches, and slightly higher absorption intensity in the area of the band wings, as well as a minor contaminant band near $2350 \mathrm{~cm}^{-1}$.

\subsubsection{Ethane}

The ethane molecule, $\mathrm{C}_{2} \mathrm{H}_{6}$, is the second most abundant hydrocarbon in the terrestrial atmosphere after methane. Ethane is concentrated mostly in the lower troposphere due to its short lifetime [49]. It also has been observed in the atmospheres of gas giants and comets (see Ref. [49] and links within).

In HITRAN, the ethane spectra are contained in both line-by-line and cross-section formats. The line-by-line spectral transition data and its latest update were described in the HITRAN2016 paper [2]. The line-by-line data cover the three strongest spectral features of ethane in the IR at 3, 6.5, and $11.7 \mu \mathrm{m}$. Along with line-by-line data, 14 absorption cross-sections provided by Harrison et al. [42] at $3 \mu \mathrm{m}$ have been adopted in HITRAN2016 from the previous database release without any changes. These data cover the full range of the spectral feature at $3 \mu \mathrm{m}$ which compensates for the incompleteness of the line-by-line data in this region. Intensities were calibrated using the PNNL spectra at three temperatures [42].

For the HITRAN2016 update, the data from two sources were considered. First, the PNNL data for $25^{\circ} \mathrm{C}$ and atmospheric pressure have been compared to the spectra from the line-by-line part [2] and from Ref. [42], as shown in Figure 17. Both of the latter sources cover all the strongest bands of ethane in the IR. The PNNL dataset for three temperatures $(278.15,298.15$, $323.15 \mathrm{~K}$ ) has been placed in the supplemental folder for the reason of having wider temperature range (up to $50^{\circ} \mathrm{C}$ ) and minor absorption features above $3500 \mathrm{~cm}^{-1}$.

More recent data on ethane in the near-infrared range 5950-5967 $\mathrm{cm}^{-1}$ were provided by Reed and Hodges [49]. The spectra were recorded using frequency-stabilized cavity ring-down technique (FS-CRDS) with $200 \mathrm{kHz}$ resolution. The spectra were measured both air- and selfbroadened, and the summary on the temperature and pressure sets is given in Table 15 . The selfbroadened and low-pressure air-broadened spectra (at 5, 10, and 50 Torr) had minor artifacts, namely the similar spectral points with different absorptions, which occurred possibly due to the interruptions in data acquisition, which led to changes in the cavity base losses. These artifacts 
1 were smoothed using the Akima spline provided in the Scipy package (https://www.scipy.org/),

2 and the spectra were interpolated on an equidistant grid.

3 The Figure 17 inset shows the comparison of the spectra at room temperature and

4 atmospheric pressure from PNNL [13] and Reed and Hodges [49]. The insets show three strong absorption bands in the atmospheric window, and the narrow near-infrared region with the new cavity ring-down data from Reed and Hodges [49]. The line shapes of FTS and CRDS spectra are similar with a slight shift in intensity, which can be due to micro-fluctuations of the FTS baseline. The near-infrared spectrum can be useful in remote sensing of hydrocarbons since interference by other molecules is minor in this region [49]. The data from Reed and Hodges have been provided to the users via the HITRANonline web interface.

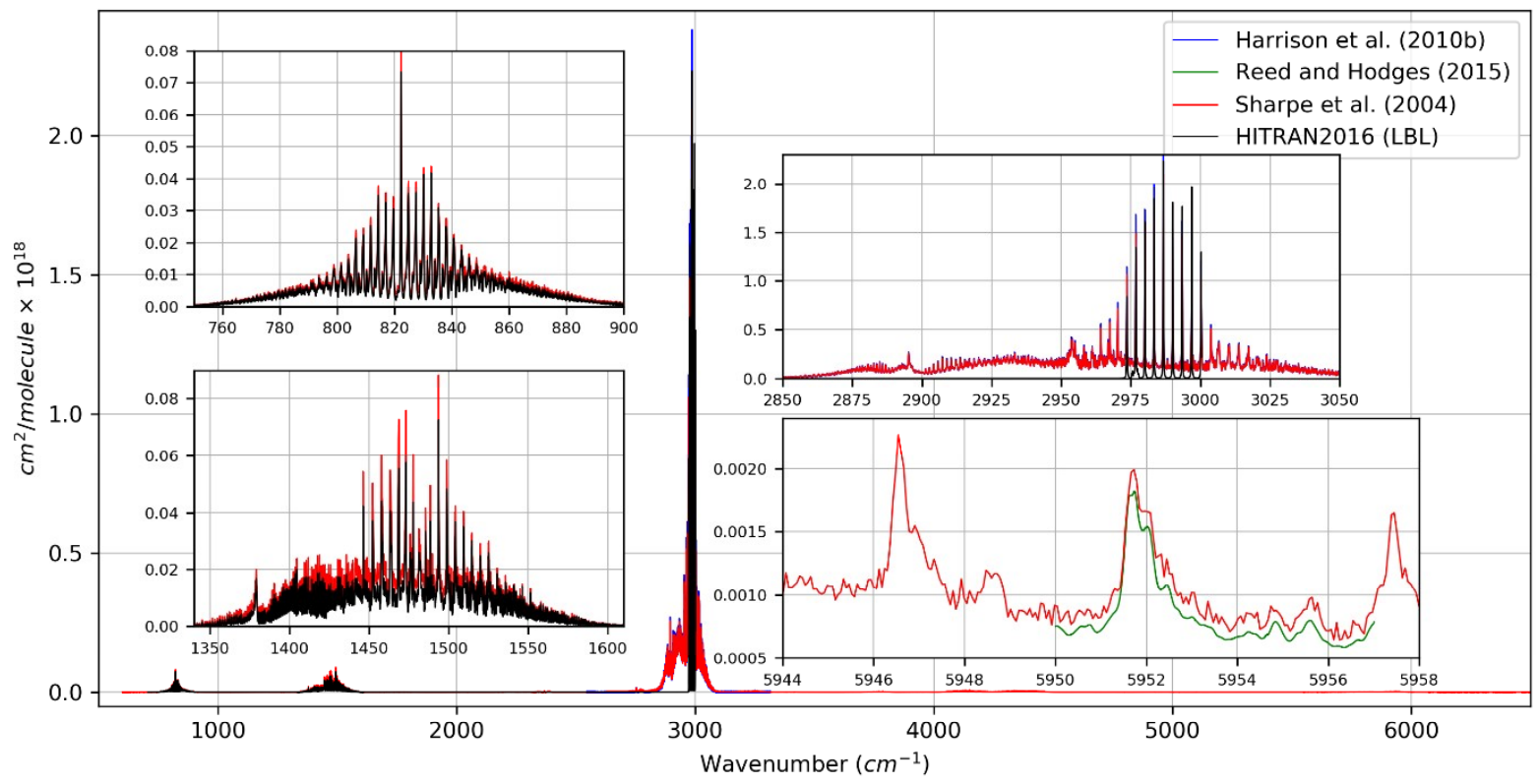

Figure 17. Ethane spectra at $296 \mathrm{~K}$ and 760 Torr. The absorption cross-sections generated from the HITRAN2016 line-by-line transitions are given in black.

Table 14. PNNL data for hydrocarbons

\begin{tabular}{|c|c|c|c|}
\hline Molecule & CAS & Range, $\mathrm{cm}^{-1}$ & $\mathbf{T}, \mathbf{K}$ \\
\hline \multicolumn{4}{|c|}{ PNNL - SERDP/Johnson et al. (2010) [22] } \\
\hline 2-Carene & $554-61-0$ & $600-7300$ & $298.15,323.15$ \\
\hline 3-Carene & $13466-78-9$ & $600-7300$ & $298.15,323.15$ \\
\hline D-Limonene & $5989-27-5$ & $520-6500$ & $298.15,323.15$ \\
\hline DL-Limonene & $138-86-3$ & $580-6500$ & $298.15,323.15$ \\
\hline n-Hexadecane & $544-76-3$ & $550-6500$ & 323.15 \\
\hline n-Pentadecane & $629-62-9$ & $570-6500$ & $298.15,323.15$ \\
\hline Myrcene & $123-35-3$ & $520-6500$ & $298.15,323.15$ \\
\hline Vinyl toluene & $100-80-1$ & $550-6500$ & $298.15,323.15$ \\
\hline \multicolumn{4}{|c|}{ PNNL-DOE / Sharpe et al. (2004) [13] } \\
\hline 1,3-Butadiene & $106-99-0$ & $530-6500$ & $\begin{array}{l}278.15,298.15, \\
323.15\end{array}$ \\
\hline
\end{tabular}




\begin{tabular}{|c|c|c|c|}
\hline 1-Butene & $25167-67-3$ & $525-6500$ & $\begin{array}{l}278.15,298.15, \\
323.15\end{array}$ \\
\hline 1-Nonene & $124-11-8$ & $550-6500$ & $298.15,323.15$ \\
\hline 2-Ethyltoluene & 611-14-3 & $520-6500$ & $298.15,323.15$ \\
\hline 4-Ethyltoluene & $622-96-8$ & $600-6500$ & $298.15,323.15$ \\
\hline alpha-Pinene (1S)(-) & $7785-26-4$ & $600-6500$ & $298.15,323.15$ \\
\hline beta-Pinene (1S) (-) & $18172-67-3$ & $600-6500$ & $298.15,323.15$ \\
\hline n-Heptane & $142-82-5$ & $600-6500$ & $\begin{array}{l}278.15,298.15, \\
323.15\end{array}$ \\
\hline n-Hexane & $110-54-3$ & $600-6500$ & $\begin{array}{l}278.15,298.15, \\
323.15\end{array}$ \\
\hline Isobutane & $75-28-5$ & $600-6500$ & $\begin{array}{l}278.15,298.15, \\
323.15\end{array}$ \\
\hline Isobutene & $115-11-7$ & $600-6500$ & $\begin{array}{l}278.15,298.15, \\
323.15\end{array}$ \\
\hline Isopentane & $78-78-4$ & $600-6500$ & $\begin{array}{l}278.15,298.15, \\
323.15\end{array}$ \\
\hline Isoprene & $78-79-5$ & $600-6500$ & $\begin{array}{l}278.15,298.15, \\
323.15\end{array}$ \\
\hline Naphthalene & $91-20-3$ & $600-6500$ & 323.15 \\
\hline n-Butane & $106-97-8$ & $600-6500$ & $\begin{array}{l}278.15,298.15, \\
323.15\end{array}$ \\
\hline Octane & $111-65-9$ & $600-6500$ & $\begin{array}{l}278.15,298.15, \\
323.15\end{array}$ \\
\hline Pentane & $109-66-0$ & $570-6500$ & $\begin{array}{l}278.15,298.15, \\
323.15\end{array}$ \\
\hline Propane & $74-98-6$ & $600-6500$ & $\begin{array}{l}278.15,298.15, \\
323.15\end{array}$ \\
\hline Styrene (monomer) & $100-42-5$ & $600-6500$ & $298.15,323.15$ \\
\hline Toluene & $108-88-3$ & $600-6500$ & $\begin{array}{l}278.15,298.15, \\
323.15\end{array}$ \\
\hline m-Xylene & $108-38-3$ & $580-6500$ & $298.15,323.15$ \\
\hline o-Xylene & $95-47-6$ & $600-6500$ & $298.15,323.15$ \\
\hline p-Xylene & $106-42-3$ & $580-6500$ & $298.15,323.15$ \\
\hline
\end{tabular}

1 Spectra from the PNNL database. All spectra are broadened by nitrogen and recorded at 0.112

$2 \mathrm{~cm}^{-1}$ resolution.

3 Table 15. Ethane absorption cross-sections in the near-infrared range (Reed and Hodges [49]).

\begin{tabular}{lrrl}
\hline Range, $\mathbf{~ c m}^{-1}$ & T, K & p, Torr & Broadener \\
\hline $5950-5968$ & 296 & 5 & air \\
\hline $5950-5957$ & 295.6 & 10 & air \\
\hline $5950-5957$ & 295.8 & 50 & air \\
\hline $5951-5957$ & 295.8 & 300 & air \\
\hline $5950-5957$ & 295.9 & 759.9 & air \\
\hline $5948-5967$ & 296.1 & 0.022 & self \\
\hline
\end{tabular}

4 Cavity Ring Down Spectroscopy (CRDS) measurements of ethane air and self-broadened spectra

5 published by Reed and Hodges [49]. Measurements were made at $200 \mathrm{kHz}$ frequency resolution. 


\subsection{Hydrochlorofluorocarbons}

2

3

4

5

6

HCFCs were primarily viewed as transitional replacements for the CFCs in industrial and domestic applications. While still containing chlorine, and hence being ODSs, controlled by the

Montreal Protocol, the presence of at least one hydrogen atom makes them susceptible to

reaction with $\mathrm{OH}$ in the troposphere, and thus they have shorter lifetimes than $\mathrm{CFCs}$, ranging

from about 1 month to 2 decades [1] and, for a given emission, are less able to accumulate in the

stratosphere. With the worldwide CFC phase-out achieved, the focus has shifted to ending the use of HCFCs themselves, with a final phase-out currently scheduled for 2040 in the developing world and 2030 for developed countries. By far the most abundant HCFC in the atmosphere is HCFC-22, with current concentrations of about 240 pptv and still rising, followed by HFC-141b and HFC142b (concentrations of 20-25 pptv, which have leveled off in recent years) [94]. The 2011 radiative forcing due to the HCFCs is about $0.05 \mathrm{~W} \mathrm{~m}^{-2}$, about $3 \%$ of that due to $\mathrm{CO}_{2}$ [3]. Their contribution to ozone depletion, measured by the EESC, is about $3 \%$ of the total midlatitude EESC [107]. In this section, we give a summary for newly added compounds (Table 16 and Table 17), as well as compare the cross-section datasets for some of the molecules. For each sub-section, the cross-section comparison is displayed in the corresponding panel of Figure 18. 


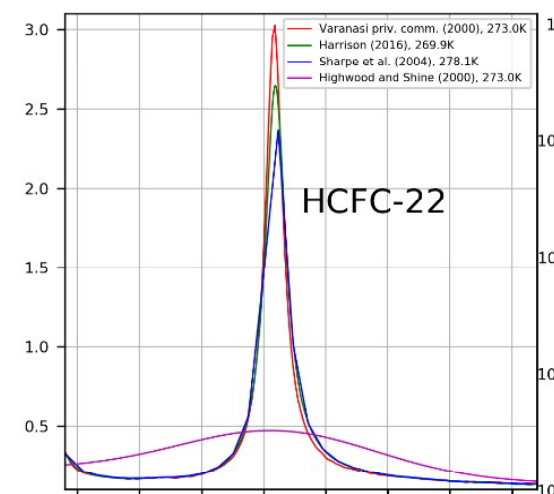

828.25828 .50828 .75829 .00829 .25829 .50829 .75830 .00
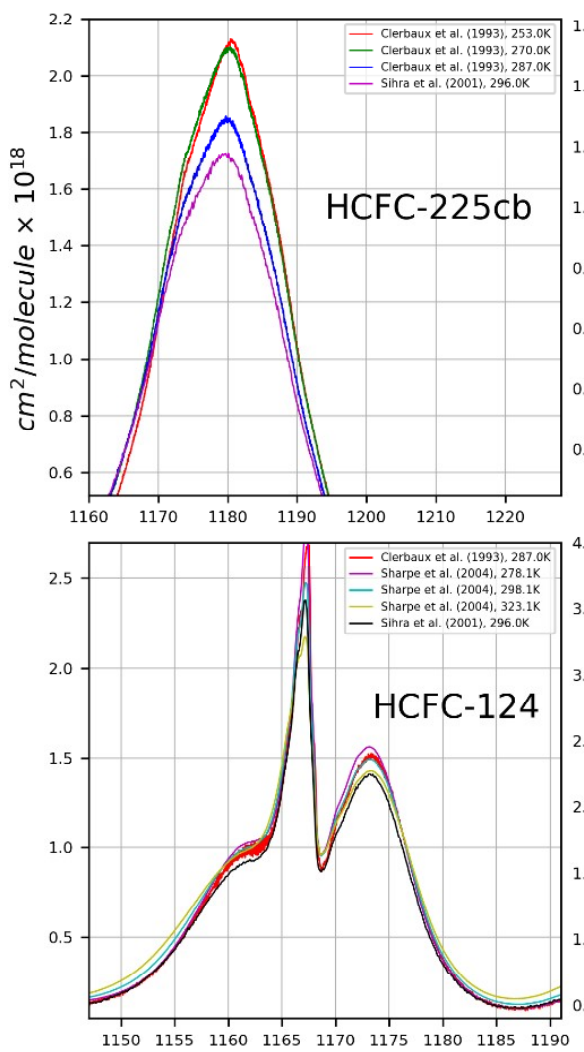

1

\subsubsection{HCFC-22}
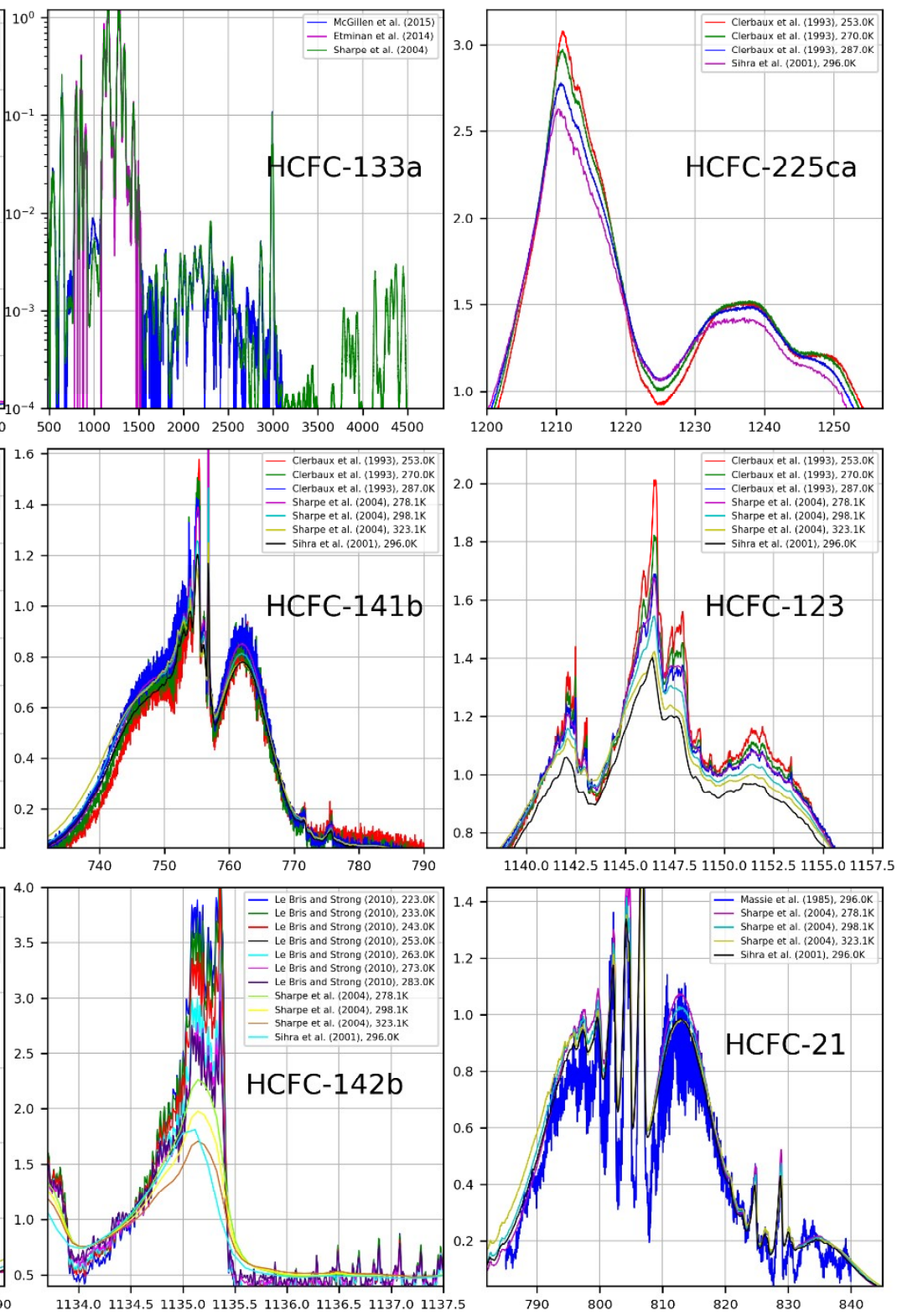

Wavenumber $\left(\mathrm{cm}^{-1}\right)$

Figure 18. Cross-section comparison for selected bands of hydrochlorofluorocarbons (HCFCs). In each group, the comparison was taken between the datasets with similar conditions.

Chlorodifluoromethane (HCFC-22) is the most widely-used HCFC and has been commercially available since the 1930 s. HCFC-22 is a strong greenhouse gas with a 100 -year GWP of 1760 [3], an atmospheric lifetime of 11.9 years [3], and an ODP of 0.034 [115].

Remote-sensing measurements of HCFC-22 in the atmosphere have been made by a number of instruments, for example ATMOS [120], MIPAS [121], and the ACE-FTS [122].

The absorption cross-sections for HCFC-22 have been represented in previous HITRAN compilations by the air-broadened dataset from Varanasi et al. (supplied to the database in 2000 as a private communication), as well as self-broadened data from Clerbaux et al. [18]. For HITRAN 2016, the air-broadened dataset from Varanasi et al. has been replaced by a new 
1 dataset from Harrison [27]. New high-resolution cross-sections for air-broadened HCFC-22 have

2 been determined over the spectral range $730-1380 \mathrm{~cm}^{-1}$. Spectra were recorded using a high-

3 resolution Fourier transform spectrometer (Bruker IFS 125HR) for mixtures of HCFC-22 with

4 dry synthetic air in a 26-cm-pathlength cell at spectral resolutions between 0.01 and $0.03 \mathrm{~cm}^{-1}$

5 (calculated as 0.9/MOPD) over a range of temperatures and pressures appropriate for upper

6 troposphere - lower stratosphere conditions (7.5 - 762 Torr and $191-295 \mathrm{~K})$. The intensity was

7 calibrated using the spectra from PNNL [13].

8 The detailed comparison of the new data from Harrison with Varanasi et al. is provided in

9 Ref. [27]. Figure 18 contains the comparison for the datasets at the $270 \mathrm{~K}$ temperatures with

10 additional data from Highwood and Shine [90], which were an average over measurements from

115 laboratories in the intercomparison reported by Ballard et al. [123]. All cross-sections were

12 compared in the region, and good agreement has been demonstrated (around $3.2 \%$ in the worst case between the data from Ref. [27] and Ref. [90]). The spectrum from Ref. [90] was supplied with lower resolution and contains no additional features; thus it was omitted. The PNNL data were also included in HITRANonline as having a higher range of temperature. The dataset from Varanasi et al. is available in the supplemental folder.

\subsubsection{HCFC-133a}

HCFC-133a (2-chloro-1,1,1-trifluoroethane, $\mathrm{C}_{2} \mathrm{H}_{2} \mathrm{ClF}_{3}$ ) is used in pharmaceutics and chemical synthesis [124] and has an atmospheric lifetime of 4 years. It is removed from the atmosphere primarily by reactions with $\mathrm{OH}$ radicals and by UV photolysis. Recently it was detected in the atmosphere for the first time (see the Nature review by Laube et al. [125]). We have compared data from three sources for this molecule: PNNL [13], and more recently published data from McGillen et al. [124] and Etminan et al. [43]. The stated resolution for spectra from McGillen et al. is $1 \mathrm{~cm}^{-1}$, which is lower than for both the other sources, and has somewhat less agreement with Refs. $[13,43]$ for intensities, integrated in two ranges: $\sim 6 \%$ in $780-920 \mathrm{~cm}^{-1}$ range, and $2 \%$ in $1080-1520 \mathrm{~cm}^{-1}$ range. Both recently-measured data from Refs. $[43,124]$ are recorded at low pressures $(20$ Torr He-broadened and 6.96 Torr self-broadened respectively). The data from Refs. [13] and [43] have been included in HITRANonline. The Hebroadened data from McGillen et al. have a similar line shape as the PNNL spectra, and do not contain additional features. Since the overall agreement is good, it has been decided to include these data in the supplemental folder, to demonstrate the independence of these spectra on broadener and pressure. 


\subsubsection{HCFC-225ca and HCFC-225cb}

The spectra for HCFC-225ca $\left(\mathrm{CHCl}_{2} \mathrm{CF}_{2} \mathrm{CF} 3\right)$ and $\mathrm{HCFC}-225 \mathrm{cb}\left(\mathrm{CClF}_{2} \mathrm{CF}_{2} \mathrm{CHClF}\right)$ have been included in the previous versions of HITRAN. These data have been published by Clerbaux et al. [18] and span the 253-287 K temperature range. No dependence on pressure of these crosssections was found [18], so in principle these cross-sections can be used at higher pressures. The compared data from Sihra et al. [61] shows good agreement for both molecules, and the integrated intensities agree well within experimental uncertainties of Ref. [18]. The data from the latter source can be used in conjunction with the set from Clerbaux et al. since it agrees well with the temperature dependence of the spectra from Clerbaux et al. The spectra from Sihra et al. were included in HITRANonline for this molecule.

\subsection{4. $\mathrm{HCFC}-141 \mathrm{~b}$}

For the HCFC-141b (1,1-dichloro-1-fluoroethane, $\left.\mathrm{CH}_{3} \mathrm{CCl}_{2} \mathrm{~F}\right)$ molecule, the HITRAN database includes high-resolution self-broadened data from Clerbaux et al. [18] for three temperatures $(253,270$, and $287 \mathrm{~K})$, having each temperature dataset split into three regions (710-790, 895-1210, and 1325-1470 $\left.\mathrm{cm}^{-1}\right)$, corresponding to the strong, medium, and weak absorption regions respectively. The new data for this comparison come from PNNL [13] and Sihra et al. [61] which provide spectra at atmospheric pressure broadened by nitrogen and synthetic air, and Le Bris et al. [34] which provide pure vapor spectra.

The comparison of the old spectra from Ref. [18] shows several things to note. First, the $270 \mathrm{~K}$ spectra from Clerbaux et al. contain a unique spectral feature in the region between 990-1070 $\mathrm{cm}^{-1}$, which is not contained in the datasets for different temperatures from Clerbaux et al. as well as from Refs. [13,61]. This artifact has been identified as a contaminant [34]. Users should be aware of that when processing these spectra. The PNNL data (given at three standard temperatures), and data from Clerbaux agree well for the temperatures that can be compared (i.e. one set around $270 \mathrm{~K}$, and another around $290 \mathrm{~K}$ ) with integrated intensities within $3 \%$ at $296 \mathrm{~K}$ and within $5.5 \%$ at $270 \mathrm{~K}$ for all spectral features except the weakest one (at $1400 \mathrm{~cm}^{-1}$ ). The data from Le Bris et al. also agree very well with those from PNNL (within 1.5\%) and Clerbaux et al. (within 2\%) around $283 \mathrm{~K}$. At lower temperatures, however, the integrated intensities of Clerbaux et al. decrease by $12 \%$ at $253 \mathrm{~K}$, while those from Le Bris et al. do not change appreciably. The Le Bris et al. data cover a larger spectral range $\left(570-3100 \mathrm{~cm}^{-1}\right)$ and a wider temperature range $(223 \mathrm{~K}$ to $283 \mathrm{~K})$ and this dataset is preferred.

The spectra from Refs [13,34] have been included in HITRANonline (Ref. [34] as a postrelease update) because of the good agreement with the spectra from Clerbaux et al. The data 
1 from Sihra et al. [61] disagree somewhat with the two other sources $(8-10 \%$ for integral

2 intensities) and have been omitted. Self-broadened data from Ref. [18] was relegated to the

3 supplemental folder.

4 3.7.5. $\mathrm{HCFC}-123$

For HCFC-123 (2,2-dichloro-1,1,1-trifluoroethane, $\mathrm{CHCl}_{2} \mathrm{CF}_{3}$ ), the previous HITRAN issues

6 had a set of spectra from Clerbaux et al. [18] for three temperatures $(253,270$, and $287 \mathrm{~K})$, each set split into two regions (740-886 $\mathrm{cm}^{-1}$ and $\left.1080-1450 \mathrm{~cm}^{-1}\right)$. New data come from PNNL [13] and Sihra et al. [61]. The agreement between the PNNL and Clerbaux spectra is excellent (1.4\% for the region of the strong absorption, and less than a percent difference for weak absorption region at lower wavenumbers). The spectra from Sihra et al. [61] agree less well with other sources, with a discrepancy of approximately $9 \%$. It should be noted that in the region $960-1150$ $\mathrm{cm}^{-1}$, data from Sihra et al. contain additional spectral features at the strong band near $1200 \mathrm{~cm}^{-1}$. These artifacts are absent in other sources and possibly are due to the presence of contaminants. In addition, the PNNL spectra have an additional strong feature at $670 \mathrm{~cm}^{-1}$, while the spectrum from Sihra et al. is zeroed in this region. The spectra from PNNL have been included in HITRANonline, while the Sihra et al. data were omitted.

\subsubsection{HCFC-124}

For HCFC-124 (2-chloro-1,1,1,2-tetrafluoroethane, $\mathrm{CHClFCF}_{3}$ ), data from previous HITRAN issues include only Clerbaux et al. [18] for $287 \mathrm{~K}$. New data from PNNL [13] are given for three standard temperatures, and data from Sihra et la. [61] for 296K. PNNL have been included in HITRANonline owing to the good agreement with Ref. [18] ( 2.8\%) for the 790-430 $\mathrm{cm}^{-1}$ range. Data from Sihra et al. have been omitted.

\subsubsection{HCFC-142b}

HCFC-142b (1-chloro-1,1-difluoroethane, $\mathrm{CH}_{3} \mathrm{CClF}_{2}$ ) is a compound that has been detected in the Earth's atmosphere (see [126] and references within). The previous HITRAN editions contained cross-sections for this molecule provided by Le Bris and Strong [33]. These data are self-broadened and recorded at multiple temperatures in the $223-283 \mathrm{~K}$ range. The new data in this comparison includes PNNL [13] and Sihra et al. [61]. The comparison of the integrated intensities in two ranges (I: $860-1000 \mathrm{~cm}^{-1}$, II: $1050-1300 \mathrm{~cm}^{-1}$ ) shows good agreement between Le Bris and Strong, and PNNL ( $\sim 3.2 \%$ for region I, and $1.9 \%$ for region II). The spectrum from Sihra et al. agrees within $6 \%$ with both of these sources, but lacks the feature at $680 \mathrm{~cm}^{-1}$. The spectrum from Sihra et al. shows a slight wavenumber shift $\left(\sim 0.25 \mathrm{~cm}^{-1}\right)$ in comparison to other 
sources. The data from PNNL were included in HITRANonline, while the spectra from Sihra et

2 al. were omitted.

\begin{tabular}{lll}
\hline \multicolumn{1}{c}{ Molecule } & CAS & Range, $\mathbf{c m}^{-1}$ \\
\hline 1,2-Dichloroethane & $107-06-2$ & $600-6500$ \\
\hline HCFC-132 & $431-06-1$ & $550-6500$ \\
\hline HCFC-121 & $354-14-3$ & $560-6500$ \\
\hline HCFC-123 & $306-83-2$ & $500-6500$ \\
\hline HCFC-123a & $354-23-4$ & $520-6500$ \\
\hline HCFC-124 & $2837-89-0$ & $500-6500$ \\
\hline HCFC-141b & $1717-00-6$ & $550-6500$ \\
\hline HCFC-142b & $75-68-3$ & $600-6500$ \\
\hline HCFC-124a & $75-43-4$ & $600-7300$ \\
\hline HCFC-132a & $354-25-6$ & $525-6500$ \\
\hline HCFC-133a & $471-43-2$ & $510-6500$ \\
\hline HCFC-141 & $75-88-7$ & $500-7100$ \\
\hline Spect & $430-57-9$ & $550-6500$
\end{tabular}

17 Spectra from Sharpe et al. (2004) [13] broadened by $\mathrm{N}_{2}$. Spectra were recorded at $278.15 \mathrm{~K}$,

$18298.15 \mathrm{~K}$, and $323.15 \mathrm{~K}, 760$ Torr total pressure, and $0.112 \mathrm{~cm}^{-1}$ resolution.

19 Table 17. Spectra from the halocarbon review [1] and more recently-measured data for 20 hydrochlorofluorocarbons

\begin{tabular}{lccccccc}
\hline \multicolumn{1}{c}{ Molecule } & CAS & $\begin{array}{c}\text { Range } \\
\left(\mathrm{cm}^{-1}\right)\end{array}$ & $\begin{array}{c}\mathrm{T} \\
(\mathrm{K})\end{array}$ & $\begin{array}{c}\text { P } \\
(\text { Torr })\end{array}$ & $\begin{array}{c}\text { Broa } \\
\text { dener }\end{array}$ & $\begin{array}{c}\text { Resolution } \\
\left(\mathrm{cm}^{-1}\right)\end{array}$ & Source \\
\hline HCFC-141b & $1717-00-6$ & $560-3100$ & $223-283$ & & & 0.02 & Le Bris et al. (2012) [34] \\
\hline 1,2-Dichloroethane & $107-06-2$ & $620-1570$ & 293 & & & & $\begin{array}{l}\text { Vander Auwera (2000) } \\
\text { [95] }\end{array}$ \\
\hline HCFC-225ca & & & & & & & Sir \\
\hline HCFC-225cb & $522-56-0$ & $650-1400$ & 296 & 700 & 0.5 & Sihra et al. (2001) [61] \\
\hline
\end{tabular}


\begin{tabular}{llllllll}
\hline (E)-1-Chloro-3,3,3- & $102687-$ & $600-2000$ & 295 & 700 & air & 0.25 & Andersen et al. (2008) [77]
\end{tabular} trifluoroprop-1-ene $\quad 65-0$

\begin{tabular}{|c|c|c|c|c|c|c|}
\hline HCFC-133a & $75-88-7$ & $690-1730$ & 295 & 6.96 & 0.01 & Etminan et al. (2014) [43] \\
\hline HCFC-22 & $75-45-6$ & $730-1380$ & $\begin{array}{l}190.8- \\
294.8\end{array}$ & $\begin{array}{l}7.496- \\
761.6\end{array}$ & $0.01-0.03$ & (2016) $[27] \dagger$ \\
\hline
\end{tabular}

$1 \dagger$ The full list of cross-sections and a more detailed description of the experimental conditions

2 can be found in Ref. [27].

$3 \quad 3.8$. Nitriles, amines and other nitrogenated hydrocarbons

$4 \quad$ Nitrogenated hydrocarbons are an atmospherically-important class of molecules; they have

5 both anthropogenic and natural sources. These compounds, in particular, are produced by

6 biomass burning.

7 In previous HITRAN editions, this category was limited to methyl cyanide (acetonitrile,

$8 \mathrm{CH}_{3} \mathrm{CN}$ ), which was presented both in the line-by-line part in the far infrared region, and cross-

9 sections in the range up to $4580 \mathrm{~cm}^{-1}[127-129]$. The HITRAN2016 edition expands this

10 category to more than 25 molecules including nitrogen-containing acids,-alkyl nitrites, amines

11 and aromatic amines, and nitriles.

The summary of the molecules in the update is given in the Table 18. It should be noted that the data for most of the molecules come from PNNL measurements $[13,22]$. The spectra for some of the molecules from the PNNL database, such as 2-vinylpyridine and N,N-diethyl formamide, have been provided in the newer set of data, the PNNL-SERDP database by Johnson et al. [22].

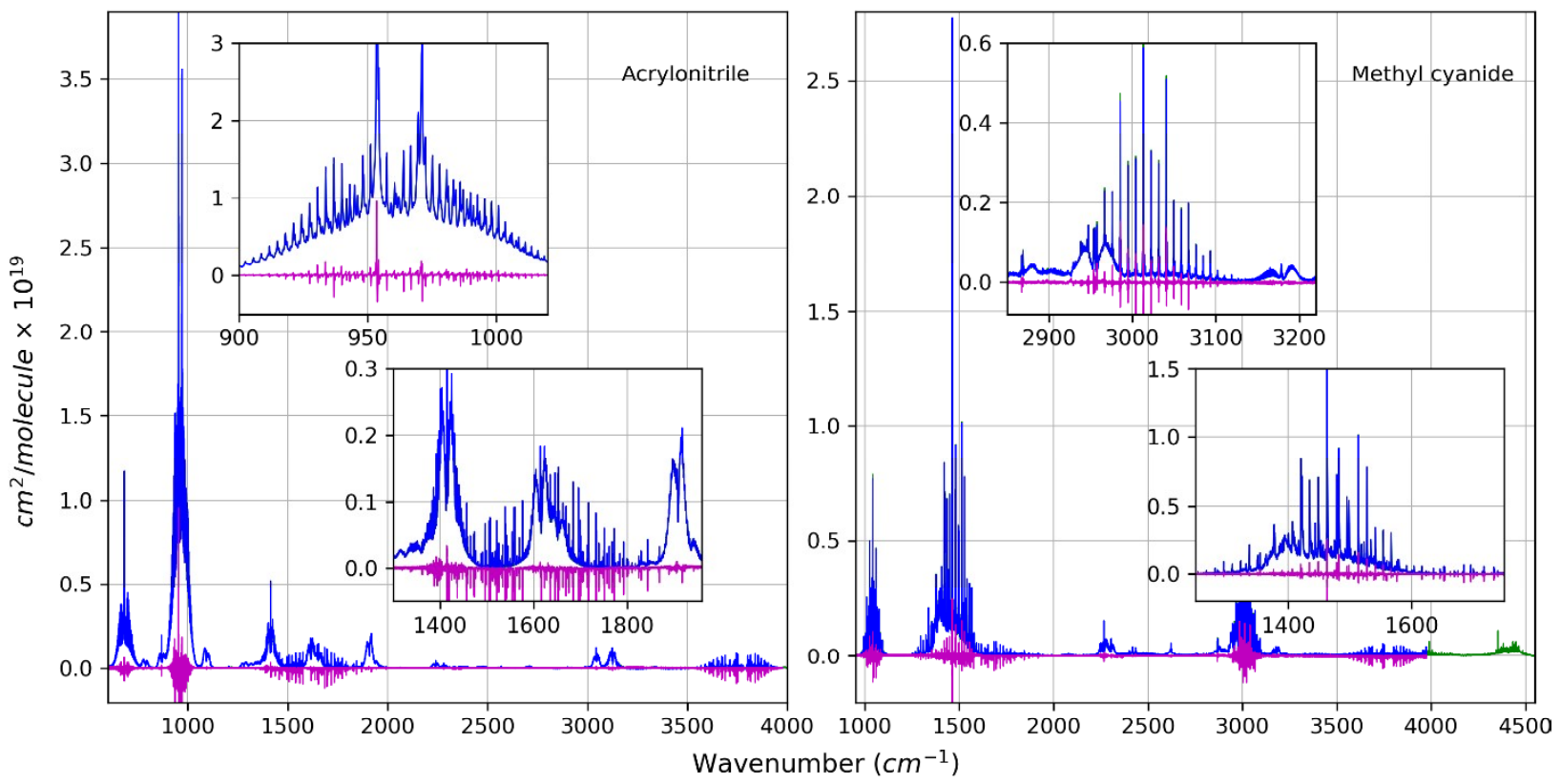

Figure 19. NIST (blue) and PNNL (green) spectra for acrylonitrile (left panel) and methyl 19 cyanide (right panel). PNNL-NIST differences in magenta. The insets show the most noticeable 20 discrepancies which include minor water contamination in the spectra from Ref. [17]. 


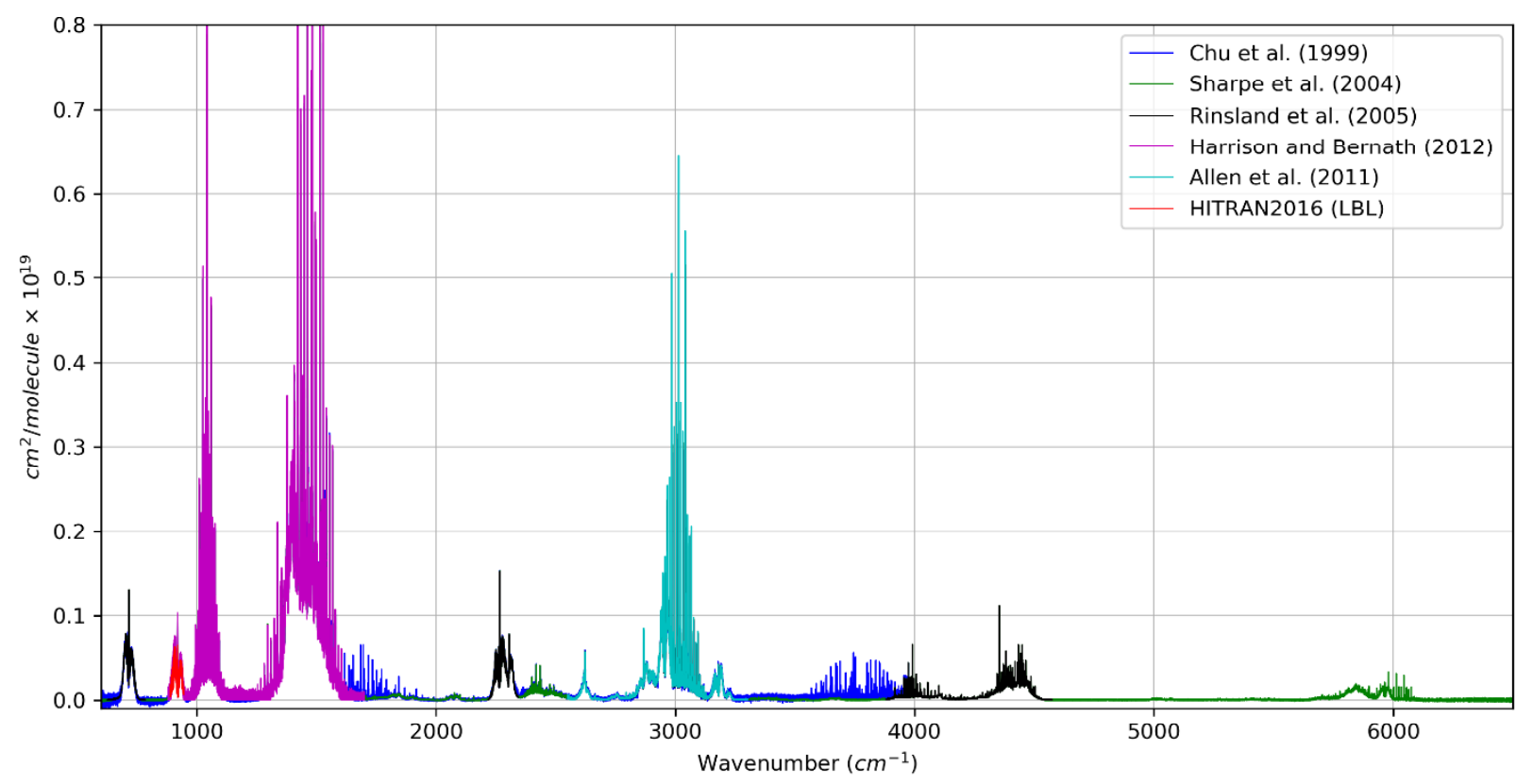

Figure 20. Spectra for methyl cyanide. The spectrum generated from the line-by-line HITRAN2016 data is given in red.

PNNL [13] and NIST [17] spectra for acrylonitrile and methyl cyanide were compared. For acrylonitrile, very good agreement in the integrated intensities were observed $(\sim 0.5 \%$ for the strongest features near $\left.800 \mathrm{~cm}^{-1}\right)$. For methyl cyanide, the agreement is also very good $(\sim 1.5 \%)$.

From the visual comparison given in Figure 19, it can be seen that for line shapes, the agreement is worse and in some ranges (see insets in the figure) there are substantial differences, mostly due to presence of the sharp lines in NIST spectra that are absent in PNNL (likely trace $\mathrm{H}_{2} \mathrm{O}$ contaminants). For acrylonitrile, the PNNL data have been included in HITRANonline.

For methyl cyanide, the previous HITRAN edition included the cross-sections from Rinsland et al. [127], Allen et al. [129] , and Harrison and Bernath [128], which cover all strong features in the spectral range from 600 to $5000 \mathrm{~cm}^{-1}$, and a wide range of pressures and temperatures. The full range can be seen in the corresponding papers, or at the HITRANonline web-site. Besides the wide-range cross-section data, the HITRAN database contains the set of transitions in the line-by-line part in the narrow spectral region $\left(890-946 \mathrm{~cm}^{-1}\right)$ which are plotted in Figure 20 in red. The cross-section datasets are of high quality and are retained in the HITRAN2016 database, while the PNNL dataset has been omitted since it does not contain additional strong features to those sources already present in the database. 
Table 18. PNNL data for nitriles, amines and other nitrogenated hydrocarbons

\begin{tabular}{|c|c|c|c|}
\hline Molecule & CAS & Range, $\mathrm{cm}^{-1}$ & $\mathbf{T}, \mathbf{K}$ \\
\hline \multicolumn{4}{|c|}{ PNNL-SERDP / Johnson et al. (2010) [22] } \\
\hline 2-Vinylpyridine & $100-69-6$ & $540-7300$ & $298.15,323.15$ \\
\hline $\mathrm{N}, \mathrm{N}$-diethyl formamide & $617-84-5$ & $520-6500$ & $298.15,323.15$ \\
\hline \multicolumn{4}{|c|}{ PNNL-DOE / Sharpe et al. (2004) [13] } \\
\hline Acrylonitrile & $107-13-1$ & $550-6500$ & $278.15,298.15,323.15$ \\
\hline Diethylamine & $109-89-7$ & $590-7000$ & $278.15,298.15,323.15$ \\
\hline Diisopropylamine & $108-18-9$ & $550-6500$ & $278.15,298.15,323.15$ \\
\hline Dimethylamine & $124-40-3$ & $550-6700$ & $278.15,298.15,323.15$ \\
\hline Ethylamine & $75-04-7$ & $600-7000$ & $278.15,298.15,323.15$ \\
\hline Ethylenediamine & $107-15-3$ & $550-6500$ & $278.15,298.15,323.15$ \\
\hline Hydrazine & $302-01-2$ & $600-7000$ & $298.15,323.15$ \\
\hline Isocyanic acid & $75-13-8$ & $500-7000$ & 298.15 \\
\hline Isopropylamine & $75-31-0$ & $600-6800$ & $278.15,323.15$ \\
\hline Methyl isothiocyanate & $556-61-6$ & $600-6500$ & $278.15,298.15,323.15$ \\
\hline Methyl nitrite & $624-91-9$ & $520-6500$ & $278.15,298.15,323.15$ \\
\hline $\mathrm{N}, \mathrm{N}$-Diethylaniline & $91-66-7$ & $550-6500$ & $298.15,323.15$ \\
\hline n-Butylamine & $109-73-9$ & $600-7000$ & $278.15,298.15,323.15$ \\
\hline Nitrobenzene & $98-95-3$ & $550-6500$ & $298.15,323.15$ \\
\hline Nitrogen trifluoride & $7783-54-2$ & $600-6500$ & $278.15,298.15,323.15$ \\
\hline Nitrous acid & $7782-77-6$ & $550-6500$ & 298.15 \\
\hline o-Toluidine & $95-53-4$ & $550-7300$ & $298.15,323.15$ \\
\hline Piperidine & $110-89-4$ & $510-6700$ & $278.15,298.15,323.15$ \\
\hline Propylenimine & $75-55-8$ & $600-6700$ & $278.15,298.15,323.15$ \\
\hline sec-Amylamine & $625-30-9$ & $540-6900$ & $278.15,298.15,323.15$ \\
\hline Triethylamine & $121-44-8$ & $575-7100$ & $278.15,298.15,323.15$ \\
\hline Trimethylamine & $75-50-3$ & $600-6500$ & $278.15,298.15,323.15$ \\
\hline
\end{tabular}

2 Spectra were recorded in 760 Torr total pressure of $\mathrm{N}_{2}$ with $0.112 \mathrm{~cm}^{-1}$ resolution.

\subsection{Fully-Fluorinated Species}

The fully-fluorinated species in HITRAN2016 consist predominantly of perfluorocarbons (PFCs), but include four other species: nitrogen trifluoride $\left(\mathrm{NF}_{3}\right)$, sulfur hexafluoride $\left(\mathrm{SF}_{6}\right)$, sulfuryl fluoride $\left(\mathrm{SO}_{2} \mathrm{~F}_{2}\right)$, and trifluoromethyl sulfur pentafluoride $\left(\mathrm{SF}_{5} \mathrm{CF}_{3}\right)$. The listed molecules also belong to another category (nitriles, amines, and other nitrogenated compounds for $\mathrm{NF}_{3}$, and sulfur-containing species for the remaining three). The saturated PFCs are very long-lived (more than a thousand years, and up to 50,000 years in the case of $\mathrm{CF}_{4}$ ), while unsaturated PFCs can have lifetimes of approximately one day [1] but they are generally characterised by particularly strong absorption in the $1200-1300 \mathrm{~cm}^{-1}$ region, making them potent greenhouse gases. They are not ODSs. The most abundant $\mathrm{PFC}$ is $\mathrm{CF}_{4}$ with concentrations of approximately $80 \mathrm{pptv}$ and rising, and is released during aluminum production. $\mathrm{CF}_{4}$ has a significant natural background concentration estimated to be $35 \mathrm{pptv}$ [3]. $\mathrm{SF}_{6}$, used extensively in electrical insulation, and $\mathrm{NF}_{3}$, used in the electronics industry, have abundances of around 7 and 0.9 pptv [3], respectively and rising. Emissions of many PFCs and $\mathrm{SF}_{6}$ are part of the 
1 collection of gases whose emissions fall under the Kyoto Protocol, with $\mathrm{NF}_{3}$ added in the second

2 commitment period of the protocol. The 2011 radiative forcing due to these fully fluorinated

3 species was about $0.01 \mathrm{~W} \mathrm{~m}^{-2}$, about $0.5 \%$ of the forcing due to $\mathrm{CO}_{2}$ [3].

4 As in other sections, we present comparisons of the spectra for the molecules for which a 5 number of different sources were given. In particular, it includes the recent measurements of 6 perfluorotributylamine [21], made self-broadened and provided at zero pressure limit.

7 Measurements of isomers of perfluorodecalin, a compound of medical use $[38,130]$, are also

8 supplied. The spectra for several perfluorinated alkanes [53] ) and alkenes [5] are also available

9 in HITRAN for the first time. The full list of these fluorinated compounds available via

10 HITRANonline is given in Table 19 and Table 20. Below we give the description of some of the compounds of the most atmospheric importance, comparisons for which are also provided in Figure 21.
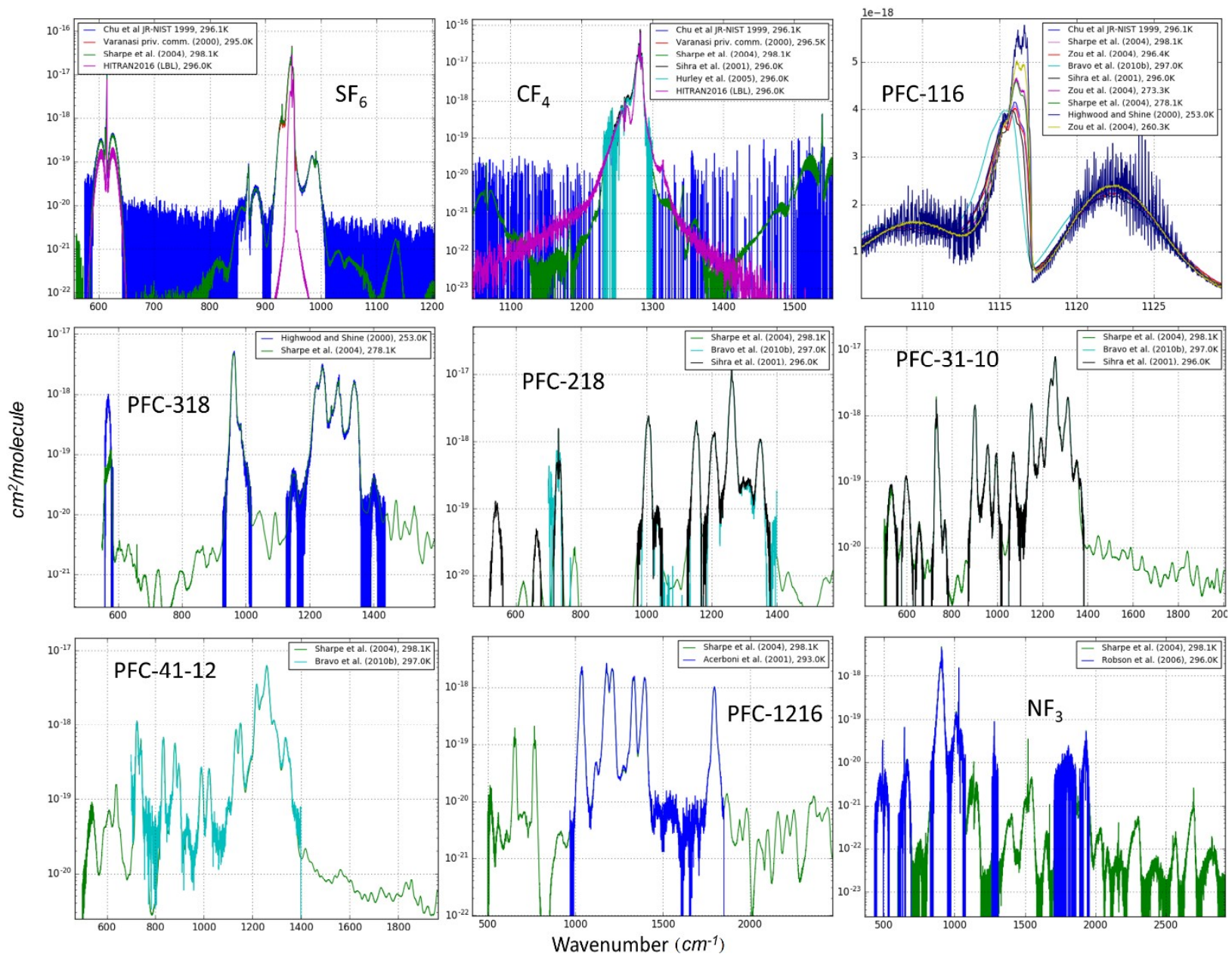

Figure 21. Cross-section comparison for fully fluorinated species.

\subsubsection{Sulfur hexafluoride}

Sulfur hexafluoride $\left(\mathrm{SF}_{6}\right)$ is a gas included in the Kyoto Protocol, with a lifetime of 3200 years and a 100-year GWP of 23,500 [3]. The HITRAN2016 database contains an extensive list 
of transitions for two regions $\left(580-650 \mathrm{~cm}^{-1}\right.$ and $\left.900-1000 \mathrm{~cm}^{-1}\right)$, and for three bands $\left(v_{3}, v_{4}\right.$, and $\left.v_{4}+v_{6}-v_{6}\right)$. This effective Hamiltonian dataset was described in the HITRAN2008 paper [131].

Since $\mathrm{SF}_{6}$ is a heavy polyatomic molecule, for which the spectral analysis based on the molecular quantum structure is quite complicated, the cross-section data have been included in previous HITRAN issues. Data have been provided by Varanasi and co-workers [132], and via private communication [133]). The data from Ref. [132] are self-broadened low-pressure sets for 216K, given for three pressures from 25-90 Torr. The air-broadened data, provided by Varanasi to HITRAN2000, span a wide range of temperatures and pressures (180-295K, 20-60 Torr) and are measured with a $0.03 \mathrm{~cm}^{-1}$ resolution in the $925-925$ region. All these data reside in the recent version of HITRAN. Other data for the comparison, besides the line-by-line and Varanasi datasets, are from the PNNL [13] and NIST [17] databases.

Comparison of the line-by-line data to experimental cross-sections demonstrates the lack of bands in the line-by-line data, and possible line-mixing effects. We have compared the crosssection data at room temperature (i.e. not including Ref. [132]) in the region of the strongest absorption $925-955 \mathrm{~cm}^{-1}$. The best agreement for the intensities, integrated in this region, is between PNNL and Varanasi $(\sim 1.6 \%)$, while the NIST data, although agreeing well, differs by $5-$ $7 \%$ and has systematically higher absorption. The PNNL data have been included in HITRANonline to enable the higher-temperature interpolation.

\subsubsection{Carbon tetrafluoride}

Carbon tetrafluoride $\left(\mathrm{CF}_{4}\right)$ is a long-lived substance with an estimated lifetime of 50000 years and 100-yr GWP of 6630 [3] . Its strongest absorption is situated in the $1000-1500 \mathrm{~cm}^{-1}$ atmospheric window and it is included in the Kyoto protocol basket of gases [134].

The line-by-line part of the HITRAN2016 edition had been updated with a new line list from the global Effective Hamiltonian fit [2,135]. However, due to the overall complexity of the spectra of this molecule, the HITRAN database also includes the IR cross-section datasets.

In previous HITRAN editions, the air-broadened cross-sections for $\mathrm{CF}_{4}$ have been included from Varanasi and co-workers (HITRAN2000 [133], private communication). These data have been recorded at a set of pressures and temperatures (180-296 K and 22-761 Torr) with a resolution of $0.03 \mathrm{~cm}^{-1}$. In addition, in this comparison we have the data from Hurley at al. [134], which provide revised room-temperature cross-sections, measured at Ford in Sihra et al. [61].

The integrated intensities for the room-temperature cross-section data have been compared in the $1250-1300 \mathrm{~cm}^{-1}$ interval. There is good agreement between the data from Varanasi, PNNL, 
1 and NIST ( $\sim 1.6 \%$ ), while the spectrum from Hurley et al. lies outside of this group by $5.3 \%$.

2 From the visual comparison given in the Figure 21, the good agreement of the band shapes can

3 be seen for the cross-section data. The data from Sihra et al. [61] is shifted in wavenumber scale,

4 and the integrated cross-section disagrees with other data by more than $10 \%$. More detailed

5 discussion and comparisons of the datasets from Hurley et al. and from Sihra et al. is provided in

6 Ref. [134].

7 The spectra generated from the line list $[2,135]$ lacks absorption in the region where it is 8 strong, which can be both due to missing bands or line-shape effects, e.g. line mixing. For the

9 weak absorption, the line-by-line data give a stronger absorption than that which is measured

10 directly, see Figure 21. The data from PNNL have been included in HITRANonline, while data

11 from other sources (Refs. [61,134] ) have been omitted.

\subsubsection{Perfluoroethane}

Perfluoroethane (PFC-116, $\mathrm{C}_{2} \mathrm{~F}_{6}$ ) has a lifetime of 10000 years and 100-year GWP of 11100 [3]. Previous HITRAN editions included the data for this molecule supplied by Zou et al. [46]. range of temperatures and pressures (180-296 K and 5-760 Torr). This dataset has not undergone changes in the HITRAN2016 edition.

The PNNL [13] and NIST [17] databases provide cross-section for this comparison: PNNL at three temperatures $(273 \mathrm{~K}, 296 \mathrm{~K}$, and $323 \mathrm{~K})$, and NIST at $296 \mathrm{~K}$.

Two data sources from Ref. [1] provided the room temperature cross-sections. In Sihra et al. [61], the atmospheric pressure air-broadened spectra had been measured at Ford. Measurement resolution for this source is $0.5 \mathrm{~cm}^{-1}$. The second source, Bravo et al. [53], provided the selfbroadened spectrum measured in the Rutherford Appleton Laboratories (RAL).

The lower-temperature spectra at $253 \mathrm{~K}$ have been provided in the compilation by Highwood and Shine [90]. These data originate from the work by Ballard et al. [136]. The spectra were measured self-broadened with $0.03 \mathrm{~cm}^{-1}$ resolution. The cross-sections have been split into three regions containing the strong absorption bands: $680-750 \mathrm{~cm}^{-1}, 1075-1165 \mathrm{~cm}^{-1}$, and $1170-1380$ $\mathrm{cm}^{-1}$.

Comparisons of the integrated intensities were made at three different temperatures. At $\mathrm{T} \sim 253 \mathrm{~K}$, only data from Ref. [90] (Highwood and Shine, see Ballard et al. for measurement details) and Ref. [46] (Zou et al.) are available. The agreement is around 3\%, which is inside the combined experimental uncertainties of these sources. For $\mathrm{T} \sim 275 \mathrm{~K}$, the data were available from 
1 Zou et al. and PNNL, which also show a good agreement (1.5\% for the strongest feature at 1250

$2 \mathrm{~cm}^{-1}$ ). At the $296 \mathrm{~K}$ temperature, all the above listed sources (except Highwood and Shine which

3 do not contain room temperature data) have been compared. The situation here is less

4 straightforward, although it can be seen that two groups of sources are close together: 1) NIST

5 and Bravo et al., 2) Zou et al. and Sihra et al. cross-sections from these two groups agree within

$60.6 \%$ on the intensity, integrated in $1170-1400 \mathrm{~cm}^{-1}$ wavenumber range. The PNNL data have a

7 reasonable residual compared to all the sources, with the worst case of $\sim 6 \%$ in comparison with

8 Sihra et al. The agreement with NIST is $1.1 \%$, and with Zou et al. is $1.8-5 \%$. It should be

9 pointed out that the spectrum from Bravo et al. has a wavenumber shift which is displayed in

10 Figure 21. The spectra from PNNL and Ref. [90] were included in HITRANonline.

\subsubsection{PFC-318}

Data for PFC-318 (perfluorocyclobutane, $\mathrm{C}_{4} \mathrm{~F}_{8}$ ) are available from two sources: PNNL [13], and Highwood and Shine [90]. The data from Highwood and Shine are for pure gas, and measured at $253 \mathrm{~K}$ temperature with $0.03 \mathrm{~cm}^{-1}$ resolution. These data were initially supplied by Ballard et al. [136]. The agreement of the integrated intensities is good between these two sources (within 1.7\%). The PNNL data has an artifact at the lower wavenumber range (see Figure 21) which is due to the signal saturation. In this region, using Highwood and Shine data is preferable. Both sources were included in HITRANonline as having different broadening conditions.

\subsection{5. $\mathrm{PFC}-218$}

Cross-sections for PFC-218 (perfluoropropane, $\mathrm{C}_{3} \mathrm{~F}_{8}$ ) were published in PNNL [13], Bravo et al. [53], and Sihra et al. [61]. Spectra published in Bravo et al. have been measured in RAL as a pure vapor. The agreement of integrated intensities is $1.2 \%$ between PNNL and Sihra et al., and $\sim 3 \%$ between Bravo et al. and Sihra et al. The spectrum from Sihra et al. is better resolved than both of the other sources. PNNL spectra have been included in HITRANonline, while the data of Sihra et al. were placed into the supplemental folder. The spectrum from Bravo et al. has been omitted due to the presence of digitization artifacts.

\subsubsection{PFC-31-10}

Cross-sections for PFC-31-10 (perfluorobutane, $\mathrm{C}_{4} \mathrm{~F}_{10}$ ) have been published in PNNL [13], Bravo et al. [53], and Sihra et al. [61]. The spectrum from Bravo et al. contains data from Sihra et al. with a wavenumber scale correction. These data have more resolved spectral features but lack temperature dependence; they have thus been placed into the supplemental folder. The 
1 PNNL data have been included in HITRANonline, while the spectrum from Sihra et al. has been omitted.

\subsubsection{PFC-41-12}

For PFC-41-12 (perfluoropentane, $n-\mathrm{C}_{5} \mathrm{~F}_{12}$ ), spectra were supplied by PNNL [13] (for three temperatures) and Bravo et al. [53]. The latter data were given only at room temperature and measured self-broadened at RAL. These data are more resolved, but the wavenumber scale differs from PNNL by a shift of approximately $1 \mathrm{~cm}^{-1}$. Since they were measured at higher resolution, these data can possibly be useful in retrievals. For this reason, they have been placed into the supplemental folder, while the PNNL dataset was included in HITRANonline.

\subsection{8. $\mathrm{PFC}-1216$}

PFC-1216 (perfluoropropene, $\mathrm{C}_{3} \mathrm{~F}_{6}$ ) spectra were supplied by PNNL [13] (at three temperatures) and Acerboni et al. [5]. Data from Acerboni et al. are air-broadened and measured at $293 \mathrm{~K}$ and 740 Torr. The agreement between the cross-section from Acerboni et al. and PNNL is $3.83 \%$, which is well within the combined experimental uncertainties [5]. The data from Acerboni et al. are more resolved. They have been placed in the supplemental folder, while PNNL spectra were included in HITRANonline.

\subsubsection{Nitrogen trifluoride}

Spectral data for nitrogen trifluoride $\left(\mathrm{NF}_{3}\right)$ are available from PNNL [13] and Robson et al. [137]. The agreement of the integrated intensities within the $800-1100 \mathrm{~cm}^{-1}$ interval is $2.5 \%$. The spectrum from Robson et al. was measured only at room temperature and 700 Torr pressure. This spectrum, however, provides a band missing in PNNL data at $490 \mathrm{~cm}^{-1}$. For this reason, it has been put into the supplemental folder. The PNNL spectra have been included in HITRANonline.

\subsubsection{Perfluorodecalin}

Perfluorodecalin (PFD, $\mathrm{C}_{10} \mathrm{~F}_{18}$ ) is a cyclic fluorocarbon used in medical and cosmetic applications. It is usually sold as a mixture of cis- and trans-isomers. Spectra have been published by Shine et al. [130] and Le Bris et al. [38]. In both studies the spectra of the transisomer have been extracted by subtracting the spectra of a sample of cis-PFD solution from the spectra of a PFD mixture. This leads to higher uncertainties for the trans-PFD cross-sections. The comparison of the integrated cross-sections around $300 \mathrm{~K}$ shows a difference between the two studies of $6.5 \%$ for $c i s-P D F$ and $11 \%$ for trans-PDF. The data from Le Bris et al. have been added as a post-release update, while the data from Ref. [130] were placed in a supplemental folder. 
Table 19. PNNL-DOE data for fully fluorinated species

\begin{tabular}{lll}
\hline \multicolumn{1}{c}{ Molecule } & CAS & Range, $\mathbf{c m}^{-1}$ \\
\hline Hexafluorobenzene $\dagger$ & $392-56-3$ & $580-6500$ \\
\hline Nitrogen trifluoride & $7783-54-2$ & $600-6500$ \\
\hline PFC-1216 & $116-15-4$ & $500-6500$ \\
\hline PFC-14 & $75-73-0$ & $570-6500$ \\
\hline PFC-218 & $76-19-7$ & $600-6500$ \\
\hline PFC-31-10 & $355-25-9$ & $500-6500$ \\
\hline PFC-318 & $115-25-3$ & $550-6500$ \\
\hline PFC-41-12 + & $678-26-2$ & $500-6500$ \\
\hline Perfluoroethane & $76-16-4$ & $500-6500$ \\
\hline Sulfuryl fluoride & $2699-79-8$ & $500-6500$ \\
\hline Sulphur hexafluoride & $2551-62-4$ & $560-6500$
\end{tabular}

2 Spectra from Sharpe et al. [13] broadened by $\mathrm{N}_{2}$. Spectra were recorded at $278.15 \mathrm{~K}, 298.15 \mathrm{~K}$, 3 and $323.15 \mathrm{~K}$ (except hexafluorobenzene and PFC-41-12), 760 Torr total pressure, and $0.112 \mathrm{~cm}^{-}$ 41 resolution.

$5 \dagger$ Spectra for hexafluorobenzene were recorded at $298.15 \mathrm{~K}$ and $323.15 \mathrm{~K}$

$6+$ Spectra for PFC-41-12 were recorded at $278.15 \mathrm{~K}$ and $323.15 \mathrm{~K}$

8 Table 20. Spectra from the halocarbon review [1] and recently published data for fully 9 fluorinated species

\begin{tabular}{|c|c|c|c|c|c|c|c|}
\hline Molecule & CAS & $\begin{array}{l}\text { Range } \\
\left(\mathrm{cm}^{-1}\right)\end{array}$ & $\begin{array}{c}\mathbf{T} \\
(\mathbf{K})\end{array}$ & $\begin{array}{c}P \\
\text { (Torr) }\end{array}$ & Brd & Res & Source \\
\hline Perfluorodecalin (E,Z) & $306-94-5$ & $560-3000$ & $300-340$ & & & 0.1 & Le Bris et al. (2017) [38] \\
\hline PFTBA $\dagger$ & $311-89-7$ & $550-2000$ & $298-344$ & & & 0.1 & Godin et al. (2016) [21] \\
\hline Perfluorobuta-1,3-diene & $685-63-2$ & $100-2600$ & 293 & 740 & air & 1 & \multirow{2}{*}{ Acerboni et al. (2001) [5] } \\
\hline PFC-1114 & $116-14-3$ & $100-2600$ & 293 & 740 & air & 1 & \\
\hline PFC-41-12 & $678-26-2$ & $700-1400$ & 297 & & & 0.01 & \multirow{3}{*}{ Bravo et al. (2010) [53] } \\
\hline PFC-51-14 & $355-42-0$ & $700-1400$ & 297 & & & 0.01 & \\
\hline PFC-71-18 & $307-34-6$ & $700-1400$ & 297 & & & 0.01 & \\
\hline Perfluoroethane & $76-16-4$ & $680-1380$ & 253 & & & 0.03 & \multirow{2}{*}{ Ballard et al. (2000) [136] } \\
\hline PFC-318 & $115-25-3$ & $555-1460$ & 253 & & & 0.03 & \\
\hline $\mathrm{E}-\mathrm{C} 10 \mathrm{~F} 18^{\star}$ & $60433-12-7$ & $650-1500$ & 296 & 700 & air & 0.5 & \multirow{3}{*}{ Shine et al. (2005) [130] } \\
\hline PFC-91-18 & $306-94-5$ & $0-2000$ & 296 & 700 & air & 0.5 & \\
\hline Z-C10F18 & 60433-11-6 & $650-1500$ & 296 & 700 & air & 0.5 & \\
\hline Perfluorobut-1-ene & $357-26-6$ & $600-2000$ & 296 & 700 & $\mathrm{~N}_{2}$ & 0.25 & Young et al. (2009) [69] \\
\hline
\end{tabular}

$\dagger$ A summary of temperature and pressure sets and experimental conditions is given in Ref. [55].

- Supplemental folder

\subsection{Chlorofluorocarbons}

CFCs were widely-used in industrial and domestic applications before concerns about their role in ozone depletion led to a phase-out of their production and consumption via the Montreal Protocol. They are generally long-lived compounds (atmospheric lifetimes from decades to centuries [1]) which are mostly removed by either UV photolysis or reaction with $\mathrm{O}\left({ }^{1} \mathrm{D}\right)$ in the stratosphere. Despite the production phase-out, CFCs are still the most abundant in the atmosphere of all the molecules considered in this paper due to their long atmospheric lifetimes and large historic emissions. Atmospheric concentrations of CFC-11 and CFC-12 are in excess of $200 \mathrm{ppt}$ and $500 \mathrm{ppt}$, and are falling slowly from their peaks in about 1994 and 2003 
1 respectively [94]. The rate of decline of CFC-11 atmospheric concentration has slowed down,

2 which presumably reflects an increase in emissions [138]. Some CFCs (CFC-112, CFC-112a

3 and CFC-113a) have recently been detected in the atmosphere [125], with CFC-113a

4 concentrations increasing [139], the only known CFC to be doing so, now with typical values of

$5 \quad 0.7$ ppt. The 2011 radiative forcing due to CFCs is about $0.26 \mathrm{~W} \mathrm{~m}^{-2}$, about $14 \%$ of that due to

$6 \mathrm{CO}_{2}$ [3]. Their contribution to ozone depletion is measured via the Equivalent Effective

7 Stratospheric Chlorine (EESC) metric [115]. Recent data (2017) [107] for the mid-latitude

8 ESSC indicate that the CFCs contribute about $40 \%$ of the total EESC.

For many of the CFCs considered in this paper, previous HITRAN issues contain high-quality cross-sections. In HITRAN2016 some datasets, such as CFC-12, have been improved by integrating recent measurements [26], and for some of the molecules, such as CFC-114a, CFC112, CFC-112a, CFC-113a, new room temperature data have been included. The full summary of CFCs included in HITRANonline is given in Table 21 and Table 22. The next subsections provide comparisons for several CFCs where cross-evaluation of different sources has been made (see Figure 22).
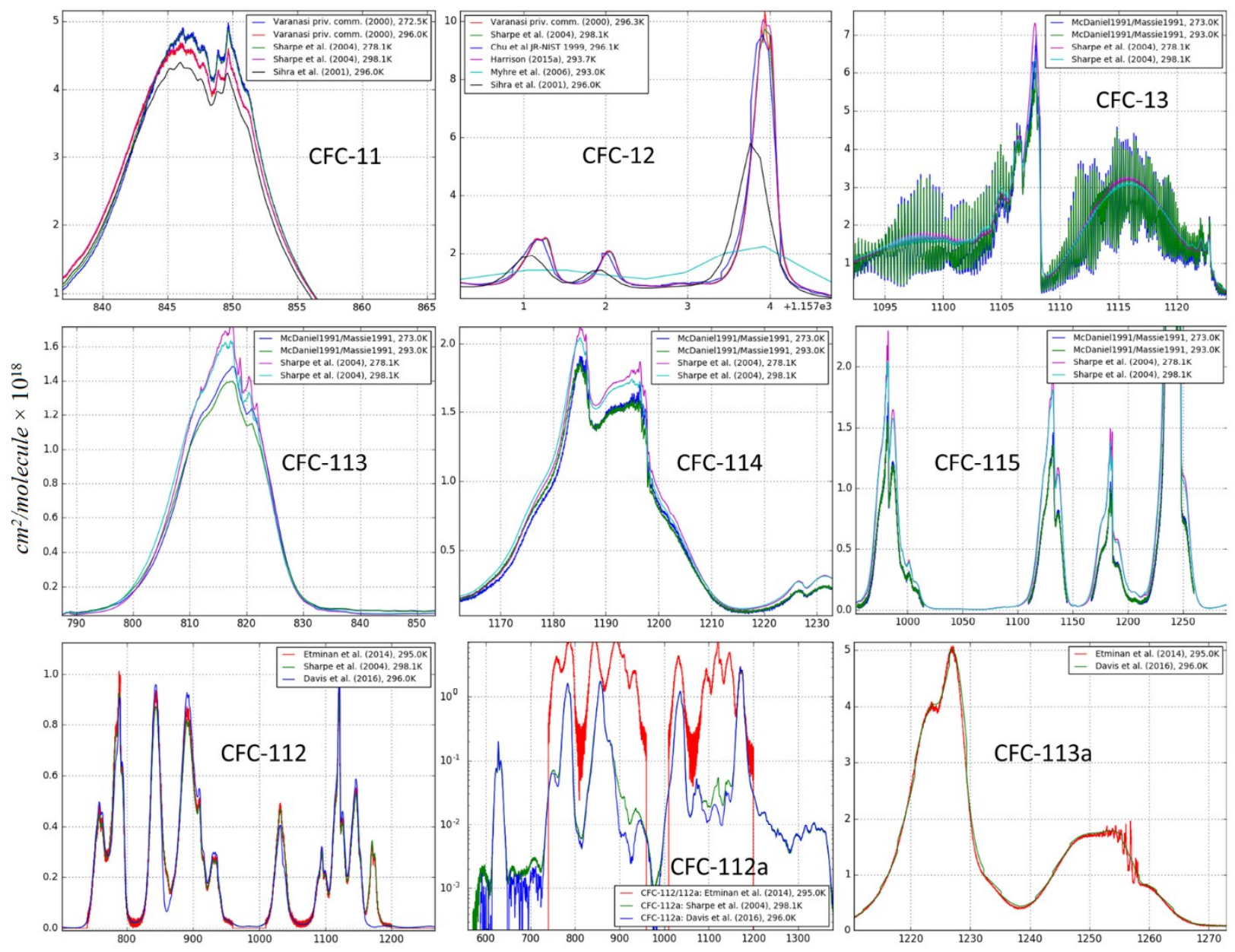

Wavenumber $\left(\mathrm{cm}^{-1}\right)$ 
1 Figure 22. Cross-section comparison for selected CFC bands. In each group, the comparison

2 was taken between the datasets with the closest temperature and pressure conditions. The CFC-

$3112 / 112$ a spectra from Etminan et al. [43] is scaled by 9 to visually match the isolated CFC-112a

4 feature at $1170 \mathrm{~cm}^{-1}$ with other sources on the plot.

5 3.10.1. CFC-11

6 CFC-11 (trichlorofluoromethane, $\mathrm{CCl}_{3} \mathrm{~F}$ ) has been included in the cross-section part of

7 HITRAN in previous issues. The air-broadened dataset measured by Varanasi et al. was included

8 in HITRAN2000 [133] and covers a wide range of temperatures and pressures (190-296 K and

9 7.5-760 Torr). Datasets from two new sources, PNNL [13] and Sihra et al. [61], have been

10 considered in the current evaluation. Data from PNNL were provided at standard temperatures

$11(278.15,298.15$, and $323.15 \mathrm{~K})$ and at atmospheric pressure (760 Torr) broadened by nitrogen.

12 The spectrum from Sihra et al. was measured only at room temperature [61]. Comparing the

13 intensities, integrated in two regions, $810-880 \mathrm{~cm}^{-1}$ and $1050-1120 \mathrm{~cm}^{-1}$, we found an excellent agreement between Varanasi and PNNL data for $273 \mathrm{~K}$ and $296 \mathrm{~K}(\sim 0.7 \%$ for both temperatures and ranges). The data from Sihra et al. agree with the rest of the sources at the level of $\sim 8 \%$ which is within the combined experimental accuracies. Data from PNNL include cross-sections at higher temperature $(323.15 \mathrm{~K})$ which is not available in the set of Varanasi et al. To facilitate the extrapolation, and taking into account very good agreement between these two sources, the PNNL data have been included into the HITRAN database and included in HITRANonline. The data from Sihra et al. were omitted, while the data provided by Varanasi et al. remain available through the web interface.

\subsubsection{CFC-12}

CFC-12 (dichlorodifluoromethane, $\mathrm{CCl}_{2} \mathrm{~F}_{2}$ ) is the most abundant CFC in the Earth's atmosphere and the single largest contributor to the atmospheric loading of chlorine. A very strong greenhouse gas with a 100-yr GWP of 10200 [3], a strong ODS with an ozone depletion potential (ODP) of 0.73 [115], and a long atmospheric lifetime of 100 years [3] make this, unsurprisingly, a molecule of much interest to the atmospheric monitoring community, particularly as its decline, due to the success of the Montreal Protocol, is linked to stratospheric ozone recovery.

A number of IR remote-sensing instruments have taken atmospheric measurements of CFC12 over the years, including ATMOS (Atmospheric Trace MOlecule Spectroscopy) [120], MIPAS (Michelson Interferometer for Passive Atmospheric Sounding) [140], and the ACE-FTS [122]. The CFC-12 cross-section dataset in previous HITRAN compilations was provided by 
1 improved cross-section dataset from Harrison [26] over the spectral range $800-1270 \mathrm{~cm}^{-1}$,

2 determined from spectra recorded using a high-resolution Fourier transform spectrometer

3 (Bruker IFS 125HR) and a 26-cm-pathlength cell. Spectra of CFC-12 / dry synthetic air

4 mixtures were recorded at resolutions between 0.01 and $0.03 \mathrm{~cm}^{-1}$ over a range of temperatures and pressures $(7.5-761$ Torr and $190-294 \mathrm{~K})$ appropriate for atmospheric conditions.

CFC-12 spectra from Harrison et al., Chu et al. (NIST IR database) [17], Sharpe et al. (PNNL database) [13], Sihra et al. [61], and Myhre et al. [141] are shown in Figure 22. The PNNL spectrum has the highest signal-to-noise ratio. The agreement between all sources except Sihra et al. is very good and discrepancies do not exceed $2.25 \%$ for the integrated intensities for room temperature (two regions were used in the comparison: $850-950 \mathrm{~cm}^{-1}$ and $1050-1200 \mathrm{~cm}^{-1}$ ). It should be noted that, for spectra from Harrison et al., intensity was calibrated using the PNNL spectra, thus the best agreement is obviously between those two sources. The $296 \mathrm{~K}$ spectrum from Sihra et al. disagrees with the rest of the data by $\sim 12 \%$ and has a slight shift in wavenumber. Besides the new data from Harrison [26], which were included in HITRANonline, the spectra from PNNL have been placed in the supplemental folder. In the HITRAN2016 issue, the data from Varanasi et al. for this molecule have been placed into the supplemental folder. Data from the other sources were omitted.

\subsubsection{CFC-13}

Temperature-dependent infrared absorption cross-sections for CFC-13 (chlorotrifluoromethane, $\mathrm{CClF}_{3}$ ) for previous HITRAN editions were taken from McDaniel et al. [44] and Massie et al. [45]. These cross-sections were recorded self-broadened for 203, 213, 233, 253, 273, and 293K, and split into three regions (I: 765-805, II: 1065-1140, and III: 1170-1235 $\left.\mathrm{cm}^{-1}\right)$. The data have been measured with a total estimated error of $15 \%$ [44]. In Ref. [44], investigations were made to establish the effects of a foreign gas on the infrared spectra of CFC13 and related compounds (CFC-113, CFC-114, and CFC-115). "The resultant spectra did show line broadening with increasing foreign gas pressure" [44]. For CFC-13, the temperature dependence of the integrated intensities was pointed out in Ref. [44]. The authors supposed that this could be due to the "anharmonicity in gas phase polyatomic molecules" [44].

More recent data for CFC-13 were provided by PNNL [13] at 278.15, 298.15, and 323.15 K and atmospheric pressure. Here we have performed comparisons of the integrated intensities for regions I, II, and III between data from Refs. [44,45] and PNNL. The integrated intensities agree on the order of $5 \%$ for region I for the weakest absorption, and of $15 \%$ for regions II and III. Also, it can be seen from the visual comparison (Figure 22), that the PNNL data are insufficiently resolved. 
The PNNL spectra for CFC-13 contain additional spectral features. They have been placed in the supplemental folder to encourage using the data with higher resolution, although the user should account for the most appropriate temperature, pressure, and broadening conditions to pick

4 the right dataset.

For CFC-113 (1,1,2-Trichlorortrifluoroethane, $\left.\mathrm{CCl}_{2} \mathrm{FCClF}_{2}\right)$ a comparison of the data from Refs. [44,45] with PNNL [13] was performed in two spectral regions (I: 780.5-1000 $\mathrm{cm}^{-1}$, and II: $\left.1005.5-1232 \mathrm{~cm}^{-1}\right)$, which correspond to the splitting of the data from Refs. [44,45]. For the first region, the discrepancy for integrated intensities is $5-7 \%$, while for the second region it goes up to $12.5 \%$ which is within the uncertainty range for Refs. [44,45]. Visual comparison (see Figure 22) shows some minor discrepancies in the band heads. The spectrum at $203 \mathrm{~K}$ from Ref. [44] features an important increase of its integrated intensities (15-19\% relative to its values at $213 \mathrm{~K}$ ) and should be used with caution. The resolution value for CFC-113 data from Refs. [44,45] have been corrected to $1.0 \mathrm{~cm}^{-1}$ in the HITRAN database according to Ref. [45]. A more recent dataset has been introduced by Le Bris et al. [32]. For the first region, the discrepancy for integrated intensities is 3\% with Ref. [44] and 5\% with PNNL. For the second region, the integrated intensities differ by $6 \%$ relative to Ref. [44] and 4\% relatively to PNNL. At lower temperatures, Refs. [32] and [44] are in agreement for comparable temperatures. However, the integrated cross-sections of Le Bris et al. do not show the upward trend with decreasing temperature observed in the data from McDaniels et al.

It should be mentioned that the data from PNNL includes additional spectral features in the range below $780 \mathrm{~cm}^{-1}$ and above $1230 \mathrm{~cm}^{-1}$. The cross-sections from Refs. [13,32] have been included in HITRANonline (latter source as a post-release update), while the data from Refs. $[44,45]$ were relegated to the supplemental folder

\subsubsection{CFC-114}

The data for CFC-114 (1,2-dichlorotetrafluoroethane, $\mathrm{CClF}_{2} \mathrm{CClF}_{2}$ ) from Refs. [44,45] were split into four regions (I: $815-860 \mathrm{~cm}^{-1}$, II: $870-960 \mathrm{~cm}^{-1}$, III: $1030-1067 \mathrm{~cm}^{-1}$, and IV: $1095-$ $1285 \mathrm{~cm}^{-1}$ ) for each temperature set. The PNNL data agree well with the old data from HITRAN for all regions (2-5\% for I and II, and 9-12\% in III and IV), which is within the experimental uncertainty of the old data (15\%). The PNNL dataset has additional spectral features below 815 $\mathrm{cm}^{-1}$ and above $1285 \mathrm{~cm}^{-1}$, and has been included in HITRANonline. 
2 For CFC-115 (chloropentafluoroethane, $\mathrm{CClF}_{2} \mathrm{CF}_{3}$ ), the HITRAN data from Refs. [44,45] are 3 split into three regions (I: $955-1015 \mathrm{~cm}^{-1}$, II: $1110-1145 \mathrm{~cm}^{-1}$, and III: $1167-1260 \mathrm{~cm}^{-1}$ ). For all

4 regions, the integrated intensity differs by more than 30 percent. The discrepancy can possibly be

5 due to different concentrations (zero pressure limit in McDaniel et al [115], 1 ppm-meter for

6 PNNL). The PNNL spectrum is less resolved than that from McDaniel et al. which has $0.03 \mathrm{~cm}^{-1}$

7 resolution. Since PNNL provides the data with better accuracy, it was decided to include it into

8 the supplemental folder. For future HITRAN editions, it should be considered whether to scale

9 the data from Refs. $[44,45]$ to match the PNNL integrated intensities.

The CFC-112 (1,2-difluorotetrachloroethane, $\mathrm{C}_{2} \mathrm{Cl}_{4} \mathrm{~F}_{2}$ ) spectra were included into HITRAN for the first time. Cross-sections for this molecule were published by Sharpe et al. [13], and more recently by Davis et al. [80] and Etminan et al. [43]. It should be noted that Etminan et al. provide the spectra of a mixture of CFC-112/CFC-112a. All sources have a good total accuracy (2.1\% for PNNL, $2.7 \%$ for Etminan et al., and $4 \%$ for Davis et al.). The intensities, integrated in the $700-1158 \mathrm{~cm}^{-1}$ range, also give good agreement (within 4\%). However, the comparison shows that the PNNL data also represent a mixture of CFC-112 and CFC-112a, but not a pure CFC-112. This can be demonstrated in Figure 22, where significant spectral features near 1200 $\mathrm{cm}^{-1}$ and $600 \mathrm{~cm}^{-1}$ can be seen both in PNNL and Etminan et al., and are completely absent in Davis et al. In addition, the PNNL data are, as stated in the original description, "contaminated with R-141B [0.481\%] and corrected by rescaling and subtraction on the composite spectrum". However, since the PNNL data have more complete temperature coverage than both Davis et al. and Etminan et al., they have been placed into the supplemental folder. The data from Davis et al., as containing the pure CFC-112 spectrum, have been included in HITRANonline. It should also be noted that for CFC-112 and related molecules (CFC-112a, CFC-113a, CFC-114a) from Ref. [80], the measured infrared spectra were independent of total pressure over the pressure range 20-250 Torr with $\mathrm{He}$ as a bath gas.

\subsubsection{CFC-112a}

For CFC-112a (2,2-difluorotetrachloroethane, $\left.\mathrm{C}_{2} \mathrm{Cl}_{4} \mathrm{~F}_{2}\right)$, the data from PNNL [13] and Davis et al. [80] have been compared. In Figure 22, we plot the spectra from these sources (the PNNL one is for $278.15 \mathrm{~K}$ ) and overlay them on the mixture spectra from Etminan et al. [43]. Excellent agreement $(<1 \%)$ between PNNL and Davis et al. can be found for the intensities, integrated in the $700-1300 \mathrm{~cm}^{-1}$ spectral region. The PNNL data were supplied at three standard temperatures 
$1(278.15,298.15$, and $323.15 \mathrm{~K})$, and were included in HITRANonline. Data from Davis are

2 given only at $296 \mathrm{~K}$ and lower resolution (however sufficient for the purposes of Ref. [80]). As

3 seen on the log scale comparison (Figure 22), the PNNL data have very minor contaminants,

4 which are absent in the Davis at al. spectra. The data from the latter source have been placed into

5 the supplemental folder as the one having lower resolution and only $296 \mathrm{~K}$ temperature.

\subsubsection{CFC-113a}

The data for CFC-113a (1,1,1-trichlorotrifluoroethane, $\left.\mathrm{C}_{2} \mathrm{Cl}_{3} \mathrm{~F}_{3}\right)$ have been added to the HITRAN database for the first time. The comparison consisted of two sources of data: Davis et al. [80] and Etminan et al. [43]. Both sources provide room-temperature spectra at low pressures (zero-pressure limit for Davis et al., and 2.7 Torr for Etminan et al.). The description of the spectroscopic assignment for the strongest features of this molecule is given in Ref. [43]. The integrated intensity agreement between these two sources is good and goes from $2.5 \%$ for the strongest feature at $1250 \mathrm{~cm}^{-1}$ to $8.2 \%$ for the weakest one at $910 \mathrm{~cm}^{-1}$. The data from Etminan et al. have been included in HITRANonline, while data from Davis et al. have been placed in supplemental folder. However, the latter is smoother (although with less stated total accuracy and resolution), and displays more of the weaker features.

Table 21. PNNL-DOE data for chlorofluorocarbons

\begin{tabular}{lll}
\multicolumn{1}{c}{ Molecule } & CAS & Range, cm $^{-1}$ \\
\hline CFC-11 & $75-69-4$ & $570-6500$ \\
\hline CFC-113 & $76-13-1$ & $620-5000$ \\
\hline CFC-114 & $76-14-2$ & $600-5000$ \\
\hline CFC-112a & $76-11-9$ & $570-6500$ \\
\hline CFC-112 & $76-12-0$ & $550-6500$ \\
\hline C-56 † & $77-47-4$ & $575-6500$ \\
\hline
\end{tabular}

18 Spectra from Sharpe et al. [13] broadened by $\mathrm{N}_{2}$. Spectra were recorded at $278.15 \mathrm{~K}, 298.15 \mathrm{~K}$, 19 and $323.15 \mathrm{~K}$ temperatures (except for hexachlorocyclopentadiene), 760 Torr total pressure, and $20 \quad 0.112 \mathrm{~cm}^{-1}$ resolution.

$21 \uparrow$ Spectra for C-56 (hexachlorocyclopentadiene) were recorded at $323.15 \mathrm{~K}$

22 Table 22. More recent data on chlorofluorocarbons.

\begin{tabular}{|c|c|c|c|c|c|c|c|}
\hline Molecule & CAS & $\begin{array}{l}\text { Range } \\
\left(\mathbf{c m}^{-1}\right)\end{array}$ & $\begin{array}{c}\mathbf{T} \\
(\mathbf{K})\end{array}$ & $\begin{array}{c}\mathbf{P} \\
\text { (Torr) }\end{array}$ & Brd & $\begin{array}{c}\text { Resolution } \\
\left(\mathbf{c m}^{-1}\right)\end{array}$ & Source \\
\hline CFC-12 & $75-71-8$ & $800-1270$ & $189.5-294.2$ & $7.492-761$ & air & $0.01-0.03$ & Harrison (2015) $[26] \dagger$ \\
\hline CFC-113 & $76-13-1$ & $600-1250$ & $223-283$ & & & 0.05 & Le Bris et al (2011) [32]† \\
\hline CFC-113a & $354-58-5$ & $690-1730$ & 295 & 2.7 & & 0.01 & Etminan et al. (2014) [43] \\
\hline CFC-114a & $374-07-2$ & $550-1397$ & 296 & & & 1 & Davis et al. (2016) [80] \\
\hline
\end{tabular}




\subsection{Sulfur-containing species}

2 The sulfur-containing species in this edition include compounds that are released into the 3 atmosphere due to industrial activities. Many species from this category strongly absorb in the 4 atmospheric window $\left(800-1800 \mathrm{~cm}^{-1}\right)$. A number of species from this category have large

5 lifetimes, such as trifluoromethyl sulfur pentafluoride $\left(\mathrm{SF}_{5} \mathrm{CF}_{3}\right)$ and sulfur hexafluoride.

6 Although these molecules so far have minor abundances in the terrestrial atmosphere, they can

7 be considered as species of potential interest in climate applications.

8 A number of sulfur-containing species existed before in previous HITRAN issues. For 9 instance, the line-by-line part of HITRAN contains transitions for carbonyl sulfide (OCS), sulfur 10 dioxide $\left(\mathrm{SO}_{2}\right)$, sulfur trioxide $\left(\mathrm{SO}_{3}\right)$, and sulfur hexafluoride $\left(\mathrm{SF}_{6}\right)$. The discussion of the cross11 sections of $\mathrm{SF}_{6}$ is given in the Section 3.9.1 as it is also categorized as a fully fluorinated species.

12 In the HITRAN2016 update, several new molecules were added belonging to such sub-classes 13 as sulfates, sulfites, and mercaptans. The set of cross-section available through HITRANonline 14 incorporates the PNNL spectral data. In addition, the spectra provided in Hodnebrog et al. [1] 15 have been included in the supplemental folder in the case where they had additional features in 16 the lower wavenumber range. The summary of the sulfur-containing molecules available via 17 HITRANonline interface is given in Table 23. Below we give comparisons for each molecule 18 for which the data from different sources were available (including the line-by-line part of 19 HITRAN). 

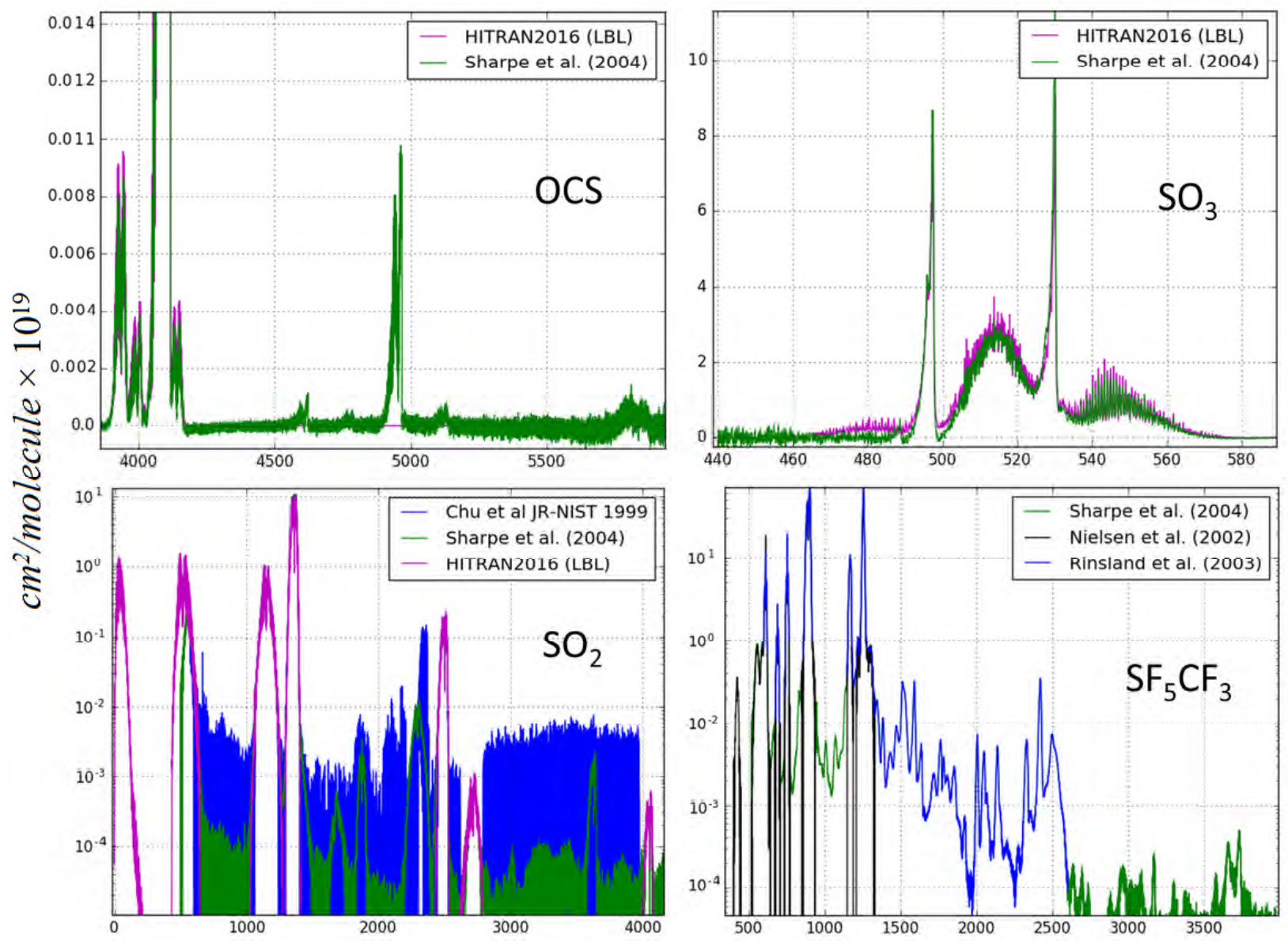

Wavenumber $\left(\mathrm{cm}^{-1}\right)$

Figure 23. Cross-section comparison for selected bands of carbonyl sulfide (OCS), sulfur dioxide $\left(\mathrm{SO}_{2}\right)$, sulfur trioxide $\left(\mathrm{SO}_{3}\right)$, and trifluoromethyl sulfur pentafluoride $\left(\mathrm{CF}_{5} \mathrm{CF}_{3}\right)$. The cross-sections generated from the line-by-line data from HITRAN2016 [2] are highlighted in magenta. Note that the spectral ranges of the line-by-line data for some of the molecules in HITRAN are larger than ones covered in this figure.

\subsubsection{Carbonyl sulfide}

Carbonyl sulfide (OCS) is an important molecule of astrophysical and atmospheric interest.

The HITRAN database has high-quality line-by-line data for this molecule spanning the wide wavenumber range from microwave to near-infrared [2]. The infrared spectra for this molecule have a strong feature centered near $2000 \mathrm{~cm}^{-1}$; the rest of the bands are relatively weak. For this molecule, only the data from PNNL are presented in the cross-section format for 278.15, 298.15, and $323.15 \mathrm{~K}$ temperature and 760 Torr pressure. The comparison of these data with crosssections, generated from the OCS line list from HITRAN2016, is displayed in Figure 23 and shows generally good agreement of the spectral band shapes and integrated intensities. For bands in the region above $1900 \mathrm{~cm}^{-1}$ containing the strong spectral feature, the integrated intensities agree within $2.4-3.7 \%$, while the agreement is worse $(\sim 9 \%)$ in the lower wavenumber region (800-1100 $\left.\mathrm{cm}^{-1}\right)$. It should be noted that the group of bands near $520 \mathrm{~cm}^{-1}$ in PNNL suffers from distortion caused by the fall-off of the detector response. Second, the PNNL data contains weak 
but noticeable spectral features which are lacking in the line-by-line spectra (for instance, the ones centered near 3700, 5000, and $6000 \mathrm{~cm}^{-1}$ ). We consider the line-by-line data preferable over the full spectral range, thus relegating the PNNL data to the supplemental folder.

\subsubsection{Sulfur dioxide}

The line-by-line data for sulfur dioxide $\left(\mathrm{SO}_{2}\right)$ exist in HITRAN2016 in a wide spectral range, from the microwave up to $4093 \mathrm{~cm}^{-1}$. HITRAN has included $\mathrm{SO}_{2} \mathrm{UV}$ cross-sections since 2012. The cross-sectional data considered in this comparison were provided by PNNL and NIST, with the spectral coverage of all datasets presented in Figure 23. It should be noted that both PNNL and NIST data near $550 \mathrm{~cm}^{-1}$ have an intensity decline due to the nonlinear detector response (MCT is not sensitive to light at longer wavelengths). Again, despite the good agreement between the integrated intensities, all three sources (PNNL, NIST and HITRAN2016 line-byline) lie within $4 \%$ for common features near $1300 \mathrm{~cm}^{-1}$ and $2500 \mathrm{~cm}^{-1}$. The NIST spectra contain additional spectral bands probably due to other molecules, as well as the baseline slightly shifted to the negative values. When comparing the line-by-line data and absorption crosssections in a given spectral interval, the former is usually favored for the reasons explained in Section 2 (unless the line-by-line parameters have low accuracy). $\mathrm{For}_{2} \mathrm{SO}_{2}$, the line-by-line data have most of the bands in the IR region, while PNNL spectra have additional weak features (e.g. at $1750 \mathrm{~cm}^{-1}, 1850 \mathrm{~cm}^{-1}, 2300 \mathrm{~cm}^{-1}$, and $3600 \mathrm{~cm}^{-1}$ ) which can be useful in some applications. Thus, we have added the PNNL data to the supplementary folder.

\subsubsection{Sulfur trioxide}

Sulfur trioxide $\left(\mathrm{SO}_{3}\right)$ is an atmospherically-relevant molecule produced during the oxidation of $\mathrm{SO}_{2}$. The HITRAN2016 edition provides an updated line list for the principal isotopologue of $\mathrm{SO}_{3}[2]$. The absorption cross-sections come only from PNNL which has only one cross-section set at room temperature. The agreement between the cross-sectional and line-by-line data for $\mathrm{SO}_{3}$ is worse than for OCS. Similar to the case of carbonyl sulfide, the PNNL spectra for $\mathrm{SO}_{3}$ distort at the beginning of the wavenumber range $\left(\sim 450 \mathrm{~cm}^{-1}\right)$. The corresponding panel in Figure 23 shows the comparison of the band feature around $500 \mathrm{~cm}^{-1}$ which was partly distorted in the PNNL spectra due to the spectrometer response fall-off. Surprisingly, the best agreement of the integrated intensities with the line-by-line data can be observed for this low-wavenumber feature $(\sim 9 \%)$, while the disagreement is around $17 \%$ for the strongest band near $1400 \mathrm{~cm}^{-1}$, which corresponds well to the HITRAN uncertainty codes for this region. The PNNL spectra contain an additional feature near $2450 \mathrm{~cm}^{-1}$ which is absent in the line-by-line. Again, as for OCS, to encourage the user to take advantage of the line-by-line data (which offers more 
1 flexibility), the PNNL spectrum for $296 \mathrm{~K}$ and 760 Torr has been placed in the supplemental

2 folder.

\section{$3 \quad 3.11 .4$. Trifluoromethyl sulfur pentafluoride}

4 Trifluoromethyl sulfur pentafluoride $\left(\mathrm{SF}_{5} \mathrm{CF}_{3}\right)$ is a long-lived greenhouse gas with an 800

5 year lifetime and 17400 100-yr GWP [3]. For this molecule, the HITRAN database included the

6 air-broadened cross-sections for 30 temperatures (213-323K) and atmospheric pressure provided

7 by Rinsland et al. [142]. These data coincide with the spectra from Sharpe et al. [13] for 278K,

$8298 \mathrm{~K}$, and 323K. Thus the PNNL spectra were omitted from inclusion into the HITRAN2016

9 issue for this molecule. The third dataset in this comparison is Nielsen et al. [143]. The data from

10 this source were measured at Ford at 296K. The authors of this paper remark that "because the

11 spectral line shape was independent of pressure and resolution, the reported spectral data are

12 recorded without air as diluent" [143]. For this reason, we did not fill the broadener and pressure

13 fields, but mention that these spectra can be used at atmospheric pressure as well. Data from

14 Nielsen et al. are in the good agreement with PNNL and have additional features at lower

15 wavenumber range. These data have been added to the supplemental folder. The log-scale

16 comparison of the datasets is presented in the Figure 23.

\subsubsection{Sulfuryl fluoride}

18 Sulfuryl fluoride $\left(\mathrm{SO}_{2} \mathrm{~F}_{2}\right)$ is a greenhouse gas with a lifetime of 36 years and a 4090100 -year 19 GWP [1]. It has three strong spectral features in the $800-1800 \mathrm{~cm}^{-1}$ spectral window. Data for 20 this molecule are new to HITRAN, and two sources are considered in the comparison given in the Figure 24. The data measured at atmospheric pressure have been provided by PNNL at three standard temperatures $(278.15,298.15$, and $323.15 \mathrm{~K})$, and by Andersen et al. [1,144]. Despite good agreement in the integrated intensities $(2.42 \%)$, there is a significant discrepancy $\left(\sim 1.1 \mathrm{~cm}^{-}\right.$

$24{ }^{1}$ ) on the wavenumber scale which can point to differences in the wavenumber calibration 25 between these two sources. The spectrum from Andersen et al. contains additional absorption in 26 the 1300-1700 $\mathrm{cm}^{-1}$ range (see the Figure 24) possibly due to contaminants. We have placed the 27 PNNL spectra in HITRANonline due to higher resolution and wider spectral coverage. The data from Andersen et al. have been omitted. 


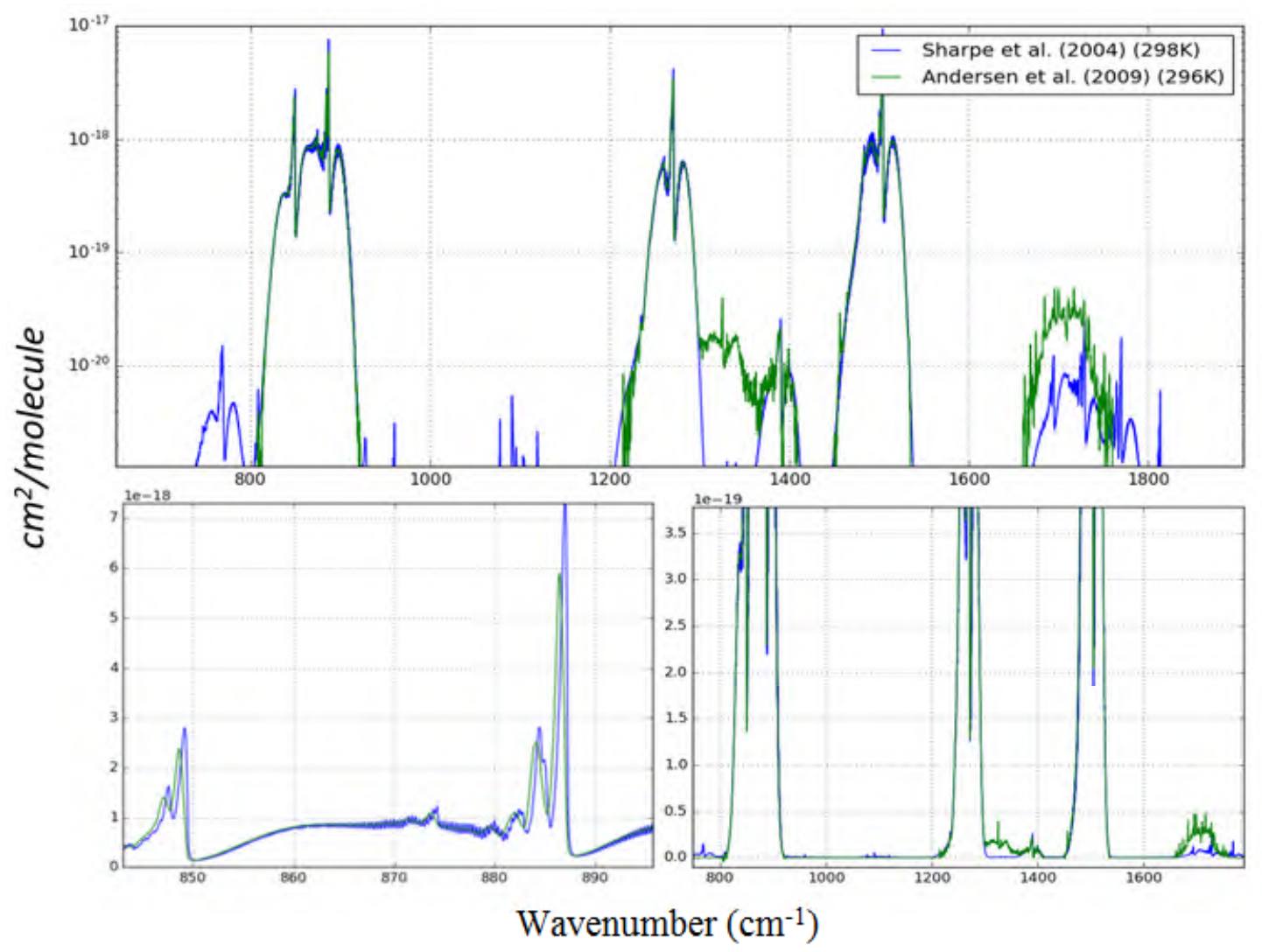

2 Figure 24. Comparison of sulfuryl fluoride $\left(\mathrm{SO}_{2} \mathrm{~F}_{2}\right)$ cross-sections at room temperature and 3 atmospheric pressure.

4 Table 23. PNNL-DOE data for sulfur-containing species

\begin{tabular}{lll}
\hline \multicolumn{1}{c}{ Molecule } & CAS & Range, $\mathbf{~ c m}^{-1}$ \\
\hline Carbon disulfide & $75-15-0$ & $600-6500$ \\
\hline Dimethyl disulfide & $624-92-0$ & $600-6500$ \\
\hline Dimethyl sulfate $\dagger$ & $77-78-1$ & $525-6500$ \\
\hline Dimethyl sulfide & $75-18-3$ & $600-6500$ \\
\hline Dimethyl sulfoxide $\dagger$ & $67-68-5$ & $575-6500$ \\
\hline Methyl isothiocyanate & $556-61-6$ & $600-6500$ \\
\hline Methyl mercaptan & $74-93-1$ & $600-6500$ \\
\hline Sulfuryl fluoride & $2699-79-8$ & $500-6500$ \\
\hline Sulphur hexafluoride & $2551-62-4$ & $560-6500$
\end{tabular}

5 Spectra from Sharpe et al. [13] broadened by $\mathrm{N}_{2}$. Spectra were recorded at $278.15 \mathrm{~K}, 298.15 \mathrm{~K}$, 6 and $323.15 \mathrm{~K}$ temperatures (except for dimethyl sulfate and dimethyl sulfoxide), 760 Torr total 7 pressure, and $0.112 \mathrm{~cm}^{-1}$ resolution.

$8 \uparrow$ Spectra for dimethyl sulfate and dimethyl sulfoxide were recorded at $298.15 \mathrm{~K}$ and $323.15 \mathrm{~K}$

\section{3.12. Iodocarbons and hydroiodocarbons}

10 For iodine containing species, previous editions of the HITRAN database included only HI (hydrogen iodide) in the line-by-line part. The HITRAN2016 update brings the iodocarbons and hydroiodocarbons into the database for the first time. We have included the three most atmospherically-important species from this category found in the PNNL [13] database: methyl iodide $\left(\mathrm{CH}_{3} \mathrm{I}\right)$, diiodomethane $\left(\mathrm{CH}_{2} \mathrm{I}_{2}\right)$, and ethyl iodide $\left(\mathrm{C}_{2} \mathrm{H}_{5} \mathrm{I}\right)$. A brief summary of the included molecules is given in Table 24. 


\begin{tabular}{lll}
\hline \multicolumn{1}{c}{ Molecule } & CAS & Range, cm $^{-1}$ \\
\hline Diiodomethane & $75-11-6$ & $530-7100$ \\
\hline Ethyl iodide & $75-03-6$ & $600-6500$ \\
\hline Methyl iodide & $74-88-4$ & $500-6900$
\end{tabular}

2 Spectra from Sharpe et al. [13] broadened by $\mathrm{N}_{2}$. Spectra were recorded at $278.15 \mathrm{~K}, 298.15 \mathrm{~K}$,

3 and $323.15 \mathrm{~K}$ temperatures (except for Diiodomethane), 760 Torr total pressure, and $0.112 \mathrm{~cm}^{-1}$

4 resolution.

$5+$ Spectra for Diiodomethane were recorded at $298.15 \mathrm{~K}$ and $323.15 \mathrm{~K}$

\section{Searching the cross-sections with HITRAN online}

Access to the cross-section data from the HITRAN2016 edition is provided by the open information system HITRANonline (http://hitran.org) [20], or by the HITRAN Application Programming Interface [9].

HITRANonline is a new information system which provides access to the data from the HITRAN [2] database. This system enables the user to select, download, and visualize the spectral line-by-line and cross-section data. This system also allows access to collision induced absorption, aerosol refractive indices, and high-temperature line lists from the HITEMP database [19]. For line-by-line transitions, which are the most frequently used part of the HITRAN database, a flexible approach to the data selection and representation is implemented: the user can create custom ASCII and binary output formats, specify the parameters for output, browse interactively the resulting line lists, impose search conditions (for example, for isotopologues, bands, and wavenumber ranges), and generate the bibliography in different formats. Hill et al. [20] provide a detailed description of the line-by-line part of HITRANonline. This HITRANonline information system is recommended for users to access the HITRAN database since it always provides the most up-to-date database version. In the following sections we describe how the cross-section data can be found and downloaded using HITRANonline and HAPI.

\subsection{Interactive data search}

To view and download the cross-section data, a user must be logged in on the internet browser. For anonymous users, an automatic invitation for logging in will appear after requesting certain cross-section temperature and pressure sets. To log in, the user should be registered in the system. This can be done either by clicking on the "register" link on the main page (see Figure 25), or on the invitation page as mentioned above.

After registering, a user account should be activated. After successful activation of the account, a user will get full access to all the data in the interactive part of the HITRANonline 
1 system. The link to the cross-sections main search page is located in a menu, which can be

2 opened either by hovering a mouse over the "Data Access" menu item, or by clicking on it

3 (Figure 25).

4

5

\section{HITRANonline}

Home

Data Access

The HITRAN Da

HITRAN is an acronym
database. HITRAN is a
of computer codes use
of light in the atmosph

Line-by-line

Absorption Cross

Sections

Collision Induced

Absorption

of light in the atmosph Aerosol Properties

HITEMP

HAPI

Supplemental

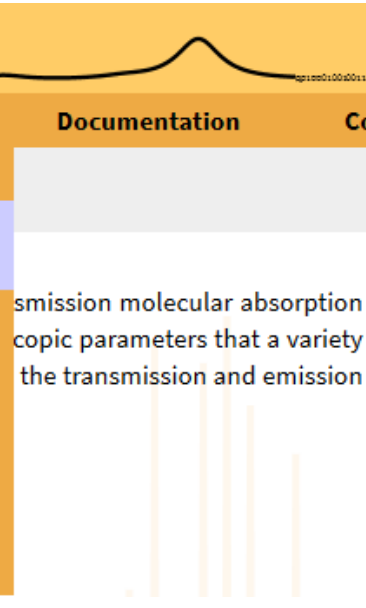

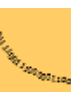

Conferences

$x^{2}$

Links

About

News

Database Updates

Figure 25. HITRANonline main page.

The cross-section search main page of HITRANonline is shown in Figure 25. As with the initial version of this page, described in Hill et al. (2016) [20], the new version contains the molecule search form.

Molecules can be searched by a number of synonyms or aliases, such as those given in Table 25. Apart from these names, other types of molecular identifiers will be added to HITRANonline. Although the search is robust, the user should be aware of using multiple synonyms to ensure that the molecule of interest is present in the database. Also, since in some cases, for instance for isomers, the common molecular formulae are the same for different species (e.g. for propene and cyclopropane the molecular formula is $\mathrm{C}_{3} \mathrm{H}_{6}$ ), it is advisable to use more reliable aliases in the search, such as molecule identifiers (CAS, InChi, or InChiKey). 


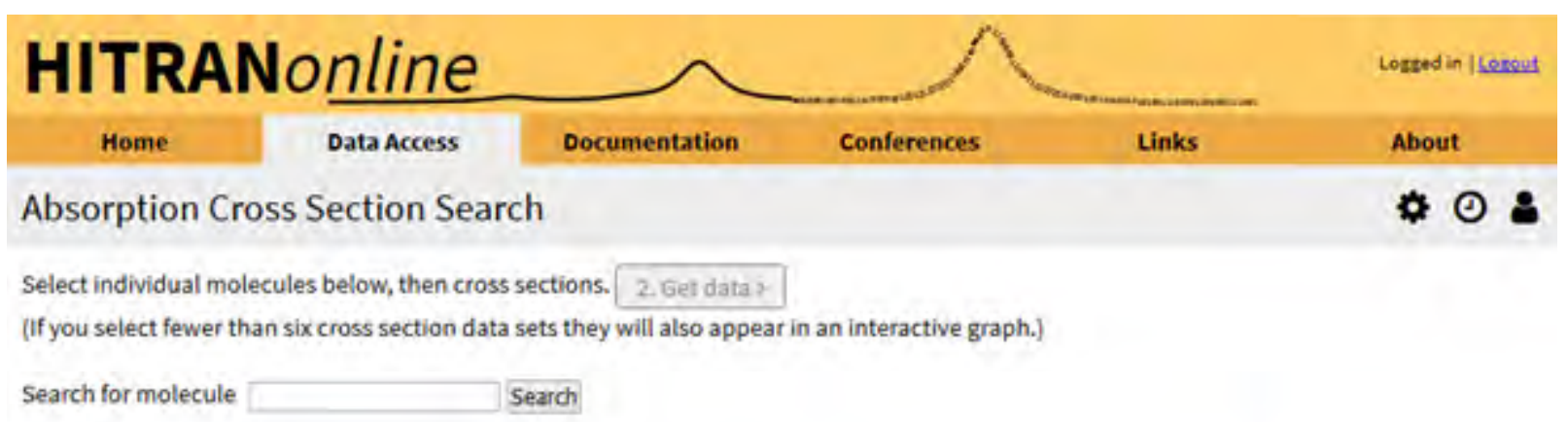

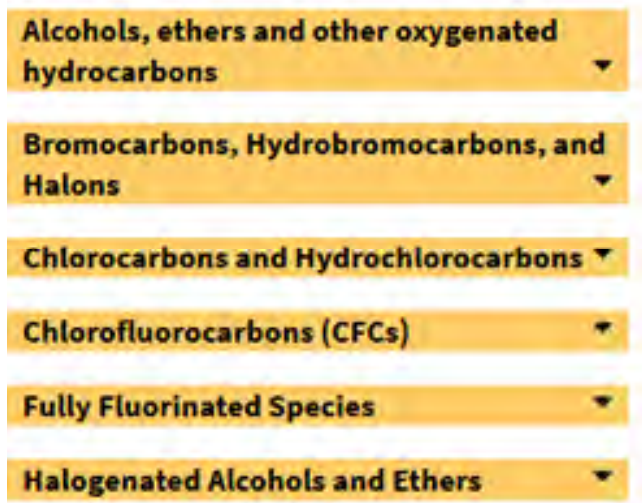

2 Figure 26. Molecular search and category browser.

3 Table 25. Molecule aliases available in HITRANonline.

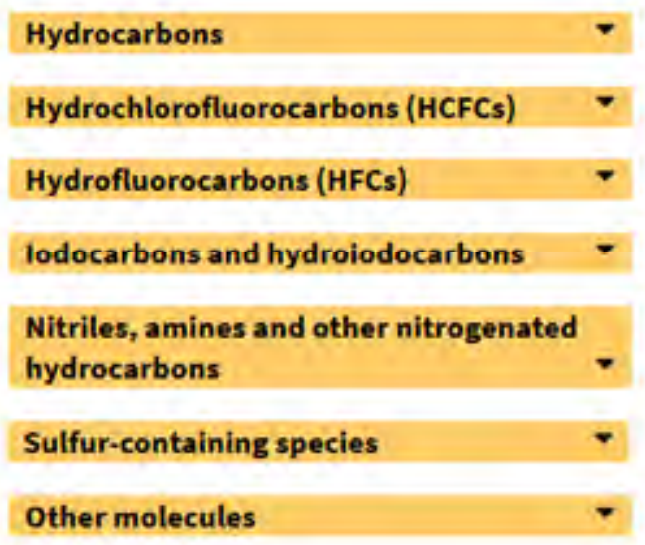

\begin{tabular}{lll}
\hline TYPE & EXPLANATION & EXAMPLE \\
\hline Name & Common molecule name & Dichlorodifluoromethane \\
Formula & $\begin{array}{l}\text { Molecular formula not containing } \\
\text { atomic weights. }\end{array}$ & CCl2F2 \\
$\begin{array}{l}\text { Tradename or } \\
\text { acronym }\end{array}$ & $\begin{array}{l}\text { Tradename or conventional molecular } \\
\text { acronym (such as defined by lUPAC }{ }^{\dagger} \text { CFC-12 }\end{array}$ & \\
CAS & $\begin{array}{l}\text { Chemical Abstract Service registry } \\
\text { number }\end{array}$ & 75-71-8 \\
InChI & $\begin{array}{l}\text { International chemical identifier } \\
\text { (IUPAC) }\end{array}$ & InChI=1S/CCI2F2/c2-1(3,4)5 \\
InChiKey & $\begin{array}{l}\text { Machine-friendly hash string produced } \\
\text { for the InChl }\end{array}$ & PXBRQCKWGAHEHS-UHFFFAOYSA-N
\end{tabular}

* Depends on the order of atoms in the molecule formula. $\uparrow$ International Union of Physics and Chemistry

5 For the user's convenience, the molecules are grouped into a number of chemical categories.

6 The list of the categories is growing and an up-to-date list of the categories is available on the

7 HITRANonline site. Most categories were adopted from the Hodnebrog et al. halocarbon review

8 [1], but several new categories were added prior to the HITRAN2016 database release, such as:

9 hydrocarbons, alcohols, ethers and other oxygenated hydrocarbons, nitriles, amines and other 
1 nitrogenated hydrocarbons, sulfur-containing species, and iodocarbons and hydroiodocarbons. In

2 the section devoted to the spectral data, we discussed a number of molecules from each category

3 in detail. Note that some molecules belong to several categories.

$4 \quad$ Clicking on a category name (Figure 26) gives a drop-down menu containing all molecules

5 from this category (Figure 27). In the dropdown list, general information on each molecule is

6 presented, such as spectral coverage (IR or UV), molecule common name, and ordinary formula.

7 Clicking on a molecule in the menu opens a panel in the right part of the screen containing a full

8 list of cross-sections temperature and pressure sets ( $T, p$-sets). The supplemental folder contains

9 the alternate data in static text files.

10 Once the list of the $T, p$-sets for the chosen molecule is opened, a summary metadata on each 11 set is displayed. Such metadata includes a wavenumber range, temperature, pressure, resolution, 12 broadener, and the number of data points in each cross-section set. By checking the $T$, $p$-sets in

13 this list, the user defines which data should be downloaded and visualized. The source of the data 14 can be viewed by hovering a mouse over the corresponding $T, p$ dataset. 


\section{HITRANonline}

Absorption Cross Section Search

Select individual molecules below, then cross sections. 2. Get data $>$

(If you select fewer than six cross section data sets they will also appear in an interactive graph.)

Search for molecule CFC-12

Search

Supplemental folder

\begin{tabular}{|c|c|c|c|}
\hline \multicolumn{4}{|c|}{$\begin{array}{l}\text { Alcohols, ethers and other oxygenated } \\
\text { hydrocarbons }\end{array}$} \\
\hline \multicolumn{4}{|c|}{ Bromocarbons, Hydrobromocarbons, and } \\
\hline \multicolumn{3}{|c|}{ Halons } & 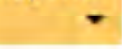 \\
\hline \multicolumn{4}{|c|}{ Chlorocarbons and Hydrochlorocarbons } \\
\hline \multicolumn{4}{|c|}{ Chlorofluorocarbons (CFCs) } \\
\hline IR & UV/Vis & Common Name & Formula \\
\hline ○ & 0 & CFC-11 & $\mathrm{CCl}_{3} \mathrm{~F}$ \\
\hline (9) & 0 & $\mathrm{CFC}-13$ & $\mathrm{CClF}_{3}$ \\
\hline ○ & 0 & CFC.113 & $\mathrm{C}_{2} \mathrm{Cl}_{3} \mathrm{~F}_{3}$ \\
\hline$\ominus$ & 0 & CFC-114 & $\mathrm{C}_{2} \mathrm{Cl}_{2} \mathrm{~F}_{4}$ \\
\hline$\theta$ & 0 & CFC-115 & $\mathrm{C}_{2} \mathrm{ClF}_{5}$ \\
\hline$\theta$ & 0 & CFC-12 & $\mathrm{CCl}_{2} \mathrm{~F}_{2}$ \\
\hline$\theta$ & 0 & CFC- $113 a$ & $\mathrm{C}_{2} \mathrm{Cl}_{3} \mathrm{~F}_{3}$ \\
\hline e & 0 & CFC-114a & $\mathrm{C}_{2} \mathrm{Cl}_{2} \mathrm{~F}_{4}$ \\
\hline () & 0 & Hexachlorocyclopentadiene & $\mathrm{C}_{5} \mathrm{Cl}_{6}$ \\
\hline
\end{tabular}

\begin{tabular}{|c|c|c|c|c|c|c|}
\hline \multicolumn{7}{|c|}{ CFC-12: $\mathrm{CCl}_{2} \mathrm{~F}_{2}$} \\
\hline & vrange $/ \mathrm{cm}^{-1}$ & $T / K$ & p/Torr & Resolution & npts & Broadener \\
\hline$\checkmark$ & $800,0=12 \mathrm{~T} 0,0$ & 216.2 & 129.4 & 0,02 uाt-1 & 187181 & ail \\
\hline$\checkmark$ & $800.0-1270.0$ & 189.5 & 170.4 & $0.05 \mathrm{~cm}-1$ & 187181 & air \\
\hline$\checkmark$ & $300.0<1270.0$ & 200.4 & 231.3 & $0.03 \mathrm{em}-1$ & 13718: & air \\
\hline$\checkmark$ & $800.0-1270.0$ & 200.6 & 170.4 & $0.03 \mathrm{~cm}-1$ & 187161 & air \\
\hline$\checkmark$ & $800.0-1270.0$ & 216.2 & 280.9 & $0.03 \mathrm{~cm}-1$ & 187191 & air \\
\hline & $300.0-1270.0$ & 216.2 & 379.5 & $0.03 \mathrm{~cm}-1$ & 187151 & air \\
\hline & $800.0-1270.0$ & 233.1 & 1971 & $0.03 \mathrm{~cm}-1$ & 187181 & alr \\
\hline & $800.0-1270.0$ & 235.2 & 350.8 & $0.03 \mathrm{~cm}-1$ & 137131 & ait \\
\hline & $800.0-1270.0$ & 244.8 & 171.0 & $0.03 \mathrm{~cm}-1$ & 187180 & air \\
\hline & $800.0-1270.0$ & 244.8 & 444.6 & $0.03 \mathrm{~cm}-1$ & 187180 & gir \\
\hline & $390.0-1270.0$ & 244.8 & 550.0 & $0.03 \mathrm{~cm}-1$ & 137130 & air \\
\hline & $800.0-1270.0$ & 209.0 & 109.8 & $0.03 \mathrm{~cm}-1$ & 187180 & air \\
\hline & $800.0-1270.0$ & 269.0 & 350.9 & $0.03 \mathrm{~cm}-1$ & 187180 & atr \\
\hline
\end{tabular}

Figure 27. Cross-sections menu. Example of accessing CFC-12.

Clicking on the "Get data" link opens the search result page as shown in Figure 28. The page

4 provides separate links to the HITRAN-formatted files for each $T$, $p$-set along with the single

5 bibliography file. To simplify the download of a large number of cross-section sets they are

6 compressed into a zip file. Figure 28 displays the spectra from the requested $T, p$-sets. It is worth

7 noting that the cross-sections displayed in the interactive plot are a downsampled version of the

8 actual spectra stored in the database, since plotting the spectra in their original resolution can

9 slow down or freeze the internet browser. The user should be aware of that when visualizing the

10 subtle spectral features, because the "light" versions of the spectra were obtained by downsampling of the original data. 


\section{$\mathrm{CCl}_{2} \mathrm{~F}_{2}$}

5 cross sections were found.

CCl2F2 189.5K-170.4Torr 800.0-1270.0 00.xsc [1.8 MB] Cross section file (HITRAN .xsc format) CCl2F2 200.4K-281.3Torr 800.0-1270.0 00.xsc [1.8 MB] Cross section file (HITRAN .xsc format) CCl2F2 200.6K-170.4Torr 800.0-1270.0 00.xsc [1.8 MB] Cross section file (HITRAN .xsc format) CCl2F2 216.2K-129.4Torr 800.0-1270.0 00.xsc [1.8 MB] Cross section file (HITRAN .xsc format) CCl2F2 216.2K-280.9Torr 800.0-1270.0 00.xsC [1.8 MB] Cross section file (HITRAN .xsc format) 5a1f781f.bib.html $\underline{5 a 1 f 781 f . b i b}$ [1.9 KB] List of sources (HTML format) [1.2 KB] List of sources (BibTeX format)

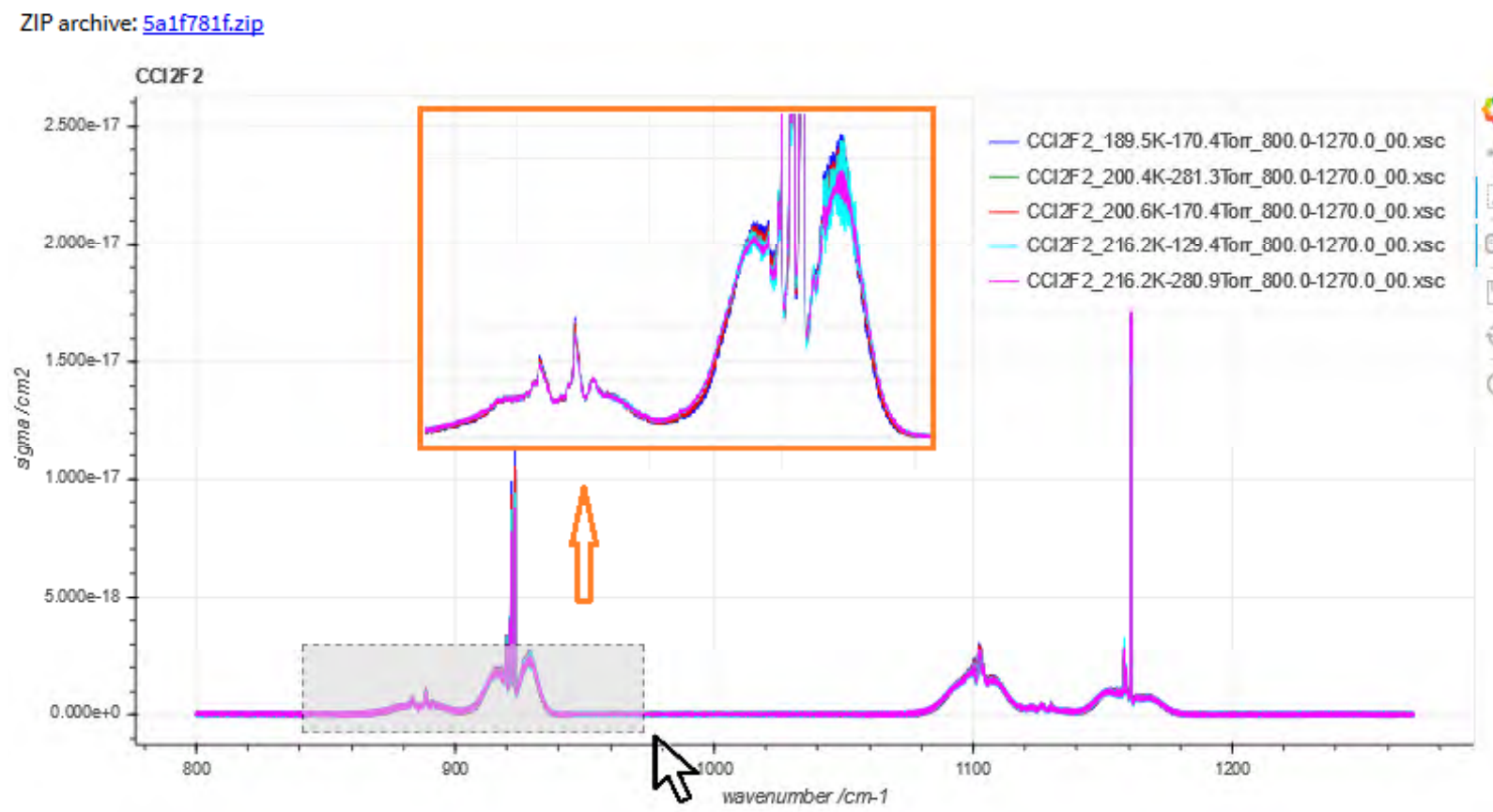

Figure 28. Interactive spectra view.

A sample of the HITRAN-formatted file is shown in Figure 29. The plain text file in this format (an extension .xsc has been used) contains header and data. The header incorporates the cross-section $T$, $p$-set parameters which were explained in Table 3.

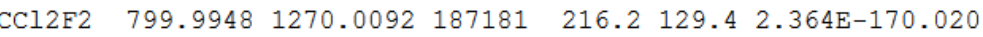

$\begin{array}{llllllllll}0.000 \mathrm{E}+00 & 0.000 \mathrm{E}+00 & 0.000 \mathrm{E}+00 & 0.000 \mathrm{E}+00 & 0.000 \mathrm{E}+00 & 0.000 \mathrm{E}+00 & 0.000 \mathrm{E}+00 & 0.000 \mathrm{E}+00 & 2.421 \mathrm{E}-21 & 4.848 \mathrm{E}-21\end{array}$

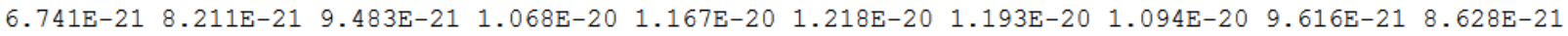
$\begin{array}{llllllllll}8.625 \mathrm{E}-21 & 9.856 \mathrm{E}-21 & 1.194 \mathrm{E}-20 & 1.394 \mathrm{E}-20 & 1.465 \mathrm{E}-20 & 1.318 \mathrm{E}-20 & 9.315 \mathrm{E}-21 & 3.712 \mathrm{E}-21 & 0.000 \mathrm{E}+00 & 0.000 \mathrm{E}+00\end{array}$ $\begin{array}{lllllllllll}0.000 \mathrm{E}+00 & 0.000 \mathrm{E}+00 & 0.000 \mathrm{E}+00 & 0.000 \mathrm{E}+00 & 0.000 \mathrm{E}+00 & 2.238 \mathrm{E}-21 & 3.642 \mathrm{E}-21 & 3.958 \mathrm{E}-21 & 3.620 \mathrm{E}-21 & 3.046 \mathrm{E}-21\end{array}$ $\begin{array}{llllllllll}2.431 \mathrm{E}-21 & 1.706 \mathrm{E}-21 & 6.623 \mathrm{E}-22 & 0.000 \mathrm{E}+00 & 0.000 \mathrm{E}+00 & 0.000 \mathrm{E}+00 & 0.000 \mathrm{E}+00 & 0.000 \mathrm{E}+00 & 0.000 \mathrm{E}+00 & 0.000 \mathrm{E}+00\end{array}$ $\begin{array}{lllllllllll}0.000 \mathrm{E}+00 & 0.000 \mathrm{E}+00 & 0.000 \mathrm{E}+00 & 0.000 \mathrm{E}+00 & 0.000 \mathrm{E}+00 & 0.000 \mathrm{E}+00 & 0.000 \mathrm{E}+00 & 0.000 \mathrm{E}+00 & 0.000 \mathrm{E}+00 & 0.000 \mathrm{E}+00\end{array}$ $\begin{array}{lllllllllll}0.000 \mathrm{E}+00 & 0.000 \mathrm{E}+00 & 0.000 \mathrm{E}+00 & 0.000 \mathrm{E}+0 & 0.000 \mathrm{E}+0 & 0.000 \mathrm{E}+00 & 2.676 \mathrm{E}-21 & 5.600 \mathrm{E}-21 & 7.087 \mathrm{E}-21 & 6.969 \mathrm{E}-21\end{array}$ $\begin{array}{llllllllll}5.534 \mathrm{E}-21 & 3.368 \mathrm{E}-21 & 1.114 \mathrm{E}-21 & 0.000 \mathrm{E}+00 & 0.000 \mathrm{E}+00 & 0.000 \mathrm{E}+00 & 0.000 \mathrm{E}+00 & 0.000 \mathrm{E}+00 & 0.000 \mathrm{E}+00 & 0.000 \mathrm{E}+00\end{array}$ $\begin{array}{llllllllll}0.000 \mathrm{E}+00 & 0.000 \mathrm{E}+00 & 0.000 \mathrm{E}+00 & 0.000 \mathrm{E}+00 & 0.000 \mathrm{E}+00 & 0.000 \mathrm{E}+00 & 0.000 \mathrm{E}+00 & 1.163 \mathrm{E}-21 & 2.621 \mathrm{E}-21 & 3.499 \mathrm{E}-21\end{array}$

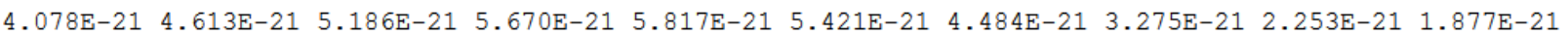

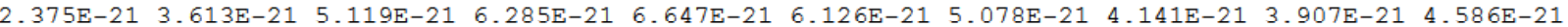
$\begin{array}{llllllllll}5.831 \mathrm{E}-21 & 6.825 \mathrm{E}-21 & 6.617 \mathrm{E}-21 & 4.576 \mathrm{E}-21 & 7.456 \mathrm{E}-22 & 0.000 \mathrm{E}+00 & 0.000 \mathrm{E}+00 & 0.000 \mathrm{E}+00 & 0.000 \mathrm{E}+00 & 0.000 \mathrm{E}+00\end{array}$ $\begin{array}{llllllllllll}0.000 \mathrm{E}+00 & 0.000 \mathrm{E}+00 & 0.000 \mathrm{E}+00 & 0.000 \mathrm{E}+00 & 0.000 \mathrm{E}+00 & 0.000 \mathrm{E}+00 & 0.000 \mathrm{E}+00 & 0.000 \mathrm{E}+00 & 0.000 \mathrm{E}+00 & 0.000 \mathrm{E}+00\end{array}$

$7 \quad$ Figure 29. Example of cross-section in HITRAN format (.xsc)

\subsection{Sources and bibliography}

The references for the source papers for each cross-section $T, p$-set are given in multiple formats. The user is able to download the bibliography for the selected cross-sections in HTML and BibTex formats, as shown in Figure 30 and Figure 31. In the generated bibliography file, all references are listed along with the initial reference for the current HITRAN issue. For each 
3 (Figure 29).

\section{The latest full release of the HIIKAN database is described in:}

I.E. Gordon, L.S Rothman, C. Hill, RV Kochanov Y. Tan PF. Bernath, M. Birk, V. Boudon, A Campargue, KV. Chance, B.J. Drouin J.-M Flaud, R R Gamache, J.T. Hodges, D. Jacquemart, VI Perevalov, A. Perrin, K P. Shine, M-A H. Smith. J. Tennyson, G.C. Toon, H. Tran, V.G. Tyuterer; A. Barbe, A.G. Csaszar, VM Devi, T. Furtenbacher, f.J. Harrison, J.-M Hartmann A Jolly, T.J. Johnson, T. Karman, I Kleiner, A.A. Kyuberis, J. Loos, O M Lyulin, S T. Massie, SN. Mithailento, N. Moazzen-Ahmadi, H.S.P. Mullet O.V. Naumenko, A.V. Nikitin, O L. Polyansky, M Rey, M Rotger, S.W Sharpe, K. Sung, E. Starikova, S.A. Tashkan, J. Vander Auwera, G. Wagner, J Wilzewski, P. Wcislo, S. Yu, E. J Zak, The HIIRAN2016 Molecular Spectroscopic Database", Joumal of Quantitative Spectroscopy and Radiative Iransfer, Available online 5 July 2017 ,ISSN 0022-4073, DOI 10.1016/f-jqsit.2017.06.038. [1ink to antucle]

\section{References by integer ID in data file}

1046. J.J. Harrison, "New and improved infrared absorption cross sections for dichlorodifluoromethane (CFC-12)" Atmospheric Measurement Techniques 8, $3197-3207$ (2015). [link to article] [ADS]

Figure 30. References view (HTML)

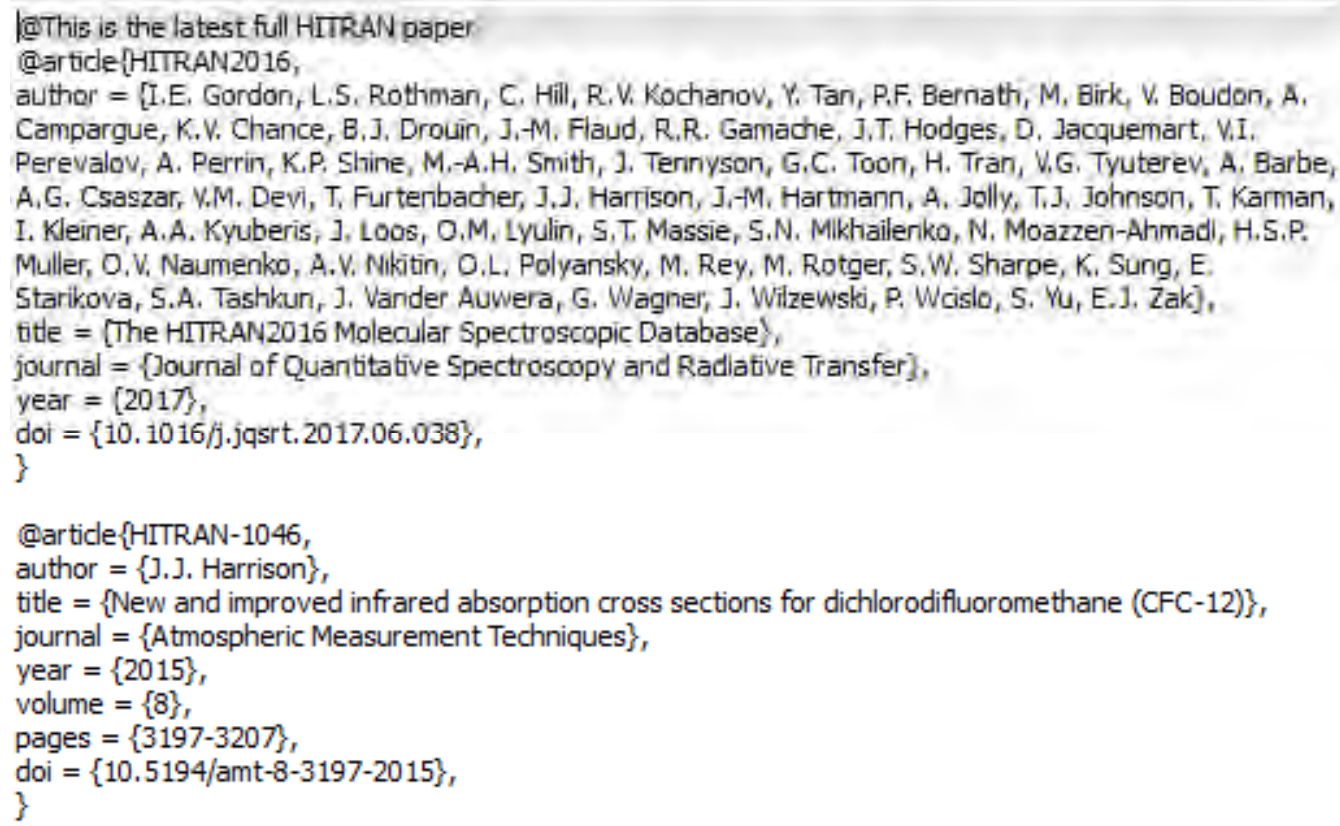

8 Figure 31. References view (Bibtex)

9 The referencing system used in the present paper corresponds to the HITRAN nomenclature.

10 According to it, each source has its own unique local ID number. The numbering is organized so different parts of HITRAN such as line-by-line parameters and cross-sections do not depend on each other. The local ID numbers for reference are given in the last field of the header of each .$x s c$ file containing cross-sections (see Figure 29 and Table 3 ). We provide a list of references for the cross-section part of the HITRAN database in the supplementary Table S1, containing local IDs and aliases for each source. Aliases are made in correspondence with the Hodnebrog et al. (2013) [1] review, and represent short unique names, by which the sources are referenced throughout the paper (e.g. "Hashikawa et al. (2004)"). Users can obtain more information on sources such as direct links, DOIs, and BIBCODEs through the interactive search interface. 
This paper presents a substantial update of the infrared absorption cross-sections in the HITRAN database, which at the present time incorporates more than 320 compounds of

4 primarily atmospheric and climate interest. More than 260 of these compounds were included in

5 the database for the first time. An extensive effort was made to collect and systematize self-

6 consistent datasets of cross-sections for those molecules which provide the most complete

7 spectral coverage. Whenever possible, extensive evaluations of the datasets were performed.

A significant effort has been made to facilitate user access to those data using the open infrastructure provided by HITRANonline [20] (at www.hitran.org) and HAPI (HITRAN Application Programming Interface) [9]. In the first place, the purpose of this data collection is to help researchers in climate and atmospheric science, industry, remote sensing, meteorology, and a variety of other applications, to assess the impact on the climate and environment, track down the possible associated environmental processes (such as, for instance, forest fires), and estimate the atmospheric abundance of the compounds in question. Among the sources of crosssection data one can mention around 220 molecules adopted from both the PNNL - DOE database [13], and the PNNL - SERDP dataset of 55 molecules from Johnson et al [22] that extended the set to include biomass burning molecules, as well as cross-sections from the review of halocarbons (Hodnebrog et al. [1] and references therein), and finally recently published data on CFCs, HCFCs, HFCs, hydrocarbons, and other related species $[21,24,36,37,43,49,80,91,92,113,124,25-31,35]$.

All IR data, provided as cross-sections in HITRAN, were measured using the FTS technique. The one exception was the air- and self-broadened ethane spectra included in HITRAN2016 that were obtained from more accurate laser CRDS measurements [49]. Due to the heterogeneous nature of the sources, data for some molecules are more complete in terms of temperature and pressure ranges than others. However, in most cases the spectral coverage is full, and includes the near-, mid-, and far-IR range. Considering the initial assignment of the data for climate and atmospheric applications, the emphasis was placed on the mid-infrared "atmospheric window" wavenumber range [1] (approximately $700-1500 \mathrm{~cm}^{-1}$ ), where most of the species given in the paper have significant absorption. However, many cross-sections cover a much wider spectral region (such as, for instance, the data from PNNL). Thus, the extended coverage can serve a broader range of applications. As the effects of climate change continue to grow in importance, it would be beneficial to have many more measurements in the far-infrared ranged between 0 and $600 \mathrm{~cm}^{-1}$ to better estimate the greenhouse effect of these molecules. 
While the update of the cross-sectional part of the database in the near-, mid-, and far-IR range is quite extensive, this work is by no means complete. In the future we plan further revisions of high-quality data that are or will become available in the literature or from new experiments. This task is often hampered by the fact that some reports and publications do not provide supplements, and spectral data can be hard to track down or are permanently lost. We would like to remind authors about the importance of making the data available with their

\section{Acknowledgements}

16 This work was supported through the NASA AURA (NNX 17AI78G) and NASA PDART publications (see for instance discussion in Ref. [145]). In addition, the utility of theoretical calculations of absorption cross-sections is increasing as such calculations become more refined, and their use in future HITRAN editions should be assessed [88,146-148].

In the near future we also plan to extend the database to include planetary-relevant crosssections that became available recently, including those given in Refs. [149-151]. The update described here did not include any data in the UV part of the spectrum. For the next edition of HITRAN we plan an extensive effort to update existing UV cross-sections and add many new datasets using approaches similar to those described here. (NNX16AG51G) grants. We would like to thank Øivind Hodnebrog (Center for International Climate Research, Oslo, Norway) for collecting the data on halocarbons, Joseph Hodges and Zachary Reed (National Institute of Standards and Technology, USA) for providing CRDS spectra for ethane, and thank Y. Tan, and R. Hargreaves of the HITRAN team for useful discussions on the subject of this paper. It is important to acknowledge Aaron Goldman and Steven Massie for their contributions to the cross-section part of HITRAN at earlier stages, and for their advice on formatting the data.

J.J.H. wishes to thank the UK Research and Innovation Natural Environment Research Council for funding via the National Centre for Earth Observation, contract number PR140015.

The PNNL data were sponsored both by the U. S. Department of Energy, National Nuclear Security Administration, Office of Defense Nuclear Nonproliferation R\&D (NA-22), as well as U.S. Department of Defense's Strategic Environmental Research and Development Program (SERDP), resources conservation project RC-2640. PNNL gratefully thanks both sponsors for their support. PNNL is operated for the U.S. Department of Energy by the Battelle Memorial Institute under contract DE-AC06-76RLO 1830.

We thank reviewers for many helpful comments. 
2 [1] Hodnebrog $\varnothing$, Etminan M, Fuglestvedt JS, Marston G, Myhre G, Nielsen CJ, et al. Global warming potentials and radiative efficiencies of halocarbons and related compounds: A comprehensive review. Rev Geophys 2013;51:300-78. doi:10.1002/rog.20013.

[2] Gordon IE, Rothman LS, Hill C, Kochanov RV, Tan Y, Bernath PF, et al. The HITRAN2016 molecular spectroscopic database. J Quant Spectrosc Radiat Transf 2017;130:4-50. doi:10.1016/j.jqsrt.2017.06.038.

[3] Myhre G, Shindell D, Breon F-M, Collins W, Fuglestvedt J, Huang J, et al. Anthropogenic and Natural Radiative Forcing. In: Stocker T., Qin D, Plattner G-K, Tignor M, Allen SK, Doschung J, et al., editors. Clim. Chang. 2013 Phys. Sci. Basis. Contrib. Work. Gr. I to Fifth Assess. Rep. Intergov. Panel Clim. Chang., Cambridge: Cambridge University Press; 2013, p. 659-740. doi:10.1017/CBO9781107415324.018.

[4] Lin HW, Abad GG, Loeb A. DETECTING INDUSTRIAL POLLUTION IN THE ATMOSPHERES OF EARTHLIKE EXOPLANETS. Astrophys J 2014;792:L7. doi:10.1088/2041-8205/792/1/L7.

[5] Acerboni G, Beukes JA, Jensen NR, Hjorth J, Myhre G, Nielsen CJ, et al. Atmospheric degradation and global warming potentials of three perfluoroalkenes. Atmos Environ 2001;35:4113-23. doi:10.1016/S1352-2310(01)00209-6.

[6] Rothman LS, Gordon IE, Babikov Y, Barbe A, Chris Benner D, Bernath PF, et al. The HITRAN2012 molecular spectroscopic database. J Quant Spectrosc Radiat Transf 2013;130:4-50. doi:10.1016/j.jqsrt.2013.07.002.

[7] McClatchey RA, Benedict WS, Clough SA, Burch DE, Calfee RF, Fox K, et al. AFCRL Atmospheric Absorption Line Parameters Compilation. Environ Res Pap 1973:1-86. doi:10.1364/AO.20.000791.

[8] Rothman LS, Rinsland CP, Goldman A, Massie ST, D.P. E, Flaud J-M, et al. The HITRAN molecular spectroscopic database and HAWKS (HITRAN Atmospheric Workstation): 1996 edition. J Quant Spectrosc Radiat Transf 1998;60:665-710. doi:10.1016/S0022-4073(98)00078-8.

[9] Kochanov RV, Gordon IE, Rothman LS, Wcisło P, Hill C, Wilzewski JS. HITRAN Application Programming Interface (HAPI): A comprehensive approach to working with spectroscopic data. J Quant Spectrosc Radiat Transf 2016;177:15-30. doi:10.1016/j.jqsrt.2016.03.005.

[10] Rothman LS, Gamache RR, Goldman A, Brown LR, Toth RA, Pickett HM, et al. The HITRAN database: 1986 edition. Appl Opt 1987;26:4058. doi:10.1364/AO.26.004058.

[11] Massie ST, Goldman A. Absorption parameters of very dense molecular spectra for the HITRAN compilation. J Quant Spectrosc Radiat Transf 1992;48:713-9. doi:10.1016/0022-4073(92)90135Q.

[12] Massie ST, Goldman A, Murcray DG, Gille JC. Approximate absorption cross sections of F12, F11, $\mathrm{ClONO}_{2}, \mathrm{~N}_{2} \mathrm{O}_{5}, \mathrm{HNO}_{3}, \mathrm{CCl}_{4}, \mathrm{CF}_{4}, \mathrm{~F} 21, \mathrm{~F} 113, \mathrm{~F} 114$, and $\mathrm{HNO}_{4}$. Appl Opt 1985;24:3426. doi:10.1364/AO.24.003426.

[13] Sharpe SW, Johnson TJ, Sams RL, Chu PM, Rhoderick GC, Johnson PA. Gas-phase databases for quantitative infrared spectroscopy. Appl Spectrosc 2004;58:1452-61. doi:10.1366/0003702042641281.

[14] Varanasi P. Absorption spectra of HCFC-22 around $829 \mathrm{~cm}^{-1}$ at atmospheric conditions. J Quant Spectrosc Radiat Transf 1992;47:251-5. doi:10.1016/0022-4073(92)90143-R. 
[15] Varanasi P. Absorption coefficients of CFC-11 and CFC-12 needed for atmospheric remote sensing and global warming studies. J Quant Spectrosc Radiat Transf 1992;48:205-19. doi:10.1016/00224073(92)90089-M.

[16] Smith K, Newnham D, Page M, Ballard J, Duxbury G. Infrared absorption cross-sections and integrated absorption intensities of HFC-134 and HFC-143a vapour. J Quant Spectrosc Radiat Transf 1998;59:437-51. doi:10.1016/S0022-4073(97)00114-3.

[17] Chu PM, Guenther FR, Rhoderick GC, Lafferty WJ. The NIST quantitative infrared database. J Res Natl Inst Stand Technol 1999;104:59. doi:10.6028/jres.104.004.

[18] Clerbaux C, Colin R, Simon PC, Granier C. Infrared cross sections and global warming potentials of 10 alternative hydrohalocarbons. J Geophys Res 1993;98:10491. doi:10.1029/93JD00390.

[19] Rothman LS, Gordon IE, Barber RJ, Dothe H, Gamache RR, Goldman A, et al. HITEMP, the hightemperature molecular spectroscopic database. J Quant Spectrosc Radiat Transf 2010;111:213950. doi:10.1016/j.jpsrt.2010.05.001.

[20] Hill C, Gordon IE, Kochanov R V., Barrett L, Wilzewski JS, Rothman LS. HITRANonline: An online interface and the flexible representation of spectroscopic data in the HITRAN database. J Quant Spectrosc Radiat Transf 2016;177:4-14. doi:10.1016/j.jqsrt.2015.12.012.

[21] Godin PJ, Cabaj A, Conway S, Hong AC, Le Bris K, Mabury SA, et al. Temperature-dependent absorption cross-sections of perfluorotributylamine. J Mol Spectrosc 2016;323:53-8. doi:10.1016/j.jms.2015.11.004.

[22] Johnson TJ, Profeta LTM, Sams RL, Griffith DWT, Yokelson RL. An infrared spectral database for detection of gases emitted by biomass burning. Vib Spectrosc 2010;53:97-102. doi:10.1016/j.vibspec.2010.02.010.

[23] Johnson TJ, Sams RL, Burton SD, Blake TA. Absolute integrated intensities of vapor-phase hydrogen peroxide ( $\mathrm{H} 2 \mathrm{O} 2)$ in the mid-infrared at atmospheric pressure. Anal Bioanal Chem 2009;395:377-86. doi:10.1007/s00216-009-2805-x.

[24] Harrison JJ. Infrared absorption cross sections for trifluoromethane. J Quant Spectrosc Radiat Transf 2013;130:359-64. doi:10.1016/j.jqsrt.2013.05.026.

[25] Harrison JJ. Infrared absorption cross sections for 1,1,1,2-tetrafluoroethane. J Quant Spectrosc Radiat Transf 2015;151:210-6. doi:10.1016/j.jqsrt.2014.09.023.

[26] Harrison JJ. New and improved infrared absorption cross sections for dichlorodifluoromethane (CFC-12). Atmos Meas Tech 2015;8:3197-207. doi:10.5194/amt-8-3197-2015.

[27] Harrison JJ. New and improved infrared absorption cross sections for chlorodifluoromethane (HCFC-22). Atmos Meas Tech 2016;9:2593-601. doi:10.5194/amt-9-2593-2016.

[28] Harrison JJ, Boone CD, Bernath PF. New and improved infra-red absorption cross sections and ACE-FTS retrievals of carbon tetrachloride (CCI4). J Quant Spectrosc Radiat Transf 2017;186:13949. doi:10.1016/j.jpsrt.2016.04.025.

[29] Wagner G, Birk M. New infrared spectroscopic database for bromine nitrate. J Mol Spectrosc 2016;326:95-105. doi:10.1016/j.jms.2016.03.007.

[30] Rodríguez A, Bravo I, Rodríguez D, Tajuelo M, Diaz-de-Mera Y, Aranda A. The environmental impact of unsaturated fluoroesters: atmospheric chemistry towards $\mathrm{OH}$ radicals and $\mathrm{Cl}$ atoms, radiative behavior and cumulative ozone creation. RSC Adv 2016;6:21833-43. doi:10.1039/C6RA00630B. 
[31] Rodríguez A, Rodríguez D, Moraleda A, Bravo I, Moreno E, Notario A. Atmospheric chemistry of HFE-7300 and HFE-7500: Temperature dependent kinetics, atmospheric lifetimes, infrared spectra and global warming potentials. Atmos Environ 2014;96:145-53. doi:10.1016/j.atmosenv.2014.07.033.

[32] Le Bris K, Pandharpurkar R, Strong K. Mid-infrared absorption cross-sections and temperature dependence of CFC-113. J Quant Spectrosc Radiat Transf 2011;112:1280-5. doi:10.1016/j.jqsrt.2011.01.023.

[33] Le Bris K, Strong K. Temperature-dependent absorption cross-sections of HCFC-142b. J Quant Spectrosc Radiat Transf 2010;111:364-71. doi:10.1016/j.jqsrt.2009.10.005.

[34] Le Bris K, McDowell J, Strong K. Measurements of the infrared absorption cross-sections of HCFC141b (CH3CFCl2). J Quant Spectrosc Radiat Transf 2012;113:1913-9. doi:10.1016/j.jqsrt.2012.05.004.

[35] Le Bris K, Graham L. Quantitative comparisons of absorption cross-section spectra and integrated intensities of HFC-143a. J Quant Spectrosc Radiat Transf 2015;151:13-7. doi:10.1016/j.jqsrt.2014.09.005.

[36] Godin PJ, Le Bris K, Strong K. Conformational analysis and global warming potentials of 1,1,1,3,3,3-hexafluoro-2-propanol from absorption spectroscopy. J Quant Spectrosc Radiat Transf 2017;203:522-9. doi:10.1016/j.jqsrt.2017.04.031.

[37] Godin PJ, Cabaj A, Xu L-H, Le Bris K, Strong K. A study of the temperature dependence of the infrared absorption cross-sections of 2,2,3,3,3-pentafluoropropanol in the range of 298-362K. J Quant Spectrosc Radiat Transf 2017;186:150-7. doi:10.1016/j.jqsrt.2016.05.031.

[38] Le Bris K, DeZeeuw J, Godin PJ, Strong K. Cis - and trans -perfluorodecalin: Infrared spectra, radiative efficiency and global warming potential. J Quant Spectrosc Radiat Transf 2017;203:53841. doi:10.1016/j.jqsrt.2017.01.011.

[39] Le Bris K, DeZeeuw J, Godin PJ, Strong K. Infrared absorption cross-sections, radiative efficiency and global warming potential of HFC-43-10mee. J Mol Spectrosc 2018;348:64-7. doi:10.1016/j.jms.2017.06.004.

[40] Lonardo GD, Masciarelli G. Infrared absorption cross-sections and integrated absorption intensities of HFC-125 and HFC-143a. J Quant Spectrosc Radiat Transf 2000;66:129-42. doi:10.1016/S0022-4073(99)00212-5.

[41] Smith K, Newnham D, Page M, Ballard J, Duxbury G. INFRARED BAND STRENGTHS AND ABSORPTION CROSS-SECTIONS CROSS-SECTIONS OF HFC-32 VAPOUR 1996;56:73-82. doi:10.1016/0022-4073(96)00019-2.

[42] Harrison JJ, Allen NDC, Bernath PF. Infrared absorption cross sections for ethane (C2H6) in the 3 ??m region. J Quant Spectrosc Radiat Transf 2010;111:357-63. doi:10.1016/j.jqsrt.2009.09.010.

[43] Etminan M, Highwood EJ, Laube JC, McPheat R, Marston G, Shine KP, et al. Infrared absorption spectra, radiative efficiencies, and global warming potentials of newly-detected halogenated compounds: CFC-113a, CFC-112 and HCFC-133a. Atmosphere (Basel) 2014;5:473-83. doi:10.3390/atmos5030473.

[44] McDaniel AH, Cantrell CA, Davidson JA, Shetter RE, Calvert JG. The temperature dependent, infrared absorption cross-sections for the chlorofluorocarbons: CFC-11, CFC-12, CFC-13, CFC-14, CFC-22, CFC-113, CFC-114, and CFC-115. J Atmos Chem 1991;12:211-27. doi:10.1007/BF00048074. 
[45] Massie ST, Goldman A, McDaniel AH, Cantrell CA, Davidson JA, Shetter RE, et al. Temperature Dependent Infrared Cross Sections for CFC-11, CFC-12, CFC-13, CFC-14, CFC-22, CFC-113, CFC114, and CFC-115. NCAR Technical Note/TN-358+STR. 1991.

[46] Zou Q, Sun C, Nemtchinov V, Varanasi P. Thermal infrared cross-sections of C2F6 at atmospheric temperatures. J Quant Spectrosc Radiat Transf 2004;83:215-21. doi:10.1016/S00224073(02)00353-9.

[47] Sellevag SR, Kelly T, Sidebottom H, Nielsen CJ. A study of the IR and UV-Vis absorption crosssections, photolysis and $\mathrm{OH}$-initiated oxidation of $\mathrm{CF} 3 \mathrm{CHO}$ and $\mathrm{CF} 3 \mathrm{CH} 2 \mathrm{CHO}$. Phys Chem Chem Phys 2004;6:1243-52. doi:10.1039/b315941h.

[48] Young CJ, Hurley MD, Wallington TJ, Mabury SA. Atmospheric chemistry of CF3CF2H and CF3CF2CF2CF2H: Kinetics and products of gas-phase reactions with $\mathrm{Cl}$ atoms and $\mathrm{OH}$ radicals, infrared spectra, and formation of perfluorocarboxylic acids. Chem Phys Lett 2009;473:251-6. doi:10.1016/j.cplett.2009.04.001.

[49] Reed ZD, Hodges JT. Self- and air-broadened cross sections of ethane (C2H6) determined by frequency-stabilized cavity ring-down spectroscopy near $1.68 \mu \mathrm{m}$. J Quant Spectrosc Radiat Transf 2015;159:87-93. doi:10.1016/j.jqsrt.2015.03.010.

[50] D'Anna B, Sellevåg SR, Wirtz K, Nielsen CJ. Photolysis Study of Perfluoro-2-methyl-3-pentanone under Natural Sunlight Conditions. Environ Sci Technol 2005;39:8708-11. doi:10.1021/es048088u.

[51] Nielsen OJ, Javadi MS, Sulbaek Andersen MP, Hurley MD, Wallington TJ, Singh R. Atmospheric chemistry of CF3CFCH2: Kinetics and mechanisms of gas-phase reactions with $\mathrm{Cl}$ atoms, $\mathrm{OH}$ radicals, and O3. Chem Phys Lett 2007;439:18-22. doi:10.1016/j.cplett.2007.03.053.

[52] Nilsson EJK, Nielsen OJ, Johnson MS, Hurley MD, Wallington TJ. Atmospheric chemistry of cis$\mathrm{CF} 3 \mathrm{CH}$ \{double bond, long\}CHF: Kinetics of reactions with $\mathrm{OH}$ radicals and $\mathrm{O} 3$ and products of $\mathrm{OH}$ radical initiated oxidation. Chem Phys Lett 2009;473:233-7. doi:10.1016/j.cplett.2009.03.076.

[53] Bravo I, Aranda A, Hurley MD, Marston G, Nutt DR, Shine KP, et al. Infrared absorption spectra, radiative efficiencies, and global warming potentials of perfluorocarbons: Comparison between experiment and theory. J Geophys Res Atmos 2010;115:1-12. doi:10.1029/2010JD014771.

[54] Østerstrøm FF, Nielsen OJ, Sulbaek Andersen MP, Wallington TJ. Atmospheric chemistry of CF $3 \mathrm{CH} 2 \mathrm{OCH}$ 3: Reaction with chlorine atoms and $\mathrm{OH}$ radicals, kinetics, degradation mechanism and global warming potential. Chem Phys Lett 2012;524:32-7. doi:10.1016/j.cplett.2011.12.047.

[55] Oyaro N, Sellevåg SR, Nielsen CJ. Study of the $\mathrm{OH}$ and Cl-Initiated Oxidation, IR Absorption CrossSection, Radiative Forcing, and Global Warming Potential of Four C 4 -Hydrofluoroethers. Environ Sci Technol 2004;38:5567-76. doi:10.1021/es0497330.

[56] Oyaro N, Sellevåg SR, Nielsen CJ. Atmospheric Chemistry of Hydrofluoroethers: Reaction of a Series of Hydrofluoroethers with $\mathrm{OH}$ Radicals and $\mathrm{Cl}$ Atoms, Atmospheric Lifetimes, and Global Warming Potentials. J Phys Chem A 2005;109:337-46. doi:10.1021/jp047860c.

[57] Bravo I, Díaz-de-Mera Y, Aranda A, Smith K, Shine KP, Marston G. Atmospheric chemistry of C4F9OC2H5 (HFE-7200), C4F9OCH3 (HFE-7100), C3F7OCH3 (HFE-7000) and C3F7CH2OH: temperature dependence of the kinetics of their reactions with $\mathrm{OH}$ radicals, atmospheric lifetimes and global warming potentials. Phys Chem Chem Phys 2010;12:5115-25. doi:10.1039/b923092k.

[58] Sulbaek Andersen MP, Waterland RL, Sander SP, Nielsen OJ, Wallington TJ. Atmospheric chemistry of $\mathrm{CxF} 2 \mathrm{x}+1 \mathrm{CHCH} 2$ ( $\mathrm{x}=1,2,4,6$ and 8 ): Radiative efficiencies and global warming 
potentials. J Photochem Photobiol A Chem 2012;233:50-2.

doi:10.1016/j.jphotochem.2012.02.020.

[59] Sellevåg SR, Nielsen CJ, Søvde OA, Myhre G, Sundet JK, Stordal F, et al. Atmospheric gas-phase degradation and global warming potentials of 2-fluoroethanol, 2,2-difluoroethanol, and 2,2,2trifluoroethanol. Atmos Environ 2004;38:6725-35. doi:10.1016/j.atmosenv.2004.09.023.

[60] Myhre G, Nielsen C., Powell D., Stordal F. Infrared absorption cross section, radiative forcing, and GWP of four hydrofluoro(poly)ethers. Atmos Environ 1999;33:4447-58. doi:10.1016/S13522310(99)00208-3.

[61] Sihra K, Hurley MD, Shine KP, Wallington TJ. Updated radiative forcing estimates of 65 halocarbons and nonmethane hydrocarbons. JGeophysRes 2001;106:20493-505. doi:10.1029/2000JD900716.

[62] Andersen MPS, Nielsen OJ, Wallington TJ, Karpichev B, Sander SP. Assessing the impact on global climate from general anesthetic gases. Anesth Analg 2012;114:1081-5. doi:10.1213/ANE.0b013e31824d6150.

[63] Wallington TJ, Hurley MD, Ball JC, Ellermann T, Nielsen OJ, Sehested J. Atmospheric Chemistry of HFC-152: UV Absorption Spectrum of CH2FCFHO2 Radicals, Kinetics of the Reaction CH2FCFHO2 $+\mathrm{NO}$.fwdarw. CH2FCHFO + NO2, and Fate of the Alkoxy Radical CH2FCFHO. J Phys Chem 1994;98:5435-40. doi:10.1021/j100072a008.

[64] Wallington TJ, Schneider WF, Barnes I, Becker KH, Sehested J, Nielsen OJ. Stability and infrared spectra of mono-, di-, and trichloromethanol. Chem Phys Lett 2000;322:97-102. doi:10.1016/S0009-2614(00)00384-5.

[65] Wallington TJ, Hurley MD, Nielsen OJ, Sulbaek Andersen MP. Atmospheric Chemistry of CF 3 CFHCF 2 OCF 3 and CF 3 CFHCF 2 OCF $2 \mathrm{H}$ : Reaction with Cl Atoms and OH Radicals, Degradation Mechanism, and Global Warming Potentials. J Phys Chem A 2004;108:11333-8. doi:10.1021/jp046454q.

[66] Wallington TJ, Hurley MD, Nielsen OJ. The radiative efficiency of HCF2OCF2OCF2CF2OCF2H (HGalden 1040x) revisited. Atmos Environ 2009;43:4247-9. doi:10.1016/j.atmosenv.2009.05.046.

[67] Waterland RL, Hurley MD, Misner J a., Wallington TJ, Melo SML, Strong K, et al. Gas phase UV and IR absorption spectra of $\mathrm{CF} 3 \mathrm{CH} 2 \mathrm{CH} 2 \mathrm{OH}$ and $\mathrm{F}(\mathrm{CF} 2 \mathrm{CF} 2) \times \mathrm{CH} 2 \mathrm{CH} 2 \mathrm{OH}(\mathrm{x}=2,3,4)$. J Fluor Chem 2005;126:1288-96. doi:10.1016/j.jfluchem.2005.06.010.

[68] Young CJ, Hurley MD, Wallington TJ, Mabury SA. Atmospheric lifetime and global warming potential of a perfluoropolyether. Environ Sci Technol 2006;40:2242-6. doi:10.1021/es052077z.

[69] Young CJ, Hurley MD, Wallington TJ, Mabury SA. Atmospheric chemistry of perfluorobutenes (CF3CFCFCF3 and CF3CF2CFCF2): Kinetics and mechanisms of reactions with $\mathrm{OH}$ radicals and chlorine atoms, IR spectra, global warming potentials, and oxidation to perfluorocarboxylic acids. Atmos Environ 2009;43:3717-24. doi:10.1016/j.atmosenv.2009.04.025.

[70] Gohar LK et al. Updated radiative forcing estimates of four halocarbons. J Geophys Res 2004;109:D01107. doi:10.1029/2003JD004320.

[71] Mashino M, Kawasaki M, Wallington TJ, Hurley MD. Atmospheric Degradation of CF 3 OCFCF 2 : Kinetics and Mechanism of Its Reaction with $\mathrm{OH}$ Radicals and $\mathrm{Cl}$ Atoms. J Phys Chem A 2000;104:2925-30. doi:10.1021/jp9942264.

[72] Inoue $\mathrm{Y}$, Kawasaki M, Wallington TJ, Hurley MD. Atmospheric chemistry of CF3CH2CF2CH3 (HFC$365 \mathrm{mfc}$ ): Kinetics and mechanism of chlorine atom initiated oxidation, infrared spectrum, and 
global warming potential. Chem Phys Lett 2008;462:164-8. doi:10.1016/j.cplett.2008.07.054.

[73] Hurley MD, Ball JC, Wallington TJ. Atmospheric Chemistry of the Z and E Isomers of CF 3 CFCHF; Kinetics, Mechanisms, and Products of Gas-Phase Reactions with $\mathrm{Cl}$ Atoms, $\mathrm{OH}$ Radicals, and $\mathrm{O} 3$. J Phys Chem A 2007;111:9789-95. doi:10.1021/jp0753530.

[74] Hashikawa Y, Kawasaki M, Waterland RL, Hurley MD, Ball JC, Wallington TJ, et al. Gas phase UV and IR absorption spectra of CxF2x+1CHO ( $x=1-4)$. J Fluor Chem 2004;125:1925-32. doi:10.1016/j.jfluchem.2004.07.006.

[75] Sellevag, S. R., B. D'Anna and CJN. Infrared Absorption Cross-Sections and Estimated Global Warming Potentials of $\mathrm{CF} 3 \mathrm{CH} 2 \mathrm{CH} 2 \mathrm{OH}$, CHF2CF2CH2OH, CF3CF2CH2OH, CF3CHFCF2CH2OH, and CF3CF2CF2CH2OH. Asian Chem Lett 2007;11:33-40.

[76] Sulbaek Andersen MP, Sander SP, Nielsen OJ, Wagner DS, Sanford TJ, Wallington TJ. Inhalation anaesthetics and climate change. Br J Anaesth 2010;105:760-6. doi:10.1093/bja/aeq259.

[77] Andersen MPS, Nilsson EJK, Nielsen OJ, Johnson MS, Hurley MD, Wallington TJ. Atmospheric chemistry of trans-CF3CHCHCl: Kinetics of the gas-phase reactions with $\mathrm{Cl}$ atoms, $\mathrm{OH}$ radicals, and O3. J Photochem Photobiol A Chem 2008;199:92-7. doi:10.1016/j.jphotochem.2008.05.013.

[78] Sulbaek Andersen MP, Hurley MD, Wallington TJ, Blandini F, Jensen NR, Librando V, et al. Atmospheric chemistry of $\mathrm{CH} 3 \mathrm{O}(\mathrm{CF} 2 \mathrm{CF} 2 \mathrm{O}) \mathrm{nCH} 3(\mathrm{n}=1-3)$ : Kinetics and mechanism of oxidation initiated by $\mathrm{Cl}$ atoms and $\mathrm{OH}$ radicals, IR spectra, and global warming potentials. J Phys Chem $\mathrm{A}$ 2004;108:1964-72. doi:10.1021/jp036615a.

[79] Ryan SM, Nielsen CJ. Global warming potential of inhaled anesthetics: Application to clinical use. Anesth Analg 2010;111:92-8. doi:10.1213/ANE.0b013e3181e058d7.

[80] Davis ME, Bernard F, McGillen MR, Fleming EL, Burkholder JB. UV and infrared absorption spectra, atmospheric lifetimes, and ozone depletion and global warming potentials for $\mathrm{CCl}_{2} \mathrm{FCCl}_{2} \mathrm{~F}$ (CFC-112), $\mathrm{CCl}_{3} \mathrm{CClF}_{2}$ (CFC-112a), CCl<. Atmos Chem Phys 2016;16:8043-52. doi:10.5194/acp-168043-2016.

[81] Chance K, Orphal J. Revised ultraviolet absorption cross sections of $\mathrm{H} 2 \mathrm{CO}$ for the HITRAN database. J Quant Spectrosc Radiat Transf 2011;112:1509-10. doi:10.1016/j.jqsrt.2011.02.002.

[82] Tereszchuk KA, Bernath PF. Infrared absorption cross-sections for acetaldehyde (CH3CHO) in the 3??m region. J Quant Spectrosc Radiat Transf 2011;112:990-3. doi:10.1016/j.jqsrt.2010.12.003.

[83] Harrison JJ, Humpage N, Allen NDC, Waterfall AM, Bernath PF, Remedios JJ. Mid-infrared absorption cross sections for acetone (propanone). J Quant Spectrosc Radiat Transf 2011;112:457-64. doi:10.1016/j.jqsrt.2010.09.002.

[84] Harrison JJ, Allen NDC, Bernath PF. Infrared absorption cross sections for acetone (propanone) in the 3??m region. J Quant Spectrosc Radiat Transf 2011;112:53-8. doi:10.1016/j.jqsrt.2010.08.011.

[85] Waterfall AM. Measurement of organic compounds in the upper troposphere using infrared remote sensing. D.Phil. thesis. University of Oxford, 2004.

[86] Kochanov R V., Gordon IE, Rothman LS, Sharpe SW, Johnson TJ, Sams RL. Comment on "Radiative forcings for 28 potential Archean greenhouse gases" by Byrne and Goldblatt (2014). Clim Past 2015;11:1097-105. doi:10.5194/cp-11-1097-2015.

[87] Good DA, Francisco JS, Jain AK, Wuebbles DJ. Lifetimes and global warming potentials for dimethyl ether and for fluorinated ethers: CH 3 OCF 3 (E143a), CHF 2 OCHF 2 (E134), CHF 2 OCF 3 
[88] Papanastasiou DK, Beltrone A, Marshall P, Burkholder JB. Global warming potential estimates for the C\&amp;It;sub\&amp;gt;1\&amp;It;/sub\&amp;gt;-

C\&amp;It;sub\&amp;gt;3\&amp;It;/sub\&amp;gt; hydrochlorofluorocarbons (HCFCs) included in the Kigali Amendment to the Montreal Protocol. Atmos Chem Phys 2018;18:6317-30. doi:10.5194/acp-18-6317-2018.

[89] Ninomiya Y, Kawasaki M, Guschin A, Molina LT, Molina MJ, Wallington TJ. Atmospheric Chemistry of n-C3F7 OCH 3 : Reaction with $\mathrm{OH}$ Radicals and $\mathrm{Cl}$ Atoms and Atmospheric Fate of n-C3F7OCH2 O(•) Radicals. Environ Sci Technol 2000;34:2973-8. doi:10.1021/es991449z.

[90] Highwood E., Shine K. Radiative forcing and global warming potentials of 11 halogenated compounds. J Quant Spectrosc Radiat Transf 2000;66:169-83. doi:10.1016/S00224073(99)00215-0.

[91] Papadimitriou VC, Burkholder JB. OH Radical Reaction Rate Coefficients, Infrared Spectrum, and Global Warming Potential of $\left(\mathrm{CF}_{3}\right)_{2} \mathrm{CFCH}=\mathrm{CHF}$ (HFO-1438ezy $(E)$ ). J Phys Chem $\mathrm{A}$ 2016;120:6618-28. doi:10.1021/acs.jpca.6b06096.

[92] González S, Jiménez E, Ballesteros B, Martínez E, Albaladejo J. Hydroxyl radical reaction rate coefficients as a function of temperature and IR absorption cross sections for $\mathrm{CF} 3 \mathrm{CH}=\mathrm{CH} 2$ (HFO1243zf), potential replacement of CF3CH2F (HFC-134a). Environ Sci Pollut Res 2014:4793-805. doi:10.1007/s11356-014-3426-2.

[93] UNEP 2011. HFCs: A Critical Link in Protecting Climate and the Ozone Layer. United Nations Environment Programme (UNEP), 36pp. n.d.

[94] WMO Greenhouse Gas Bulletin No 13, 30 October 2017. World Meteorological Organization Geneva ISSN 2078-0796 https://library.wmo.int/opac/doc_num.php?explnum_id=4022. n.d.

[95] Vander Auwera J. Infrared absorption cross-sections for two substituted ethanes: 1,1difluoroethane (HFC-152a) and 1,2-dichloroethane. J Quant Spectrosc Radiat Transf 2000;66:143-51. doi:10.1016/S0022-4073(99)00213-7.

[96] Beukes J., Nicolaisen F. Infrared absorption cross-sections and integrated absorption intensities for difluoromethane (HFC-32) and 1,1,1,2-tetrafluoroethane (HFC-134a) in the 650-50 cm-1 region. J Quant Spectrosc Radiat Transf 2000;66:185-98. doi:10.1016/S0022-4073(99)00216-2.

[97] Harrison JJ, Boone CD, Brown AT, Allen NDC, Toon GC, Bernath PF. First remote sensing observations of trifluoromethane (HFC-23) in the upper troposphere and lower stratosphere. J Geophys Res Atmos 2012;117:n/a-n/a. doi:10.1029/2011JD016423.

[98] Nassar R, Bernath PF, Boone CD, McLeod SD, Skelton R, Walker KA, et al. A global inventory of stratospheric fluorine in 2004 based on Atmospheric Chemistry Experiment Fourier transform spectrometer (ACE-FTS) measurements. J Geophys Res Atmos 2006;111:1-10. doi:10.1029/2006JD007395.

[99] Nemtchinov V, Varanasi P. Absorption cross-sections of HFC-134a in the spectral region between 7 and. J Quant Spectrosc Radiat Transf 2004;83:285-94. doi:10.1016/S0022-4073(02)00356-4.

[100] Newnham D, Ballard J, Page M. Infrared band strengths of HFC-134a vapour. J Quant Spectrosc Radiat Transf 1996;55:373-81. doi:10.1016/0022-4073(95)00164-6.

[101] Fang X, Miller BR, Su S, Wu J, Zhang J, Hu J. Historical Emissions of HFC-23 $\left(\mathrm{CHF}_{3}\right)$ in China and Projections upon Policy Options by 2050. Environ Sci Technol 2014;48:4056-62. doi:10.1021/es404995f. 
[102] Chung KC. Absorption cross-sections off HFC-23 at atmospheric conditions. J Quant Spectrosc Radiat Transf 2005;96:281-7. doi:10.1016/j.jqsrt.2005.04.004.

[103] McPheat R, Duxbury G. Infrared absorption cross-sections and integrated absorption intensities of chloroform and fluoroform vapour. J Quant Spectrosc Radiat Transf 2000;66:153-67. doi:10.1016/S0022-4073(99)00214-9.

[104] Arnold T, Ivy DJ, Harth CM, Vollmer MK, Mühle J, Salameh PK, et al. HFC-43-10mee atmospheric abundances and global emission estimates. Geophys Res Lett 2014;41:2228-35. doi:10.1002/2013GL059143.

[105] Søndergaard R, Nielsen OJ, Hurley MD, Wallington TJ, Singh R. Atmospheric chemistry of transCF3CHCHF: Kinetics of the gas-phase reactions with $\mathrm{Cl}$ atoms, OH radicals, and O3. Chem Phys Lett 2007;443:199-204. doi:10.1016/j.cplett.2007.06.084.

[106] McLinden MO, Brown JS, Brignoli R, Kazakov AF, Domanski PA. Limited options for low-globalwarming-potential refrigerants. Nat Commun 2017;8:1-9. doi:10.1038/ncomms14476.

[107] S.A. Montzka, G. Dutton, J.H. Butler. The NOAA Ozone Depleting Gas Index: Guiding Recovery of the Ozone Layer (2017); https://www.esrl.noaa.gov/gmd/odgi/n.d.

[108] Daniel JS, Solomon S, Portmann RW, Garcia RR. Stratospheric ozone destruction: The importance of bromine relative to chlorine. J Geophys Res Atmos 1999;104:23871-80. doi:10.1029/1999JD900381.

[109] World Meteorological Organization (WMO), Scientific Assessment of Ozone Depletion: 2014, World Meteorological Organization, Global Ozone Research and Monitoring Project-Report No. 55, 416 pp., Geneva, Switzerland, 2014. n.d.

[110] Hopfner M, Orphal J, Stiller GP, Fischer H. Stratospheric BrONO 2 observed by MIPAS. Atmos Chem Phys 2009;9:1735-46. doi:10.5194/acp-9-1735-2009.

[111] G. Wetzel, H. Oelhaf, F. Friedl-Vallon, A. Ebersoldt, T. Gulde, M. Höpfner, S. Kazarski, O. Kirner, A. Kleinert, G. Maucher, H. Nordmeyer, J. Orphal, R. Ruhnke, B.-M. Sinnhuber, Geophysical Research Abstracts Vol. 17 (2015) EGU2015-1552, 2015 EGU General n.d.

[112] Burkholder J, Ravishankara A, Solomon S. UV/visible and IR absorption cross sections of BrONO2. J Geophys ... 1995;100. doi:10.1029/95JD01223.

[113] Wallington TJ, Pivesso BP, Lira AM, Anderson JE, Nielsen CJ, Andersen $\mathrm{NH}$, et al. $\mathrm{CH} 3 \mathrm{Cl}, \mathrm{CH} 2 \mathrm{Cl}$, $\mathrm{CHCl} 3$, and $\mathrm{CCl} 4$ : Infrared spectra, radiative efficiencies, and global warming potentials. J Quant Spectrosc Radiat Transf 2016;174:56-64. doi:10.1016/j.jqsrt.2016.01.029.

[114] Liang Q, Newman PA, Daniel JS, Reimann S, Hall BD, Dutton G, et al. Constraining the carbon tetrachloride $(\mathrm{CCl} 4)$ budget using its global trend and inter-hemispheric gradient. Geophys Res Lett 2014;41:5307-15. doi:10.1002/2014GL060754.

[115] Harris, N.R.P. and Wuebbles, D.J. (Lead Authors), Daniel, J.S., Hu, J., Kuijpers, L.J.M., Law, K.S., Prather, M.J., and Schofield, R.: Scenarios and information for policymakers, Chapter 5 in Scientific Assessment of Ozone Depletion: 2014, Global Ozone Re. n.d.

[116] SPARC, 2016: SPARC Report on the Mystery of Carbon tetrachloride. Q. Liang, P.A. Newman, and S. Reimann (Eds.), SPARC Report No. 7, WCRP-13/2016, available at www.sparcclimate.org/publications/sparc-reports/sparc-report-no7. n.d.

[117] Allen NDC, Bernath PF, Boone CD, Chipperfield MP, Fu D, Manney GL, et al. Global carbon tetrachloride distributions obtained from the Atmospheric Chemistry Experiment (ACE). Atmos 
[118] Nemtchinov $V$, Varanasi P. Thermal infrared absorption cross-sections of $\mathrm{CCl}_{4}$ needed for atmospheric remote sensing. J Quant Spectrosc Radiat Transf 2003;82:473-481.

[119] Nikitin AV, Dmitrieva TA, Gordon IE. Improved spectroscopic line list of methyl chloride in the 1900-2600 $\mathrm{cm}^{-1}$ spectral region. J Quant Spectrosc Radiat Transf 2015. doi:10.1016/j.jqsrt.2016.03.007.

[120] Irion FW, Gunson MR, Toon GC, Chang AY, Eldering A, Mahieu E, et al. Atmospheric Trace Molecule Spectroscopy (ATMOS) Experiment Version 3 data retrievals. Appl Opt 2002;41:696879. doi:10.1364/AO.41.006968.

[121] Chirkov M, Stiller GP, Laeng A, Kellmann S, Von Clarmann T, Boone CD, et al. Global HCFC-22 measurements with MIPAS: Retrieval, validation, global distribution and its evolution over 20052012. Atmos Chem Phys 2016;16:3345-68. doi:10.5194/acp-16-3345-2016.

[122] Brown AT, Chipperfield MP, Boone C, Wilson C, Walker KA, Bernath PF. Trends in atmospheric halogen containing gases since 2004. J Quant Spectrosc Radiat Transf 2011;112:2552-66. doi:10.1016/j.jqsrt.2011.07.005.

[123] Ballard J, Knight RJ, Newnham DA, Auwera JV, Herman M, Lonardo GD, et al. An intercomparison of laboratory measurements of absorption cross-sections and integrated absorption intensities for HCFC-22. J Quant Spectrosc Radiat Transf 2000;66:109-28. doi:10.1016/S00224073(99)00211-3.

[124] McGillen MR, Bernard F, Fleming EL, Burkholder JB. HCFC-133a (CF 3 CH 2 Cl): OH rate coefficient, UV and infrared absorption spectra, and atmospheric implications. Geophys Res Lett 2015;42:6098-105. doi:10.1002/2015GL064939.

[125] Laube JC, Newland MJ, Hogan C, Brenninkmeijer CAM, Fraser PJ, Martinerie P, et al. Newly detected ozone-depleting substances in the atmosphere. Nat Geosci 2014;7:266-9. doi:10.1038/ngeo2109.

[126] Mahieu E, Lejeune B, Bovy B, Servais C, Toon GC, Bernath PF, et al. Retrieval of HCFC-142b (CH3CCIF2) from ground-based high-resolution infrared solar spectra: Atmospheric increase since 1989 and comparison with surface and satellite measurements. J Quant Spectrosc Radiat Transf 2017;186:96-105. doi:10.1016/j.jqsrt.2016.03.017.

[127] Rinsland CP, Sharpe SW, Sams RL. Temperature-dependent infrared absorption cross sections of methyl cyanide (acetonitrile). J Quant Spectrosc Radiat Transf 2005;96:271-80. doi:10.1016/j.jqsrt.2005.03.004.

[128] Harrison JJ, Bernath PF. Mid- and long-wave infrared absorption cross sections for acetonitrile. J Quant Spectrosc Radiat Transf 2012;113:221-5. doi:10.1016/j.jqsrt.2011.11.003.

[129] Allen NDC, Harrison JJ, Bernath PF. Acetonitrile ( $\mathrm{CH} 3 \mathrm{CN}$ ) infrared absorption cross sections in the $3 \mu \mathrm{m}$ region. J Quant Spectrosc Radiat Transf 2011;112:1961-6. doi:10.1016/j.jqsrt.2011.04.001.

[130] Shine KP, Gohar LK, Hurley MD, Marston G, Martin D, Simmonds PG, et al. Perfluorodecalin: Global warming potential and first detection in the atmosphere. Atmos Environ 2005;39:175963. doi:10.1016/j.atmosenv.2005.01.001.

[131] Rothman LS, Gordon IE, Barbe A, Benner DC, Bernath PF, Birk M, et al. The HITRAN 2008 molecular spectroscopic database. J Quant Spectrosc Radiat Transf 2009;110:533-72. doi:10.1016/j.jqsrt.2009.02.013. 
[132] Varanasi P, Li Z, Nemtchinov V, Cherukuri A. Spectral absorption-coefficient data on HCFC-22 and SF6 for remote-sensing applications. J Quant Spectrosc Radiat Transf 1994;52:323-32. doi:10.1016/0022-4073(94)90162-7.

[133] Rothman LS, Barbe A, Chris Benner D, Brown LR, Camy-Peyret C, Carleer MR, et al. The HITRAN molecular spectroscopic database: edition of 2000 including updates through 2001. J Quant Spectrosc Radiat Transf 2003;82:5-44. doi:10.1016/S0022-4073(03)00146-8.

[134] Hurley MD, Wallington TJ, Buchanan GA, Gohar LK, Marston G, Shine KP. IR spectrum and radiative forcing of CF4 revisited. J Geophys Res D Atmos 2005;110:1-8. doi:10.1029/2004JD005201.

[135] Carlos M, Gruson O, Richard C, Boudon V, Rotger M, Thomas X, et al. High-resolution spectroscopy and global analysis of CF4rovibrational bands to model its atmospheric absorption. J Quant Spectrosc Radiat Transf 2017;201:75-93. doi:10.1016/j.jqsrt.2017.06.039.

[136] Ballard J, Knight RJ, Newnham DA. Infrared absorption cross-sections and integrated absorption intensities of perfluoroethane and cis-perfluorocyclobutane. J Quant Spectrosc Radiat Transf 2000;66:199-212. doi:10.1016/S0022-4073(99)00217-4.

[137] Robson JI, Gohar LK, Hurley MD, Shine KP, Wallington TJ. Revised IR spectrum, radiative efficiency and global warming potential of nitrogen trifluoride. Geophys Res Lett 2006;33:2-4. doi:10.1029/2006GL026210.

[138] Montzka SA, Dutton GS, Yu P, Ray E, Portmann RW, Daniel JS, et al. An unexpected and persistent increase in global emissions of ozone-depleting CFC-11. Nature 2018;557:413-7. doi:10.1038/s41586-018-0106-2.

[139] Adcock KE, Reeves CE, Gooch LJ, Leedham Elvidge E, Ashfold MJ, Brenninkmeijer CAM, et al. Continued increase of $\mathrm{CFC}-113$ a ( $\mathrm{CCl} 3 \mathrm{CF} 3$ ) mixing ratios in the global atmosphere: Emissions, occurrence and potential sources. Atmos Chem Phys 2018;18:4737-51. doi:10.5194/acp-184737-2018.

[140] Kellmann S, Von Clarmann T, Stiller GP, Eckert E, Glatthor N, Höpfner M, et al. Global CFC-11 (CCl3F) and CFC-12 (CCl2F2) measurements with the Michelson Interferometer for Passive Atmospheric Sounding (MIPAS): Retrieval, climatologies and trends. Atmos Chem Phys 2012;12:11857-75. doi:10.5194/acp-12-11857-2012.

[141] Myhre G, Stordal F, Gausemel I, Nielsen CJ, Mahieu E. Line-by-line calculations of thermal infrared radiation representative for global condition: CFC-12 as an example. J Quant SpectrosC Radiat Transf 2006;97:317-31. doi:10.1016/j.jqsrt.2005.04.015.

[142] Rinsland CP, Sharpe SW, Sams RL. Temperature-dependent absorption cross-sections in the thermal infrared bands Of SF5CF3. Fally, S 2003;82:483-90. doi:Doi 10.1016/S00224073(03)00172-9.

[143] Nielsen OJ, Nicolaisen FM, Bacher C, Hurley MD, Wallington TJ, Shine KP. Infrared spectrum and global warming potential of SF5CF3. Atmos Environ 2002;36:1237-40. doi:10.1016/S13522310(01)00551-9.

[144] Sulbaek Andersen MP, Blake DR, Rowland FS, Hurley MD, Wallington TJ. Atmospheric Chemistry of Sulfuryl Fluoride: Reaction with $\mathrm{OH}$ Radicals, $\mathrm{Cl}$ Atoms and $\mathrm{O} 3$, Atmospheric Lifetime, IR Spectrum, and Global Warming Potential. Environ Sci Technol 2009;43:1067-70. doi:10.1021/es802439f.

[145] Gordon IE, Potterbusch MR, Bouquin D, Erdmann CC, Wilzewski JS, Rothman LS. Are your spectroscopic data being used? J Mol Spectrosc 2016;327:232-8. doi:10.1016/j.jms.2016.03.011. 
[146] Kazakov A, McLinden MO, Frenkel M. Computational Design of New Refrigerant Fluids Based on Environmental, Safety, and Thermodynamic Characteristics. Ind Eng Chem Res 2012:120917100332001. doi:10.1021/ie3016126.

[151] Wong A, Billinghurst B, Bernath PF. Helium broadened propane absorption cross sections in the far-IR. Mol Astrophys 2017;8:36-9. doi:10.1016/J.MOLAP.2017.06.003. 